\title{
ALTERNATING POLYSTANNANES: SYNTHESIS, PREPARATION, CHARACTERIZATION AND A COMPUTATIONAL STUDY
}

By

Shane Harrypersad, BSc., Ryerson University, 2013

\author{
A thesis \\ presented to Ryerson University \\ in partial fulfillment of the \\ requirments for the degree of \\ Master of Science \\ in the Program of \\ Molecular Science
}

Toronto, Ontario Canada 2015

(C) Shane Harrypersad 2015 


\section{Author's Declaration}

\section{AUTHOR'S DECLARATION FOR ELECTRONIC SUBMISSION OF A THESIS}

I hereby declare that I am the sole author of this thesis. This is a true copy of the thesis, including any required final revisions, as accepted by my examiners.

I authorize Ryerson University to lend this thesis to other institutions or individuals for the purpose of scholarly research.

I further authorize Ryerson University to reproduce this thesis by photocopying or by other means, in total or in part, at the request of other institutions or individuals for the purpose of scholarly research.

I understand that my thesis may be made electronically available to the public. 


\title{
ALTERNATING POLYSTANNANES: SYNTHESIS, PREPARATION, CHARACTERIZATION AND A COMPUTATIONAL STUDY
}

\author{
Master of Science, 2015
}

\author{
Shane Harrypersad \\ Molecular Science \\ Ryerson University
}

\begin{abstract}
Polystannanes have been synthesized by a number of useful routes. Generally, these polymers have been limited to homopolymers containing a single type of substituent. We now demonstrated a novel condensation polymerization utilizing dialkyl or diaryl tin dihydrides and dialkyl tin diamides to prepare alternating polymers with neighbouring tin centers possessing different group functionalities. Three new alternating polystannanes containing both organically solubilizing (n-Bu, Me) and less solubilizing $(\mathrm{Ph})$ side groups as well as the homopolymer dibutylpolystannane have been prepared. A variety of closely related model tristannanes using the same synthetic methodology was also completed. We have also carried out a computational study of a number of model stannanes in order to optimize structures of the oligo- and polystannanes synthetically prepared and predict their spectral properties by using time dependent density functional theory (TD-DFT). This study has yielded results that can be influential in predicting chemical orientation, bonding properties and electronics.
\end{abstract}




\section{Acknowledgments}

I would like to thank a multitude of people. Starting with my parents, I would like to immensely thank them for their love and support. For always having been there for anything I needed, in any situation. This entire process would not have been possible and I could not thank you enough. To the rest of my family, thank you for your love and support and your attempts at learning and understanding what I do, with varying levels of success.

Next I would like to thank Dr. Daniel Foucher. The guidance, knowledge and wisdom he has imparted is immeasurable and I could not thank him enough. He took a chance on me in my undergraduate degree taught me the skills necessary to pursue further steps in my academic and personal life. To Dr. Khan, thank you for your support. Always being there to lean on for a question, advice or generally to have a conversation with to pass the time. I could not thank you enough for the amount of times you have bailed me out with my work and reassured me before I proceeded. I'm sure my eyebrows are still here in part to your knowledge and training. To my committee members, Dr. George, Dr. McWilliams and Dr. Wylie; thank you for your added support and advice with very helpful directions and insight into my work as well as helping me progress forward with the research, especially Dr. Wylie for his editorial insight and direction.

To my friends who have helped me along the way. There are too many important people to name, past, present, close and far away; thank you. You have always been there for all of the necessary outlets throughout my time, whether that was going for a beer, helping me with a reaction, there to play videogames, there to escape for a round of golf or generally around as motivation to kicking my butt to do work. The support and dedication you have shown in making this possible is immense and this support and an outlet are absolutely unbound. To everyone in KHN202 over the years, thank you for the support, guidance, knowledge, assistance, laughs and for being there for all the good times and the bad, even if the research got in the way of the good times spent in the backroom. Lastly I would like to thank the department of Chemistry and Biology. Everyone in the department at some point has played a role and has helped in the further progress of my work. Thanks as well to Ryerson University for their funding and their resources as well as the use of facilities in order to facilitate my research. 


\section{Table of Contents}

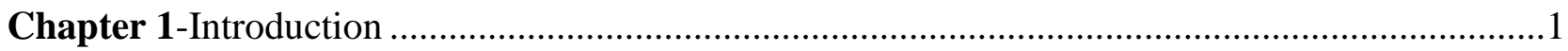

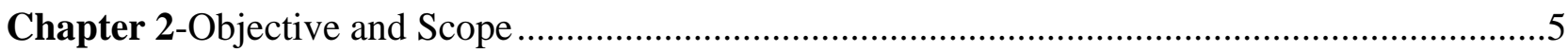

Chapter 3-Alternating Polystannanes: Syntheses and Properties .....................................................6

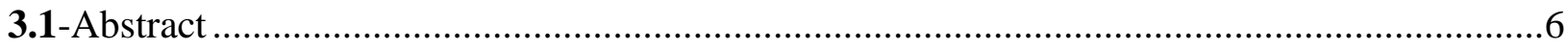

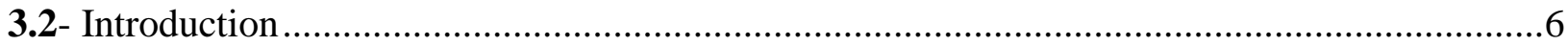

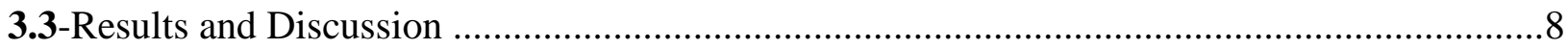

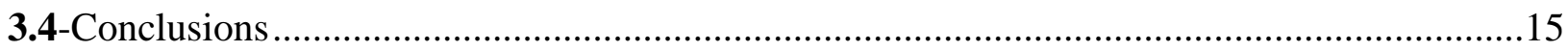

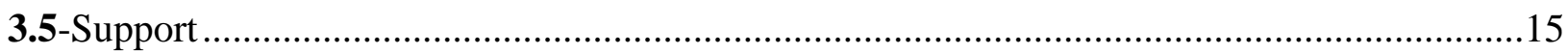

Chapter 4-Linear Oligostannanes: a Synthetic and TD-DFT Study ...............................................16

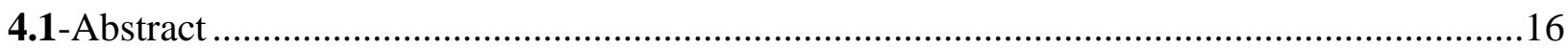

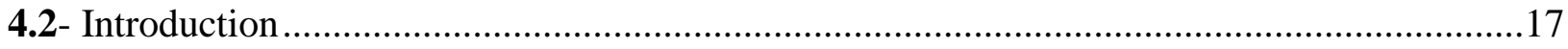

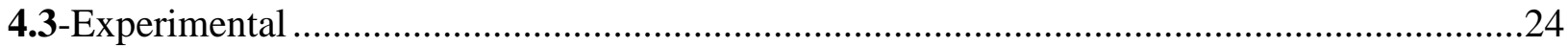

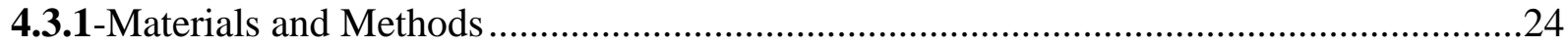

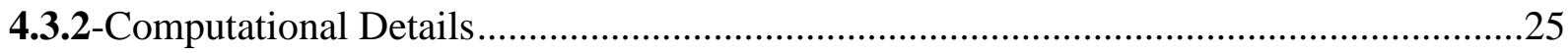

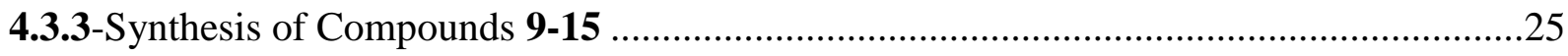

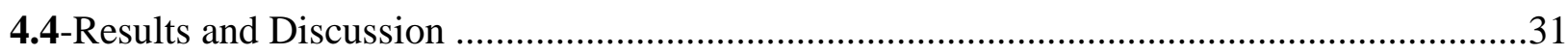

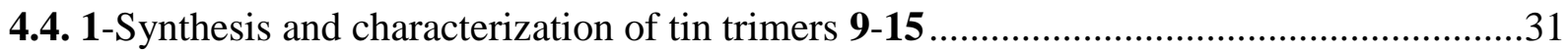

4.4.2-Experimental UV-Vis and calculated TD-DFT data for Trimers 9-15 ............................34

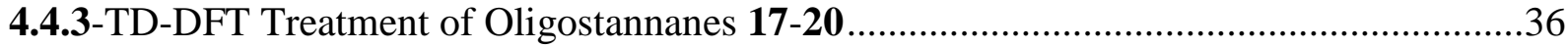

4.4.4-TD-DFT Treatment of Oligostannanes …………………………………………….........39

4.4.5-TD-DFT Treatment of Group 14 Metallanes ..................................................................41

4.4.6-TD-DFT Asymmetrical Polystannanes .........................................................................44

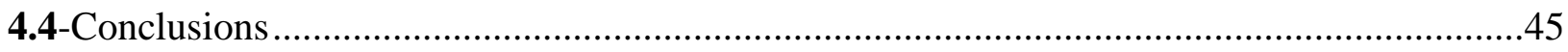

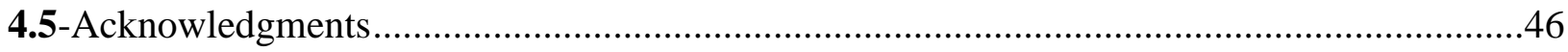


Chapter 5-Conclusions and Future Outlook

Chapter 6-Appendices

6.1-Alternating Polystannanes: Syntheses and Properties. .50

6.1.1-Materials and Methods .50

6.1.2.-Elemental Analysis .58

6.1.3-Differential Scanning Calorimetry .... .59

6.1.4-Polymer Images . .60

6.1.5-Gel Permeation Chromatography . 61

6.1.6-NMR .63

6.2-Linear Oligostannanes: A Synthetic and TD-DFT Study .74

6.2.1-Synthesis Summary ..... . .74

6.2.2-NMR Spectra .75

6.2.3-DFT Figures and Images .94

6.2.4-Tables .97

References .98 


\section{List of Tables and Scheme}

Chapter 3-Alternating Polystannanes: Synthesis and Properties ............................................6

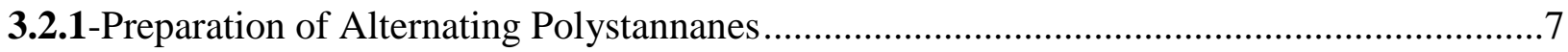

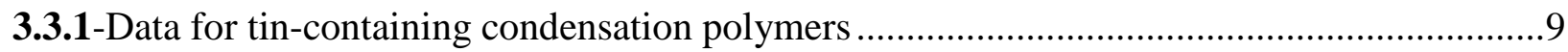

Chapter 4-Linear Oligostannanes: A Synthetic and TD-DFT Study .......................................16

4.4.1.3- ${ }^{119}$ Sn NMR data, experimental UV-Vis (THF) and Calculated (TD-DFT) First

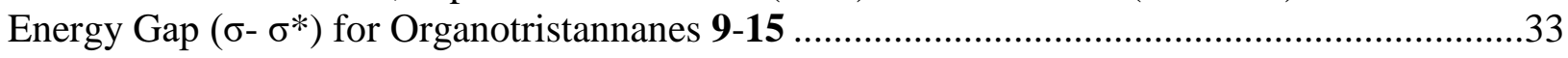

4.4.3.1-Experimental ${ }^{16}$ and calculated bond lengths, angles and absorption maxima for a

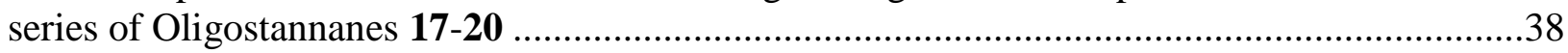

4.4.5.2-Comparison of calculated band gap energies for Group 14 Metallanes in both TP (trans-planar) and GH (guache-helical) geometries...........................................................43

4.4.6.2-Experimental and theoretical $\lambda_{\max }$ values for model Oligostannanes and

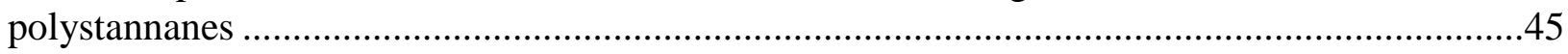

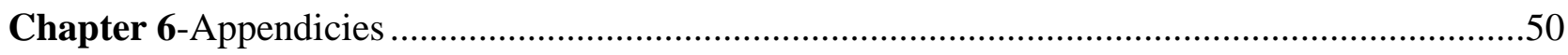

6.2.4.1-Minimized Trimer Energies using LSDA/SDD Basis Set ........................................98

6.2.4.2-Hartree-Fock optimization values and DFT LSDA/SDD optimization values ...............98 


\section{List of Figures and Schemes}

Chapter 1-Introduction

1.1- An idealized cartoon of the $\sigma-\sigma$ delocalization between $\mathrm{Sn}-\mathrm{Sn} \mathrm{sp}^{3}$ hybrid orbitals revealing extensive overlap along the Sn backbone

1.2- Various Polystannanes via Different Polymerization Techniques..............................................

Chapter 3-Alternating Polystannanes: Syntheses and Properties ......................................................6

3.3.2-Polystannanes 6 and 7 After Exposure to Ambient Light for 7 days......................................10

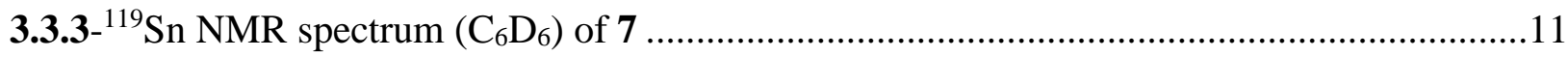

3.3.4- GPC of polymer 7 in THF ……………………………...........................................13

3.3.5 -UV-Vis (normalized) of 6-8 Alternating Polymers Compared to the Homopolymer 5

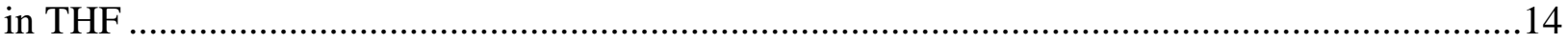

Chapter 4-Linear Oligostannanes: A Synthetic and TD-DFT Study ...............................................16

4.2.1-Contributions to the Absorption Peak from Sn-Sn Chromophores of Varying Lengths

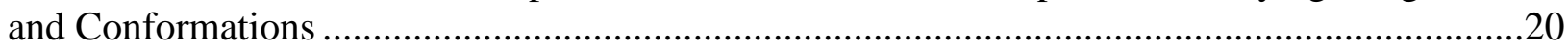

4.3.3.1-Structures of Stannyl Hydrides and Amides Used to prepare Tristannanes 9-15 .............26

4.4.1.1-General preparative routes to model tin trimers used in this study....................................32

4.4.1.2-Trimers, Oligostannanes and Polymetallanes...TD-DFT in this study .............................33

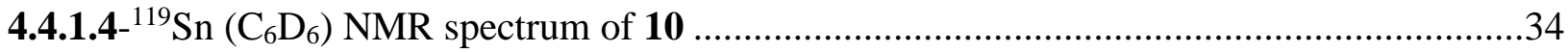

4.4.2.1-UV-vis spectra of Tristannanes 9-15 in THF....................................................................35

4.4.2.2- Left: HOMO of 9, Right: LUMO of 9 (Isoelectric Constant: 0.02) .................................36

4.4.2.3- Left: HOMO of 13, Right: LUMO of 13 (Isoelectric Constant: 0.02) ……………..........36

4.4.3.2- a) HOMO and b) LUMO MO of 19 (Isoelectric Constant: 0.02) .....................................38

4.4.4.1-Comparison of Experimental and Calculated First Band Gap Energies for Oligostannanes 20a-m. .41

4.4.5.1-First Band Gap Energies of Group 14 Metallanes $\left[\mathrm{MH}_{2}\right]_{\mathrm{n}},(\mathrm{M}=\mathrm{Si}, \mathrm{Ge}, \mathrm{Sn}) \ldots \ldots \ldots \ldots \ldots \ldots . . . .43$

4.4.6.1-Model Oligostannanes and Alternating Polystannanes........................................................44 
Chapter 5-Conclusions and Future Outlook

5.1-Possible Dye Based Polystannane Moiety ....................................................................48

5.2-HOMO (Left) LUMO (Right) of Theorized Push-Pull System ........................................48

5.3- Possible Outline of Stannane-Alt-Silane Polymer ......................................................49

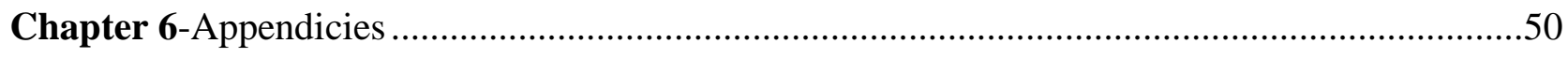

6.1.1.1-General reaction scheme for dihydrides ...........................................................5

6.1.1.2-General reaction scheme for tin diamides ............................................................52

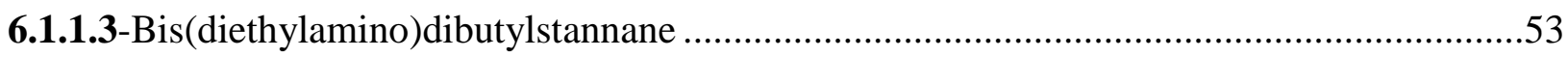

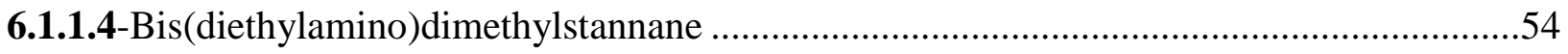

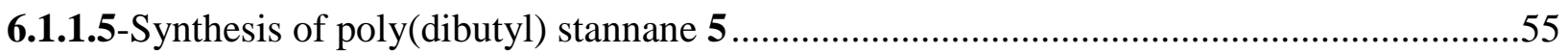

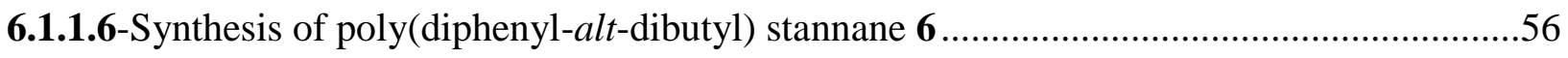

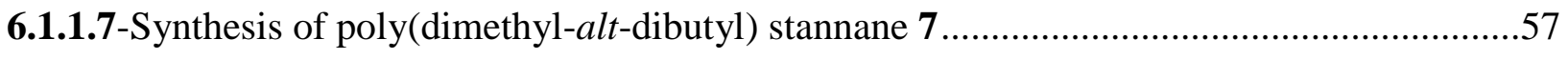

6.1.1.8-Synthesis of poly(dimethyl-alt-dibutyl) stannane 8............................................57

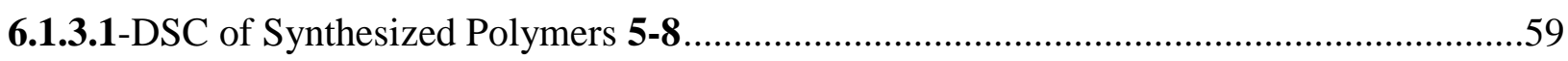

6.1.4.1-Images of all the Synthesized Polymers .............................................................60

6.1.5.1-GPC Chromatograms of Polymers 5-8 .............................................................61

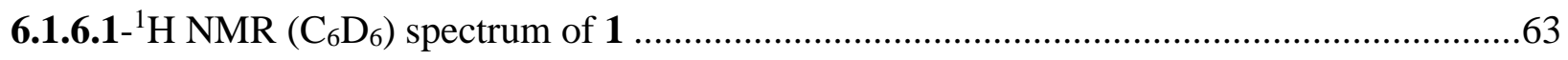

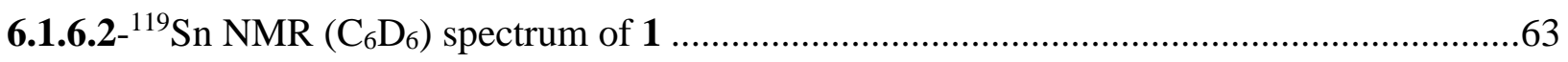

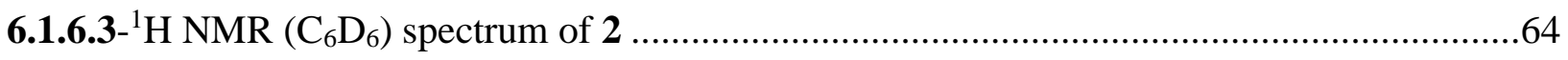

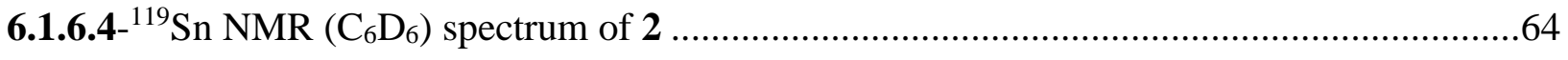

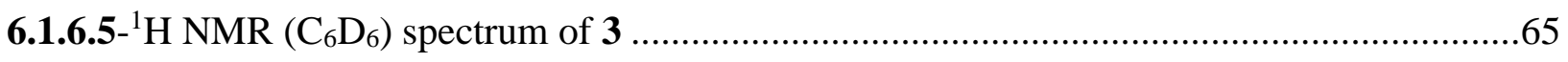

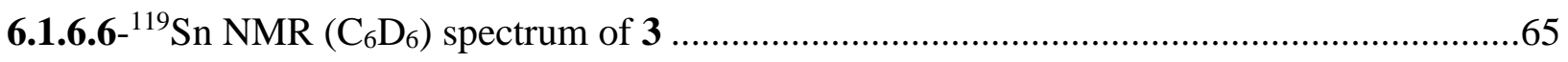

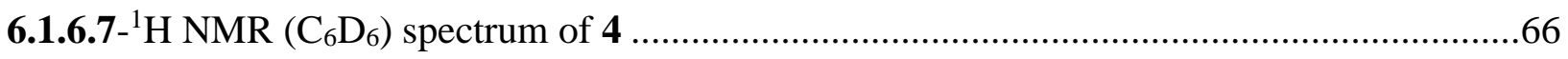

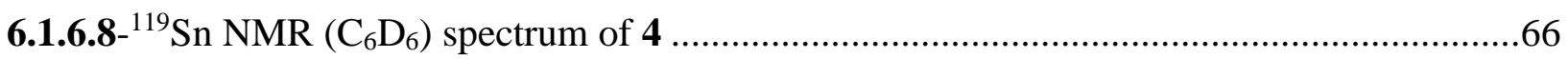

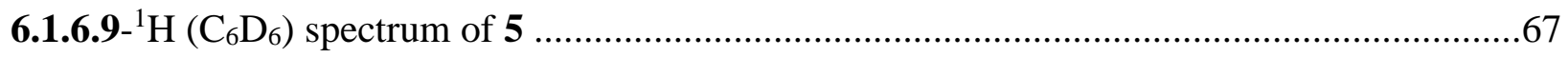

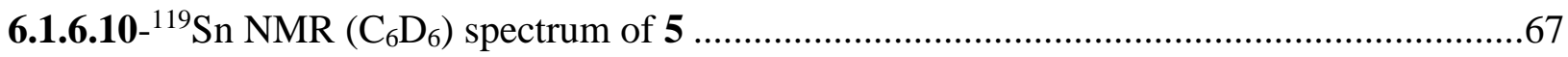




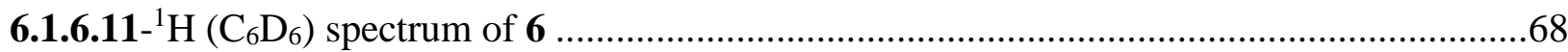

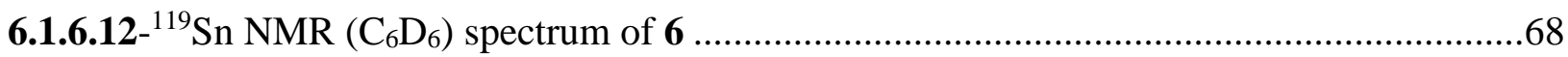

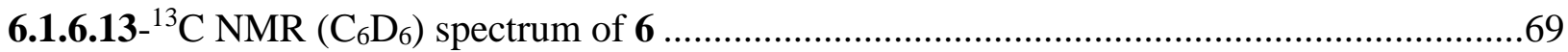

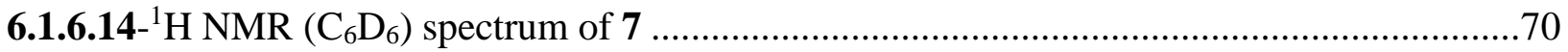

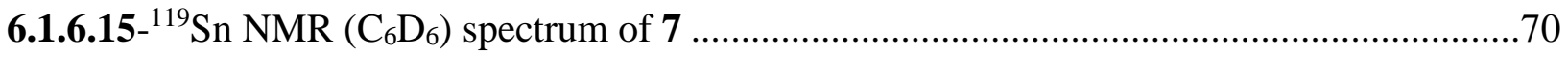

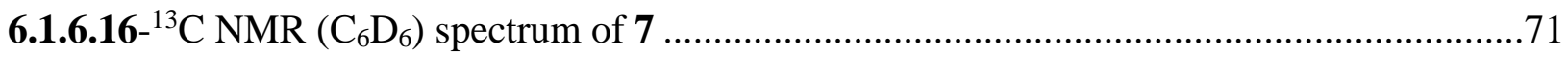

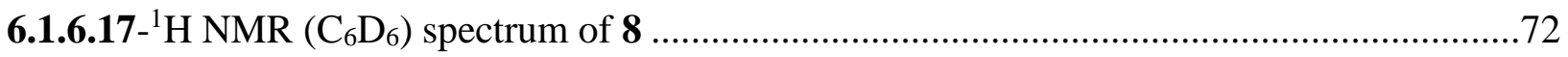

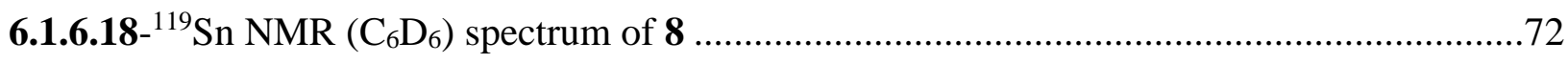

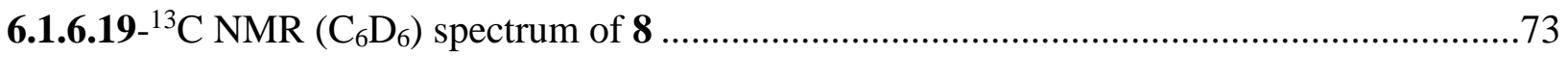

6.2.1.1-Structures of Starting Materials and Tristannanes 9-16..........................................74

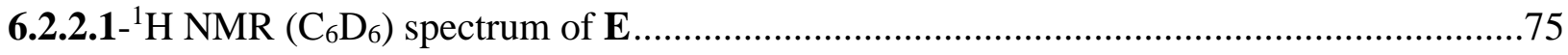

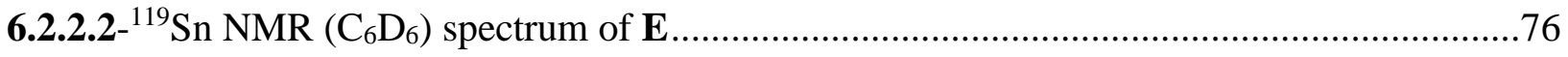

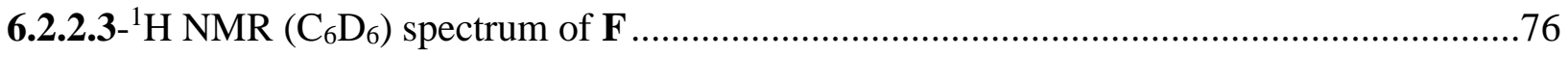

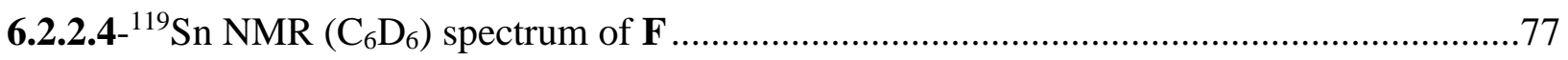

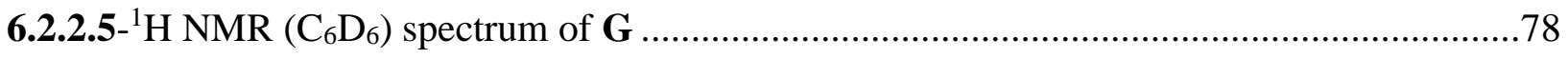

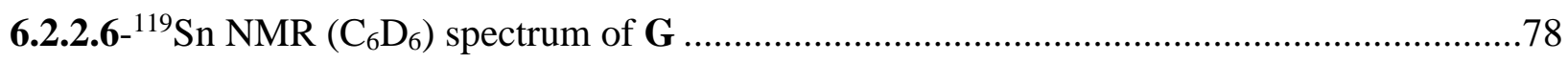

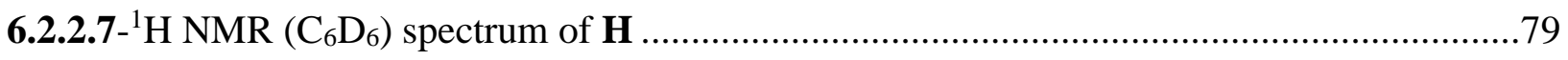

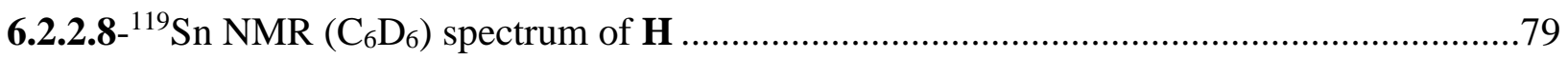

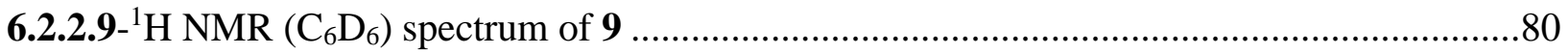

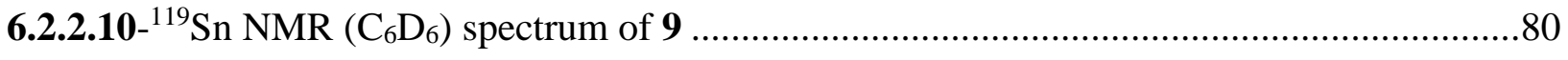

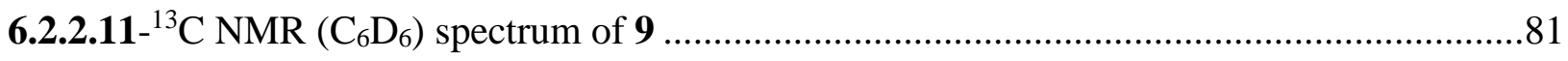

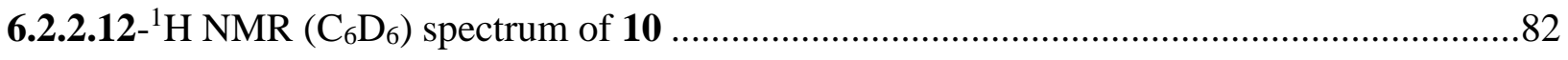

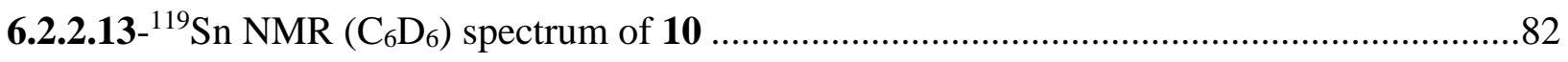

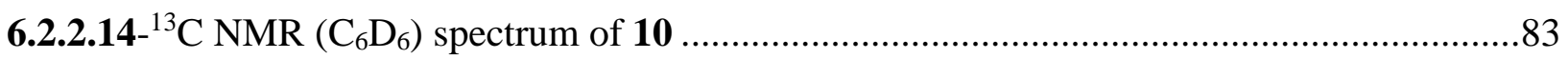

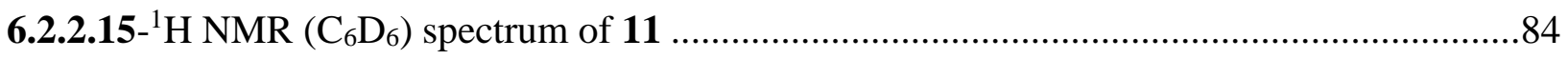

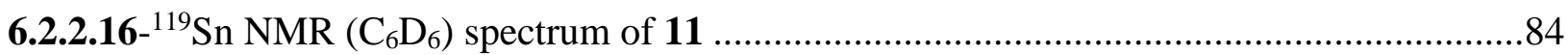




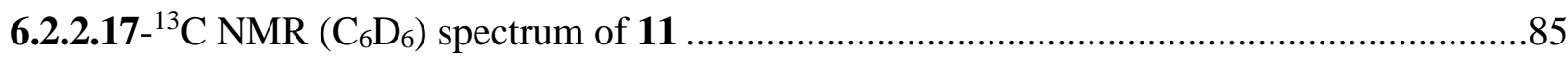

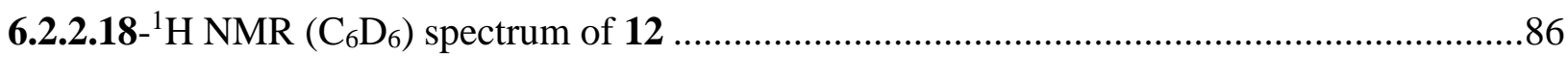

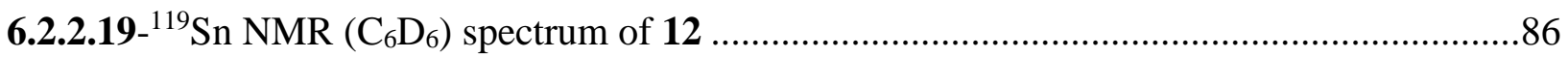

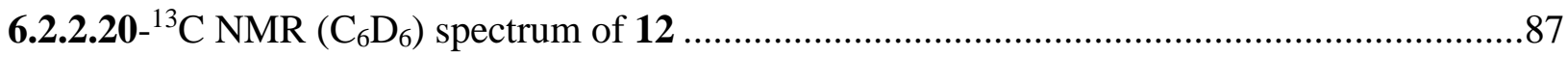

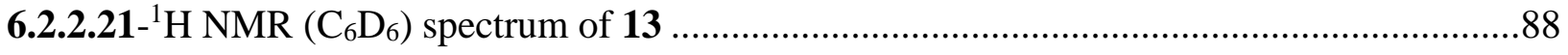

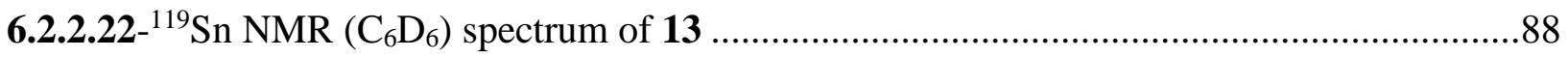

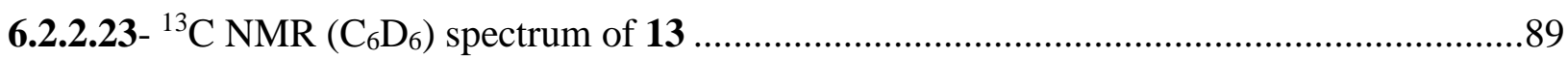

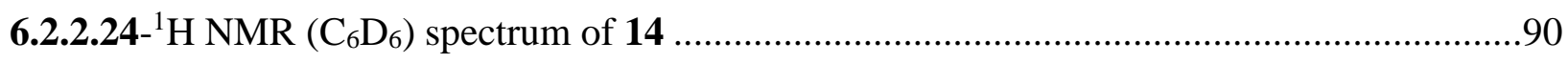

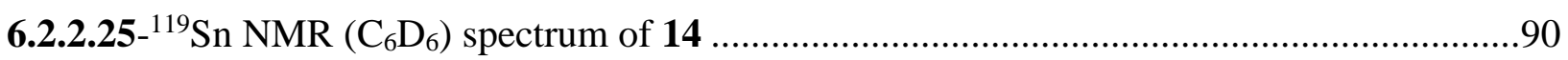

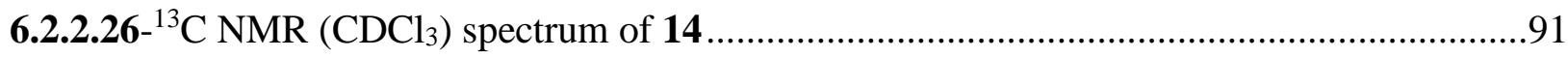

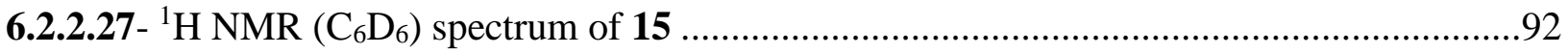

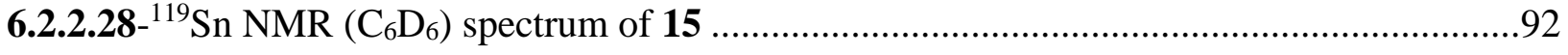

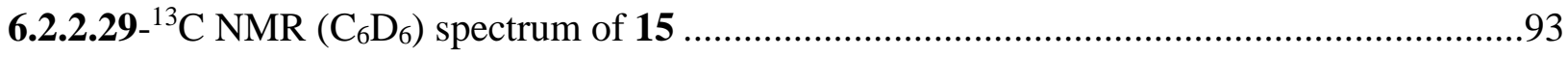

6.2.3.1-Predicted TD-DFT UV-Vis structures of Trimers 9-15.......................................94

6.2.3.2-(Left) LUMO and (Right) HOMO of 9........................................................... 95

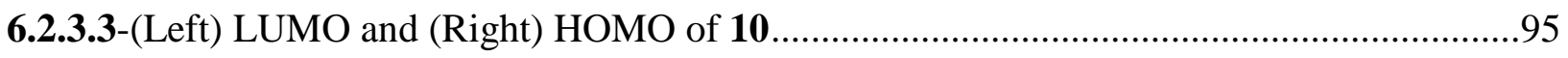

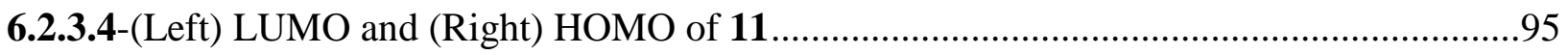

6.2.3.5-(Left) LUMO and (Right) HOMO of 12 .................................................................95

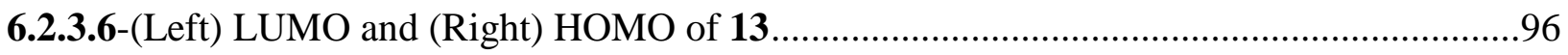

6.2.3.7-(Left) LUMO and (Right) HOMO of 14 .........................................................96

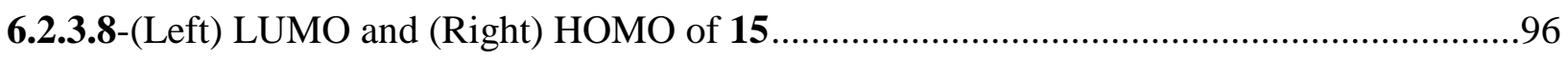




\section{List of Abbreviations}

\begin{tabular}{|c|c|}
\hline$\AA$ & Angstrom \\
\hline$n \mathrm{Bu}$ & $n$-butyl R Group \\
\hline DFT & Density Functional Theory \\
\hline $\mathrm{C}_{6} \mathrm{D}_{6}$ & Hexa-Deuterobenzene \\
\hline $\mathrm{CDCl}_{3}$ & Deuterochloroform \\
\hline DCM & Dichloromethane \\
\hline $\mathrm{Et}_{2} \mathrm{O}$ & Diethyl Ether \\
\hline DSC & Differential Scanning Calorimetry \\
\hline EA & Elemental Analysis \\
\hline Et & Ethyl \\
\hline GPC & Gel Permeation Chromatography \\
\hline $\mathrm{HF}$ & Hartree-Fock \\
\hline HOMO & Highest Occupied Molecular Orbital \\
\hline $\mathrm{h}$ & Hours \\
\hline LSDA & Local Spin Density Approximation \\
\hline LUMO & Lowest Unoccupied Molecular Orbital \\
\hline MS & Mass Spectrometry \\
\hline $\mathrm{Me}$ & Methyl \\
\hline
\end{tabular}


MO

$\mathrm{M}_{\mathrm{w}}$

NMR

$\mathrm{Ph}$

PDI

TD-DFT

THF

$\mathrm{UV}-\mathrm{V}$ is
Molecular Orbital

Molecular Weight

Nuclear Magnetic Resonance

Phenyl

Polydispersity Index

Time Dependent DFT

Tetrahydrofuran

Ultraviolet-Visible Spectroscopy 


\section{Chapter 1- Introduction}

Polystannanes are main group polymers that possess a backbone containing Sn atoms bonded to each other in a linear, repeating fashion $-\left(\mathrm{R}_{2} \mathrm{Sn}\right) \mathrm{n}^{-}($where $\mathrm{R}=$ alkyl or aryl $) .{ }^{1}$ These unique organometallic polymers are natural semi-conductors and have been considered for use as flexible polymeric wires in electric circuitry. ${ }^{1}$ Ideally, materials of this type are envisioned as plastic wires that can be processed, printed in a roll to roll fashion, are tunable and may potentially be more efficient than their copper analogues. ${ }^{2}$ These materials were originally discovered in the late 1800's; however many important developments and discoveries have only occurred with these materials in the last 25 years. ${ }^{1}$ The breakthroughs came mainly in the form of new synthetic techniques that allowed for relatively straightforward preparations of polystannanes in high yield, high purity and good reproducibility. ${ }^{2}$ Further investigations of their electronic properties have demonstrated that these materials behave similarly to other Group 14 materials of similar structure: polygermanes, or polysilanes. ${ }^{2,3}$ Unlike polyacetylene which uses a $\pi-\pi$ network to transport electrons, polysilanes, polygermanes and polystannanes utilize a $\sigma-\sigma$ delocalized system to shuttle electrons throughout the backbone, making them intrinsic semi-conductors. ${ }^{4}$ The conductivity of group 14 polymers may be enhanced with doping, which increases the efficiency of electronic transport of these materials. ${ }^{4}$

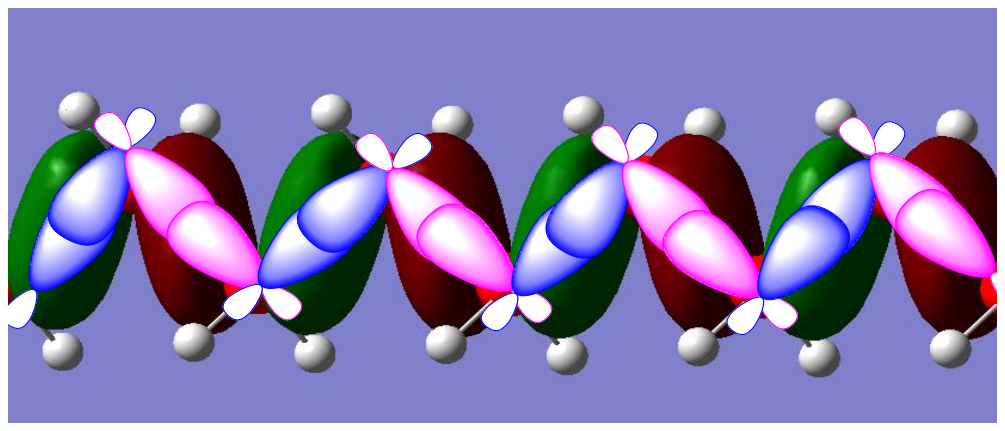

Figure 1.1 An idealized cartoon of the $\sigma-\sigma$ delocalization between Sn-Sn $s p^{3}$ hybrid orbitals revealing extensive overlap along the Sn backbone. ${ }^{4}$ 
However, polystannanes present a few specific challenges that must be addressed before of commercial applications or potential can be fully realized. These challenges are their susceptibility to nucleophilic attack and their propensity to be photodegraded. Polystannanes are vulnerable to moisture in the atmosphere, which can break $\mathrm{Sn}-\mathrm{Sn}$ bonds via nucleophilic attack of $\mathrm{OH}_{2}$ lone pairs towards the Lewis acidic Sn centers. The Sn-Sn bond is relatively long and the overlap is diffuse due to the compartively large size of the Sn valence orbital (5p). As a result, the orbital overlap which weakens the bond and leads to increased susceptibility. ${ }^{4}$ The second concern stems from exposure to photons possess enough energy (approximately $400 \mathrm{~nm}$ ) to excite an electron in this bond. ${ }^{5}$ When these photons interact with the weak Sn-Sn bond they cause photoscission and create two very active tin radicals, which through multiple rearrangement processes, form smaller degraded polymers, oligomers or cyclics. NMR $\left({ }^{119} \mathrm{Sn}\right)$ of the photodegraded products indicate that the majority of oligomers formed are inert and chemically uninteresting 5- or 6- membered stannyl rings. 3,4

Progress in solving these long-standing, seemingly insurmountable problems with polystannanes require new synthetic methodologies and strategies to successfully and reproducibly prepare high yield, stable polymers with minimal undesirable side products. Figure $\mathbf{1 . 2}$ shows the known synthetic routes to these polymers. ${ }^{5}$ 


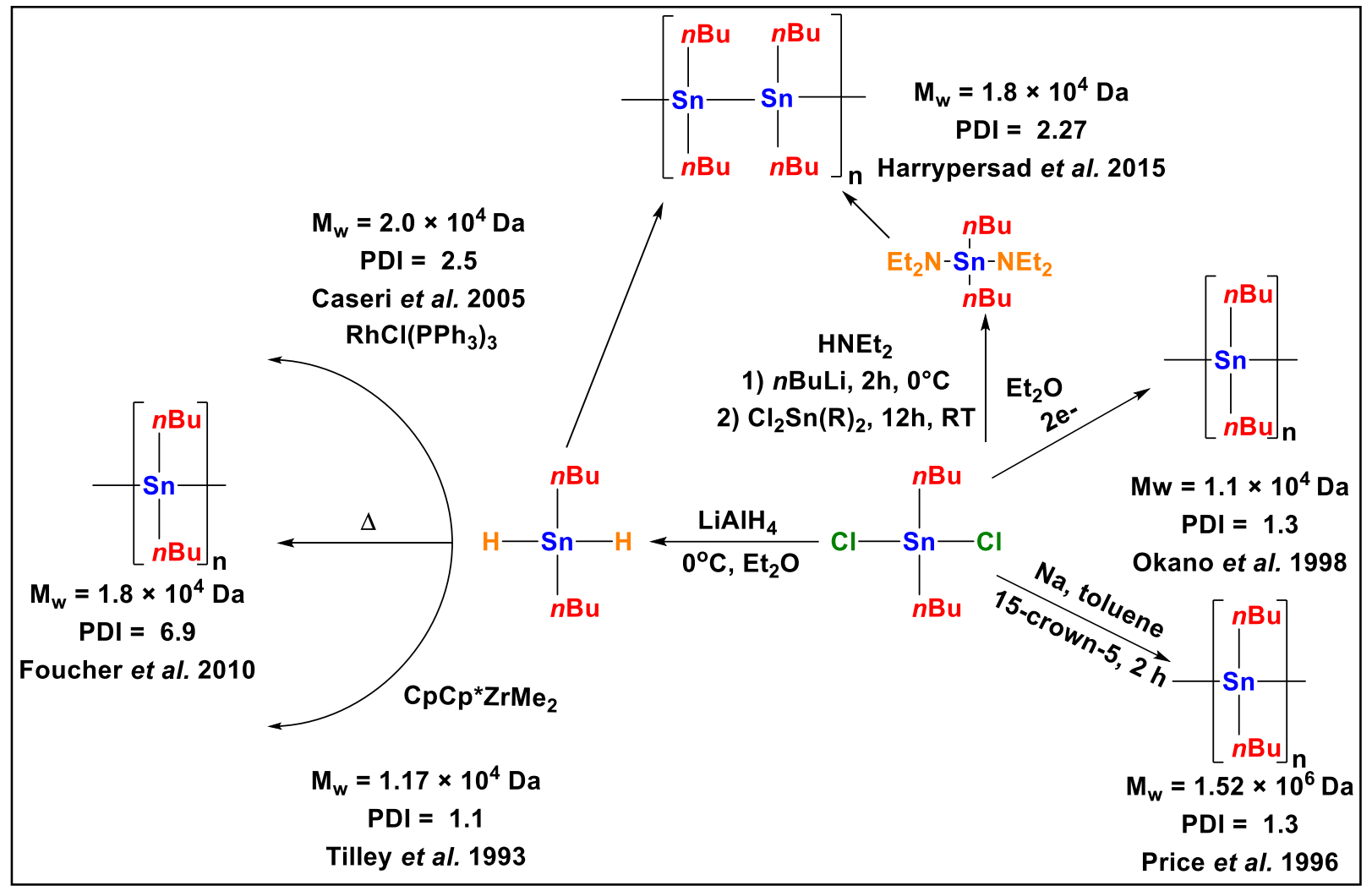

Figure 1.2 Various polystannanes via different polymerization techniques.

The first major advancement in the preparation of polystannanes was demonstrated by Tilley and coworkers in $1993 .^{5}$ They showed that a dehydrocoupling reaction of dialkyl or diaryl tin dihydrides using a zirconocene catalyst could effectively result in the formation of the desired polystannanes. ${ }^{5}$ These simple tin dihydrides were readily synthesized via a hydrogenation of a tin dihalides. Dialkyl and diaryl tin dihalides can also be used to form polystannanes via reductive Wurtz coupling (Price et al. 1996) or electrochemically (Okano et al. in 1998). ${ }^{6,7}$ Both Wurtz coupling and dehydropolymerization methods used to prepare polystannanes share common problems in achieving consistent high molecular weights, low PDI, are often low yielding and are relatively expensive to prepare. Research in this field was relatively dormant until Caseri et al. employed Wilkinson's dehydropolymerization catalyst $\left(\mathrm{RhCl}\left(\mathrm{PPh}_{3}\right)_{3}\right.$ with dialkyl tin dihydrides to produce high molecular weight polydialkylstannanes that were essentially oligomer free. ${ }^{8}$ This afforded the first opportunity to characterize properties the properties of polystannanes that were 
cyclic free. The results of these characterization studies have proved invaluable to a more complete understanding of these systems. ${ }^{9}$ The main points of interest are that polystannanes are susceptible to red light, water in the air but are oxidatively stable as well as relatively stable to heat. In 2010 Foucher et al. ${ }^{10}$ were able to show that catalyst-free, thermally driven dehydrocoupling of tin dihydrides was possible. ${ }^{10,11}$ This discovery dramatically reduced the expenditure of these polymers as the catalysts are costly. The second outcome was that it showed these polymers are thermally stable $\left(>200^{\circ} \mathrm{C}\right.$ ) which for semi-conductors is a valuable asset as heat has shown to increase conductivity. ${ }^{11}$ 


\section{Chapter 2-Objective and Scope}

The objective of this project was to determine a new synthetic route and an entirely new classification of polystannanes with a backbone consisting of different $\mathrm{R}$ groups on each neighboring atom. The synthesis of these polymers, as well as their characterization is covered in Chapter 3. These concepts and techniques are further examined with model trimers. These oligostannanes were extensively studied by a multitude of techniques including TD-DFT. The TDDFT study was then expanded to review and update previously synthesized molecules and to create a wide library of stannyl compounds that can be further referenced as a comparative study. Chapter 4 covers this work in detail.

Chapter 3: Harrypersad, S.; Foucher, D. Chem. Commun., 2015, 51, 7120-7123.

Specific contributions by both authors are evident in the preceding publication. S. Harrypersad was responsible for all of the synthesis, characterization and interpretation of the work as well as production of figures and an original version of the manuscript. D. Foucher covered much of the wiritng, editing and direction of the publication as well as motivation to the other author.

Chapter 4: Harrypersad, S.; Liao, L.; Khan, A.; Wylie, R. S.; Foucher, D. J. Inorg. Organomet Polym. 2015 25, 515-528.

The contributions made by each author vary more than for the previous publication. S. Harrypersad contributed with the synthesis, characterization and generation of figures with the writing of the experimental and some computational results. L. Liao was the originator of some of the calculations, attributing to the catennate calculations. A. Khan oversaw the interpretation of the NMR spectrum, interpretation of data and formatting. S. Wylie and D. Foucher provided the writing, with Wylie focused mainly on the DFT section and Foucher on the synthesis and direction. 


\section{Chapter 3- Alternating Polystannanes: Syntheses and Properties}

\section{1 - Abstract}

A new condensation polymerization route leading to Alternating Polystannanes is presented. The stoichiometric reaction of tin dihyrides and tin diamines in diethyl ether or toluene under mild reaction conditions afford three new moderate molecular weight Alternating Polystannanes, $\left[\mathrm{Ph}_{2} \mathrm{Sn}-\mathrm{Alt}-\mathrm{Sn}(n-\mathrm{Bu})_{2}\right]_{\mathrm{n}^{-}},-\left[\mathrm{Ph}_{2} \mathrm{Sn}-\mathrm{Alt}-\mathrm{SnMe}_{2}\right]_{\mathrm{n}^{-}},-\left[\mathrm{Me}_{2} \mathrm{Sn}-\mathrm{Alt}-\mathrm{Sn}(n-\mathrm{Bu})_{2}\right]_{\mathrm{n}^{-}}$in addition to a known homopolymer - $\left[\mathrm{Sn}(n-\mathrm{Bu})_{2}\right]_{\mathrm{n}}-$.

\section{2-Introduction}

For more than 20 years, dialkyl and diaryl homopolystannanes have been prepared by reductive coupling of either tindichlorides ${ }^{7,8,12-17}$ or tindihydrides..$^{5,6,9,18-33}$ These intriguing polymers possess a backbone of $\sigma-\sigma$ delocalized $^{6,7,8,12,15-24,26,24}$ organotins envisioned for use as processable intrinsic semiconductors ${ }^{12-15,18,24,26,33}$ or printable polymeric wires. ${ }^{13-17,23}$ Along with the considerable synthetic challenges in preparing later Group 14 polymeric materials is their profound sensitivity to moisture and light ${ }^{5,6,8,9,12,16-21,31-33}$ increasing down the period. In the case of polystannanes, the Lewis acidic nature of formally $\mathrm{Sn}(\mathrm{IV})$ centers results in weak $\sigma-\sigma$ overlap between neighbouring tin centers and a likely cause of their inherent susceptibility. ${ }^{6,18,21,23,22-26,28}$ Despite the original promise of these materials, a relatively limited number of researchers have continued to pursue improved alternative synthetic methods and stabilization strategies with polystannanes. Dialkylpolystannanes, $\left[\mathrm{R}_{2} \mathrm{Sn}\right]_{\mathrm{n}^{-}},\left(\mathrm{R}=\mathrm{Et}^{9,17-21,24-26,28,30}, \mathrm{Pr}^{9,17-21,25-26,28}, n-\mathrm{Bu}^{5,6,7,15-18,22-26}\right.$, hexyl ${ }^{8,20,22-24}$, etc. $)$ are soluble in most organic solvents where as diarylpolystannanes $\left(\mathrm{R}=\mathrm{Ph}^{28}\right.$ etc. $)$ are often considerably less soluble but demonstrate a dramatic red shift of the $\sigma-\sigma^{*}$ transition in the UV-visible range in addition to their increased stability. Random dialkyl ( $n$-Bu, octyl, 
dodecyl) and diphenyl polystannanes were recently prepared by Caseri et al. ${ }^{9}$ via a two-step $\mathrm{Na}$ Wurtz coupling in liquid ammonia. The recovered polymers are only partially THF soluble and of moderate molecular weight. ${ }^{18}$ Polystannanes with improved light stability were afforded by utilizing ethyl spacers directly attached to tin were also described by Caseri et $a l .{ }^{9,25-28,} 32$ This was done in part to facilitate dehydrocoupling with a bulky Rh catalyst as a minimum of an ethyl spacer unit must be present separating the tin atoms from an aryl carbon. $^{31}$

Our approach to preparing polystannanes employs condensation polymerization where both diaryl and dialkyl substituents can be introduced alternatively into the backbone to ensure increased solubility ${ }^{32}$ and, surprisingly, an improved degree of light stability. Toluene or $\mathrm{Et}_{2} \mathrm{O}$ solutions of equimolar quantities of high purity tin dihydrides and tin diamides (NMR) were added together at $0^{\circ} \mathrm{C}$ to facilitate optimal polycondensation conditions. ${ }^{18,34}$ This condensation (Scheme 3.2.1) produces volatile diethyl amine, which along with the reaction solvent, is removed in vacuo resulting in the recovery of a relatively pure polymer.

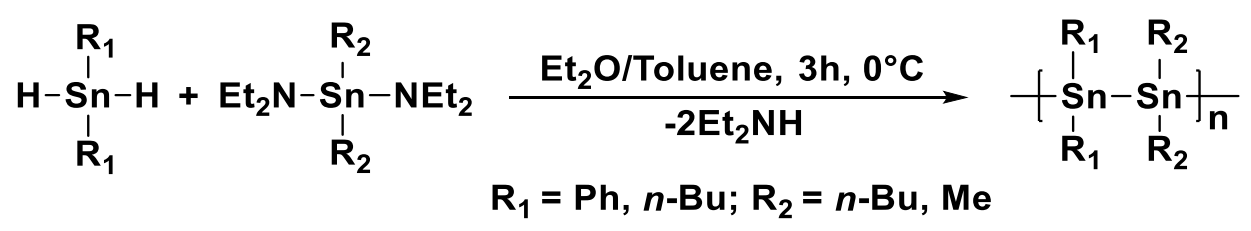

Scheme 3.2.1 Preparation of alternating polystannanes

Related examples of oligostannanes prepared by transmetalation or condensation were described independently by both Dräger and Sita. Dräger et al. ${ }^{11,34}$ prepared a series of oligostannanes with one to four $(t-\mathrm{Bu})_{2} \mathrm{Sn}$ moieties as the central core capped on each end with a $\mathrm{Ph}_{3} \mathrm{Sn}$ unit. Sita et al. ${ }^{23}$ carried out a careful, stepwise condensation of $(n-\mathrm{Bu})_{2} \mathrm{SnH}_{2}$ with $(n-$ $\mathrm{Bu})_{2} \mathrm{Sn}\left(\mathrm{OCH}_{2} \mathrm{CH}_{2} \mathrm{OEt}\right)\left(\mathrm{NMe}_{2}\right)$ in the presence of a strong base to produce linear oligostannanes 
containing 3-15 tin atoms. For both the Dräger and Sita oligomers, a red shift of the $\sigma-\sigma^{*}$ transition was observed with increasing catenation.

\section{3-Results and Discussion}

Alternating polystannanes prepared by polycondensation of tin hydrides with tin amides are listed in Table 1. Four starting materials, $(n-\mathrm{Bu})_{2} \mathrm{SnH}_{2}(\mathbf{1}), \mathrm{Ph}_{2} \mathrm{SnH}_{2}(\mathbf{2}), \quad(n-\mathrm{Bu})_{2} \mathrm{Sn}\left(\mathrm{NEt}_{2}\right)_{2}(\mathbf{3})$ and $\mathrm{Me}_{2} \mathrm{Sn}\left(\mathrm{NEt}_{2}\right)_{2}$ (4) were prepared in good yield following literature methods. ${ }^{25,35}$ The choice of these starting materials was based on ease and safety. Dimethyltin dihydride, $\mathrm{Me}_{2} \mathrm{SnH}_{2}$, is a gas at room temperature and is extremely toxic. ${ }^{36}$ All possible combinations of polymers were then made incorporating the four compounds listed above.

The polystannane $\left(-\left[(n-\mathrm{Bu})_{2} \mathrm{Sn}\right]_{\mathrm{n}}-\right), \mathbf{5}$, was chosen in order to validate the condensation polymerization process, as extensive characterization of this homopolymer has been previously carried out. Under an inert atmosphere in the absence of light, an ethereal solution of $\mathbf{1}$ was added slowly at $0^{\circ} \mathrm{C}$ to a Schlenk flask containing 3 in $\mathrm{Et}_{2} \mathrm{O}$ and the mixture allowed to react for 3 hours at $0^{\circ} \mathrm{C}$. The solvent and diethylamine co-product were then removed in vacuo. 


\begin{tabular}{|c|c|c|c|c|}
\hline Cmpd. & $\begin{array}{c}{ }^{119} \mathrm{Sn} \text { NMR } \\
\delta\left(\mathrm{C}_{6} \mathrm{D}_{6}\right) \mathrm{ppm}\end{array}$ & $\begin{array}{c}\boldsymbol{T}_{\mathbf{g}} \\
\left({ }^{\circ} \mathbf{C}\right)\end{array}$ & $\begin{array}{c}M_{w} \\
(\text { KDa), } \\
\text { PDI }\end{array}$ & EA \\
\hline $5^{19}$ & -191 & 1 & $\begin{array}{l}91, \\
2.53\end{array}$ & $\begin{array}{c}\text { C calc/found: } 40.76 / 41.25 \\
\mathrm{H}_{\text {calc/found: }} 7.79 / 7.61\end{array}$ \\
\hline 5 & -191 & 1 & $\begin{array}{l}18.1, \\
2.27\end{array}$ & $\begin{array}{c}\text { C calc/found: } 40.76 / 39.81 \\
\mathrm{H}_{\text {calc/found: }} 7.79 / 7.13\end{array}$ \\
\hline 6 & $-187,-208$ & 117 & $\begin{array}{l}18.8 \\
2.86\end{array}$ & $\begin{array}{c}\mathrm{C}_{\text {calc/found }} \text { 47.30/46.56 } \\
\mathrm{H}_{\text {calc/found: }} 5.95 / 5.39\end{array}$ \\
\hline 7 & $-60,-201$ & 118 & $\begin{array}{l}242.5, \\
2.03\end{array}$ & $\begin{array}{c}\mathrm{C}_{\text {calc/found }} 34.81 / 33.72 \\
\mathrm{H}_{\text {calc/found: }} 5.50 / 5.63\end{array}$ \\
\hline 8 & $-186,-235$ & -6 & $\begin{array}{l}82.1, \\
2.86\end{array}$ & $\begin{array}{c}\text { Ccalc/found: } 31.30 / 29.26 \\
\mathrm{H}_{\text {calc/found: }} 6.28 / 6.37\end{array}$ \\
\hline
\end{tabular}

Table 3.3.1 Data for tin-containing condensation polymers.

Condensations were carried out at $0^{\circ} \mathrm{C}$ in an effort to avoid thermally promoted selfpolymerization of the heat sensitive alkyl or aryl stannyl dihydrides, as well as to limit possible termination reactions. Polymer $\mathbf{5}$ was recovered as a brightly yellow coloured solid and characterized by NMR $\left({ }^{119} \mathrm{Sn},{ }^{1} \mathrm{H},{ }^{13} \mathrm{C}\right)$, GPC, UV-Vis spectroscopy and DSC. GPC analysis showed the polymer to be of modest molecular weight (Table 3.3.1). Three new alternating polymers, $6\left(-\left[\mathrm{Ph}_{2} \mathrm{Sn}-A L T-\mathrm{Sn}(n-\mathrm{Bu})_{2}\right]_{\mathrm{n}}-\right), 7\left(-\left[\mathrm{Ph}_{2} \mathrm{Sn}-A L T-\mathrm{SnMe}_{2}\right]_{\mathrm{n}}-\right)$, and $8(-$ $\left.\left[\mathrm{Me}_{2} \mathrm{Sn}-A L T-\mathrm{Sn}(n-\mathrm{Bu})_{2}\right]_{\mathrm{n}}-\right)$ were also synthesized using the same methodology. Their data is listed in Table 1. The calculated elemental analysis was based on the relative degree of polymerization of the sample and accounts for the uncertainty in the process. For more details on the methodology used for this estimation, see supplementary (S1). 


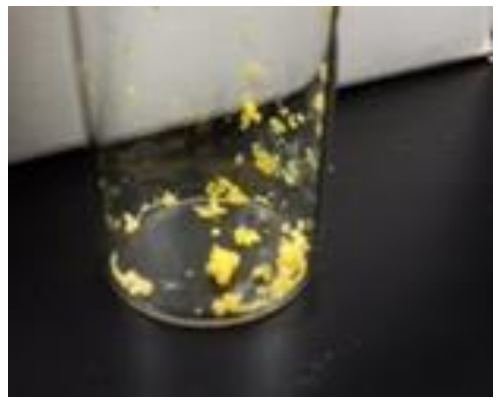

6

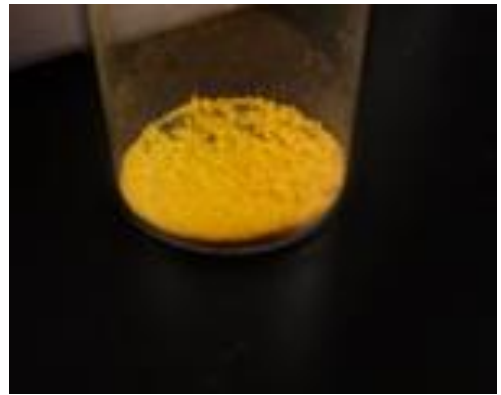

7

Fig. 3.3.2 Polystannanes 6 and 7 after exposure to ambient light for 7 days

A hydrostannolysis ${ }^{45}$ reaction of the two difunctional monomers results in the release of $\mathrm{HNEt}_{2}$ and formation of $\mathrm{Sn}-\mathrm{Sn}$ bonds; thus promoting a facile condensation polymerization. This type of condensation has previously been demonstrated in part by others for tin systems, including oligostannanes, ${ }^{23}$ but to our knowledge has not been used exclusively for the preparation of polystannanes. This methodology allows for the reaction to be carried out in a single vessel, at modest temperature, with short polymerization period(s) and proceeds without the aid of an external catalyst. The phenyl-containing polymer derivatives 6 and 7 (Figure 3.3.2) showed increased chemical stability to light and moisture in the solid state with exposure up to 5 days with no apparent loss of colour or change in the ${ }^{119} \mathrm{Sn}$ NMR spectroscopic profile. Similar stability of homopolystannanes bearing phenyl derivatives as side groups was reported by Tilley. ${ }^{6}$ Under these same conditions, the alkylated polymer $\mathbf{8}$ experienced a more rapid degradation with a noticeable colour change from a yellow semi-solid texture to a white powder; possibly this represents formation of a stannoxane. Polymer $\mathbf{5}$ degraded to a similar white powder in much the same way as previously described by Tilley and others. $5,6,16-18,24,38$ 
NMR $\left({ }^{1} \mathrm{H},{ }^{13} \mathrm{C},{ }^{119} \mathrm{Sn}\right)$ analysis of the new alternating polymers $(\mathbf{6}, \mathbf{7}$, and 8$)$ revealed resonances corresponding to both attached $\mathrm{R}$ groups as well as two well separated ${ }^{119} \mathrm{Sn}$ NMR resonances. ${ }^{1} \mathrm{H}$ NMR spectroscopy for polymers 6-8 support the integration of both monomer units at an approximately 1:1 ratio $\left(\mathbf{6}, 1: 0.98 \mathrm{SnPh}_{2}\right.$ to $\mathrm{Sn}(n-\mathrm{Bu})_{2}, \mathbf{7}, 1: 0.99 \mathrm{SnPh}_{2}$ to $\mathrm{SnMe}_{2}, \mathbf{8}$, 1:0.96 of $\mathrm{SnMe}_{2}$ to $\left.\mathrm{Sn}(n-\mathrm{Bu})_{2}\right)$. The alternating polymers 7 and $\mathbf{8}$ showed a distinct downfield ${ }^{119} \mathrm{Sn}$ resonance $(-60$ and $-186 \mathrm{ppm})$ for the Me substituents, whereas the $\mathrm{Ph}(-200 \mathrm{ppm})$ and

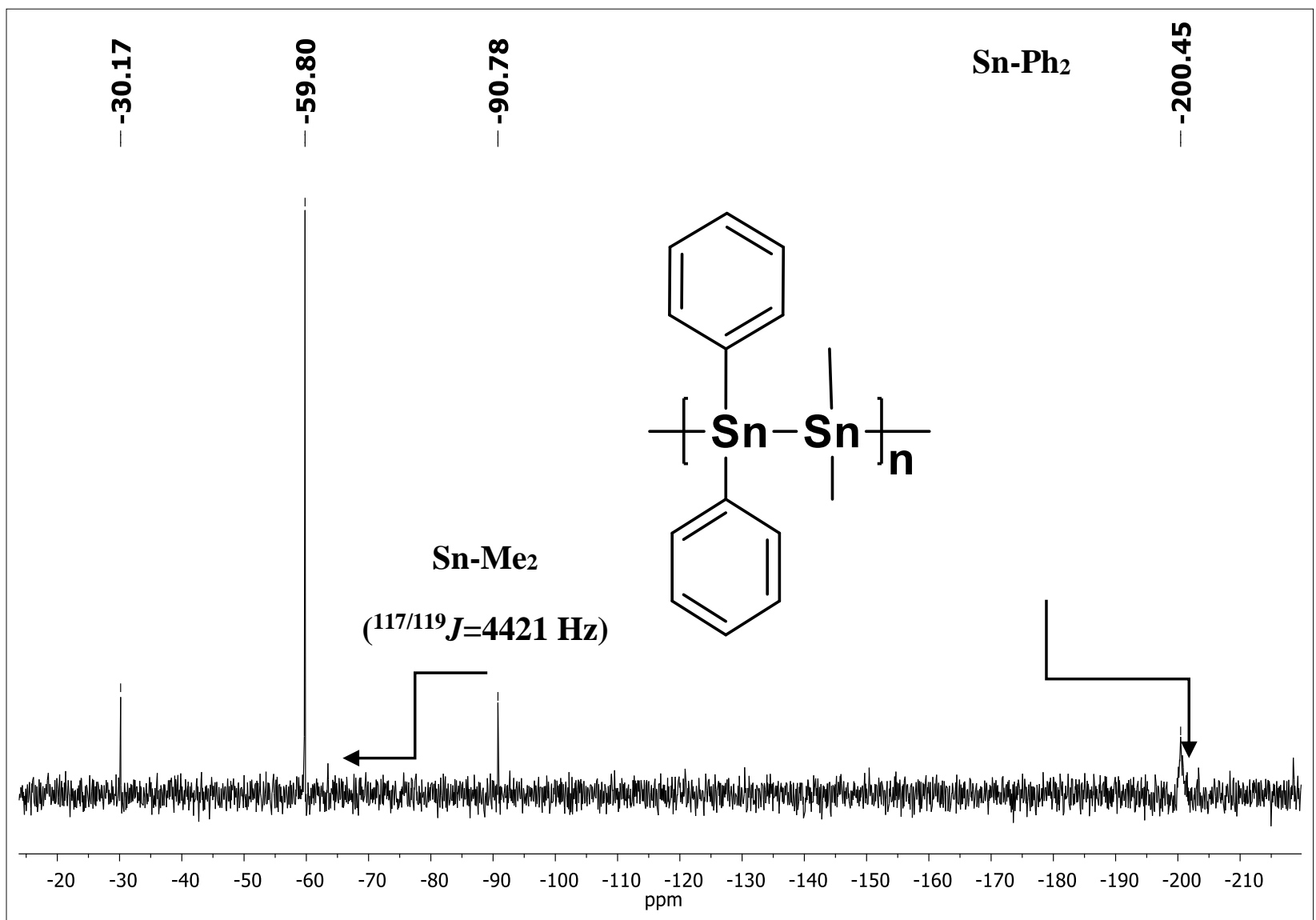

Fig. 3.3.3 ${ }^{119} \mathrm{Sn} \mathrm{NMR}\left(\mathrm{C}_{6} \mathrm{D}_{6}\right)$ of 7

$n$-Bu (-235 ppm) substituents are found in the region more typical of known cyclic stannanes and polystannanes. Evidence of strong Sn-Sn coupling (Figure 3.3.3) was also observed for methylated tin center of $7\left({ }^{119 / 117} J=4421 \mathrm{~Hz}\right)$ and is similar to reported ${ }^{1} \boldsymbol{J}$ couplings for methylated stannanes ${ }^{43}$ and a polyferrocenyldistannane. ${ }^{47}$ Polymers $\mathbf{5}, \mathbf{6}$ and $\mathbf{8}$ are found in a region more typical of most polystannanes $(\delta=-190$ to $-210 \mathrm{ppm})$ with one 
exception. $5,6,7,9,12,18-20,21,24-26,28,33$ The $\operatorname{Sn}(n-\mathrm{Bu})_{2}$ chemical shift of $\mathbf{8}(\delta=-235$ ppm $)$ was displaced up-field by a further $45 \mathrm{ppm}$ relative to $\mathbf{5}(\delta=-190 \mathrm{ppm})$.

There is no evidence (NMR) for either end group in any of the polymers prepared by condensation. As all efforts were made to keep samples away from reactive solvents or moisture, it is presumed that one of the terminal ends contains a $\mathrm{Sn}-\mathrm{H}$ bond and, the other a $\mathrm{Sn}_{-\mathrm{NEt}_{2}}$ containing unit. Alternatively, termination maybe the result of macrocyclic cyclization and an absence of end groups.

DSC analysis of $\mathbf{5}$ produced by our condensation polymerization shows a nearly identical glass transition $\left(T_{g}=1^{\circ} \mathrm{C}\right)$ to polymers of $\mathbf{5}$ produced by reductive coupling. ${ }^{19}$ Polymer $\mathbf{5}$ recovered from the catalyst free condensation polymerization described earlier is a yellow coloured solid absent of 5- and 6-membered cyclic stannanes (GPC, NMR). ${ }^{9,13,18}$ The alternating polystannanes 6 and 7 (Table 3.3.1) display higher glass transitions $\left(6 T_{g}=117^{\circ} \mathrm{C}, 7 T_{g}=118^{\circ} \mathrm{C}\right)$ compared to the homopolymer $\left(5 T_{g}=1^{\circ} \mathrm{C}\right)$, while a slightly lower glass transition $\left(T_{g}=-6^{\circ} \mathrm{C}\right)$ was detected for the mixed dialkyl polystannane $\mathbf{8}$. Like 5, polymers $\mathbf{6}, \mathbf{7}$ and $\mathbf{8}$ appear to be amorphous with no detectable melt transition in the scan range $\left(-50\right.$ to $\left.225^{\circ} \mathrm{C}\right)$. 


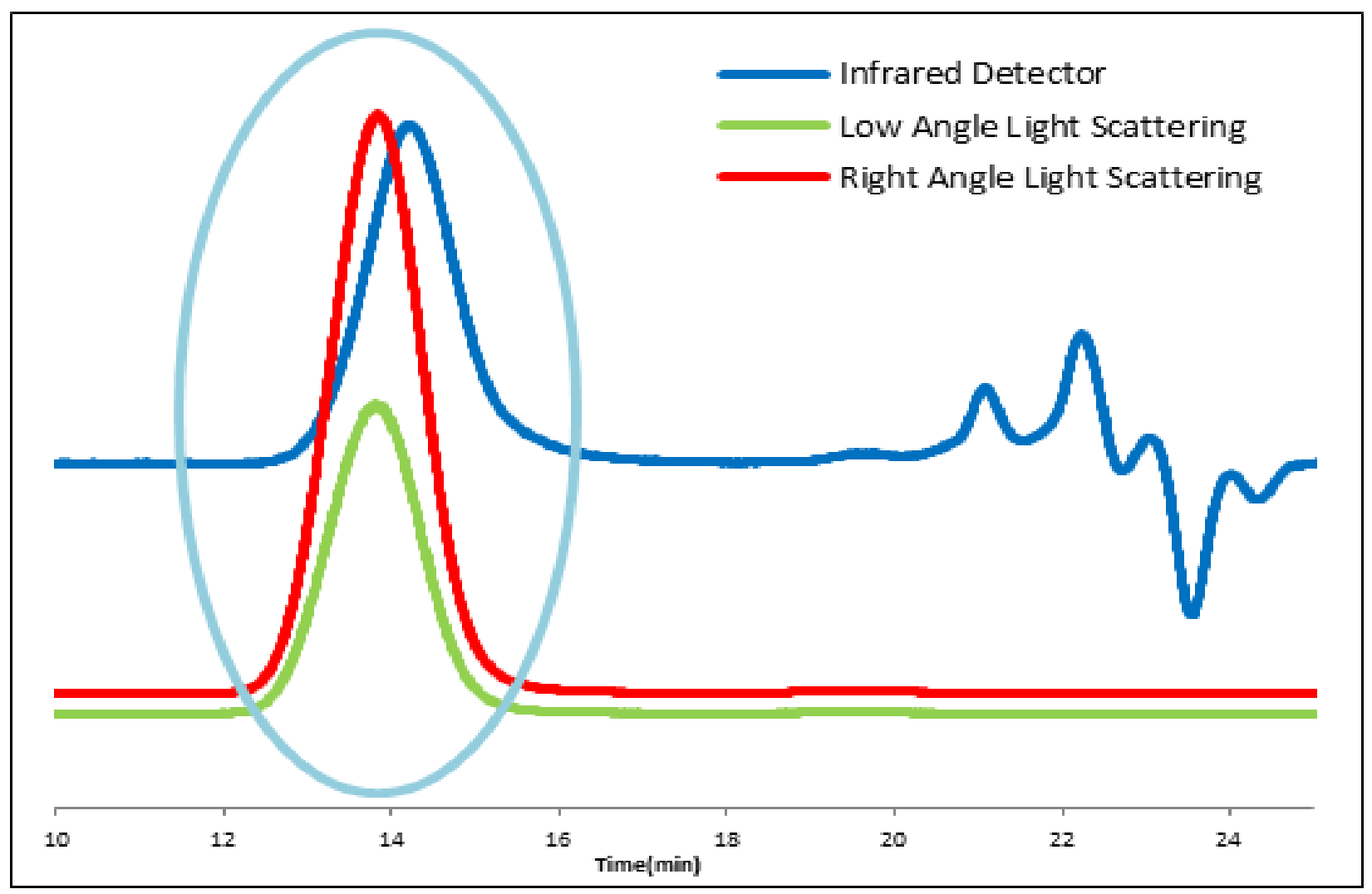

Fig. 3.3.4 GPC of polymer 7 in THF

The GPC analysis (Table 3.3.1) for the condensation polymers (5-8) shows PDI's between 2 and 3 with the value expected for an ideal condensation polymerization to be closer to 2 . With the exception of the 7, the molecular weights of polymers prepared by condensation are lower than polystannanes prepared by dehydrocoupling reactions. The triple detection GPC traces of polymers (Figure 3.3.4) appear to be monomodal for the most part.

Dräger et $a l .{ }^{11,34}$, Sita et $a l^{2}{ }^{2}$, and others ${ }^{16-21,22-26,28-32}$ have observed a red shift of the $\sigma-\sigma^{*} \max$ transition with increasing catenation. What differs in the previous studies with this work is that two of the polymers $(6,7)$ have two phenyl rings near each $\mathrm{Sn}$-Sn bond with one tin possessing a direct Sn- $\mathrm{C}_{\text {aromatic }}$ bond. The aromatic rings are themselves capable of $\sigma+\pi$ orbital mixing with Sn, but can also act as a chromophore to absorb light energy that might damage Sn-Sn bonds. The polymer remains reasonable soluble in solution as the repeat unit consists of at least two dialkyl substituents 
(Me or $n$-Bu). Figure 4 shows the UV-Vis spectra of the alternating polymers as well as for the homopolymer 5 prepared by condensation, which is in good agreement with literature values. ${ }^{25}$

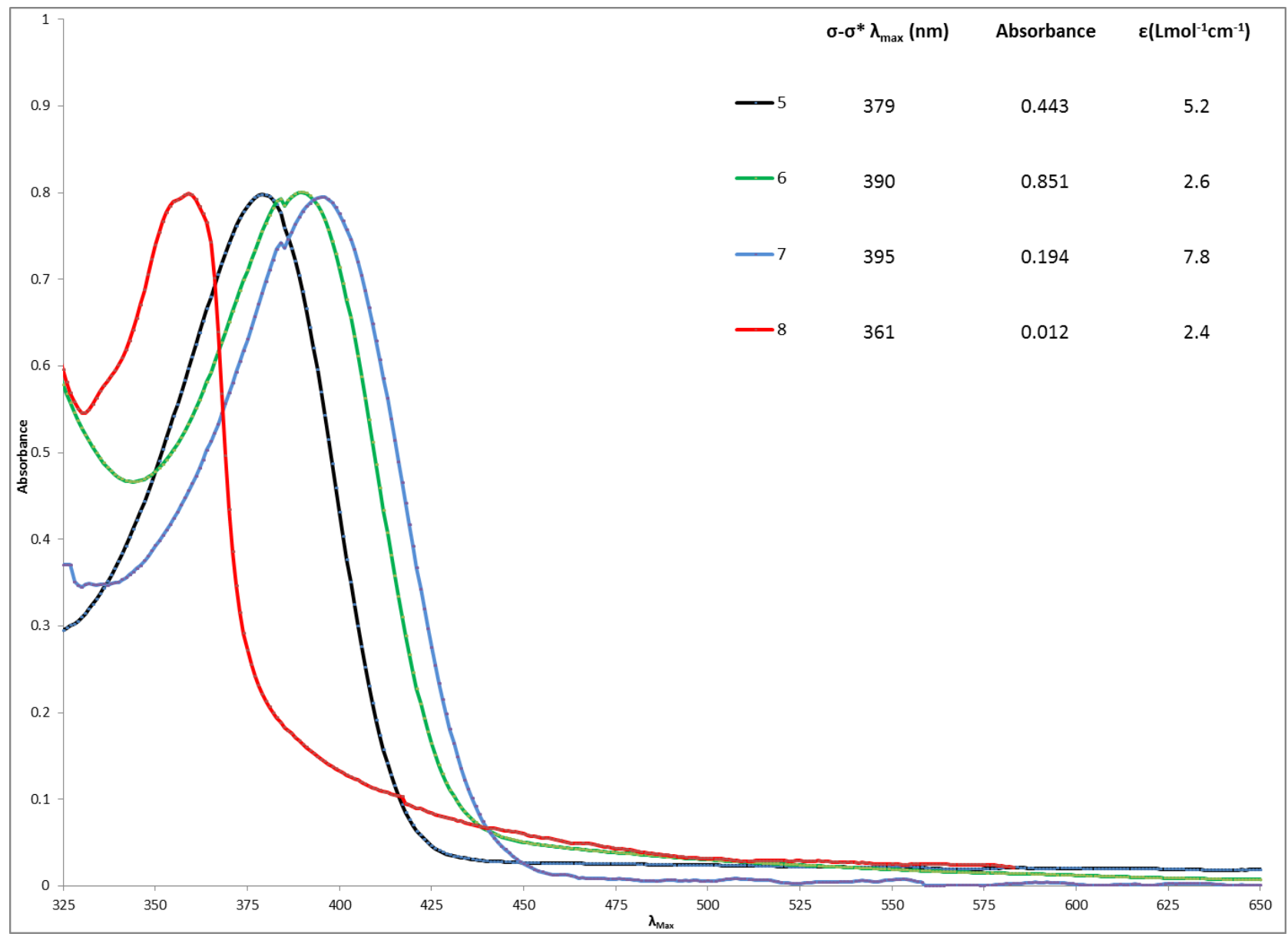

Fig. 3.3.5 UV-Vis (normalized) of 6-8 alternating polymers compared to the homopolymer $\mathbf{5}$ in THF.

Polystannanes $\mathbf{6}$ and 7 comprised of alternating alkyl and aryl substituents display a small redshift $(10-15 \mathrm{~nm})$ of their $\sigma-\sigma^{*}$ transition relative to $\mathbf{5}\left(\lambda_{\max }=379 \mathrm{~nm}\right)$ while a blue shift of similar magnitude $(16 \mathrm{~nm})$ was observed for the mixed alkyl polymer $\mathbf{8}$. The redshift of polymers $\mathbf{6}$ and 7 is likely a consequence of $\sigma+\pi$ conjugation from the $\mathrm{Ph}$ substituents attached to $\mathrm{Sn} .^{23}$ 


\section{4-Conclusions}

A new condensation route to homopolystannanes and previously unknown alternating polystannanes has been demonstrated. This thermally favourable condensation reaction offers a relatively straightforward process and enables design features that could lead to even more light and moisture stable polystannanes.

\section{5- Support}

This work supported by Ryerson University as well as an NSERC Discovery grant. We would also like to thank the Chemistry and Biology Department for their support and the editorial support provided by Dr. Robert Gossage, Dr. Russell Viirre, and Dr. Timothy Burrow (NMR). DF would like to thank the Department of Chemistry at the Universidade Federal De Santa Catarina, Brazil for their support. 


\section{Chapter 4- Linear oligostannanes: a Synthetic and TD-DFT study}

Shane Harrypersad, ${ }^{\mathrm{a}}$ Laura Liao, ${ }^{\mathrm{b}}$ Aman Khan, ${ }^{\mathrm{a}}$ Stephen Wylie, ${ }^{\mathrm{a}}$ and Daniel A. Foucher ${ }^{\mathrm{a},{ }^{*}}$

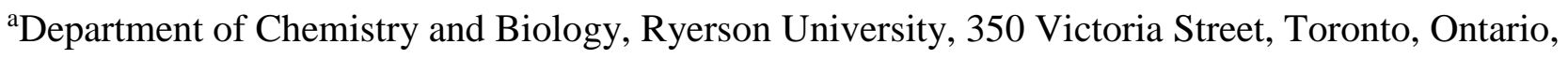
Canada M5B-2K3

${ }^{\mathrm{b}}$ Department of Physics, Ryerson University, 350 Victoria Street, Toronto, Ontario, Canada M5B$2 \mathrm{~K} 3$

\section{1-Abstract}

A series of model linear tristannanes, $\left(\left({ }^{1} \mathrm{R}\right)_{3} \mathrm{Sn}\right)_{2}\left({ }^{2} \mathrm{R}\right)_{2} \mathrm{Sn}\left(9\right.$ : ${ }^{1} \mathrm{R}={ }^{2} \mathrm{R}=n$-Bu, 10: ${ }^{1} \mathrm{R}=\mathrm{Ph},{ }^{2} \mathrm{R}=n$ $\mathrm{Bu}, 11:{ }^{1} \mathrm{R}=\mathrm{Me},{ }^{2} \mathrm{R}=n$-Bu, 12: ${ }^{1} \mathrm{R}=n$-Bu, ${ }^{2} \mathrm{R}=\mathrm{Ph}, 13:{ }^{1} \mathrm{R}=\mathrm{Me},{ }^{2} \mathrm{R}=\mathrm{Ph}, 14:{ }^{1} \mathrm{R}=n$-Bu, ${ }^{2} \mathrm{R}=$ Me, 15: ${ }^{1} \mathrm{R}=\mathrm{Ph},{ }^{2} \mathrm{R}=\mathrm{Me}$ ) were prepared by condensation reactions of one equivalent of a dialkyl or diaryl tin diamide or dihydride and two equivalents of a trialkyl or triaryl tin hydride or amide respectively, and characterized by NMR $\left({ }^{1} \mathrm{H},{ }^{13} \mathrm{C},{ }^{119} \mathrm{Sn}\right)$ and UV-Vis spectroscopy, and elemental analysis. An LSDA/SDD level of DFT and TD-DFT for trimers 9-15 predicts significant structural differences as a function and nature of the substituents bound to tin and calculated electronic transitions for these compounds in fair relative agreement with experimental results. Calculated electronic spectra obtained from equivalent DFT studies of the sequentially lengthened oligomers $\mathrm{Ph}_{3} \mathrm{Sn}\left[t-\mathrm{Bu}_{2} \mathrm{Sn}\right]_{\mathrm{n}} \mathrm{SnPh}_{3}$ (16-19 where $\left.\mathrm{n}=1-4\right)$ previously prepared by Dräger are in good agreement with the reported experimental UV-visible spectroscopic and X-ray diffraction data which show a red shift of the $\sigma-\sigma^{*}$ absorption transition $\left(\lambda_{\max }\right)$ and bond lengthening and bond angle widening of the central tin atoms as the oligostannane is extended. TD-DFT studies of the alkoxy terminated di(n-butyl) oligostannanes 20a-m $\quad\left(\mathrm{CH}_{3} \mathrm{CH}_{2} \mathrm{OCH}_{2} \mathrm{CH}_{2}[\mathrm{Sn}(n\right.$ $\left.\mathrm{Bu})_{2}\right]_{n} \mathrm{CH}_{2} \mathrm{CH}_{2} \mathrm{OCH}_{2} \mathrm{CH}_{3}$ ); $\mathrm{n}=3-15$ ) indicate lower limiting energy gaps as the polymer chain size is increased. The calculated data deviates significantly from results found experimentally by Sita 
and suggests that even smaller energy gaps are possible if the polymer (21) resides in an all trans configuration. TD-DFT studies at the LSDA/SDD level were also carried out on a model oligoand polystannane $16\left(\mathrm{H}\left[\mathrm{SnH}_{2}\right]_{\mathrm{n}} \mathrm{H}, \mathrm{n}=1-40\right)$ to investigate the impact of $\mathrm{Sn}$ catenation on the intrinsic band gap of the material and compared to both the Si and Ge analogues 22 and 23 $\left(\mathrm{H}\left[\mathrm{MH}_{2}\right]_{\mathrm{n}} \mathrm{H}, \mathrm{M}=\mathrm{Si}, \mathrm{Ge}: \mathrm{n}=1-40\right)$. The modelling of the polymetallanes reveals the expected limiting energy gap of the $\sigma-\sigma^{*}$ transition in a trans-planar configuration with $\mathrm{Sn}(2.681 \mathrm{eV})<\mathrm{Ge}$ $(3.096 \mathrm{eV})<\mathrm{Si}(3.719 \mathrm{eV})$ in good agreement with previous studies by Takeda. Finally, comparison of the TD-DFT calculated data for model alternating oligostannanes (24-26) with the UV-Vis spectroscopic data for alternating polystannanes (27-29) recently prepared by polycondensation is made.

\section{2-Introduction}

Conductive polymers have found useful applications as ITO(Indium tin oxide)-free replacement materials in photonic devices ${ }^{40}$ and as semi-conducting polymers for organic thin-film transistors $(\mathrm{OTFT})^{41}$. While $\sigma$-conjugated organic materials, such as PEDOT (Poly(3,4ethylenedioxythiophene) are of prevailing interest for such applications ${ }^{42}$, considerably less attention has been turned towards the use of processable $\sigma$-conjugated inorganic materials, such as polystannanes. By understanding how to manipulate structural features to achieve the desired electronic properties, materials may be endowed with such properties in a rational way. To a degree, the factors which affect the electronic properties of linear polystannanes are understood ${ }^{6,43-}$ ${ }^{44}$, and while considerable improvement in the utility of these materials to make them industrially useful is still required, predictive tools available to computational chemistry ${ }^{44}$ may resolve the current gray areas in comprehension. Structural predictions for large sets of molecules can be rapidly screened for their desirable properties and lead to tailored materials with improved conductivity, light stability, moisture resistance and solubility. In this work we propose both an 
experimental and theoretical investigation of oligostannanes, of ligand effects on the band gaps of these materials and the stability contributions of various aspects to the $\mathrm{Sn}$ - $\mathrm{Sn}$ bond for the purposes of achieving stable, potentially conductive materials.

Compared to the higher Group 14 elements silicon and germanium, tin forms the weakest covalent metal-metal bonds ${ }^{45-47}$ (BDE for single $\sigma$ bond: Sn-Sn 146 kJ/mol, Ge-Ge 188 kJ/mol, SiSi $222 \mathrm{~kJ} / \mathrm{mol})^{48}$; oligo- and polystannanes do not easily remain as catenates and show increased sensitivity to light and moisture. Tin catenates are interesting for the fact that, structurally, they resemble saturated hydrocarbons, yet they exhibit conjugation that is more typical of $\pi$-bonded alkenes. Instead, organotin polymers possess a highly delocalized, $\sigma$-conjugated backbone due to the diffuse overlap of $5 p_{x}$ orbitals of neighbouring Sn centers. ${ }^{45}$ Analogous $\sigma$-conjugation had been noted previously for polymers with either $\mathrm{Si}-\mathrm{Si}$ or $\mathrm{Ge}-\mathrm{Ge}$ backbones, with polysilanes and polygermanes showing absorption maxima $\left(\lambda_{\max }\right)$ approaching the near-UV of the UV-vis absorption spectrum. ${ }^{45}$ In oligostannanes and polystannanes, the backbone acts as a chromophore that is responsible for the characteristic absorption peak that is observed from the near-UV through to the visible spectral region depending on the substituents attached to tin and on the length of the oligomer itself. ${ }^{49}$

The absorption maximum of oligo- and polystannanes has been assigned to a $\sigma-\pi^{*}$ transition (HOMO/LUMO) based on polysilane studies ${ }^{50}$, and serves as a useful probe of the first band gap. The $\sigma-\sigma^{*}$ transition is a key observable in deciphering the relationship between structure and electronic/optical properties of polystannanes. A comprehensive understanding of polystannane structure-property relationships affords skillful manipulation of this band gap. Based on the current study, and those already conducted in the literature, only modest alterations in the band gaps of polystannanes have been achieved. The magnitude of the band gap rests on several 
key structural attributes. Firstly, the choice of metal atom can be rationalized. According to theoretical calculations performed by Takeda and Shirashi for the simplest polymetallanes $(\mathrm{H}-$ $\left[\mathrm{MH}_{2}\right]_{\mathrm{n}}-\mathrm{H}$, where $\mathrm{M}=\mathrm{Si}$, Ge and $\mathrm{Sn}$ ) in a TP (trans planar) configuration, the band gap decreases in order of atomic number $\left(\mathrm{H}-\left[\mathrm{SiH}_{2}\right]_{n}-\mathrm{H}: 3.89 \mathrm{eV}>\mathrm{H}-\left[\mathrm{GeH}_{2}\right]_{\mathrm{n}}-\mathrm{H}: 3.31 \mathrm{eV}>\mathrm{H}-\left[\mathrm{SnH}_{2}\right]_{\mathrm{n}}-\mathrm{H}: 2.80\right.$ $\mathrm{eV}$ ), with the narrowest band gap inherent to polystannanes. ${ }^{41}$ Experimentally, the same trend was observed in the series of dibutyl-substituted polymetallanes $\left[\mathrm{M}(n-\mathrm{Bu})_{2}\right]_{\mathrm{n}}$, where the band gap energies are $\left[\mathrm{Si}(n-\mathrm{Bu})_{2}\right]_{\mathrm{n}}: 3.95,\left[\mathrm{Ge}(n-\mathrm{Bu})_{2}\right]_{\mathrm{n}}: 3.70$ and $\left[\mathrm{Sn}(n-\mathrm{Bu})_{2}\right]_{\mathrm{n}}: 3.20 \mathrm{eV}$, respectively. ${ }^{50-52}$ Secondly, geometrical deformation modifies the polystannane band gaps. Bulky side groups, such as $t$-Bu, widen $\mathrm{Sn}-\mathrm{Sn}-\mathrm{Sn}$ bond angles and elongate $\mathrm{Sn}-\mathrm{Sn}$ bond lengths ${ }^{11,41,}$ resulting in weakened ss $\sigma$ and ppr couplings (skeleton Sn atomic orbitals) and a narrowing of the band gap. ${ }^{43}$ When $\left[\mathrm{SnH}_{2}\right]_{\mathrm{n}}$ is substituted to $\left[\mathrm{Sn}(t-\mathrm{Bu})_{2}\right]_{\mathrm{n}}$, theoretical band gap calculations predict a $26 \%$ reduction in the band gap energy. ${ }^{43}$ Thus, calculations were extended to consider the possibility of achieving a metallic state by opening the $\mathrm{Sn}-\mathrm{Sn}-\mathrm{Sn}$ and $\mathrm{H}-\mathrm{Sn}-\mathrm{H}$ bond angles. When $\mathrm{Sn}-\mathrm{Sn}-\mathrm{Sn}$ angles are greater than $150^{\circ}$, the conduction band and valence band are predicted to overlap.

The effects of such distortions suggest that a metallic state can be obtained by applying pressure to films or solid polystannanes. In addition to deformation, the band edge states are greatly affected by polystannane conformation. In all trans-planar polysilanes and polystannanes, twisting primarily affects the highest occupied molecular orbital (HOMO) due to its $p_{z}$ character, while the lowest unoccupied molecular orbital (LUMO) is less responsive because of its $s$ character and symmetry. ${ }^{43,50}$ The difference between $\left[\mathrm{SnH}_{2}\right]_{\mathrm{n}}$ with an all trans-planar (TP) or all gauche-helical $(\mathrm{GH})$ conformation, is a broadening of the band gap by about a factor of $1.5 .^{43}$ Correspondingly, cyclic tin oligomers exhibit a blue shift in absorption peak as the planar arrangement in small rings changes to the twist and gauche conformations in larger rings. ${ }^{11}$ In a polystannane chain with various TP and GH segments, the longest TP chromophore absorbs at the 
longest wavelengths while the longest GH chromophore absorbs at the shortest wavelengths. A distribution of absorption components, determined by the length and conformation of chromophore segments, contribute to the overall absorption peak (Figure 4.2.1) ${ }^{53}$ TP conformation provides the narrowest band gap and optimal conjugation along the backbone. ${ }^{11}$ Powder X-ray diffraction has been used to ascertain the conformation of $\mathrm{H}\left[\left(p-t-\mathrm{Bu}-\mathrm{C}_{6} \mathrm{H}_{4}\right)_{2} \mathrm{Sn}\right]_{\mathrm{n}} \mathrm{H}$, whose $7 / 3$ helical T3GT3G0 structure has been proposed to be "optimized" to an all TP conformation ${ }^{24}$, and so $o$-Et was introduced to $\mathrm{H}\left[\left(o-\mathrm{Et}_{-} \mathrm{C}_{6} \mathrm{H}_{4}\right)_{2} \mathrm{Sn}\right]_{\mathrm{n}} \mathrm{H}$ as a directing group in order to constrain a TP conformation. Results show a greater conjugation since the $\sigma-\sigma^{*}$ transition redshifted to $468 \mathrm{~nm} ; 30 \mathrm{~nm}$ relative to both $\mathrm{H}\left[\left(p-t-\mathrm{Bu}-\mathrm{C}_{6} \mathrm{H}_{4}\right)_{2} \mathrm{Sn}\right]_{\mathrm{n}} \mathrm{H}$ and $\mathrm{H}\left[\left(p-n-\mathrm{Hex}-\mathrm{C}_{6} \mathrm{H}_{4}\right)_{2} \mathrm{Sn}\right]_{n} \mathrm{H}^{6}$

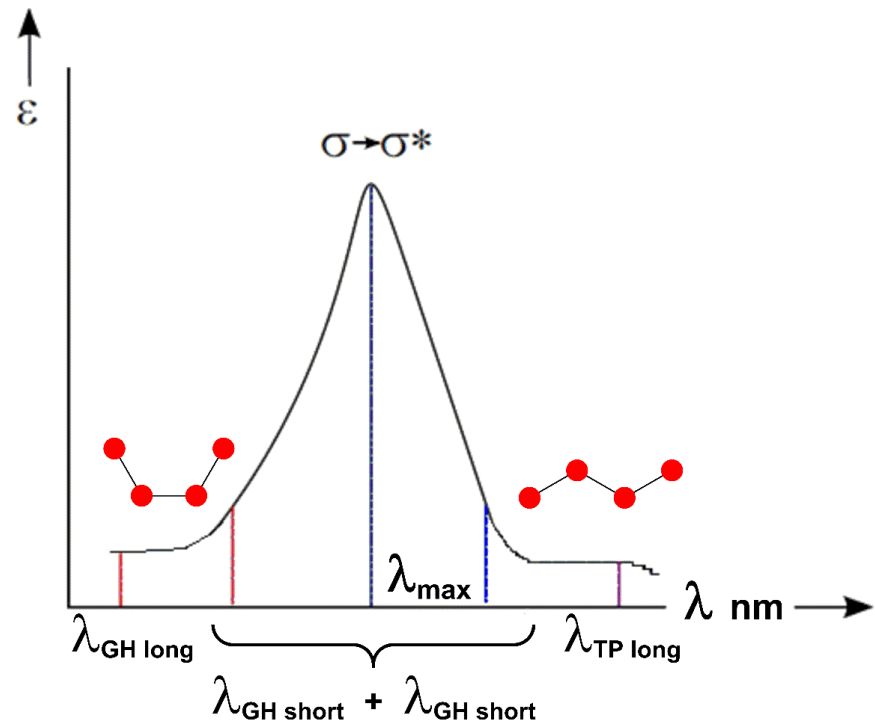

Figure 4.2.1: Contributions to the absorption peak from $\mathrm{Sn}-\mathrm{Sn}$ chromophores of varying lengths and conformations.

Lastly, substituent effects on the polystannane band gap must be considered. Alkyl substituents do not directly affect the band gap, other than by deformation of the tin backbone. ${ }^{43}$ However, by destabilizing the HOMO, permethylation of $-\left[\mathrm{SiH}_{2}\right]_{n}$ - indeed decreases the band gap. ${ }^{50}$ The change in energy is expected to be similar for various alkyl substituents on polystannanes. With aryl substituents, a more dramatic change to the band gap is expected. Compared to 
poly(dialkylstannane)s, the $\sigma-\sigma^{*}$ transition of a low molecular weight poly(diarylstannane), $\mathrm{H}\left[\mathrm{SnPh}_{2}\right]_{\mathrm{n}} \mathrm{H}$, was redshifted by $70 \mathrm{~nm}$ to $402 \mathrm{~nm}^{49}$ Furthermore, para-substituted $-[(p-\mathrm{R}-$ $\left.\left.\mathrm{C}_{6} \mathrm{H}_{4}\right)_{2} \mathrm{Sn}\right]_{\mathrm{n}^{-}}\left(\mathrm{R}=t-\mathrm{Bu}, \lambda_{\max }=432 \mathrm{~nm} ; n-\mathrm{Hex}, \lambda_{\max }=436 \mathrm{~nm}\right)$ led to a $30-40 \mathrm{~nm}$ redshift with respect to analogous poly(dialkylstannane)s. ${ }^{5}$ Incorporation of para-substituted $\pi$-donating groups on aryl substituents, such as $-\left[\left(p-n-\mathrm{BuO}-\mathrm{C}_{6} \mathrm{H}_{4}\right)_{2} \mathrm{Sn}\right]_{\mathrm{n}}$, , further narrowed the band gap by presumably destabilizing the HOMO ${ }^{47}$ Moreover, the combined effect of a directing group in conjunction with a $\pi$-donating group, in $-\left[\left(o-\mathrm{Et}-p-n-\mathrm{BuO}-\mathrm{C}_{6} \mathrm{H}_{3}\right)_{2} \mathrm{Sn}\right]_{\mathrm{n}}{ }^{-}$, produced the lowest band gap recorded to date $\left(\lambda_{\max }=506 \mathrm{~nm} ; 2.3 \mathrm{eV}\right){ }^{6}$ Evidently, aryl substituents showed significant $\sigma-\sigma$ conjugation with the tin backbone. With $-\left[\left(o-\text { Et }-p-n-\mathrm{BuO}-\mathrm{C}_{6} \mathrm{H}_{3}\right)_{2} \mathrm{Sn}\right]_{n^{-}}$, only moderate molecular weights $\left(\mathrm{M}_{\mathrm{w}}<5000 \mathrm{Da}\right)$ could be achieved. However, the overall effect on the band gap may only be comparatively assessed for high molecular weight polymers. Upon catenation, tin oligomers exhibit a redshift of the $\sigma-\sigma^{*}$ transition; regardless of substituent type.$^{2,11,45}$ The same trend is true for polysilanes, as well as polygermanes. ${ }^{45}$ As the number of metal atoms approaches thirty, the redshift plateaus to a limiting wavelength value, ${ }^{52}$ although an exception was noted recently in $\left[\left(p-n \mathrm{BuO}-\mathrm{C}_{6} \mathrm{H}_{4}\right)_{2} \mathrm{Sn}\right]_{\mathrm{n}^{-}}\left(\mathrm{n}=30 ; \lambda_{\max }=424 \mathrm{~nm} ; \mathrm{n}=80 ; \lambda_{\max }=448 \mathrm{~nm}\right){ }^{6}$

In 1992, a route to high molecular weight (HMW) polystannanes by Wurtz coupling was accomplished by Zou and Yang, and later optimized by Molloy et al. ${ }^{8,12}$ Around the same time, linear oligostannanes, with up to 15 tin atoms in the backbone were synthesized by Sita $e t$ al. via hydrostannolysis. ${ }^{2,52,56}$ Well defined and reproducibly prepared HMW polystannanes were also successful prepared by Tilley and co-workers through metal-catalyzed dehydropolymerization of secondary stannanes. ${ }^{5,6,24}$ Electrochemical synthesis of HMW dialkyl substituted polystannanes reported by Takeda et al. has rounded out the roster of synthetic methodologies. ${ }^{7}$ Cyclic oligostannanes are typically present as byproducts of polystannane degradation during synthesis. Polystannanes are known to be air- and light-sensitive, requiring protection from the ambient 
environment. ${ }^{8,11,35 \text {, and } 49}$ More specifically, polystannanes can withstand oxygen exposure, but are vulnerable to moisture. ${ }^{17}$

A possible solution to stability issues, while wielding control over the band gap, is to impose alternating "push-pull" ligands or groups onto the tin oligomers. Push-pull species are often, but not limited to, $\pi$-conjugated, vinyl substituted benzenes with diametrically opposed donor and acceptor groups. Notably, they feature spatially separated frontier orbitals which are localized onto each group. The HOMO is constrained to the donor substituent while the LUMO is constrained to the acceptor substituent. By modifying the substituents, the electron density can be shifted predictably by such a "push-pull" effect. ${ }^{57}$ Less dramatic effects are anticipated for polystannanes with less $\sigma-\pi$ orbital mixing, such as $-\left[(\text { push })_{2} \operatorname{SnSn}(\text { pull })_{2}\right]_{n^{-}}$with alternating alkyl and aryl substituents or for asymmetrical polystannanes, $-[(\text { pull }) \operatorname{Sn}(\text { push })]_{n^{-}}$, bearing one alkyl and aryl substituent per tin atom. However, it is clear that tunable modification of the substituents along the polystannane backbone is possible and that electron density can be shifted predictably by a "pushpull" approach. ${ }^{57}$

Previous models which attempted to capture electronic or optical properties of tin oligomers were generally performed at the semi-empirical level of theory. Hückel molecular orbital (HMO) theory was developed for conjugated organic systems but displayed competency in correlating chain length behaviour of oligosilanes ${ }^{58,59}$, and the theory was also successfully applied to short tin oligomers up to six atoms. ${ }^{45}$ When a larger experimental dataset of tin oligomers with up to fifteen metal atoms was obtained by Sita et al., the HMO theory was no longer successful on its own. An augmented version of HMO theory, the Sandorfy model C approximation, was next considered. ${ }^{52}$ This model had been effectively used for polysilanes and represented the polysilane backbone as interacting $\mathrm{sp}^{3}$ hybrid orbitals. Two parameters characterized the resonance integrals of vicinal $\left(\beta_{\text {vic }}\right)$ and geminal $\left(\beta_{\text {gem }}\right) \mathrm{sp}^{3}$ orbitals. Their ratio, $\beta_{\mathrm{gem}} / \beta_{\text {vic }}$, indicated the degree of $\mathrm{MO}$ 
delocalization over the polymer backbone; $\beta_{\mathrm{gem}} / \beta_{\mathrm{vic}}=0$ for total localization of MOs, $\beta_{\mathrm{gem}} / \beta_{\mathrm{vic}}=1$ for absolute delocalization. ${ }^{50}$ The model was applied to the full dataset of tin oligomers and was found suitable for describing the delocalized HOMO of heavy atoms in the more metallic tin backbone when a $\beta_{\mathrm{gem}} / \beta_{\text {vic }}$ ratio of 0:75 was assumed. ${ }^{52}$ Other models, such as Sandorfy H, account for the LUMO, focusing on the interaction between the backbone and substituent orbitals. ${ }^{50}$ Elaborations on these descriptive models have shown that the simple intuitions of HMO theory still hold. ${ }^{60}$ By employing ab initio methods such as DFT where the effective core potentials of tin are accounted for, structure predictions can be made without the requirement of existing experimental data. ${ }^{61}$

In this work, we attempt to validate TD-DFT methods quantitatively against UV-vis absorption data for a series of new mixed alkyl and aryl tristannanes prepared by condensation, known oligoand polystannanes, as well as qualitatively against complementary theoretical studies. Finally, these TD-DFT methods are applied to a recently prepared series of alternating "push-pull" polystannanes and these results are further discussed..$^{50}$ 


\section{3-Experimental}

\subsection{1-Materials and Methods}

All reagents were purchased from Sigma Aldrich. Solvents were dried using an MBraun solvent drying system. Diethylamine was distilled and kept dry over activated molecular sieves. All glassware was first dried in an oven then flame dried to remove surface moisture. ${ }^{1} \mathrm{H}$ NMR $(400 \mathrm{MHz})$, ${ }^{13} \mathrm{C}$ NMR (100.6 MHz) and ${ }^{119} \mathrm{Sn}$ NMR (149.2 MHz) spectra were recorded on a Bruker Advance $400 \mathrm{MHz}$ NMR spectrometer with a BBFO 5-mm direct probe. A ${ }^{1} \mathrm{H}$ pulse width of $30^{\circ}$ was used, acquiring a spectral window of $8223 \mathrm{~Hz}(20 \mathrm{ppm})$ using a relaxation delay of $1 \mathrm{~s}$, acquisition time 3.98s, 32k points (16 scans). The ${ }^{1} \mathrm{H} 90^{\circ}$ pulse width was $10.4 \mu \mathrm{s}$. A ${ }^{13} \mathrm{C}$ pulse width of $30^{\circ}$ was used, acquiring a spectral window of $24038 \mathrm{~Hz}(239 \mathrm{ppm})$ using a relaxation delay of $2 \mathrm{~s}$, acquisition time $1.36 \mathrm{~s}, 32 \mathrm{k}$ points (4096 scans). The ${ }^{13} \mathrm{C} 90^{\circ}$ pulse width was $8.7 \mu \mathrm{s}$. A ${ }^{119} \mathrm{Sn}$ pulse width of $30^{\circ}$ was used, $8.75 \mu \mathrm{s}$, acquiring a spectral window of $100000 \mathrm{~Hz}(670 \mathrm{ppm})$ using a relaxation delay of $1 \mathrm{~s}$, acquisition time $0.33 \mathrm{~s}, 32 \mathrm{k}$ points (15360 scans) with inverse gated proton decoupling. All results were analyzed on MestReNova LITE 5.2.5 software. Chemical shifts were calculated using the chemical deuterated standards $\left(\mathrm{C}_{6} \mathrm{D}_{6}\right.$ or $\left.\mathrm{CDCl}_{3}\right)$ as a reference for ${ }^{1} \mathrm{H}$ and ${ }^{13} \mathrm{C}$. The ${ }^{119} \mathrm{Sn}$ was referenced to $\mathrm{SnMe}_{4}$ as an internal standard. All $J$ coupling values are reported as absolute values. UV-Vis evaluations were carried out using a Perkin Elmer Lambda $20 \mathrm{UV}-\mathrm{Vis}$ spectrometer. Original samples were collected in the range of $300-800 \mathrm{~nm}$. All samples were prepared in THF at a concentration $\approx 1 \times 10^{-3} \mathrm{M}$. Elemental Analysis was performed by Atlantic Microlab, Inc. of Norcross Georgia. All reactions took place under nitrogen $\left(\mathrm{N}_{2}\right)$ atmosphere or in a sealed Schlenk flask placed under reduced pressure (closed) or finally in a Schlenk flask exposed to dynamic reduced pressure (open). Pressures measured in $\mathrm{mmHg}$ using a mercury manometer attached to the Schlenk line. 


\subsection{2-Computational Details}

All calculations were carried out using the Gaussian 09 suite of programs ${ }^{62}$, using the graphical interface GaussView to construct molecules, submit calculations and visualize results. For molecules with six or fewer tin atoms, geometries were optimized using one or both of the density functionals LSDA ${ }^{63}$ and the hybrid TPSSh ${ }^{64}$, and one or both of the basis sets: SDD ${ }^{65}$ and LANL2DZ ${ }^{66}$ as implemented by the corresponding keywords in the Gaussian program. Performance of these functionals and basis sets were generally comparable in terms of accuracy relative to known solid-state structures. In studies of structurally related tin oligomers, with some series members containing more than six tin atoms, geometries were optimized using the HartreeFock (HF) method and the basis set SDD to reduce computational time requirements. For the shorter molecules studied, optimization with HF gave comparable bond lengths and angles with DFT methods. The minimum character of optimized structures was verified by evaluation of the harmonic vibrational frequencies. Electronic spectra were calculated using time-dependent DFT (TD-DFT) ${ }^{67}$ with the LSDA density functional and the SDD basis set.

\subsection{3-Synthesis of the Compounds $9-15$}

Precursor compounds A-D (Figure 4.3.3.1) were prepared and characterized according to our earlier report of these monomers for polycondensation reactions leading to polystannanes. ${ }^{68}$ Trialkyl and triaryl stannanes $(\mathbf{E}-\mathbf{F})$ and amines $(\mathbf{G}-\mathbf{H})$ were prepared in a similar fashion to the dialkyl and diaryl stannanes ${ }^{69}$ and stannides ${ }^{43}$ from the reaction of the respective tin chloride with reducing agents such as $\mathrm{LiAlH}_{4}$ or $\mathrm{NaBH}_{4}$ or from the metal halogen exchange reaction with lithiated diethylamine. The complete data for compounds is listed below. 

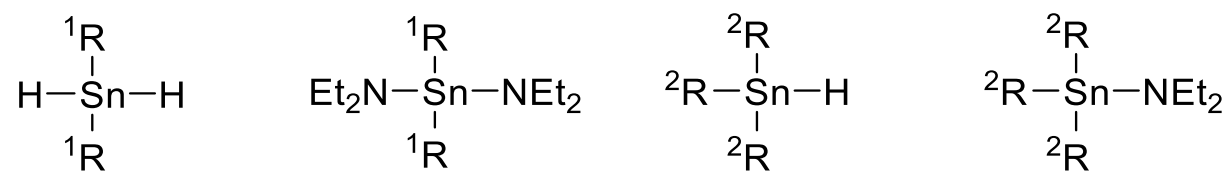
$\mathrm{A}:{ }^{1} \mathrm{R}=n-\mathrm{Bu}$
C: ${ }^{1} \mathrm{R}=n-\mathrm{Bu}$
$\mathrm{E}:{ }^{2} \mathrm{R}=n-\mathrm{Bu}$
G: ${ }^{2} \mathrm{R}=n-\mathrm{Bu}$
B: ${ }^{1} \mathrm{R}=\mathrm{Ph}$
D: ${ }^{1} \mathrm{R}=\mathrm{Me}$
F: ${ }^{2} \mathrm{R}=\mathrm{Ph}$
$\mathrm{H}:{ }^{2} \mathrm{R}=\mathrm{Me}$

Figure 4.3.3.1: Structures of stannyl hydrides and amides used to prepare tristannanes 9-15.

\subsubsection{1- Preparation of tri(n-butyl)stannane $(\mathbf{E})$}

Dry $\mathrm{Et}_{2} \mathrm{O}(30 \mathrm{~mL})$ was used to dissolve $(n-\mathrm{Bu})_{3} \mathrm{SnCl}(1.53 \mathrm{mmol}, 4.97 \mathrm{~g})$ in a $250 \mathrm{~mL}$ Schlenk flask. An equimolar solution of $\mathrm{LiAlH}_{4}$ in $\mathrm{Et}_{2} \mathrm{O}$ was added drop-wise with constant stirring over a $30 \mathrm{~min}$ period at $0^{\circ} \mathrm{C}$. The resultant solution was allowed to react for $3 \mathrm{~h}$ at constant temperature. The reaction was quenched with $30 \mathrm{~mL}$ chilled degassed water. The organic layer was separated and the aqueous layer extracted with $20 \mathrm{~mL} \mathrm{Et}_{2} \mathrm{O}$. The combined organic layers were dried over $\mathrm{CaCl}_{2}$ for $2 \mathrm{~h}$. After filtration, the volatiles from the solution containing $\mathbf{E}$ were removed in vacuo to yield a cloudy coloured liquid. The sample was stored at $-20^{\circ} \mathrm{C}$ to avoid decomposition. Yield: $4.08 \mathrm{~g}(82 \%)$.

${ }^{1} \mathrm{H}$ NMR $\left(\mathrm{C}_{6} \mathrm{D}_{6}\right): \delta 5.03\left(\mathrm{q}, 1 \mathrm{H},{ }^{1} J_{119 \mathrm{Sn}-1 \mathrm{H}}=1582 \mathrm{~Hz},{ }^{1} J_{117 \mathrm{Sn}-1 \mathrm{H}}=1512 \mathrm{~Hz},-\mathrm{Sn} H\right), 1.55(\mathrm{~m}, 6 \mathrm{H}$, $\left.{ }^{2} J_{119 \mathrm{Sn}-1 \mathrm{H}}=61 \mathrm{~Hz},{ }^{2} J_{117 \mathrm{Sn}-1 \mathrm{H}}=47 \mathrm{~Hz},-\mathrm{SnCH}_{2} \mathrm{CH}_{2} \mathrm{CH}_{2} \mathrm{CH}_{3}\right), 1.33\left(\mathrm{~m}, 6 \mathrm{H},-\mathrm{SnCH}_{2} \mathrm{CH}_{2} \mathrm{CH}_{2} \mathrm{CH}_{3}\right)$, $0.92\left(\mathrm{t}, 6 \mathrm{H},-\mathrm{SnCH}_{2} \mathrm{CH}_{2} \mathrm{CH}_{2} \mathrm{CH}_{3}\right), 0.90\left(\mathrm{t}, 9 \mathrm{H},-\mathrm{SnCH}_{2} \mathrm{CH}_{2} \mathrm{CH}_{2} \mathrm{CH}_{3}\right)$ ppm; ${ }^{119} \mathrm{Sn}\left\{{ }^{1} \mathrm{H}\right\} \mathrm{NMR}$ $\left(\mathrm{C}_{6} \mathrm{D}_{6}\right): \delta-88.8 \mathrm{ppm}$. This data is in good agreement with reported literature values. ${ }^{50,55}$ 
4.3.3.2- Preparation of triphenylstannane $(\mathbf{F})$

Compound $\mathbf{F}$ was prepared in a manner similar to that used for compound $\mathbf{E}$ above. Yield: $4.96 \mathrm{~g}$ $(84 \%)$.

${ }^{1} \mathrm{H}$ NMR $\left(\mathrm{C}_{6} \mathrm{D}_{6}\right) \delta: 7.41\left(\mathrm{dd}, 6 \mathrm{H},{ }^{4} J_{119 \mathrm{Sn}-1 \mathrm{H}}=6.3 \mathrm{~Hz},{ }^{5} J_{119 \mathrm{Sn}-1 \mathrm{H}}=3.1 \mathrm{~Hz}, o-\mathrm{C}_{6} \mathrm{H}_{5}\right), 7.10(\mathrm{dd}, 9 \mathrm{H}$, $\left.{ }^{3} J_{119 \mathrm{Sn}-1 \mathrm{H}}=4.8 \mathrm{~Hz},{ }^{3} J_{117 \mathrm{Sn}-1 \mathrm{H}}=1.8 \mathrm{~Hz},, m, p-\mathrm{C}_{6} \mathrm{H}_{5}\right), 6.91\left(\mathrm{~s}, 1 \mathrm{H},{ }^{1} J_{119 \mathrm{Sn}-1 \mathrm{H}}=1934 \mathrm{~Hz},{ }^{1} J_{117 \mathrm{Sn}-1 \mathrm{H}}=\right.$ $1848 \mathrm{~Hz},-\mathrm{Sn} H), \mathrm{ppm} ;{ }^{119} \mathrm{Sn}\left\{{ }^{1} \mathrm{H}\right\}$ NMR $\left(\mathrm{C}_{6} \mathrm{D}_{6}\right): \delta-162.8 \mathrm{ppm}$. This data is in good agreement with reported literature values. ${ }^{52}$

4.3.3.3-Preparation of (diethylamino)tributylstannane $(\mathbf{G})$

Dry $\mathrm{Et}_{2} \mathrm{O}(30 \mathrm{~mL})$ was used to dissolve $(n-\mathrm{Bu})_{3} \mathrm{SnCl}$ chloride $(1.53 \mathrm{mmol}, 4.97 \mathrm{~g})$ in a $250 \mathrm{~mL}$ Schlenk flask. In a second $250 \mathrm{~mL}$ Schlenk flask, $20 \mathrm{~mL}$ of $\mathrm{Et}_{2} \mathrm{O}$ was added along with (3.06 mmol, $2.23 \mathrm{~g}$ ) of $\mathrm{HNEt}_{2}$, cooled to $0{ }^{\circ} \mathrm{C}$, and an equimolar amount of $n$-BuLi (3.06 mmol) added dropwise over $15 \mathrm{~min}$. The mixture was allowed to warm to room temperature with stirring for $2 \mathrm{~h}$. The flask containing the lithiated amine was then cooled again to $0^{\circ} \mathrm{C}$ and the solution containing the tin halide added dropwise. A salt formed upon addition and the solution was stirred for $12 \mathrm{~h}$. After filtration, the volatiles from the solution containing $\mathbf{G}$ were removed in vacuo to yield an orange coloured liquid. Yield: $4.22 \mathrm{~g}(73 \%)$.

${ }^{1} \mathrm{H}$ NMR $\left(\mathrm{C}_{6} \mathrm{D}_{6}\right) \delta: 2.99\left(\mathrm{~m}, 2 \mathrm{H},-\mathrm{SnN}\left(\mathrm{CH}_{2} \mathrm{CH}_{3}\right), 1.77\left(\mathrm{~m}, 6 \mathrm{H},-\mathrm{SnCH}_{2} \mathrm{CH}_{2} \mathrm{CH}_{2} \mathrm{CH}_{3}\right), 1.71(\mathrm{~m}, 6 \mathrm{H}\right.$, $\left.-\mathrm{SnCH}_{2} \mathrm{CH}_{2} \mathrm{CH}_{2} \mathrm{CH}_{3}\right), 1.42\left(\mathrm{~m}, 3 \mathrm{H},-\mathrm{SnN}\left(\mathrm{CH}_{2} \mathrm{CH}_{3}\right), 1.35\left(\mathrm{~m}, 6 \mathrm{H},-\mathrm{SnCH}_{2} \mathrm{CH}_{2} \mathrm{CH}_{2} \mathrm{CH}_{3}\right), 0.90\right.$ (m, 9H, $\left.-\mathrm{SnCH}_{2} \mathrm{CH}_{2} \mathrm{CH}_{2} \mathrm{CH}_{3}\right)$ ppm; ${ }^{119} \mathrm{Sn}\left\{{ }^{1} \mathrm{H}\right\} \mathrm{NMR}\left(\mathrm{C}_{6} \mathrm{D}_{6}\right): \delta 19.63 \mathrm{ppm}$. This data is in good agreement with reported literature values. ${ }^{53}$ 
4.3.3.4- Preparation of (diethylamino)trimethylstannane $(\mathbf{H})$

Compound $\mathbf{H}$ was prepared in a manner similar to that used for compound $\mathbf{G}$ above. Yield: $5.03 \mathrm{~g}$ $(87 \%)$.

${ }^{1} \mathrm{H}$ NMR $\left(\mathrm{C}_{6} \mathrm{D}_{6}\right) \delta: 2.97\left(\mathrm{q},{ }^{3} J_{119 \mathrm{Sn}-1 \mathrm{H}}=7.0 \mathrm{~Hz}, 2 \mathrm{H},-\mathrm{SnN}\left(\mathrm{CH}_{2} \mathrm{CH}_{3}\right), 1.04\left(\mathrm{t}, 3 \mathrm{H},-\mathrm{SnN}\left(\mathrm{CH}_{2} \mathrm{CH}_{3}\right)\right.\right.$, $0.12\left(\mathrm{~s},{ }^{2} J_{119 \mathrm{Sn}-1 \mathrm{H}}=224 \mathrm{~Hz}, 9 \mathrm{H},-\mathrm{Sn}\left(\mathrm{CH}_{3}\right)_{3}\right) \mathrm{ppm} .{ }^{119} \mathrm{Sn}\left\{{ }^{1} \mathrm{H}\right\} \mathrm{NMR}\left(\mathrm{C}_{6} \mathrm{D}_{6}\right): \delta 43.52 \mathrm{ppm} . \quad$ This data is in good agreement with reported literature values. ${ }^{54}$

4.3.3.5- Preparation of 1,1,1,2,2,3,3,3-octabutyltristannane (9)

Dry $\mathrm{Et}_{2} \mathrm{O}(30 \mathrm{~mL})$ was used to dissolve $\mathbf{A}(0.25 \mathrm{mmol}, 0.59 \mathrm{~g})$ in a $50 \mathrm{~mL}$ Schlenk flask. In a second $50 \mathrm{~mL}$ Schlenk flask, $20 \mathrm{~mL}$ of $\mathrm{Et}_{2} \mathrm{O}$ was added along with $(0.50 \mathrm{mmol}, 1.57 \mathrm{~g})$ of $\mathbf{G}$, cooled to $0{ }^{\circ} \mathrm{C}$ and added dropwise over $15 \mathrm{~min}$. The mixture was kept at $0{ }^{\circ} \mathrm{C}$ with stirring for $3 \mathrm{~h}$. After filtration, the volatiles from the solution containing 9 were removed in vacuo to yield a white coloured oil. NMR $\left({ }^{119} \mathrm{Sn}\right)$ was in good agreement with reported values []. Yield: $1.81 \mathrm{~g}(89 \%)$.

Note: No resolution of the internal (Int) and external (Ext) $n$-Bu environments was observed in the ${ }^{1} \mathrm{H}$ and ${ }^{13} \mathrm{C}$ NMR spectra of 9 at the field strength of a 9.4 T magnet.

${ }^{1} \mathrm{H} \quad \mathrm{NMR}\left(\mathrm{C}_{6} \mathrm{D}_{6}\right) \quad \delta: 1.85-1.52 \quad\left(\mathrm{~m}, \quad 16 \mathrm{H},-\mathrm{Sn}_{(\mathrm{Int}+\mathrm{Ext})} \mathrm{CH}_{2} \mathrm{CH}_{2} \mathrm{CH}_{2} \mathrm{CH}_{3}\right), \quad 1.50-1.29 \quad(\mathrm{~m}, \quad 16 \mathrm{H}$, $\left.\mathrm{Sn}_{(\text {Int+Ext) }} \mathrm{CH}_{2} \mathrm{CH}_{2} \mathrm{CH}_{2} \mathrm{CH}_{3}\right), 1.26-1.06$ (m, 16H, - $\left.\mathrm{Sn}_{(\text {Int+Ext) }} \mathrm{CH}_{2} \mathrm{CH}_{2} \mathrm{CH}_{2} \mathrm{CH}_{3}\right), 1.26-0.89$ (t, 24H, $\left.\mathrm{Sn}_{(\mathrm{Int}+\mathrm{Ext})} \mathrm{CH}_{2} \mathrm{CH}_{2} \mathrm{CH}_{2} \mathrm{CH}_{3}\right) \quad \mathrm{ppm} ; \quad \delta \quad{ }^{13} \mathrm{C}\left\{{ }^{1} \mathrm{H}\right\} \quad \mathrm{NMR}\left(\mathrm{C}_{6} \mathrm{D}_{6}\right) \quad \delta: 30.81 \quad\left({ }^{2} J_{119 \mathrm{Sn}-13 \mathrm{C}}=9 \mathrm{~Hz}\right.$, $\mathrm{Sn}_{\text {(Int+Ext) }} \mathrm{CH}_{2} \mathrm{CH}_{2} \mathrm{CH}_{2} \mathrm{CH}_{3}$ ), $27.56-\mathrm{Sn}_{\text {(Int+Ext) }} \mathrm{CH}_{2} \mathrm{CH}_{2} \mathrm{CH}_{2} \mathrm{CH}_{3}, 13.58-\mathrm{Sn}_{\text {(Int+Ext) }} \mathrm{CH}_{2} \mathrm{CH}_{2} \mathrm{CH}_{2} \mathrm{CH}_{3}$, $10.09\left({ }^{1} J_{119 \mathrm{Sn}-13 \mathrm{C}}=20 \mathrm{~Hz},-\mathrm{Sn}_{(\mathrm{Int}+\mathrm{Ext})} C \mathrm{H}_{2} \mathrm{CH}_{2} \mathrm{CH}_{2} \mathrm{CH}_{3}\right) \mathrm{ppm} ;{ }^{119} \mathrm{Sn}\left\{{ }^{1} \mathrm{H}\right\} \mathrm{NMR}\left(\mathrm{C}_{6} \mathrm{D}_{6}\right): \delta-83.70$ $\left({ }^{1} J_{119 \mathrm{Sn}-119 \mathrm{Sn}}=868 \mathrm{~Hz},{ }^{1} J_{119 \mathrm{Sn}-117 \mathrm{Sn}}=862 \mathrm{~Hz},-\mathrm{Sn}(n-\mathrm{Bu})_{3}\right),-227.4 \quad-\operatorname{Sn}(n-\mathrm{Bu})_{2}$ ppm. E.A.: Anal. Calcd C, 47.27; H, 8.93. Found: C, 48.22; H, 8.93. 
4.3.3.6-Preparation of 1,1,1,3,3,3-hexabutyl-2,2-diphenyltristannane (10)

Compound $\mathbf{1 0}$ was prepared in a manner similar to that used for compound $\mathbf{9}$ above using $\mathbf{B}(0.25$ mmol, $0.69 \mathrm{~g})$ and $\mathbf{G}(0.50 \mathrm{mmol} 1.57 \mathrm{~g})$. Light yellow coloured solid. Yield: $1.53 \mathrm{~g}(75 \%)$.

${ }^{1} \mathrm{H}$ NMR $\left(\mathrm{C}_{6} \mathrm{D}_{6}\right) \delta: 7.59\left(\mathrm{~m}, 4 \mathrm{H},-\mathrm{Sn}\left(o-\mathrm{C}_{6} H_{5}\right)_{2}\right), 7.15\left(\mathrm{~m}, 6 \mathrm{H},-\mathrm{Sn}\left(m, p-\mathrm{C}_{6} H_{5}\right)_{2}\right), 1.70(\mathrm{~m}, 12 \mathrm{H},-$ $\left.\mathrm{Sn}\left(\mathrm{CH}_{2} \mathrm{CH}_{2} \mathrm{CH}_{2} \mathrm{CH}_{3}\right)_{3}\right), 1.43\left(\mathrm{~m},{ }^{3} J_{119 \mathrm{Sn}-1 \mathrm{H}}=8 \mathrm{~Hz}, 24 \mathrm{H},-\mathrm{Sn}\left(\mathrm{CH}_{2} \mathrm{CH}_{2} \mathrm{CH}_{2} \mathrm{CH}_{3}\right)_{3}\right), 1.08(\mathrm{t}, J=7.0$ $\left.\mathrm{Hz}, 18 \mathrm{H},-\mathrm{Sn}\left(\mathrm{CH}_{2} \mathrm{CH}_{2} \mathrm{CH}_{2} \mathrm{CH}_{3}\right)_{3}\right) \mathrm{ppm} ;{ }^{13} \mathrm{C}\left\{{ }^{1} \mathrm{H}\right\} \mathrm{NMR}\left(\mathrm{C}_{6} \mathrm{D}_{6}\right): \delta 163.23-\mathrm{Sn}\left(\right.$ ipso- $\left.\mathrm{C}_{6} \mathrm{H}_{5}\right), 138.15-$ $\mathrm{Sn}\left(o, m-\mathrm{C}_{6} \mathrm{H}_{5}\right), 128.37-\mathrm{Sn}\left(p-\mathrm{C}_{6} \mathrm{H}_{5}\right), 30.63-\mathrm{SnCH}_{2} \mathrm{CH}_{2} \mathrm{CH}_{2} \mathrm{CH}_{3}, 27.61-\mathrm{SnCH}_{2} \mathrm{CH}_{2} \mathrm{CH}_{2} \mathrm{CH}_{3}, 25.44$ $-\mathrm{SnCH}_{2} \mathrm{CH}_{2} \mathrm{CH}_{2} \mathrm{CH}_{3}, 13.77-\mathrm{SnCH}_{2} \mathrm{CH}_{2} \mathrm{CH}_{2} \mathrm{CH}_{3} \mathrm{ppm} ;{ }^{119} \mathrm{Sn}\left\{{ }^{1} \mathrm{H}\right\} \mathrm{NMR}\left(\mathrm{C}_{6} \mathrm{D}_{6}\right): \delta-66.52-\mathrm{Sn}(n-$ $\mathrm{Bu})_{3},-232.69\left({ }^{1} J_{117 \mathrm{Sn}-119 \mathrm{Sn}}=861 \mathrm{~Hz},-\mathrm{SnPh}_{2}\right)$ ppm. E.A.: Anal. Calcd C, 50.69; H, 7.56. Found: C, 49.50; H, 8.22.

4.3.3.7- Preparation of 1,1,1,3,3,3-hexabutyl-2,2-dimethyltristannane (11)

Compound $\mathbf{1 1}$ was prepared in a manner similar to that used for compound $\mathbf{9}$ above using $\mathbf{D}(0.25$ mmol, $0.49 \mathrm{~g})$ and $\mathbf{E}(0.50 \mathrm{mmol} 1.83 \mathrm{~g})$. White coloured solid. Yield: $1.61 \mathrm{~g} \mathrm{(79 \% ).}$

${ }^{1} \mathrm{H}$ NMR $\left(\mathrm{C}_{6} \mathrm{D}_{6}\right) \delta: 1.56\left(\mathrm{~m}, 6 \mathrm{H},-\mathrm{Sn}\left(\mathrm{CH}_{2} \mathrm{CH}_{2} \mathrm{CH}_{2} \mathrm{CH}_{3}\right)_{3}\right), 1.33\left(\mathrm{~m}, 12 \mathrm{H},-\mathrm{Sn}\left(\mathrm{CH}_{2} \mathrm{CH}_{2} \mathrm{CH}_{2} \mathrm{CH}_{3}\right)_{3}\right)$, $0.94\left(\mathrm{t},{ }^{3} \mathrm{~J}=14.2 \mathrm{~Hz}, 9 \mathrm{H},-\mathrm{Sn}\left(\mathrm{CH}_{2} \mathrm{CH}_{2} \mathrm{CH}_{2} \mathrm{CH}_{3}\right)_{3}\right), 0.91\left(\mathrm{~s}, 6 \mathrm{H},-\mathrm{SnCH}_{3}\right) \mathrm{ppm} ;{ }^{13} \mathrm{C}\left\{{ }^{1} \mathrm{H}\right\} \mathrm{NMR}$ $\left(\mathrm{C}_{6} \mathrm{D}_{6}\right): \delta 32.56-\mathrm{SnCH}_{2} \mathrm{CH}_{2} \mathrm{CH}_{2} \mathrm{CH}_{3}, 27.56-\mathrm{SnCH}_{2} \mathrm{CH}_{2} \mathrm{CH}_{2} \mathrm{CH}_{3}, 16.39-\mathrm{SnCH}_{2} \mathrm{CH}_{2} \mathrm{CH}_{2} \mathrm{CH}_{3}$, $13.60-\mathrm{SnCH}_{2} \mathrm{CH}_{2} \mathrm{CH}_{2} \mathrm{CH}_{3}, 10.11\left({ }^{1} J_{119 \mathrm{Sn}-13 \mathrm{C}}=20 \mathrm{~Hz},-\mathrm{SnCH} \mathrm{H}_{3}\right) \mathrm{ppm} ;{ }^{119} \mathrm{Sn}\left\{{ }^{1} \mathrm{H}\right\} \mathrm{NMR}\left(\mathrm{C}_{6} \mathrm{D}_{6}\right): \delta-$ $3.14-\mathrm{Sn}(n-\mathrm{Bu})_{3},-83.68\left({ }^{1} J_{117 \mathrm{Sn}-119 \mathrm{Sn}}=738 \mathrm{~Hz},-\mathrm{SnMe}_{2}\right)$ ppm. E.A.: Anal. Calcd C, 42.84; H, 8.30. Found: C, $37.33 ; \mathrm{H}, 8.09$.

4.3.3.8- Preparation of 2,2-dibutyl-1,1,1,3,3,3-hexaphenyltristannane (12)

Compound $\mathbf{1 2}$ was prepared in a manner similar to that used for compound $\mathbf{9}$ above using $\mathbf{C}(0.25$ mmol, $0.67 \mathrm{~g})$ and $\mathbf{F}(0.50 \mathrm{mmol} 1.75 \mathrm{~g})$. Light yellow coloured solid. Yield: $1.84 \mathrm{~g}(91 \%)$. 
${ }^{1} \mathrm{H}$ NMR $\left(\mathrm{C}_{6} \mathrm{D}_{6}\right) \delta: 7.58\left(\mathrm{~m}, 12 \mathrm{H},{ }^{3} J_{119 \mathrm{Sn}-1 \mathrm{H}}=56 \mathrm{~Hz},{ }^{3} J_{119 \mathrm{Sn}-1 \mathrm{H}}=44 \mathrm{~Hz},-\mathrm{Sn}\left(o-\mathrm{C}_{6} H_{5}\right)_{3}\right), 7.13(\mathrm{~m}$, 18H, $\left.-\mathrm{Sn}\left(m, p-\mathrm{C}_{6} \mathrm{H}_{5}\right)_{3}\right), 1.63\left(\mathrm{~m}, 8 \mathrm{H},-\mathrm{SnCH}_{2} \mathrm{CH}_{2} \mathrm{CH}_{2} \mathrm{CH}_{3}\right), 1.14\left(\mathrm{t}, 4 \mathrm{H},-\mathrm{SnCH}_{2} \mathrm{CH}_{2} \mathrm{CH}_{2} \mathrm{CH}_{3}\right), 0.63$ $\left(\mathrm{t},{ }^{3} J=7.3 \mathrm{~Hz}, 6 \mathrm{H},-\mathrm{SnCH}_{2} \mathrm{CH}_{2} \mathrm{CH}_{2} \mathrm{CH}_{3}\right) \mathrm{ppm} ;{ }^{13} \mathrm{C}\left\{{ }^{1} \mathrm{H}\right\} \mathrm{NMR}\left(\mathrm{C}_{6} \mathrm{D}_{6}\right): \delta 140.38\left({ }^{1} J_{119 \mathrm{Sn}-13 \mathrm{C}}=21\right.$ $\mathrm{Hz},-\mathrm{Sn}\left(\right.$ ipso- $\left.\left.\mathrm{C}_{6} \mathrm{H}_{5}\right), 137.48\left({ }^{2} J_{119 \mathrm{Sn}-13 \mathrm{C}}=31 \mathrm{~Hz}, o-\mathrm{C}_{6} \mathrm{H}_{5} \mathrm{Sn}\right)\right), 128.65-\mathrm{Sn}\left(p-\mathrm{C}_{6} \mathrm{H}_{5}\right), 128.52(m-$ $\left.\mathrm{C}_{6} \mathrm{H}_{5} \mathrm{Sn}\right), 32.40 \quad\left({ }^{3} J_{119 \mathrm{Sn}-13 \mathrm{C}}=13 \mathrm{~Hz}-\mathrm{SnCH}_{2} \mathrm{CH}_{2} \mathrm{CH}_{2} \mathrm{CH}_{3}, 27.56-\mathrm{SnCH}_{2} \mathrm{CH}_{2} \mathrm{CH}_{2} \mathrm{CH}_{3}, \quad 13.60\right.$ $\left({ }^{1} J_{119 \mathrm{Sn}-13 \mathrm{C}}=396 \mathrm{~Hz}-\mathrm{SnCH}_{2} \mathrm{CH}_{2} \mathrm{CH}_{2} \mathrm{CH}_{3}\right), 10.45\left({ }^{2} J_{119 \mathrm{Sn}-13 \mathrm{C}}=26 \mathrm{~Hz},-\mathrm{SnCH}_{2} \mathrm{CH}_{2} \mathrm{CH}_{2} \mathrm{CH}_{3}\right) \mathrm{ppm}$; ${ }^{119} \mathrm{Sn}\left\{{ }^{1} \mathrm{H}\right\} \mathrm{NMR}\left(\mathrm{C}_{6} \mathrm{D}_{6}\right): \delta-137.59\left({ }^{1} J_{119 \mathrm{Sn}-119 \mathrm{Sn}}=1087 \mathrm{~Hz}-\mathrm{Sn}(n-\mathrm{Bu})_{2}\right),-205.29\left({ }^{1} J_{117 \mathrm{Sn}-119 \mathrm{Sn}}=\right.$ $\left.1010 \mathrm{~Hz},-\mathrm{SnPh}_{3}\right)$ ppm. E.A.: Anal. Calcd C, 56.64; H, 5.19. Found: C, 55.41; H, 5.08.

4.3.3.9 -Preparation of 2,2,-dimethyl-1,1,1,3,3,3-hexaphenyltristannane (13)

Compound 13 was prepared in a manner similar to that used for compound $\mathbf{9}$ above using $\mathbf{D}(0.25$ mmol, $0.46 \mathrm{~g})$ and $\mathbf{F}(0.50 \mathrm{mmol} 1.75 \mathrm{~g})$. Yellow coloured powder. Yield: $1.67 \mathrm{~g}(82 \%)$.

${ }^{1} \mathrm{H}$ NMR $\left(\mathrm{C}_{6} \mathrm{D}_{6}\right) \delta: 7.51\left(\mathrm{~m}, 12 \mathrm{H},{ }^{3} J_{119 \mathrm{Sn}-1 \mathrm{H}}=56 \mathrm{~Hz}-\mathrm{Sn}\left(o-\mathrm{C}_{6} \mathrm{H}_{5}\right)_{3}\right), 7.10\left(\mathrm{~m}, 18 \mathrm{H},-\mathrm{Sn}\left(m, p-\mathrm{C}_{6} \mathrm{H}_{5}\right)_{3}\right)$, $0.61\left(\mathrm{~s}, 6 \mathrm{H},{ }^{2} J_{119 \mathrm{Sn}-1 \mathrm{H}}=46 \mathrm{~Hz},{ }^{2} J_{117 \mathrm{Sn}-1 \mathrm{H}}=22 \mathrm{~Hz}-\mathrm{SnCH} H_{3}\right), \mathrm{ppm} ;{ }^{13} \mathrm{C}\left\{{ }^{1} \mathrm{H}\right\} \mathrm{NMR}\left(\mathrm{C}_{6} \mathrm{D}_{6}\right): \delta 139.79$ $\left({ }^{1} J_{119 \mathrm{Sn}-13 \mathrm{C}}=21 \mathrm{~Hz},-\mathrm{Sn}\left(\right.\right.$ ipso- $\left.\left.\mathrm{C}_{6} \mathrm{H}_{5}\right)\right), 137.52-\mathrm{Sn}\left(m-\mathrm{C}_{6} \mathrm{H}_{5}\right), 137.41\left({ }^{2} J_{119 \mathrm{Sn}-13 \mathrm{C}}=7 \mathrm{~Hz},-\operatorname{Sn}(o-\right.$ $\left.\left.\mathrm{C}_{6} \mathrm{H}_{5}\right)\right), 128.70-\mathrm{Sn}\left(p-\mathrm{C}_{6} \mathrm{H}_{5}\right),-12.11\left({ }^{1} J_{119 \mathrm{Sn}-13 \mathrm{C}}=16 \mathrm{~Hz},-\mathrm{SnC} \mathrm{H}_{3}\right) \mathrm{ppm} ;{ }^{119} \mathrm{Sn}\left\{{ }^{1} \mathrm{H}\right\} \mathrm{NMR}\left(\mathrm{C}_{6} \mathrm{D}_{6}\right): \delta$ $-139.91-\mathrm{SnPh}_{3},-243.14\left({ }^{1} J_{117 \mathrm{Sn}-119 \mathrm{Sn}}=1381 \mathrm{~Hz},-\mathrm{SnMe}_{2}\right)$ ppm. E.A.: Anal. Calcd C, 36.98; H, 5.37. Found: C, 36.94; H, 5.37.

4.3.3.10 -Preparation of 2,2,-dibutyl-1,1,1,3,3,3-hexamethyltristannane (14)

Compound $\mathbf{1 4}$ was prepared in a manner similar to that used for compound $\mathbf{9}$ above using $\mathbf{C}(0.25$ mmol, $0.67 \mathrm{~g})$ and $\mathbf{H}(0.50 \mathrm{mmol} 0.94 \mathrm{~g})$. Light yellow coloured solid. Yield: $1.52 \mathrm{~g}(74 \%)$.

${ }^{1} \mathrm{H}$ NMR $\left(\mathrm{C}_{6} \mathrm{D}_{6}\right) \delta: 1.70\left(\mathrm{~m}, 6 \mathrm{H},-\mathrm{SnCH}_{2} \mathrm{CH}_{2} \mathrm{CH}_{2} \mathrm{CH}_{3}\right), 1.40\left(\mathrm{~m}, 8 \mathrm{H},-\mathrm{SnCH}_{2} \mathrm{CH}_{2} \mathrm{CH}_{2} \mathrm{CH}_{3}\right), 1.28$ $\left(\mathrm{m}, 4 \mathrm{H},-\mathrm{SnCH}_{2} \mathrm{CH}_{2} \mathrm{CH}_{2} \mathrm{CH}_{3}\right), 0.95\left(\mathrm{~s}, 18 \mathrm{H},-\mathrm{Sn}\left(\mathrm{CH}_{3}\right)_{3}\right) \mathrm{ppm} ;{ }^{13} \mathrm{C}\left\{{ }^{1} \mathrm{H}\right\} \mathrm{NMR}\left(\mathrm{C}_{6} \mathrm{D}_{6}\right): \delta 31.58-$ 
$\mathrm{SnCH}_{2} \mathrm{CH}_{2} \mathrm{CH}_{2} \mathrm{CH}_{3}, \quad 29.83-\mathrm{SnCH}_{2} \mathrm{CH}_{2} \mathrm{CH}_{2} \mathrm{CH}_{3}, \quad 27.38-\mathrm{SnCH}_{2} \mathrm{CH}_{2} \mathrm{CH}_{2} \mathrm{CH}_{3}, \quad 22.66$ $\mathrm{SnCH}_{2} \mathrm{CH}_{2} \mathrm{CH}_{2} \mathrm{CH}_{3}, 13.95-\mathrm{SnCH}_{3} \mathrm{ppm} ;{ }^{119} \mathrm{Sn} \quad\left\{{ }^{1} \mathrm{H}\right\} \quad \mathrm{NMR}\left(\mathrm{C}_{6} \mathrm{D}_{6}\right): \delta \quad-3.16-\mathrm{SnMe}_{3},-146.04$ $\left({ }^{1} J_{117 \mathrm{Sn}-119 \mathrm{Sn}}=1097 \mathrm{~Hz}, \mathrm{Sn}(n-\mathrm{Bu})_{2}\right)$ ppm. E.A.: Anal. Calcd C, 30.00; H, 6.47. Found: C, 30.01; H, 6.16.

4.3.3.11-Preparation of 2,2,-diphenyl-1,1,1,3,3,3-hexamethyltristannane (15)

Compound $\mathbf{1 5}$ was prepared in a manner similar to that used for compound $\mathbf{9}$ above using $\mathbf{D}(0.25$ mmol, $0.46 \mathrm{~g})$ and F (0.50 mmol $0.94 \mathrm{~g})$. Orange coloured solid. Yield: $1.85 \mathrm{~g}(94 \%)$.

${ }^{1} \mathrm{H}$ NMR $\left(\mathrm{C}_{6} \mathrm{D}_{6}\right) \delta: 7.57\left(\mathrm{~m}, 4 \mathrm{H},-\mathrm{Sn}\left(o-\mathrm{C}_{6} \mathrm{H}_{5}\right)\right), 7.02\left(\mathrm{~m}, 6 \mathrm{H},-\mathrm{Sn}\left(m, p-\mathrm{C}_{6} \mathrm{H}_{5}\right)\right), 1.41\left(\mathrm{t},{ }^{3} J_{119 \mathrm{Sn}-1 \mathrm{H}}=\right.$ $\left.3 \mathrm{~Hz}, 18 \mathrm{H},-\mathrm{Sn}\left(\mathrm{CH}_{3}\right)_{3}\right) \mathrm{ppm} ;{ }^{13} \mathrm{C}\left\{{ }^{1} \mathrm{H}\right\} \mathrm{NMR}\left(\mathrm{C}_{6} \mathrm{D}_{6}\right): \delta 138.25-\mathrm{Sn}\left(\right.$ ipso- $\left.\mathrm{C}_{6} \mathrm{H}_{5}\right), 136.14-\mathrm{Sn}(\mathrm{o}, m-$ $\left.\mathrm{C}_{6} \mathrm{H}_{5}\right), 128.63-\mathrm{Sn}\left(p-\mathrm{C}_{6} \mathrm{H}_{5}\right), 29.83-\mathrm{SnCH}_{3} ;{ }^{119} \mathrm{Sn}\left\{{ }^{1} \mathrm{H}\right\} \mathrm{NMR}\left(\mathrm{C}_{6} \mathrm{D}_{6}\right): \delta-81.75-\mathrm{SnMe}_{3},-217.19-$ $\mathrm{SnPh}_{2}$ ppm. E.A.: Anal. Calcd C, 36.00; H, 4.70. Found: C, 36.31; H, 4.46.

4.4- Results and Discussion:

4.4.1-Synthesis and characterization of tin trimers 9-15

Tin trimers have previously been synthesized by metal-halogen exchange reactions, such as that described by Dräger for $\mathbf{1 6}{ }^{41}$, or more recently by the preparation described by Pannell et al. of the dichlorinated tristannane, $\mathrm{Cl}-\left[(t-\mathrm{Bu})_{2} \mathrm{Sn}\right]_{3}-\mathrm{Cl}$, from the reaction of $(t-\mathrm{Bu}) \mathrm{MgCl}$ with $\mathrm{SnCl}_{4}$ in hexane. ${ }^{71} \mathrm{~A}$ tin trimer was also prepared by the hydrostannolysis of one equivalent of $(t-\mathrm{Bu})_{2} \mathrm{SnH}_{2}$ with two equivalents of di(n-butyl)(dimethylamino)(2-ethoxyethyl)stannane in the presence of a strong base. $^{72}$ Organotristannanes have been isolated in low yield as byproducts of the reduction of triorganotin oxide with formic acid in attempt to form simple distannanes. ${ }^{73}$ By comparison to these methods, the model trimers 9-15 (Figure 2) in this study were prepared in good yields (7590\%) with minimal purification required and recovered as a white coloured oil in the case of 9 or 
as light yellow coloured solids according to the general condensation reactions outlined in Scheme

\subsubsection{1.}

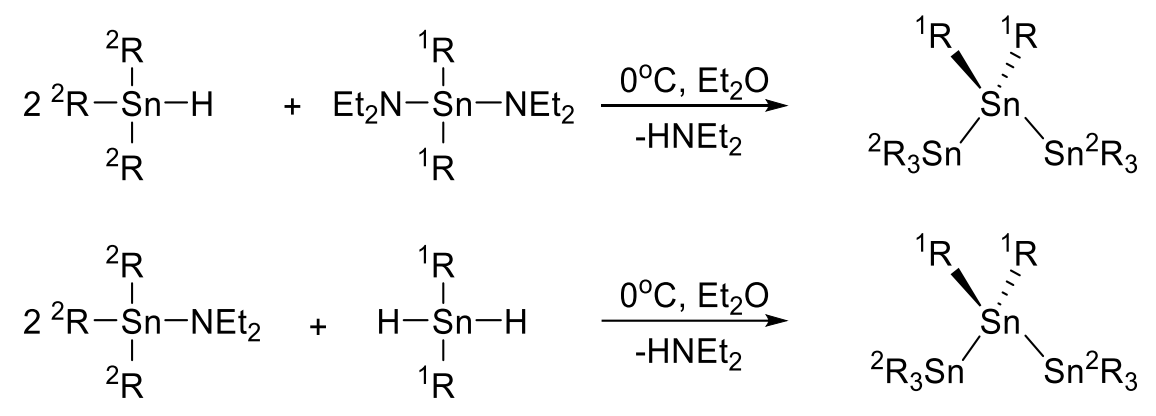

Scheme 4.4.1.1: General preparative routes to model tin trimers used in this study.

Characteristic of these trimers is the appearance of two, well separated (Figure 4.4.1.4), resonances in the ${ }^{119} \mathrm{Sn}$ NMR spectroscopy with one corresponding to the internal tin and one to the two terminal tin centers. In most instances, the internal tin resonance is found downfield relative to that of the two terminal $\mathrm{Sn}$ centers. Also representative of these trimers is the appearance of complex coupling patterns around the central resonances consistent with the relative abundance of ${ }^{117} \mathrm{Sn}$ and ${ }^{119} \mathrm{Sn}$ species. Coupling assignments of 9-15 were based on the expected modelled coupling intensities previously calculated in our group for the tin trimer bridged [3.3]ferrocenophane. ${ }^{47}$ Previous studies of the ${ }^{1} J$ and ${ }^{2} J$ Sn-Sn coupling constants for oligostannanes correlate with the relative Sn-Sn bonding and non-bonding distances respectively. A smaller ${ }^{1} J$ coupling signifies a reduction $\sigma$-orbital character in the $\mathrm{Sn}$-Sn bond bonds. The ${ }^{1} J$ coupling constants (Table 4.4.1.3) obtained for compounds 9-15 are consistent with previously published reports for related tristannanes. ${ }^{11,33}$ 


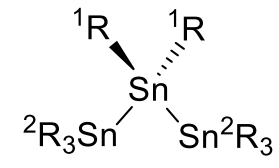

9: ${ }^{1} \mathrm{R}={ }^{2} \mathrm{R}=n$-Bu

10: ${ }^{1} \mathrm{R}=\mathrm{Ph},{ }^{2} \mathrm{R}=n-\mathrm{Bu}$

13: ${ }^{1} \mathrm{R}=\mathrm{Me},{ }^{2} \mathrm{R}=\mathrm{Ph}$

11: ${ }^{1} \mathrm{R}=\mathrm{Me},{ }^{2} \mathrm{R}=n$-Bu 15: ${ }^{1} \mathrm{R}=\mathrm{Ph},{ }^{2} \mathrm{R}=\mathrm{Me}$

12: ${ }^{1} \mathrm{R}=n-\mathrm{Bu},{ }^{2} \mathrm{R}=\mathrm{Ph}$

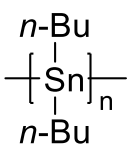

21

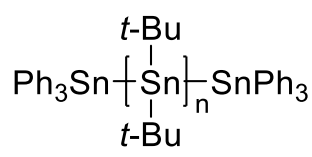

16: $\mathrm{n}=1$ 18: $\mathrm{n}=3$ 17: $n=2$ 19: $n=4$

20: a-m

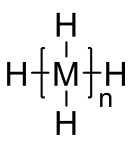

22: $\mathrm{M}=\mathrm{Si}$

23: $M=\mathrm{Ge}$

24: $M=S n$

Figure 4.4.1.2: Trimers, oligostannanes and polymetallanes modelled by TD-DFT in this study.

\begin{tabular}{|c|c|c|c|c|}
\hline Compound & $\begin{array}{l}\mathrm{d}:{ }^{119} \mathrm{Sn} \text { NMR } \\
\left(\mathrm{C}_{6} \mathrm{D}_{6}\right)(\mathrm{ppm})\end{array}$ & $\begin{array}{c}{ }^{1} J{ }^{119} \mathrm{Sn}-{ }^{119} \mathrm{Sn} \\
(\mathrm{Hz})\end{array}$ & $\begin{array}{c}I_{\max } \exp . / \varepsilon_{\max } \\
\mathrm{S}-\mathrm{S} *[\mathrm{~nm} \\
\left.\left(\mathrm{L} \mathrm{mol}^{-1} \mathrm{~cm}^{-1}\right)\right]\end{array}$ & $\begin{array}{c}\mathrm{I}_{\max } \text { calc./ Emax } \\
\mathrm{S}-\mathrm{S} *[\mathrm{~nm} \\
\left.\left(\mathrm{L} \mathrm{mol}^{-1} \mathrm{~cm}^{-1}\right)\right]\end{array}$ \\
\hline $9^{71}$ & $-75.6,-226.6$ & 798.6 & $283(\mathrm{~N} / \mathrm{A})$ & N/A \\
\hline 9 & $-76.4,-227.9$ & 820.6 & $242(\mathrm{sh})$ & $253(10500)$ \\
\hline 10 & $-66.52,-232.69$ & 861 & $292(\mathrm{sh})$ & $323(5700)$ \\
\hline 11 & $-3.14,83.68$ & 738 & $282(\mathrm{sh})$ & $266(14900)$ \\
\hline 12 & $-137.59,-205.29$ & 320 & $310(\mathrm{sh})$ & $328(12900)$ \\
\hline 13 & $-139.91,-243.14$ & 1381 & $262(\mathrm{sh})$ & 315 (19600) \\
\hline 14 & $-3.16,-146.0$ & 1097 & $293(\mathrm{sh})$ & $247(7200)$ \\
\hline 15 & $-81.75,-217.19$ & Unresolved & $320(\mathrm{sh})$ & $318(5000)$ \\
\hline
\end{tabular}

Table 4.4.1.3: ${ }^{119} \mathrm{Sn}$ NMR data, experimental UV-Vis (THF) and calculated (TD-DFT) first energy gap $\left(\sigma-\sigma^{*}\right)$ for organotristannanes 1-7. 


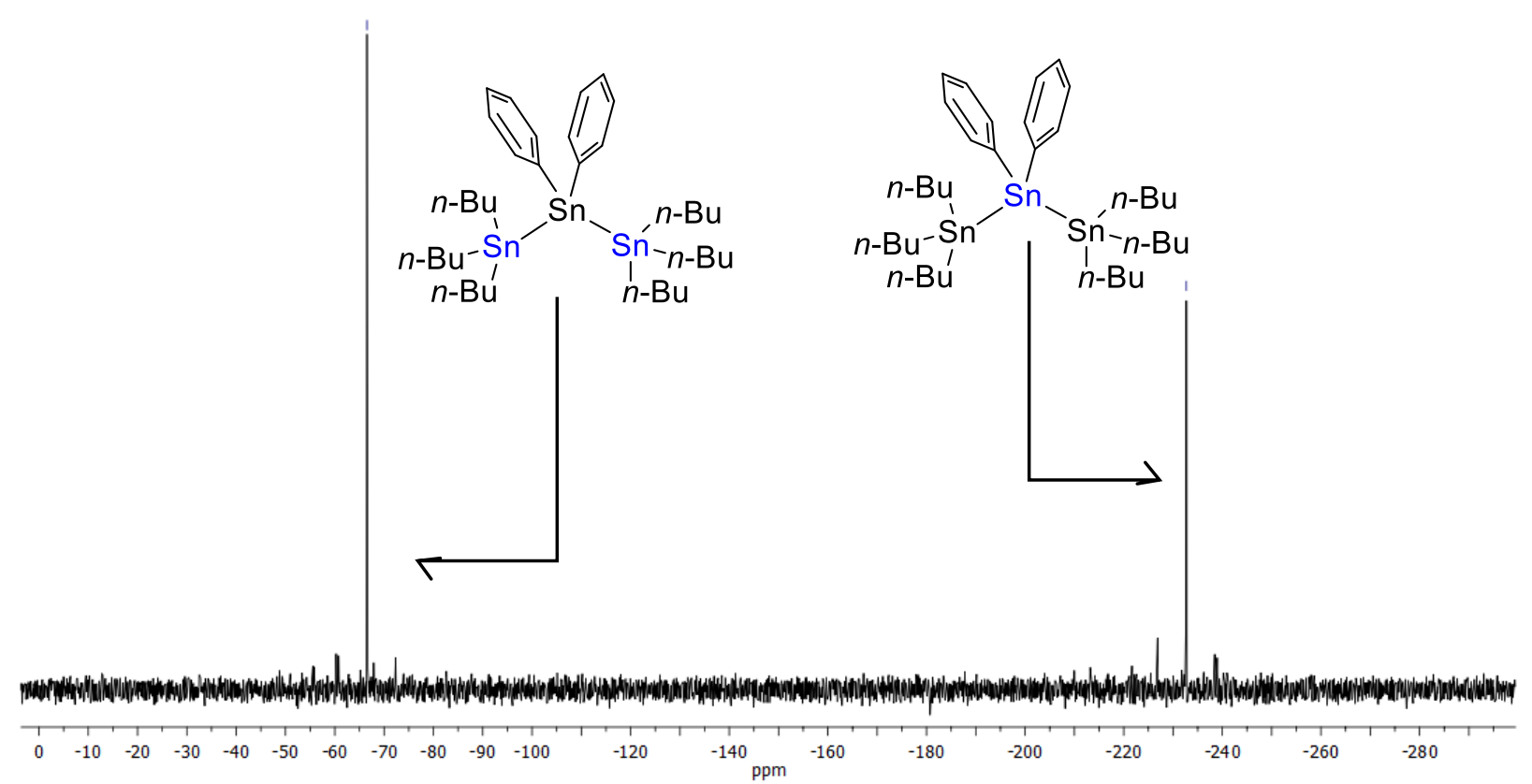

Figure 4.4.1.4: ${ }^{119} \mathrm{Sn}\left(\mathrm{C}_{6} \mathrm{D}_{6}\right) \mathrm{NMR}$ spectrum of $\mathbf{1 0}$.

\subsection{2 -Experimental UV-Vis and calculated TD-DFT data for Trimers 9-15}

The experimental and calculated $\lambda_{\max }$ data and absorptivity data for compounds 9-15 are found in Table 1 and Figure 4. All of the transitions are found in the UV with some tailing to the visible and are moderate to strongly absorbing. This is consistent with the reported first energy gap transition $\left(\sigma-\sigma^{*}\right)$ for other known organotin trimers. ${ }^{11}$ Experimentally, compounds $\mathbf{1 0}$ and $\mathbf{1 5}$ with internal aryl tin and external alkyl tin substituents are redshifted $(50-60 \mathrm{~nm})$ relative to the all alkyl substituents containing organotin trimers 9, 11 and 14. The calculated wavelengths are in reasonable agreement with the experimental values, but there is substantial uncertainty in the wavelength estimates of the shoulder transitions below $280 \mathrm{~nm}$. The calculated transition 
wavelengths for compounds with aryl substituents (2,4,5, and 7) are all red-shifted relative to the compounds with alkyl substituents only.

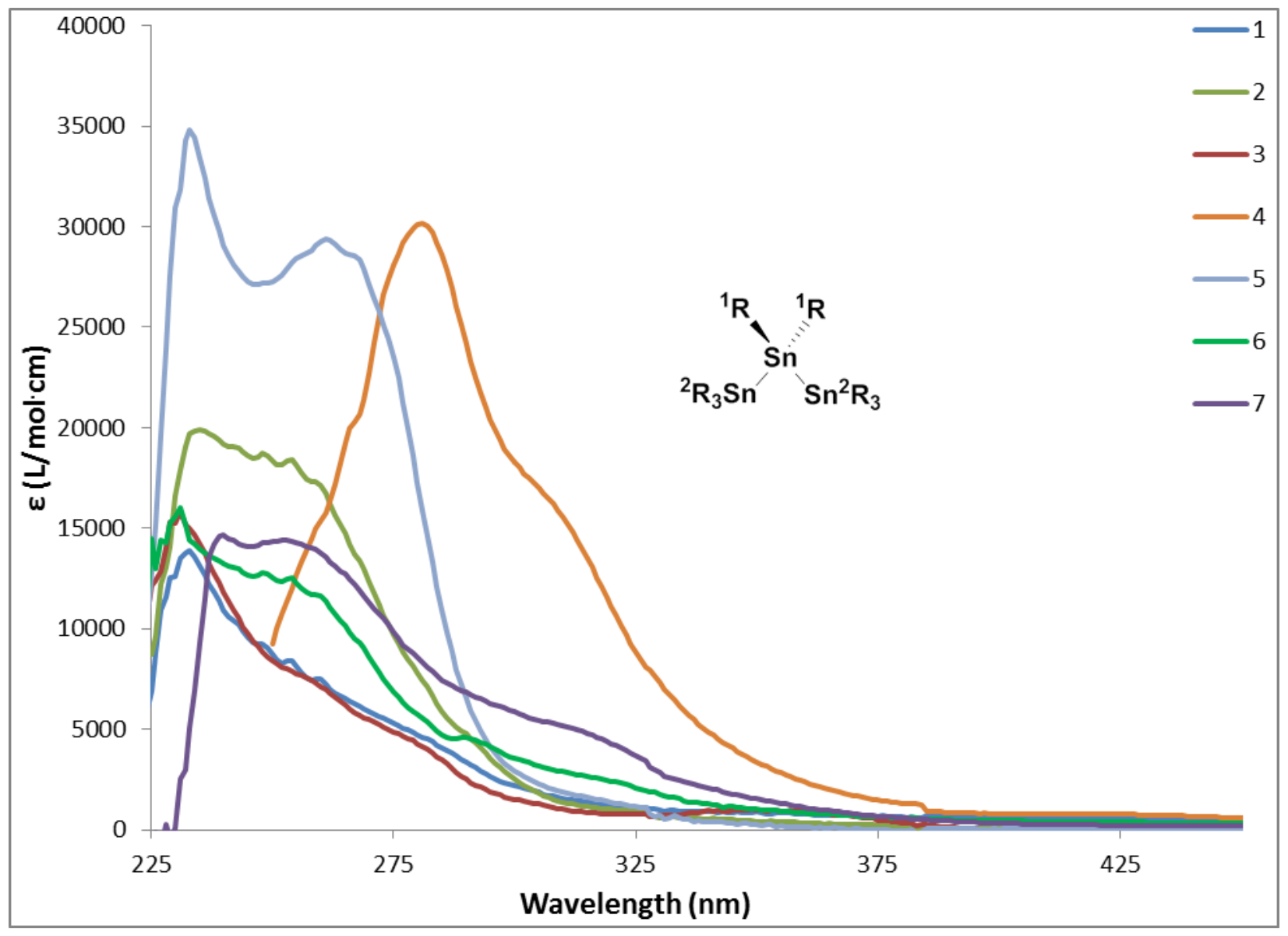

Figure 4.4.2.1: UV-vis spectra of tristannanes 9-15 in THF.

The UV-Vis spectra of the mixed aryl/alkyl tristannanes $(\mathbf{1 0}, \mathbf{1 2}, \mathbf{1 3}, \mathbf{1 5})$ are dominated by strong $\pi-\pi^{*}$ transitions with weaker, lower energy $\sigma-\sigma^{*}$ transitions that shoulder or are hidden by these stronger absorbances. The MO diagrams of these molecules illustrate the impact of differing tin substituents on the character of the transitions. The DFT (HOMO) diagram for the ground state of the all-alkyl tristannane 9 (Figure 4.4.2.1) shows a clear bonding distribution of electron density along the Sn-Sn-Sn framework. The DFT (LUMO) diagram also shows the electron density centered on the tin framework; however, in this case the MO is antibonding at the Sn centers. In contrast, the DFT MO diagrams of 13 (Figure 4.4.2.2) are representative of mixed alkyl/aryl 
tristannanes in this study and show that the center of electron density shifts between the HOMO (centered on the tin framework) and the LUMO (centered on the aryl rings).
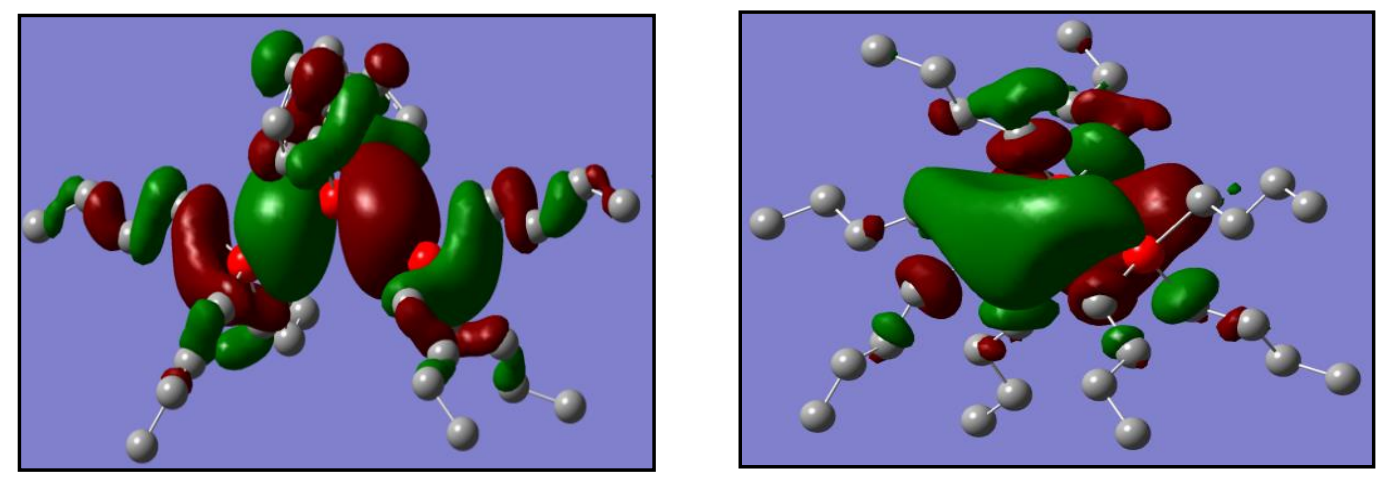

Figure 4.4.2.2: Left: HOMO of 9, Right: LUMO of 9 (Isoelectric Constant: 0.02).
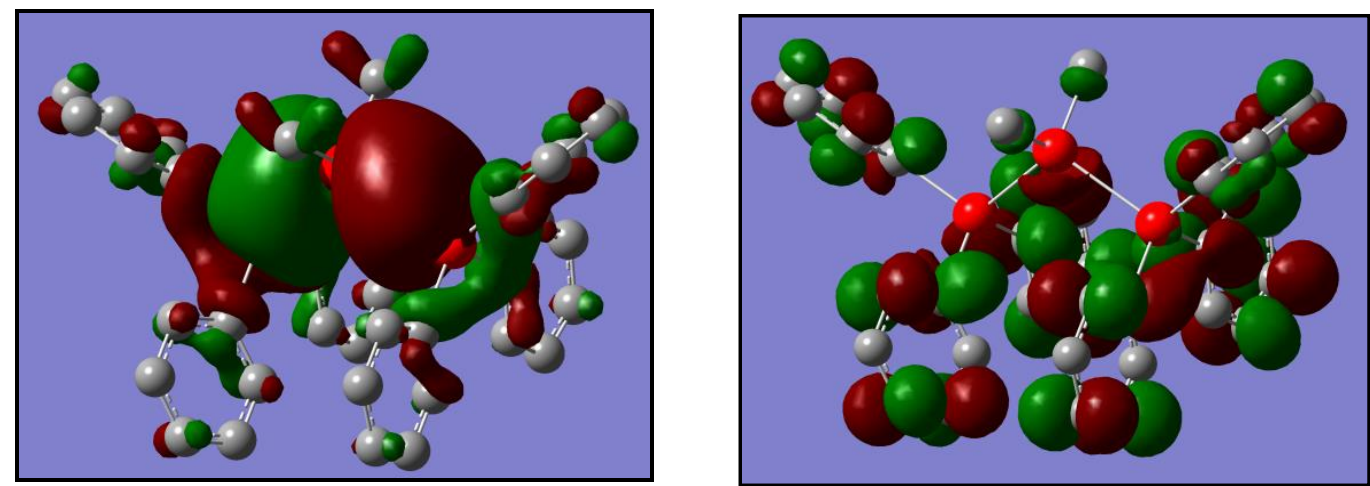

Figure 4.4.2.3: Left: HOMO of 13, Right: LUMO of 13 (Isoelectric Constant: 0.02).

\subsection{3-TD-DFT Treatment of Oligostannanes 16-19}

As a comparison with the results obtained for trimers 9-15, electronic spectra were calculated with TD-DFT (Table 4.4.3.1) for geometrically-optimized structures of a series of tin oligomers prepared by Dräger and Adams. ${ }^{34}$ Compounds 16-19 were thoroughly characterized by these authors using a variety of methods to probe structural (X-ray diffraction, ${ }^{119} \mathrm{Sn}$ NMR spectroscopy) and electronic (UV-Vis spectroscopy) differences. In each case, X-ray structure data confirmed that oligomers 16-19 adopt a TP configuration. The central Sn-Sn bond lengthens with each additional tin center to > 5\% (from $2.7 \AA$ to $2.966(3) \AA$ ) when comparing the trimer 16 to the 
hexamer 19. The bond lengthening also coincides with a gradual bond angle widening of the central $\mathrm{Sn}-\mathrm{Sn}-\mathrm{Sn}$, increasing from $107^{\circ}$ in $\mathbf{1 6}$ to $121^{\circ}$ in $\mathbf{1 9}$. These dramatic structural changes were found to directly impact the HOMO/LUMO energy gap, resulting in a significant redshift of the $\sigma$ $\sigma^{*}$ transition. Selected bond lengths and angles from calculated structures (DFT) and predicted absorption maxima (TD-DFT) (both at the LSDA/SDD level of theory) for oligomers 16-19 are compared to experimental results obtained by Dräger ${ }^{41}$ in Table 4.4.3.1. The calculated structural results compare favourably with experimental data with a reasonably good match of bond lengths and bond angles ${ }^{41}$; the overestimate of $\mathrm{Sn}-\mathrm{Sn}$ bond distances is characteristic of DFT structure predictions for bonds involving heavy atoms. DFT successfully predicts the lengthening of the central Sn-Sn bond(s) and the flattening of the central Sn-Sn-Sn angle. Relative differences of the central Sn bond(s) were found to lengthen by $0.04 \AA$ exp. (0.05 $\AA$ calc.) from $\mathbf{1 7 - 1 8}$ and by $0.06 \AA$ exp. (0.06 ^ calc.) from 18-19. A molecular representation for the calculated HOMO of oligostannane 11 (Figure 4.4.3.2a) shows clear $\sigma$-conjugation along the backbone of the oligomer with good overlap between tin atoms, whereas the LUMO (Figure 4.4.3.2b) show the expected non-bonding interactions with no overlap between tin atoms and electron density centered on the nodes of the individual tin centers. The overestimate in the calculated absorption maxima compared with experimental maxima is consistent with the tendency of DFT methods to overestimate heavy metal bond lengths (vide supra). The magnitude of the red-shifts in absorption maxima are, however, accurately predicted: (16:17 $28 \mathrm{~nm}$ [calc. $27 \mathrm{~nm}$ ], 17:18 $33 \mathrm{~nm}$ [calc. 31 $\mathrm{nm}$ ], 18:19 $35 \mathrm{~nm}$ [calc. $34 \mathrm{~nm}$ ]). Inclusion of a solvation model $\left(\mathrm{CHCl}_{3}\right.$ or $\left.\mathrm{THF}\right)$ in the TD-DFT calculations of compounds 16-19 was found to negligibly impact the calculated data (Table 4.4.3.1). It should be noted that our calculations are for the TP geometries found in the solid state. In solution, the oligostannanes may adopt a range of conformations with some degree of $\mathrm{GH}$ geometry in their backbone. This would raise the energy of the HUMO:LUMO gap and could 
partially account for the substantial redshift of the absorption maxima $(\sim 45 \mathrm{~nm})$ from experimental to calculated results.

\begin{tabular}{|c|c|c|c|}
\hline Comp. & $\begin{array}{c}\text { Central Sn-Sn } \\
\text { Bond Length }(\AA) \\
\text { exp1:calc }\end{array}$ & $\begin{array}{c}\text { Central Sn-Sn-Sn } \\
\text { Bond angle }\left(^{\circ}\right) \\
\text { exp:calc }\end{array}$ & $\begin{array}{c}\lambda_{\max }(\mathrm{nm}) \\
\exp _{\text {:calc }}(\mathrm{vac}) \text { : } \operatorname{calc}_{(\mathrm{THF})} \text { :calc }_{(\mathrm{CHCl} 3)}\end{array}$ \\
\hline 16 & $2.80: 2.80$ & 107:109 & $267: 315: 320: 319$ \\
\hline 17 & $2.87: 2.99$ & $118: 116$ & $295: 342: 346: 346$ \\
\hline 18 & $2.91: 3.04$ & 119:119 & $328: 373: 373: 380$ \\
\hline 19 & $2.966(3): 3.10$ & $121: 122$ & $363: 407: 407: 413$ \\
\hline
\end{tabular}

Table 4.4.3.1: Experimental ${ }^{14}$ and calculated bond lengths, angles and absorption maxima for a series of oligostannanes 16-19.

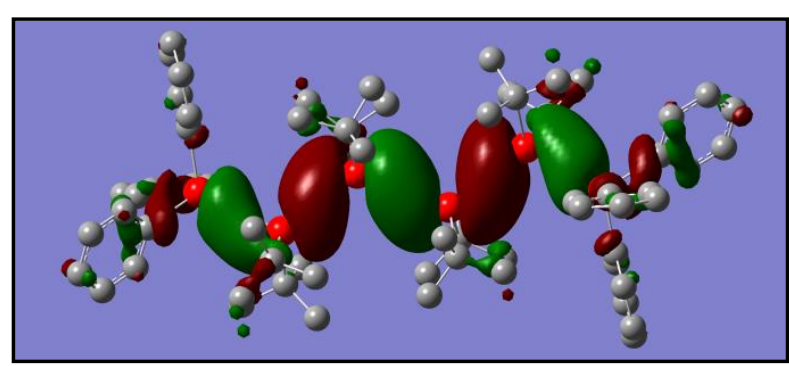

A

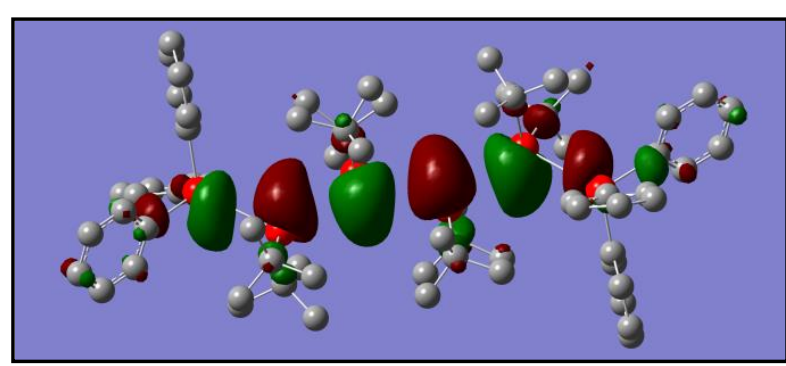

B

Figure 4.4.3.2: a) HOMO and b) LUMO MO of the hexastannane 19 (Isoelectric Constant: 0.02) 


\subsection{4- TD-DFT treatment of Oligomeric Stannanes}

Sita strategically prepared a series of oligostannanes $20 a-m\left(E t O C H_{2} \mathrm{CH}_{2}\left[(n-\mathrm{Bu})_{2} \mathrm{Sn}\right]_{n} \mathrm{CH}_{2} \mathrm{CH}_{2} \mathrm{OEt}\right.$ where $n=3-15)$ from the stepwise insertion of a reactive stannylene species into the backbone of the growing oligomer, followed by a further reaction of the hydride terminated oligomeric stannane with a tin amide to cap the chain with terminal alkoxy group. ${ }^{52}$ The sequential chain extended materials were further purified by the HPLC separation of the linear oligomeric stannanes from cyclic tin materials. Sita's semi-empirical Sandorfy:Huckel treatment of oligostannanes 20b-m was in excellent correlation with experimental data when the ratio of the resonance integrals for geminal and vicinal $\mathrm{Sn} \mathrm{sp}^{3}$ orbitals was set to 0.75 , implying that $75 \%$ of Sn-Sn interactions were delocalized in nature. The model failed for the smallest oligomer, the tristannane 20a, presumably due to "end-group" effects. ${ }^{52}$ Some orbital overlap occurs between terminal Sn atoms and adjacent ligand carbon atoms, but the Sandorfy:Huckel model only considers overlap of hybrid Sn orbitals and does not specifically account for differences in $\mathrm{Sn}$ backbone substituents. The impact of this is most significant for shorter oligostannanes, particularly tristannanes in which the end groups constitute $2 / 3$ rds of the molecule. In this work, an evaluation of oligostannanes $\mathbf{2 0 a - m}$ by TD-DFT at the SDD/LSDA level also show a similar strong correlation of decreasing energy gap with increasing oligomer length (Figure 4.4.4.1). The TD-DFT calculated data shows a strong correlation with experimental data for the smallest oligomers (3 to 6 Sn centers, 20a-d) but shows significant deviation at longer oligomer lengths. Unlike the case for Dräger oligomers, the calculated Sn-Sn central bond lengths in the oligomers 20a-m remained essentially unchanged at $\sim 2.86 \AA$ regardless of oligomer length. Modelling oligomers with 7-15 tin centers in an all TP configuration indicate that the HOMO to LUMO energy gap continues to narrow with values even lower than the experimental determined value of polymer $21\left(\lambda_{\max }=380 \mathrm{~nm}\right)$. This might suggest that the longest uninterrupted TP segments in solutions of 21, and thus the average length of the fully conjugated chromophore, may only reach 
6-8 repeat units. This is supported in part by a UV-visible study by Tilley et al. ${ }^{32}$ of a solid state film of $\mathrm{H}-\left[(n-h e x)_{2} \mathrm{Sn}\right]_{\mathrm{n}}-\mathrm{H}$ which was shown to possess a longer $\lambda_{\max }$ absorbance $(398 \mathrm{~nm})$ than that observed in solution $(384 \mathrm{~nm})$, indicating that $\sigma$-conjugation is potentially not fully optimized in either sample. ${ }^{6}$ The differences in the calculated TD-DFT energy gaps of the TP oligostannanes 20e-m compared to their experimentally determined values is likely a result of the non-optimal geometry afforded oligomers (and polymers) in solution, and to a lesser extent in non-annealed solid state films. The success of the simpler semi-empirical Sandorfy:Huckel model relative to the DFT calculations may derive from the treatment of the resonance integral ratio as an adjustable parameter, thus intrinsically correcting for contributions of solution state conformers with conjugated TP segments shorter than the lengths of the oligomers. In contrast, the DFT calculations are for all TP configurations, an assumption that becomes increasingly unrealistic for longer oligomers in solution. 


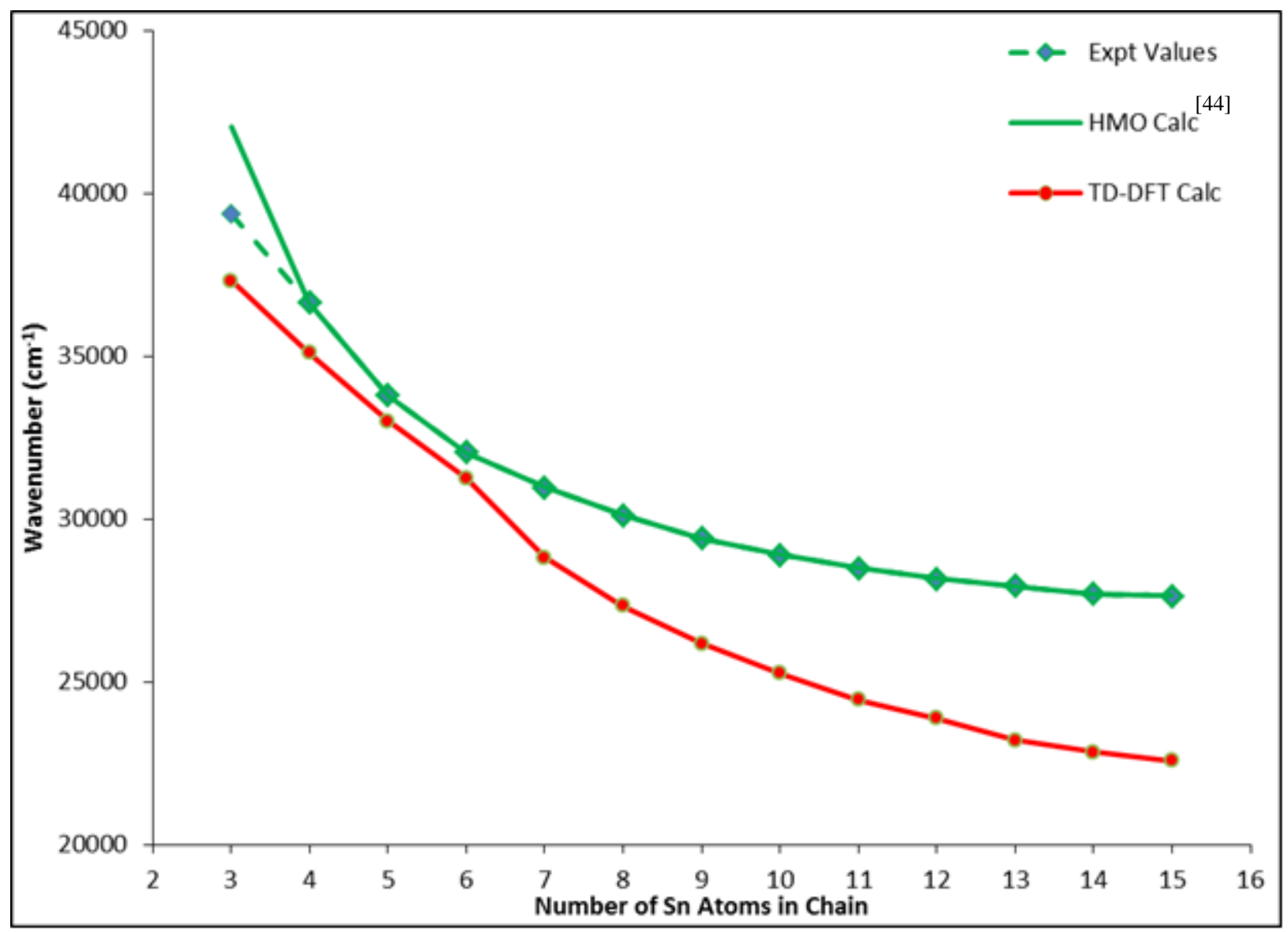

Figure 4.4.4.1: Comparison of experimental and calculated first band gap energies for oligostannanes 20a-m.

\subsection{5- TD-DFT treatment of Group 14 metallanes}

An early DFT treatment (low density functional, LDF) of the parent polymetallanes $\left(\mathrm{H}\left[\mathrm{MH}_{2}\right]_{\mathrm{n}} \mathrm{H}\right.$, $\mathrm{M}=\mathrm{Si}, \mathrm{Ge}, \mathrm{Sn}: \mathbf{2 2 - 2 4}$ ) by Takeda and Shirashi was used to investigate their electronic structures and their first band gap energies. These are listed in Table 4.4.5.2 for two possible geometries; TP where a maximum orbital overlap of neighbouring $\mathrm{Sn} 5 \mathrm{sp}^{3}$ occurs as well as a GH geometry where orbital overlap is greatly reduced. We revisited this analysis using TD-DFT, primarily to attempt to validate the hypothesis that the band gap of polystannanes could be tailored with the addition of aryl substituents to approach a "molecular metal" state. A comparison of the energy gap data calculated by LDA vs TD-DFT is remarkably consistent, with some differences (Figure 4.4.5.1). 
The calculated first excited state energy by TD-DFT is slightly lower for the TP form regardless of type of polymetallane when compared to the LDA method. A larger discrepancy is observed for the GH structure of the polystannane, where a smaller energy gap is calculated. Very recently, a DFT treatment of the hypothetical polygermane $\mathbf{2 3}$ with the Perdew-Burke-Ernzerhof (PBE) generalized gradient approximation by Fa and Zeng yielded a first band gap energy of $3.03 \mathrm{eV} .^{74}$ When the hydrogens attached to Ge were replaced with two aryl substituents, a lower direct band gap $2.2 \mathrm{eV}$, and an intrinsic, highly semi-conducting state, is predicted.

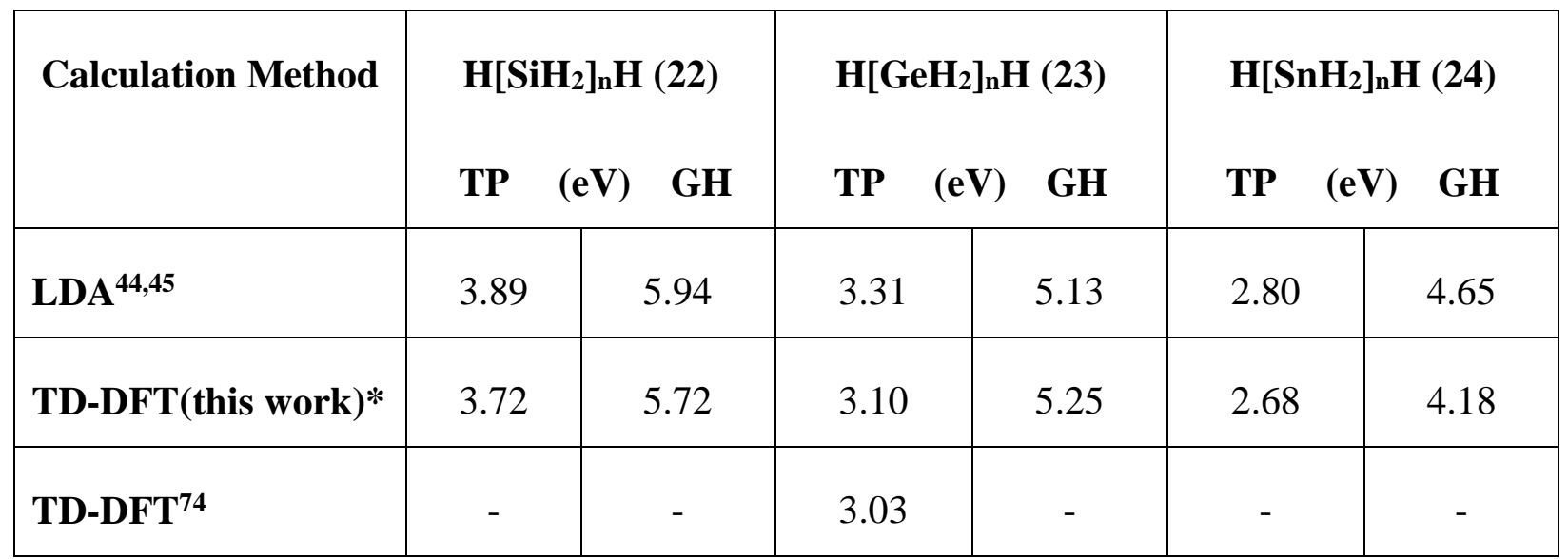

Table 4.4.5.1: First band gap energies of Group 14 metallanes $\left[\mathrm{MH}_{2}\right]_{\mathrm{n}},(\mathrm{M}=\mathrm{Si}, \mathrm{Ge}, \mathrm{Sn})$ *modelled using LSDA/SDD. 


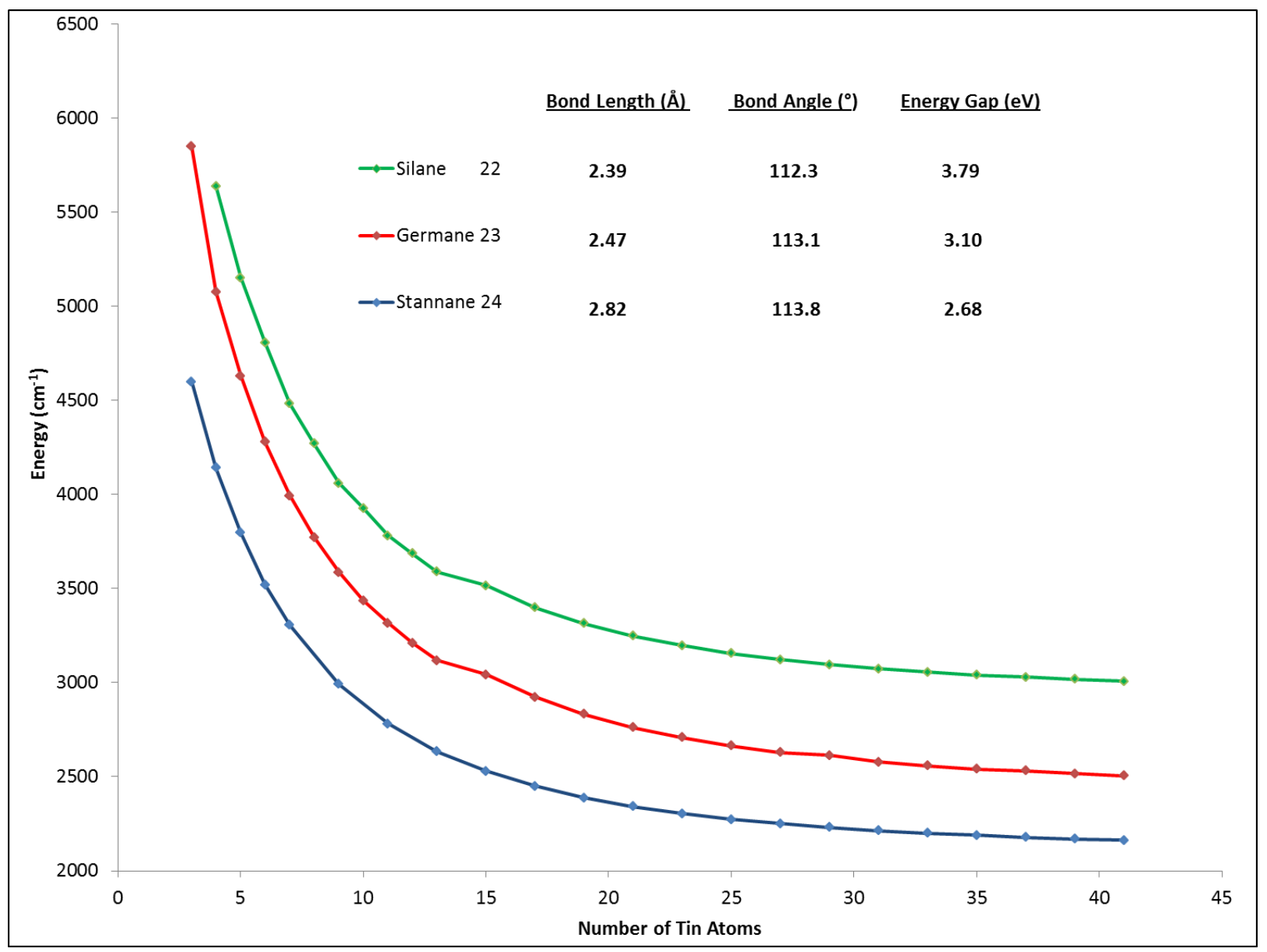

Figre4.4.5.2: Comparison of calculated band gap energies for Group 14 metallanes in both TP (trans-planar) and GH (guache-helical) geometries. 


\subsection{6 -TD-DFT Asymmetrical Polystannanes}

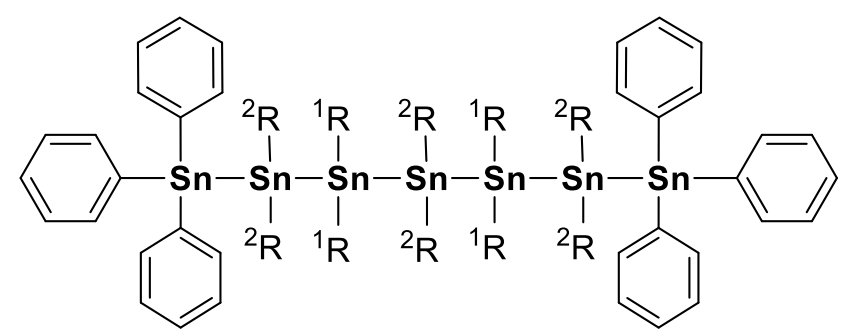

24: ${ }^{1} \mathrm{R}=\mathrm{Ph},{ }^{2} \mathrm{R}=\mathrm{Me}$

25: ${ }^{1} \mathrm{R}=\mathrm{Ph},{ }^{2} \mathrm{R}=n-\mathrm{Bu}$

26: ${ }^{1} \mathrm{R}=n-\mathrm{Bu},{ }^{2} \mathrm{R}=\mathrm{Me}$

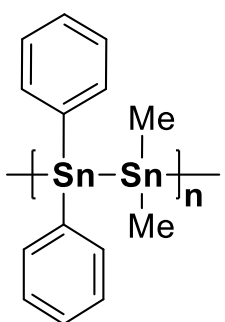

6

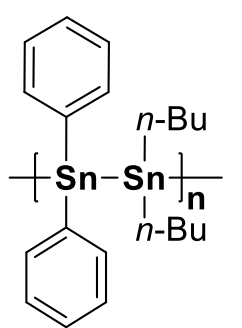

7

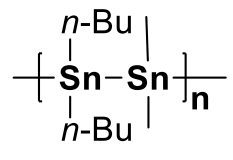

8

Figure 4.4.6.1: Model oligostannanes and alternating polystannanes.

Building from the experimental and calculated data obtained for the tin trimers, a series of asymmetrical oligostannanes 24-26 (Figure 4.4.6.1) were likewise subjected to TD-DFT. The length of the oligostannane was limited to seven tin atoms, with triphenylstannane caps at each end. The calculated energies of these 24-26 were compared to the electronic properties (UV-vis) of their parent polymers, 6-8 that were recently prepared by polycondensation reactions. These data are presented in Table 4.4.6.2. In all cases, an optimized TP orientation of the polymer chain was assumed. This "ideal" geometry may account for the smaller calculated band gaps of polymers containing aryl substituents, compared to their experimental values. By comparison, the calculated first band gap energies for the all alkyl containing polystannane, $\mathbf{8}$, is nearly identical to reported values. 


\begin{tabular}{|c|c|c|}
\hline 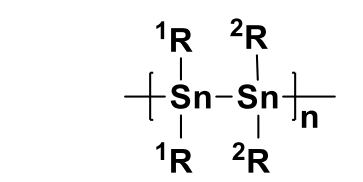 & $\begin{array}{c}\lambda_{\max }(\mathrm{nm}) \\
\text { Oligomer: Calc. }\end{array}$ & $\begin{array}{c}\lambda_{\max }(\mathrm{nm}) \\
\text { Polymer: Expt. }\end{array}$ \\
\hline${ }^{1} \mathrm{R}={ }^{2} \mathrm{R}=n-\mathrm{Bu}$ & $20 m=368$ & $5=390$ \\
\hline${ }^{1} \mathrm{R}=\mathrm{Ph},{ }^{2} \mathrm{R}=\mathrm{Me}$ & $\mathbf{2 4}=427$ & $6=395$ \\
\hline${ }^{1} \mathrm{R}=\mathrm{Ph},{ }^{2} \mathrm{R}=n-\mathrm{Bu}$ & $\mathbf{2 5}=433$ & $7=390$ \\
\hline${ }^{1} \mathrm{R}=n-\mathrm{Bu},{ }^{2} \mathrm{R}=\mathrm{Me}$ & $26=354$ & $8=361$ \\
\hline
\end{tabular}

Table 4.4.6.2: Experimental and theoretical $\lambda_{\max }$ values for model oligostannanes and polystannanes.

\section{5- Conclusions}

A series of model linear tristannanes containing mixed aryl and alkyl substituents has been prepared and characterized. DFT modelling at the LDSA level has provided useful estimations of structural and electronic data, and support for the concept of tuning electronic properties by substituent alternation in extended oligomeric and polymeric systems. Although overall accuracy of the predictions of the $\lambda_{\max }$ of the $\sigma-\sigma^{*}$ transitions is fair, the general trends are correct, suggesting a future role for these calculations when designing novel polymeric systems. For structurally homologous series of oligomers, the tool accurately predicts the expected changes in the $\lambda_{\max }$ of the $\sigma-\sigma^{*}$ transitions. The method also reasonably accounts for structurally changes imposed by larger and bulky ligands and correlates well with structural data provide by Dräger. Recalculation of work previously modelled by Sita for a series of dialkyl oligostannanes also accurately reproduced the trends in terms of relative electronic transitions, particularly at the smallest oligomer sizes. The model is less successful in accounting for the aryl contributions of 
phenyl rings attached to Sn atoms, which predicts a greater delocalization than what is observed experimentally. Further development of density functionals for heavy elements, larger basis sets and improved calculation efficiencies will likely more precisely account for these differences.

4.6- Acknowledgements: The authors are grateful for support from the NSERC Discovery Program. D.F. and S.W. thank Professor Robert Gossage for review of this manuscript. S. H. and A. K. thank the Molecular Sciences Program at Ryerson for scholarship funding. D.F. also thanks the MacDiarmid Institute for their support in the preparation of this manuscript. 


\section{Chapter 5- Conclusion and Future Outlook}

This thesis provides the first in-depth look at the synthesis and characterization of fully tunable alternating polystannanes. This versatile chemistry opens the door to a variety of group 14 polymers that were previously unachievable. The condensation nature of the polymerization allows for large substituents on tin to be placed beside smaller ones on neighbouring tins rendering what were previously insoluble polymers, soluble. This work also encompasses the first substantial comprehensive computational study on polystannanes. This permitted the work on the bench to be justified prior to carrying out experiments/work, which may save time and resources.

One possible area of continued research in the area of alternating stannanes is to introduce a light absorbing dye molecule to these polymers. These polymers are susceptible to photodegradation; at approximately a wavelength of $\sim 400 \mathrm{~nm}$. A logical approach would be to use a red-orange dye that can act as a light sink; potentially protecting the backbone from exposure to these light conditions. Some examples of dyes that can be used are Cascade blue, Pacific Blue, methoxycoumarine or even an Anisole-BODIPY as all of these dyes have excitation windows which overlap with the susceptibility region of polystannanes. Also these systems can act a nucleophilic deterrent as they may prevent the attack and addition to the tin center by providing large amounts of steric bulk by the presence of large aromatic ring systems. Figure $\mathbf{5 . 1}$ shows a possible moiety to which these polymers can be achieved. 


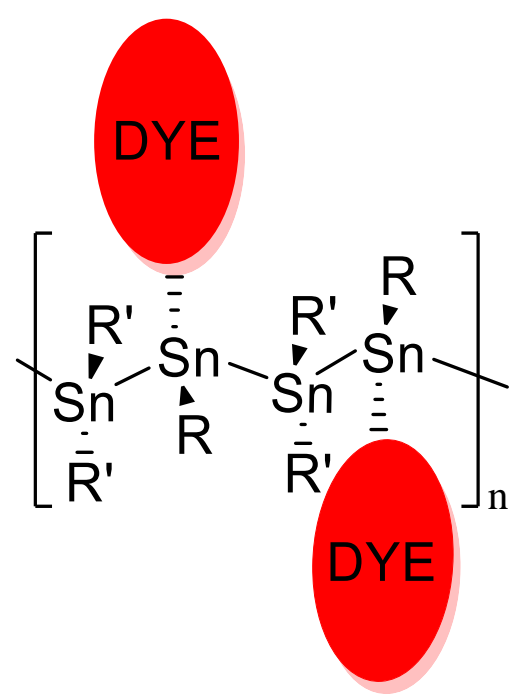

Figure 5.1: Possible Dye Based Polystannane Moiety

One possibility is that alternating polystannanes systems can be used in a dynamic involving a push-pull system. These systems will allow for the shuttling of electron density through the sigma bond connecting the tin centers, addressing some of the problems associated with the diffuse $\mathrm{Sn}-\mathrm{Sn}$ bond and ultimately stabilizing it. These push-pull systems moieties such as Figure $\mathbf{5 . 3}$ have an electron donor or acceptor at the para position which, through $\sigma$-conjugation and $\pi$-conjugation, allows communication between the centers. The $\mathrm{CF}_{3}$ groups are acting as a withdrawing substituent on the end group molecules, while the electron density is being forced from the $\mathrm{MeO}$ group on the para phenyl ring. Figure 5.2 shows the HOMO-LUMO diagram of this dynamic. It is observed that in the HOMO the electron density is shifted along $\mathrm{sp}^{3}$ hybrid axis.
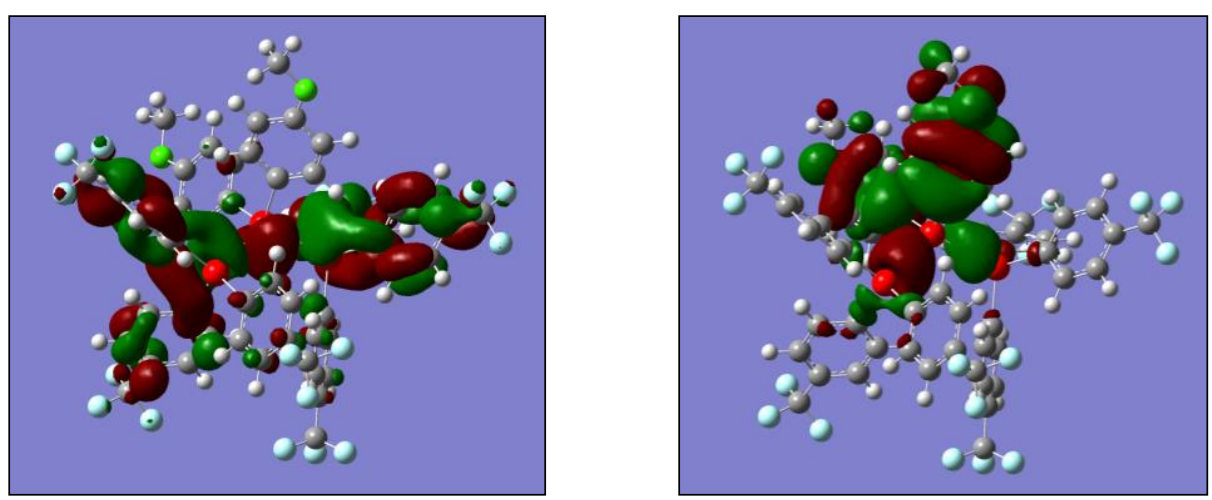

Figure 5.2: HOMO (Left) LUMO (Right) of Theorized Push-Pull System. 
Finally the possibility to introduce another element into the backbone is now achievable. Group 14 elements are all very similar in their characteristics and the insertion of another element could make the polymer still conductive and possess added stability. An example of this is the insertion of a silicon atom between the tin atoms. It will still be conductive however the tin to silane bond is substantially stronger then the polystannane bond making the theorized structure less chemically susceptible. All of the above projects have begun in the lab and are an ongoing process and a direct result of the possibilities and outcome of this work.

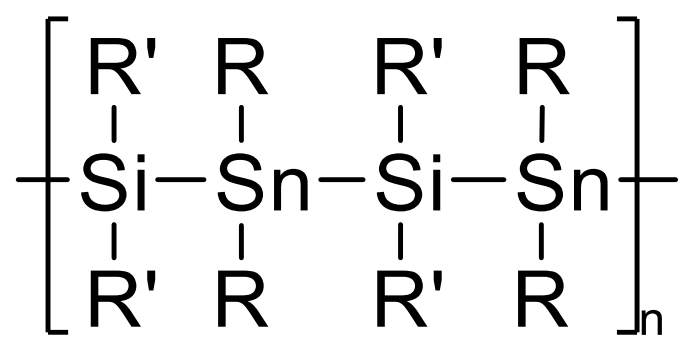

Figure 5.3: Possible Outline of Stannane-Alt-Silane Polymer. 


\section{Chapter 6- Appendices}

\section{1-Alternating Polystannanes: Syntheses and Properties}

\subsection{1- Materials and Methods}

All reagents were purchased from Sigma Aldrich. Solvents were dried using an MBraun solvent drying system. All glass-ware was first dried in an oven then flame dried to remove surface moisture. ${ }^{1} \mathrm{H}$ NMR (400 MHz), ${ }^{13} \mathrm{C}$ NMR (100.6 MHz) and ${ }^{119} \mathrm{Sn}$ NMR (149.2 MHz) spectra were recorded on a Bruker Advance $400 \mathrm{MHz}$ NMR spectrometer with a BBFO 5-mm direct probe. A ${ }^{1} \mathrm{H}$ pulse width of $30^{\circ}$ was used, acquiring a spectral window of $8223 \mathrm{~Hz}(20 \mathrm{ppm})$ using a relaxation delay of $1 \mathrm{~s}$, acquisition time $3.98 \mathrm{~s}, 32 \mathrm{k}$ points (16 scans). The ${ }^{1} \mathrm{H} 90^{\circ}$ pulse width was $10.4 \mu \mathrm{s} . \mathrm{A}^{13} \mathrm{C}$ pulse width of $30^{\circ}$ was used, acquiring a spectral window of $24038 \mathrm{~Hz}(239 \mathrm{ppm})$ using a relaxation delay of $2 \mathrm{~s}$, acquisition time $1.36 \mathrm{~s}, 32 \mathrm{k}$ points (4096 scans). The ${ }^{13} \mathrm{C} 90^{\circ}$ pulse width was $8.7 \mu \mathrm{s}$. A ${ }^{119} \mathrm{Sn}$ pulse width of $30^{\circ}$ was used, $8.75 \mu \mathrm{s}$, acquiring a spectral window of $100000 \mathrm{~Hz}(670 \mathrm{ppm})$ using a relaxation delay of 1s, acquisition time $0.33 \mathrm{~s}$, 32k points (15360 scans) with inverse gated proton decoupling. All results were analyzed on MestReNova LITE 5.2.5 software. Chemical shifts were calculated using the chemical deuterated standards as a reference for ${ }^{1} \mathrm{H}$ and ${ }^{13} \mathrm{C}$. The ${ }^{119} \mathrm{Sn}$ was referenced to $\mathrm{SnMe}_{4}$ as an internal standard. All $J$ coupling values are reported as absolute values. UV-Vis evaluations were carried out using a Perkin Elmer Lambda $20 \mathrm{UV}-$ Vis spectrometer. Elemental Analysis was performed by Atlantic Microlab, Inc. of Norcross Georgia. Time-of-flight mass spectrometry analyses were performed at the AIMS Mass Spectrometry Laboratory, University of Toronto using a JMS-T1000LC mass spectrometer (JEOL Inc., Peabody, MA) equipped with a Direct Analysis in Real Time (DART) ionization source (DART-SVP, Ionsense Inc., Saugus, MA). The DART source was operated with He gas and the temperature was adjusted in the range $100-400^{\circ} \mathrm{C}$. Isotopic distributions for the observed ionic species were calculated using the Mass Center utility (JEOL) and were in good 
agreement with the measured mass spectra. The DSC of polymers from this study were analyzed using a Perkin Elmer Pyris Diamond differential scanning calorimeter. Molecular weight determinations of polymer samples were made by GPC using a Viscotek TDAmax with THF as the elution solvent attached to a triple detector array (TDA 302). All reactions took place under nitrogen $\left(\mathrm{N}_{2}\right)$ atmosphere or in a sealed Schlenk flask placed under reduced pressure (closed) or finally in a Schlenk flask exposed to dynamic reduced pressure (open). Pressures measured in mmHg using a mercury manometer attached to the Schlenk line.

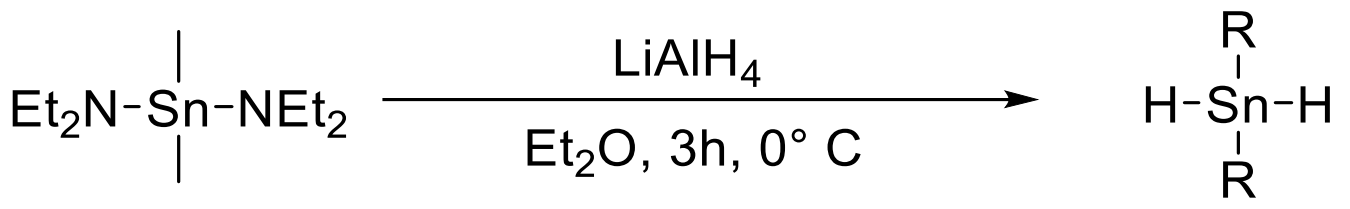

Scheme 6.1.1.1 General reaction scheme for dihydrides

6.1.1.1-Preparation of di(n-butyl)stannane (1)

Dry $\mathrm{Et}_{2} \mathrm{O}(30 \mathrm{~mL})$ was used to dissolve $(n-\mathrm{Bu})_{2} \mathrm{SnCl}_{2}(1.53 \mathrm{mmol}, 4.65 \mathrm{~g})$ in a $250 \mathrm{~mL}$ Schlenk flask. An equimolar solution of $\mathrm{LiAlH}_{4}$ in $\mathrm{Et}_{2} \mathrm{O}$ was added drop wise with constant stirring over a $30 \mathrm{~min}$ period at $0^{\circ} \mathrm{C}$. The resultant solution was allowed to react for $3 \mathrm{~h}$ at constant temperature. The reaction was quenched with $30 \mathrm{~mL}$ chilled degassed water. The organic layer was separated and the aqueous layer extracted with $20 \mathrm{~mL} \mathrm{Et}_{2} \mathrm{O}$. The combined organic layers were dried over $\mathrm{CaCl}_{2}$ for $2 \mathrm{~h}$. After filtration, the solution containing 1 was removed in vacuo to yield a cloudy coloured liquid. The sample was stored at $-20^{\circ} \mathrm{C}$ to avoid decomposition. Yield: $3.63 \mathrm{~g}(78 \%)$.

${ }^{1} \mathrm{H}$ NMR $\left(\mathrm{C}_{6} \mathrm{D}_{6}\right): \delta 0.86\left(\mathrm{t}, 6 \mathrm{H},-\mathrm{SnCH}_{2} \mathrm{CH}_{2} \mathrm{CH}_{2} \mathrm{CH}_{3}\right) ; 0.96\left(\mathrm{sex}, 4 \mathrm{H},-\mathrm{SnCH}_{2} \mathrm{CH}_{2} \mathrm{CH}_{2} \mathrm{CH}_{3}\right) ; 1.27$ (m, 4H, $\left.-\mathrm{SnCH}_{2} \mathrm{CH}_{2} \mathrm{CH}_{2} \mathrm{CH}_{3}\right) ; 1.49$ (m, 4H, $\left.-\mathrm{SnCH}_{2} \mathrm{CH}_{2} \mathrm{CH}_{2} \mathrm{CH}_{3}\right) ; 4.77$ (q, 2H, -SnH 2$)$ ppm; ${ }^{119} \mathrm{Sn}$ $\left\{{ }^{1} \mathrm{H}\right\}$ NMR $\left(\mathrm{C}_{6} \mathrm{D}_{6}\right): \delta-203.7 \mathrm{ppm}$. This data is in good agreement with reported literature values. ${ }^{2}$ 
6.1.1.2-Preparation of diphenylstannane (2)

Dry $\mathrm{Et}_{2} \mathrm{O}(30 \mathrm{~mL})$ was used to dissolve $\mathrm{Ph}_{2} \mathrm{SnCl}_{2}(1.53 \mathrm{mmol}, 4.65 \mathrm{~g})$ in a $250 \mathrm{~mL}$ Schlenk flask. An equimolar solution of $\mathrm{LiAlH}_{4}$ in $\mathrm{Et}_{2} \mathrm{O}$ was added drop wise with constant stirring over a 30 min at $0{ }^{\circ} \mathrm{C}$. The resultant solution was allowed to react for further $3 \mathrm{~h}$ at this temperature. Then reaction was quenched with $30 \mathrm{~mL}$ chilled degassed water. The organic layer was separated and aqueous layer extracted using a $20 \mathrm{~mL}$ of $\mathrm{Et}_{2} \mathrm{O}$. The combined organic layers were dried over $\mathrm{CaCl}_{2}$ for $2 \mathrm{~h}$. After filtration, the solvent was removed in vacuo yielding a cloudy white coloured liquid. The sample was stored at $-20{ }^{\circ} \mathrm{C}$ to avoid decomposition. Yield: $3.81 \mathrm{~g}(82 \%)$.

${ }^{1} \mathrm{H}$ NMR $\left(\mathrm{C}_{6} \mathrm{D}_{6}\right) \delta 6.07\left(\mathrm{~s}, 2 \mathrm{H},-\mathrm{Sn} H_{2}\right), 7.10\left(\mathrm{dd},{ }^{3} J_{119 \mathrm{Sn}-1 \mathrm{H}}=4.8 \mathrm{~Hz},{ }^{3} J_{117 \mathrm{Sn}-1 \mathrm{H}}=1.8 \mathrm{~Hz}, 4 \mathrm{H}, o-\right.$

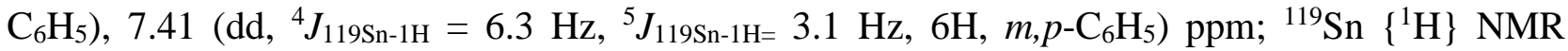
$\left(\mathrm{C}_{6} \mathrm{D}_{6}\right): \delta-234.3 \mathrm{ppm}$. This data is in good agreement with reported literature values. ${ }^{2}$

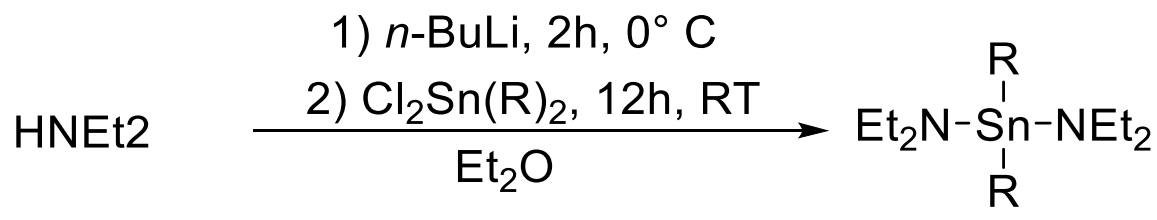

Scheme 6.1.1.2 General reaction scheme for tin diamides. 
6.1.1.3-Preparation of bis(diethylamino)dibutylstannane (3)

Dry $\mathrm{Et}_{2} \mathrm{O}(30 \mathrm{~mL})$ was used to dissolve $\left(n-\mathrm{Bu}_{2} \mathrm{SnCl}_{2}\right.$ chloride $(1.53 \mathrm{mmol}, 4.65 \mathrm{~g})$ in a $250 \mathrm{~mL}$ Schlenk flask. In a second $250 \mathrm{~mL}$ Schlenk flask, $20 \mathrm{~mL}$ of $\mathrm{Et}_{2} \mathrm{O}$ was added along with (3.06 mmol, $2.23 \mathrm{~g}$ ) of $\mathrm{HNEt}_{2}$, cooled to $0^{\circ} \mathrm{C}$, and an equimolar amount of $n$-BuLi (3.06 mmol) added dropwise over $15 \mathrm{~min}$. The mixture was allowed to warm to room temperature with stirring for $2 \mathrm{~h}$. The flask containing the lithiated amine was then cooled to again to $0{ }^{\circ} \mathrm{C}$ and the solution containing the tin halide added dropwise. A salt formed upon addition and the solution was stirred for $12 \mathrm{~h}$. The solution was filtered and the solvent removed in vacuo to yield an orange coloured liquid. Yield: $4.80 \mathrm{~g}(83 \%)$.

${ }^{1} \mathrm{H} \quad \mathrm{NMR} \quad\left(\mathrm{C}_{6} \mathrm{D}_{6}\right) \quad \delta \quad 0.93-0.81 \quad\left(\mathrm{~m}, \quad 6 \mathrm{H}, \quad-\mathrm{SnCH}_{2} \mathrm{CH}_{2} \mathrm{CH}_{2} \mathrm{CH}_{3}\right), \quad 1.08-0.99 \quad(\mathrm{~m}, \quad 4 \mathrm{H}, \quad-$ $\left.\mathrm{SnCH}_{2} \mathrm{CH}_{2} \mathrm{CH}_{2} \mathrm{CH}_{3}\right), \quad 1.17-1.08 \quad\left(\mathrm{~m}, \quad 6 \mathrm{H}, \quad-\mathrm{SnN}\left(\mathrm{CH}_{2} \mathrm{CH}_{3}\right)_{2}\right), \quad 1.39-1.26 \quad(\mathrm{~m}, \quad 4 \mathrm{H}, \quad-$ $\left.\mathrm{SnCH}_{2} \mathrm{CH}_{2} \mathrm{CH}_{2} \mathrm{CH}_{3}\right), \quad 1.64-1.52 \quad\left(\mathrm{~m}, \quad 4 \mathrm{H}, \quad-\mathrm{SnCH}_{2} \mathrm{CH}_{2} \mathrm{CH}_{2} \mathrm{CH}_{3}\right), \quad 3.15-2.99 \quad$ (m, $4 \mathrm{H}, \quad-$ $\left.\left.\mathrm{SnN}\left(\mathrm{CH}_{2} \mathrm{CH}_{3}\right)_{2}\right)\right) \mathrm{ppm} ;{ }^{119} \mathrm{Sn}\left\{{ }^{1} \mathrm{H}\right\} \mathrm{NMR}\left(\mathrm{C}_{6} \mathrm{D}_{6}\right): \delta 19.63 \mathrm{ppm}$. This data is in good agreement with reported literature values. ${ }^{4}$

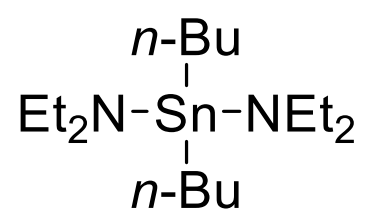

Figure 6.1.1.3 Bis(diethylamino)dibutylstannane. 
6.1.1.4-Preparation of bis(diethylamino)dimethylstannane (4)

Dry $\mathrm{Et}_{2} \mathrm{O}(30 \mathrm{~mL})$ was used to dissolve $\mathrm{Me}_{2} \mathrm{SnCl}_{2}(1.53 \mathrm{mmol}, 3.36 \mathrm{~g})$ in a $250 \mathrm{~mL}$ Schlenk flask. In a second $250 \mathrm{~mL}$ Schlenk flask, $20 \mathrm{~mL}$ of $\mathrm{Et}_{2} \mathrm{O}$ was added along with $(3.06 \mathrm{mmol} 2.23 \mathrm{~g})$ of $\mathrm{HNEt}_{2}$, cooled to $0{ }^{\circ} \mathrm{C}$, and an equimolar amount of $n$-BuLi (3.06 mmol) added dropwise over 15 min. The mixture was allowed to warm to room temperature with stirring for $2 \mathrm{~h}$. The flask containing the lithiated amine was then cooled to again to $0{ }^{\circ} \mathrm{C}$ and the solution containing the tin halide added dropwise. A salt formed upon addition and the solution was stirred for $12 \mathrm{~h}$. After filtration, the solvent was removed in vacuo to yield an orange coloured liquid. Yield: $5.03 \mathrm{~g}$ (87 $\%)$.

${ }^{1} \mathrm{H}$ NMR $\left(\mathrm{C}_{6} \mathrm{D}_{6}\right) \delta 0.19\left(\mathrm{~s},{ }^{2} J_{119 \mathrm{Sn}-1 \mathrm{H}}=2246 \mathrm{H},-\mathrm{Sn}\left(\mathrm{CH}_{3}\right)_{2}\right), 1.07\left(\mathrm{t}, 6 \mathrm{H},-\mathrm{SnN}\left(\mathrm{CH}_{2} \mathrm{CH}_{3}\right)_{2}\right), 3.02(\mathrm{q}$, $\left.{ }^{3} J_{119 \mathrm{Sn}-1 \mathrm{H}}=7.0 \mathrm{~Hz}, 4 \mathrm{H},-\mathrm{SnN}\left(\mathrm{CH}_{2} \mathrm{CH}_{3}\right)_{2}\right) \mathrm{ppm} ;{ }^{119} \mathrm{Sn}\left\{{ }^{1} \mathrm{H}\right\} \mathrm{NMR}\left(\mathrm{C}_{6} \mathrm{D}_{6}\right): \delta 43.41 \mathrm{ppm}$. This data is in good agreement with reported literature values. ${ }^{4}$

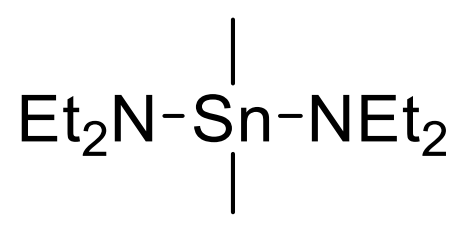

Figure 6.1.1.4 Bis(diethylamino)dimethylstannane. 
6.1.1.5-Preparation of poly(dibutyl)stannane (5)

To a dry $250 \mathrm{~mL}$ Schlenk flask wrapped in tin foil was added $30 \mathrm{~mL}$ of dry $\mathrm{Et}_{2} \mathrm{O}$ and 2 (1.50 mmol, $0.567 \mathrm{~g})$. This solution cooled to $0{ }^{\circ} \mathrm{C}$, and $\mathbf{1}(1.50 \mathrm{mmol}, 0.354 \mathrm{~g})$ was added dropwise over 15 min without notable colour change. The polymerization was allowed to proceed for $12 \mathrm{~h}$, where after the remaining solvent and by-products removed in vacuo. Yield $3.49 \mathrm{~g}$ (75\%).

${ }^{1} \mathrm{H} \mathrm{NMR}\left(\mathrm{C}_{6} \mathrm{D}_{6}\right) \delta 0.89\left(\mathrm{t},{ }^{5} J_{119 \mathrm{Sn}-1 \mathrm{H}}=4.7 \mathrm{~Hz}, 6 \mathrm{H},-\mathrm{SnCH}_{2} \mathrm{CH}_{2} \mathrm{CH}_{2} \mathrm{CH}_{3}\right), 0.95\left(\mathrm{~m},{ }^{2} J_{119 \mathrm{Sn}-1 \mathrm{H}}=17.3\right.$ $\left.\mathrm{Hz}, 4 \mathrm{H},-\mathrm{SnCH}_{2} \mathrm{CH}_{2} \mathrm{CH}_{2} \mathrm{CH}_{3}\right), 1.36\left(\mathrm{dd},{ }^{3} \mathrm{~J}_{119 \mathrm{Sn}-1 \mathrm{H}}=14.3 \mathrm{~Hz}, 4 \mathrm{H},-\mathrm{SnCH}_{2} \mathrm{CH}_{2} \mathrm{CH}_{2} \mathrm{CH}_{3}\right), 1.80(\mathrm{dd}$, $\left.{ }^{4} J_{119 \mathrm{Sn}-1 \mathrm{H}}=13.9 \mathrm{~Hz}, 4 \mathrm{H},-\mathrm{SnCH}_{2} \mathrm{CH}_{2} \mathrm{CH}_{2} \mathrm{CH}_{3}\right) \mathrm{ppm} ;{ }^{119} \mathrm{Sn}\left\{{ }^{1} \mathrm{H}\right\} \mathrm{NMR}\left(\mathrm{C}_{6} \mathrm{D}_{6}\right): \delta-190.6 \mathrm{ppm} . \mathrm{UV}-$ VIS $\lambda_{\max }(\mathrm{THF})=379 \mathrm{~nm}\left(\varepsilon=5.184 \mathrm{~L} \cdot \mathrm{mol}^{-1} \cdot \mathrm{cm}^{-1}\right)$. This data is in good agreement with reported

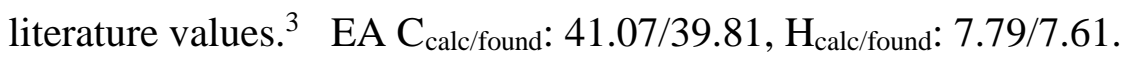

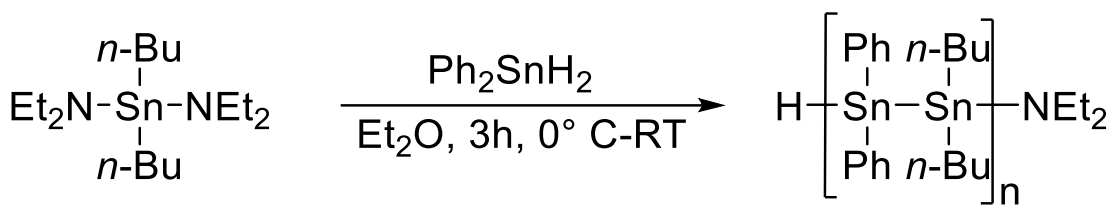

Scheme 6.1.1.5 Synthesis of poly(dibutyl) stannane.

6.1.1.6-Preparation of poly(diphenyl-alt-dibutyl) stannane (6)

To a $250 \mathrm{~mL}$ Schlenk flask wrapped in tin foil was added $30 \mathrm{~mL}$ of dry toluene and 2 (1.50 mmol, $0.567 \mathrm{~g})$. The flask was then cooled to $0^{\circ} \mathrm{C}$, after which $4(1.50 \mathrm{mmol}, 0.413 \mathrm{~g})$ was added dropwise over 15 minutes. The polymerization was allowed to proceed for $12 \mathrm{~h}$. The remaining solution and by-products were removed in vacuo. Yield: $4.00 \mathrm{~g}(86 \%)$.

${ }^{1} \mathrm{H}$ NMR $\left(\mathrm{C}_{6} \mathrm{D}_{6}\right) \delta 0.74\left(\mathrm{t},{ }^{5} J_{119 \mathrm{Sn}-1 \mathrm{H}}=7.3 \mathrm{~Hz}, 6 \mathrm{H},-\mathrm{SnCH}_{2} \mathrm{CH}_{2} \mathrm{CH}_{2} \mathrm{CH}_{3}\right), 0.98-0.75(\mathrm{~m}, 4 \mathrm{H}$, $\left.\mathrm{SnCH}_{2} \mathrm{CH}_{2} \mathrm{CH}_{2} \mathrm{CH}_{3}\right), 1.27\left(\mathrm{ddd},{ }^{3} J_{119 \mathrm{Sn}-1 \mathrm{H}}=21.4 \mathrm{~Hz}, 4 \mathrm{H}, \mathrm{SnCH}_{2} \mathrm{CH}_{2} \mathrm{CH}_{2} \mathrm{CH}_{3}\right), 1.85-1.42(\mathrm{~m}, 4 \mathrm{H}$, $\left.\mathrm{SnCH}_{2} \mathrm{CH}_{2} \mathrm{CH}_{2} \mathrm{CH}_{3}\right), 7.10-6.79\left(\mathrm{~m}, 4 \mathrm{H}, o-\mathrm{C}_{6} \mathrm{H}_{5}\right), 7.34\left(\mathrm{t},{ }^{4} J_{119 \mathrm{Sn}-1 \mathrm{H}}=10.4 \mathrm{~Hz}, 6 \mathrm{H}, m, p-\mathrm{C}_{6} \mathrm{H}_{5}\right) \mathrm{ppm}$; 
${ }^{13} \mathrm{C}\left\{{ }^{1} \mathrm{H}\right\} \mathrm{NMR}\left(\mathrm{C}_{6} \mathrm{D}_{6}\right): \delta 13.75\left(-\mathrm{SnCH}_{2} \mathrm{CH}_{2} \mathrm{CH}_{2} \mathrm{CH}_{3}\right), 25.82\left(-\mathrm{SnCH}_{2} \mathrm{CH}_{2} \mathrm{CH}_{2} \mathrm{CH}_{3}\right), 30.22$ $\left.\mathrm{SnCH}_{2} \mathrm{CH}_{2} \mathrm{CH}_{2} \mathrm{CH}_{3}\right), 67.83\left(-\mathrm{SnCH}_{2} \mathrm{CH}_{2} \mathrm{CH}_{2} \mathrm{CH}_{3}\right), 128.91\left(p-\mathrm{C}_{6} \mathrm{H}_{5}\right), 129.06\left(m-\mathrm{C}_{6} \mathrm{H}_{5}\right), 137.70(o-$ $\left.\mathrm{C}_{6} \mathrm{H}_{5}\right), 138.67\left(i-\mathrm{C}_{6} \mathrm{H}_{5}\right) \mathrm{ppm} ;{ }^{119} \mathrm{Sn}\left\{{ }^{1} \mathrm{H}\right\}$ NMR $\left(\mathrm{C}_{6} \mathrm{D}_{6}\right): \delta-187.4\left(-\mathrm{Sn}\left(n \mathrm{Bu}_{2}\right)\right)$ and $-208.0\left(-\mathrm{SnPh}_{2}\right)$ ppm. UV-VIS $\lambda_{\max }(\mathrm{THF})=390 \mathrm{~nm}\left(\varepsilon=2.554 \mathrm{~L} \cdot \mathrm{mol}^{-1} \cdot \mathrm{cm}^{-1}\right)$. EA C $\mathrm{C}_{\text {calc/found: }} 47.30 / 46.56, \mathrm{H}_{\text {calc/found: }}$ 5.95/5.39.
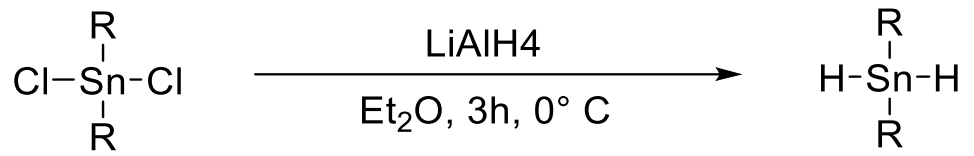

Scheme 6.1.1.6 Synthesis of poly(diphenyl-alt-dibutyl) stannane.

6.1.1.7-Preparation of poly(diphenyl-alt-dimethyl) stannane (7)

To a $250 \mathrm{~mL}$ Schlenk flask wrapped in tin foil was added $30 \mathrm{~mL}$ of dry toluene and $\mathbf{3}(1.50 \mathrm{mmol}$, $0.441 \mathrm{~g})$. The flask was then cooled to $0^{\circ} \mathrm{C}$, after which $4(1.50 \mathrm{mmol}, 0.413 \mathrm{~g})$ was added dropwise over $15 \mathrm{~min}$. The polymerization was allowed to react for $12 \mathrm{~h}$. Then the remaining solution and by-products were removed in vacuo. Yield: $3.82 \mathrm{~g}(82 \%)$.

${ }^{1} \mathrm{H}$ NMR $\left(\mathrm{C}_{6} \mathrm{D}_{6}\right): \delta 1.35\left(\mathrm{t}, 6 \mathrm{H},\left(-\mathrm{SnCH}_{3}\right)_{2}\right) ; 7.10-6.65\left(\mathrm{~m}, 6 \mathrm{H},\left(m, p-\mathrm{C}_{6} \mathrm{H}_{5}\right)_{2}\right), 7.42(\mathrm{t}, 6 \mathrm{H}, o-$ $\left.\left.\mathrm{C}_{6} \mathrm{H}_{5}\right)_{2}\right) \mathrm{ppm},{ }^{13} \mathrm{C}\left\{{ }^{1} \mathrm{H}\right\} \mathrm{NMR}\left(\mathrm{C}_{6} \mathrm{D}_{6}\right): \delta 1.03\left(-\mathrm{SnCH}_{3}\right), 128.81\left(p-\mathrm{C}_{6} \mathrm{H}_{5}\right), 129.03\left(m-\mathrm{C}_{6} \mathrm{H}_{5}\right), 136.14$ $\left(o-\mathrm{C}_{6} \mathrm{H}_{5}\right), \quad 136.26\left(i-\mathrm{C}_{6} \mathrm{H}_{5}\right) \mathrm{ppm} ;{ }^{119} \mathrm{Sn}\left\{{ }^{1} \mathrm{H}\right\}$ NMR $\left(\mathrm{C}_{6} \mathrm{D}_{6}\right): \delta-59.8\left(J_{119 \mathrm{Sn}-117 \mathrm{Sn}}=4421 \mathrm{~Hz},(-\right.$ $\left.\left.\mathrm{SnMe}_{2}\right)\right),-200.5\left(-\mathrm{SnPh}_{2}\right)$ ppm. UV-VIS $\lambda_{\max }(\mathrm{THF})=395 \mathrm{~nm}\left(\varepsilon=7.745 \mathrm{~L} \cdot \mathrm{mol}^{-1} \cdot \mathrm{cm}^{-1}\right)$. EA $\mathrm{C}_{\text {calc/found: }}$ 34.81/33.72, $\mathrm{H}_{\text {calc/found: }}$ 5.50/5.63. 


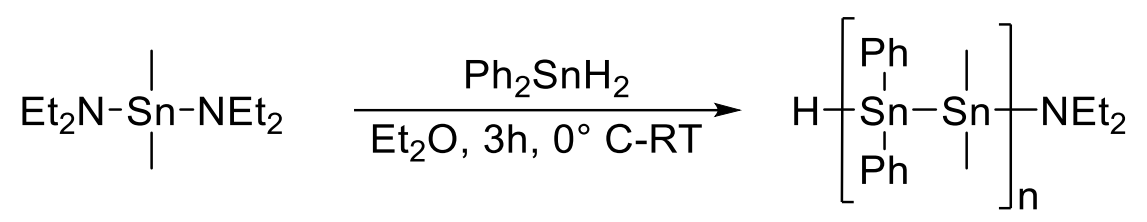

Scheme 6.1.1.7 Synthesis of poly(dimethyl-alt-dibutyl) stannane.

6.1.1.8-Preparation of poly(dimethyl-alt-dibutyl) stannane (8)

To a $250 \mathrm{~mL}$ Schlenk flask wrapped in tin foil was added $30 \mathrm{~mL}$ of dry toluene and 3 (1.50 mmol, $0.441 \mathrm{~g})$. The flask was then cooled to $0^{\circ} \mathrm{C}$, after which 1 (1.50 mmol, $\left.0.354 \mathrm{~g}\right)$ was added dropwise over $15 \mathrm{~min}$. The polymerization was allowed to react for a total of $12 \mathrm{~h}$. The remaining solution and by-products were then removed under reduced pressure. Yield: $2.93 \mathrm{~g}(63 \%)$.

${ }^{1} \mathrm{H}$ NMR $\left(\mathrm{C}_{6} \mathrm{D}_{6}\right): \delta 0.31\left(\mathrm{~s}, 3 \mathrm{H},\left(-\mathrm{SnCH}_{3}\right)_{2}\right) ; 0.64\left(\mathrm{t}, 3 \mathrm{H},-\mathrm{SnCH}_{2} \mathrm{CH}_{2} \mathrm{CH}_{2} \mathrm{CH}_{3}\right) ; 0.86(\mathrm{t}, 2 \mathrm{H}$, $\left.\mathrm{SnCH}_{2} \mathrm{CH}_{2} \mathrm{CH}_{2} \mathrm{CH}_{3}\right) ; 1.10\left(\mathrm{~m}, 2 \mathrm{H},-\mathrm{SnCH}_{2} \mathrm{CH}_{2} \mathrm{CH}_{2} \mathrm{CH}_{3}\right) ; 1.34$ (m, 2H, $\left.-\mathrm{SnCH}_{2} \mathrm{CH}_{2} \mathrm{CH}_{2} \mathrm{CH}_{3}\right) ; \mathrm{ppm}$; ${ }^{13} \mathrm{C}\left\{{ }^{1} \mathrm{H}\right\}$ NMR $\left(\mathrm{C}_{6} \mathrm{D}_{6}\right): \delta 10.11\left(J_{119 \mathrm{Sn}-13 \mathrm{C}}=120 \mathrm{~Hz}, J_{117 \mathrm{Sn}-13 \mathrm{C}}=115 \mathrm{~Hz},-\mathrm{SnCH}_{3}\right), 10.47\left(J_{119 \mathrm{Sn}-13 \mathrm{C}}\right.$ $\left.=120 \mathrm{~Hz}, J_{117 \mathrm{Sn}-13 \mathrm{C}}=115 \mathrm{~Hz},-\mathrm{SnCH}_{2} \mathrm{CH}_{2} \mathrm{CH}_{2} \mathrm{CH}_{3}\right), 13.61\left(-\mathrm{SnCH}_{2} \mathrm{CH}_{2} \mathrm{CH}_{2} \mathrm{CH}_{3}\right), 27.59(-$ $\left.\mathrm{SnCH}_{2} \mathrm{CH}_{2} \mathrm{CH}_{2} \mathrm{CH}_{3}\right), 30.82\left(-\mathrm{SnCH}_{2} \mathrm{CH}_{2} \mathrm{CH}_{2} \mathrm{CH}_{3}\right)$ ppm ; ${ }^{119} \mathrm{Sn}\left\{{ }^{1} \mathrm{H}\right\} \mathrm{NMR}\left(\mathrm{C}_{6} \mathrm{D}_{6}\right): \delta-185$ and 235 ppm. UV-VIS $\lambda_{\max }(\mathrm{THF})=311 \mathrm{~nm}\left(\varepsilon=2.420 \mathrm{~L} \cdot \mathrm{mol}^{-1} \cdot \mathrm{cm}^{-1}\right)$. EA C $C_{\text {calc/found }}$ 31.30/29.24, $\mathrm{H}_{\text {calc/found }}$ 6.83/6.37.

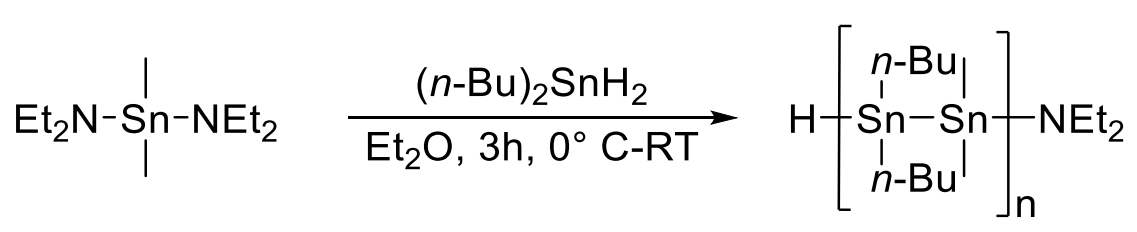

Scheme 6.1.1.8 Synthesis of poly(dimethyl-alt-dibutyl) stannane 


\subsection{2. - Elemental Analysis}

The elemental analysis was conducted by Atlantic Microlabs and was only examined for $\mathrm{C}$ and $\mathrm{H}$. These elements account for less than half of the molecular weight of one unit within the polymer chain. As a result the uncertainty of these polymers is relatively high. The process itself has an uncertainty of $\pm 0.3 \%$ which can skew values significantly when coupled with a relative weight of tin used for calculations. Lastly the PDI of these polymers is slightly $>2$, which is the value for an ideal condensation polymerization. With all of these factors in mind we used GPC to determine a rough EA calculation. Since the PDI is not a perfectly symmetrical bell curve the idealized monomer size is not exactly representative of the equally distributed polymeric chain. Assuming all of these factors we can determine approximately the number of repeat units is as follows: $\mathbf{5}=$ 77 units, $\mathbf{6}=74$ units, $7=1150$ units and $\mathbf{8}=180$ units. As observed by all of these repeat unit sizes we can determine that end group affects are negligible due to the number of units in the chain. From then each like atom in the chain (all $\mathrm{Sn}$, all $\mathrm{C}$ and all $\mathrm{H}$ ) was added together to determine their total mass contribution to the polymer. Then each was added together and the individual atoms had a $\%$ determination based off of the total polymeric weight. The collective elemental data is presented and used for calculated values. Importantly, at a 10\% deviation of the starting material ratios from 1.0 cause a pronounced decrease in molar mass is expected for a

polycondensation type reaction of the in situ formed stannides, according to Carothers equation. ${ }^{33}$ The deviation takes into account a non-idealized situation where as the calculations are assumed under an ideal working situation. 


\subsection{3- Differential Scanning Calorimetry}

5
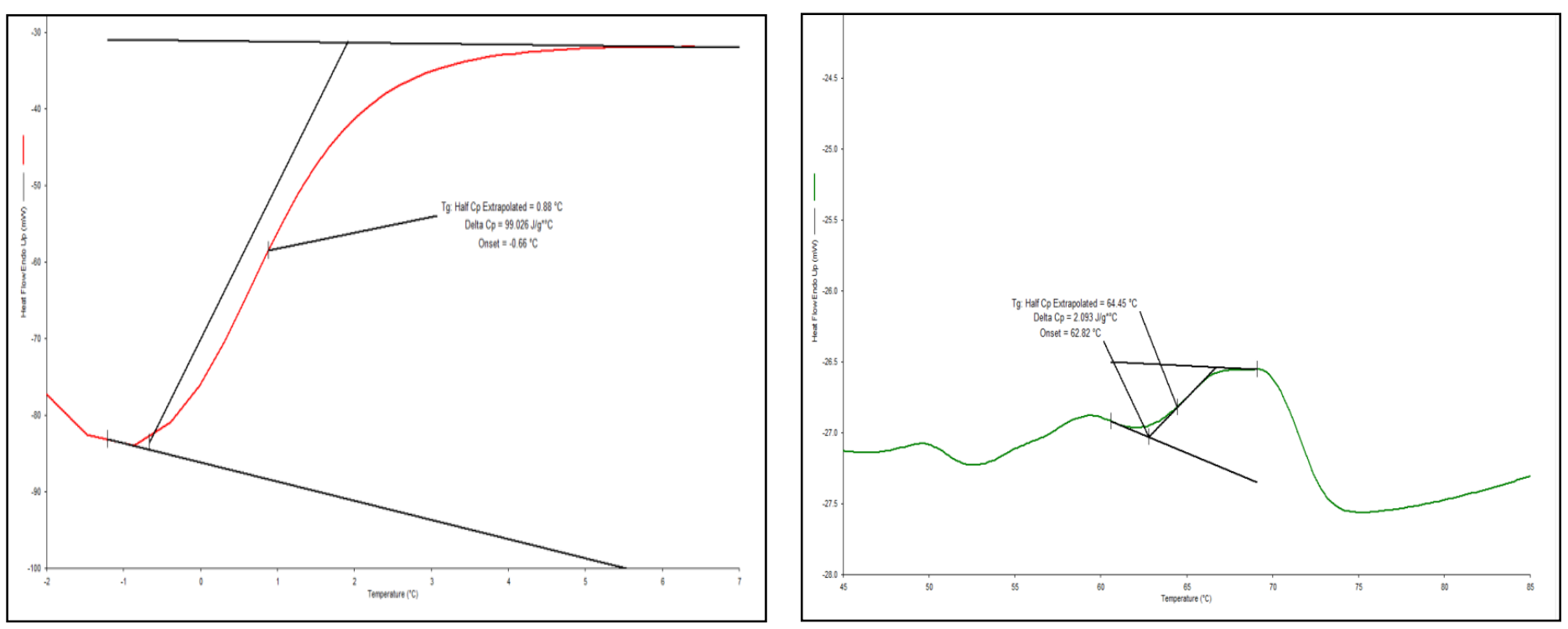

7
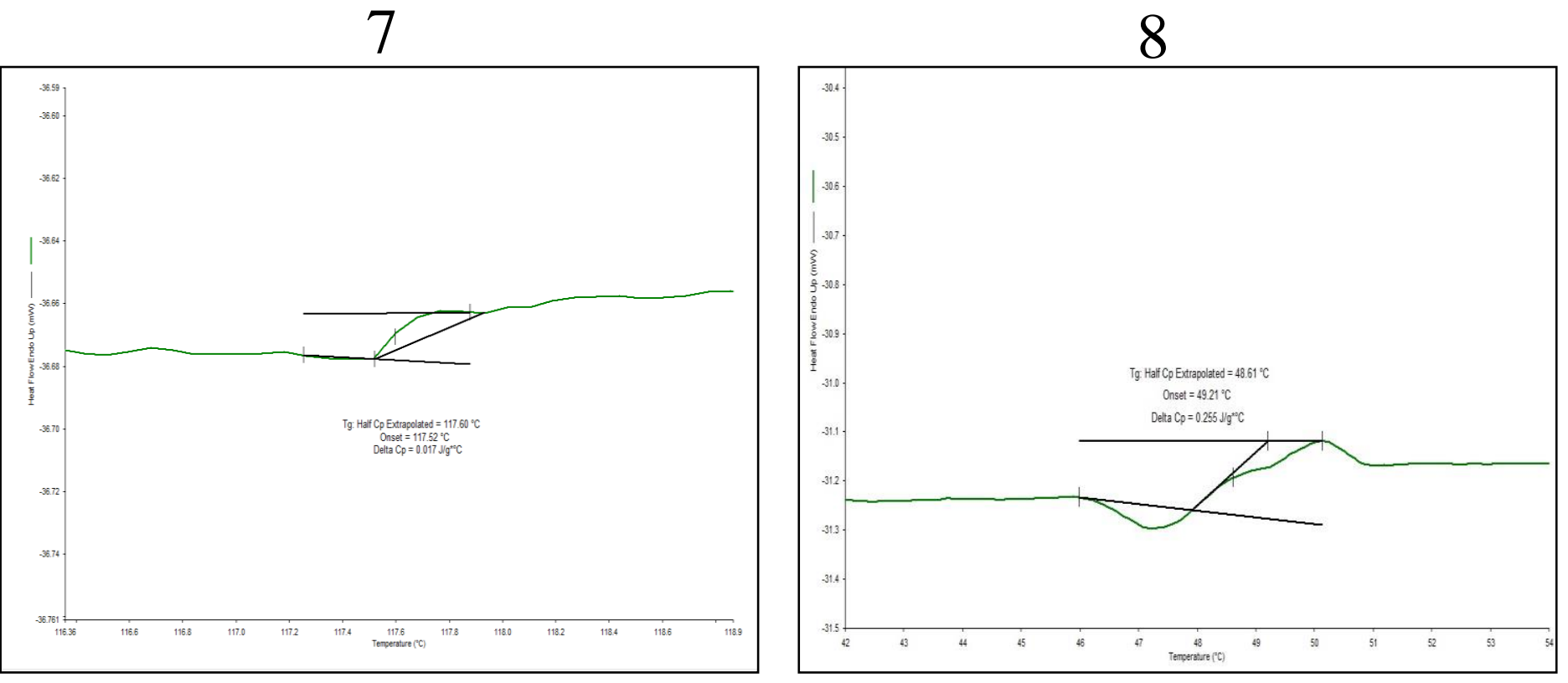

Figure 6.1.3.1 DSC of Synthesized Polymers.

Note on DSC acquisition: All of these samples were run between $-45^{\circ} \mathrm{C}-150^{\circ} \mathrm{C}$ then cooled to complete the cycle at $10^{\circ} \mathrm{C}$ a minute in triplicate with a $20 \mathrm{~mL} / \mathrm{min}$ flow of $\mathrm{N}_{2}(\mathrm{~g})$ 


\subsection{4-Polymer Images}

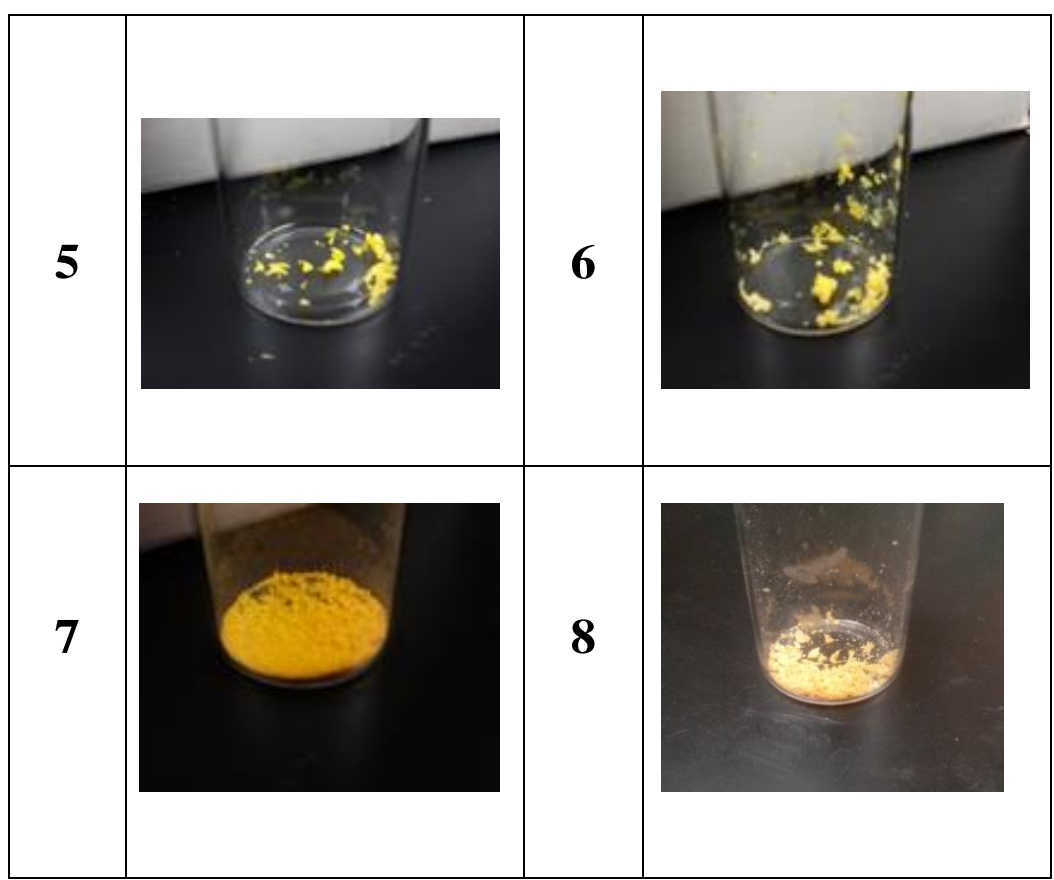

Figure 6.1.4.1 Images of all the Synthesized Polymers. 


\subsection{5.-GPC}

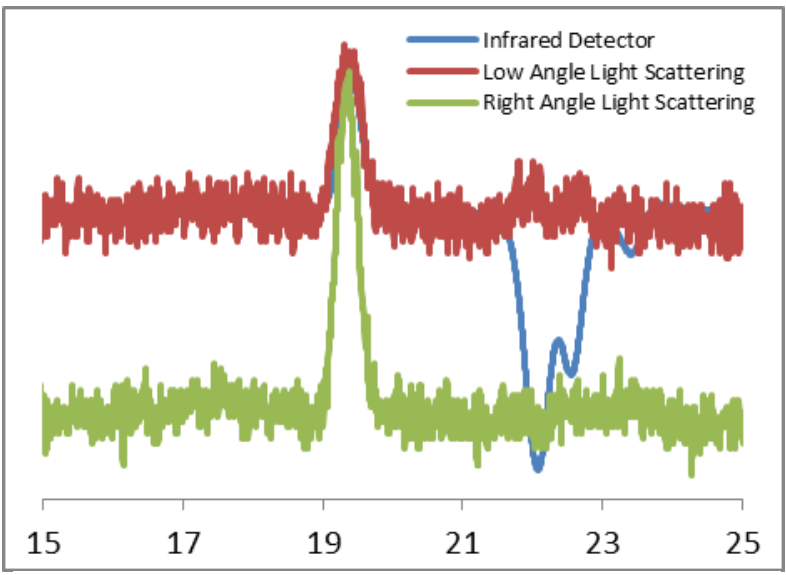

GPC of polymer 5 in THF

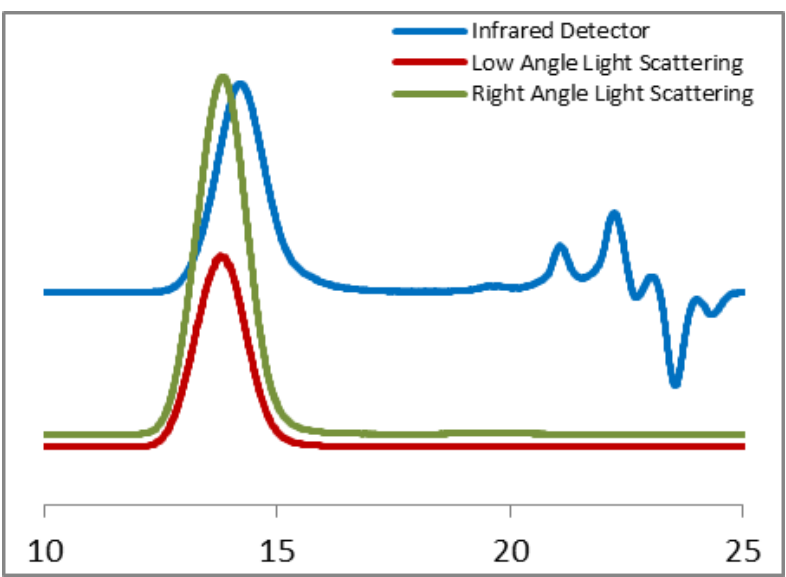

GPC of polymer 7 in THF

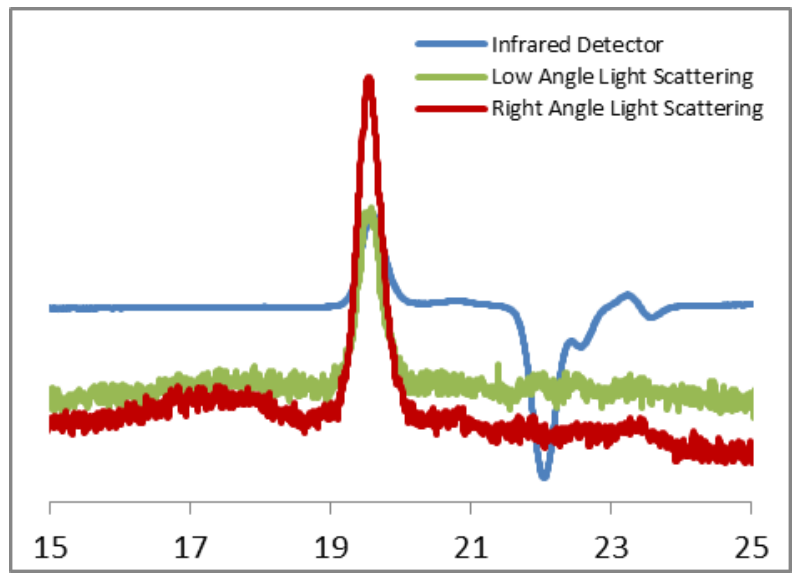

GPC of polymer 6 in THF

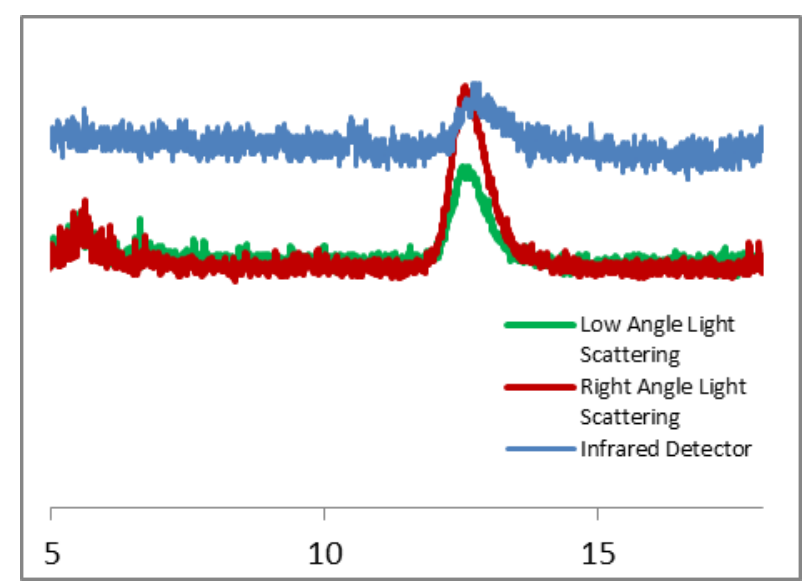

GPC of polymer 8 in THF

Figure 6.1.5.1 GPC Chromatograms of Polymers 5-8

Note on Molecular weight determinations: The GPC analysis of these polymers was done in triplicate to ensure accuracy. We estimated the molecular weights of alternating polymers by using the calculated dn/dc for homopolymer 5. This estimation allowed for a calculation of polymer PDI. While the $\mathrm{dn} / \mathrm{dc}$ for different for each of the alternating polymers is different, an estimation using the more similar identical polystannane $\mathbf{5}$ is likely to be closer to the actual molecular weight compared to conventional systems calibrated with polystyrene standards. These issues have been 
previously reported in the literature. Caseri et al. reported that as the phenyl substituents ratio increased, the polymer moved to a more insoluble state until no Mw information was obtainable. ${ }^{16}$ The solutions were made at $10 \mathrm{mg} / \mathrm{mL}$ for $\mathbf{5 , 6}$ and $\mathbf{8}$ while the $\mathbf{7}$ was made at $2 \mathrm{mg} / \mathrm{mL}$ due to solubility restraints. All solutions were run in THF. 


\subsection{6-NMR}

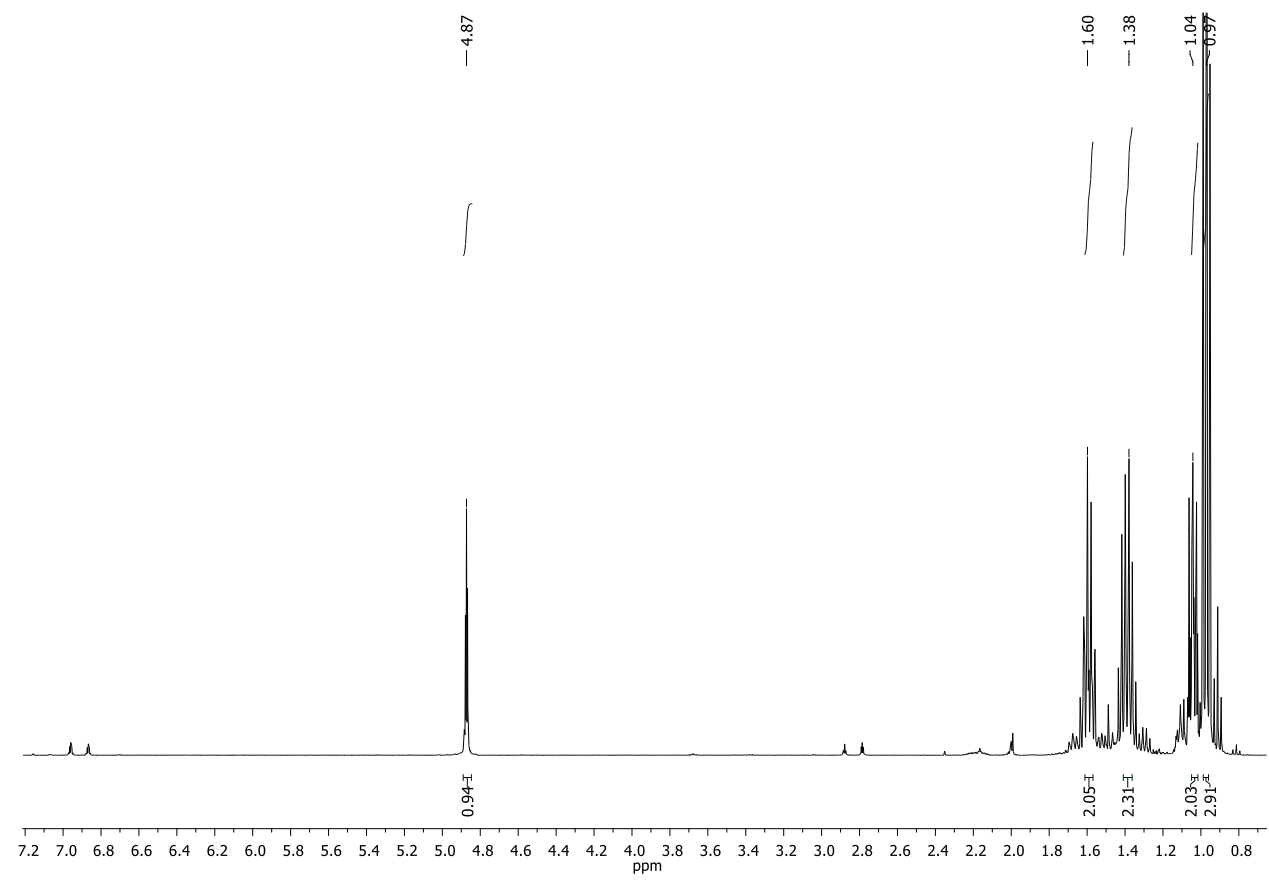

Figure 6.1.6.1 - ${ }^{1} \mathrm{H}$ NMR $\left(\mathrm{C}_{6} \mathrm{D}_{6}\right)$ spectrum of $\mathbf{1}$
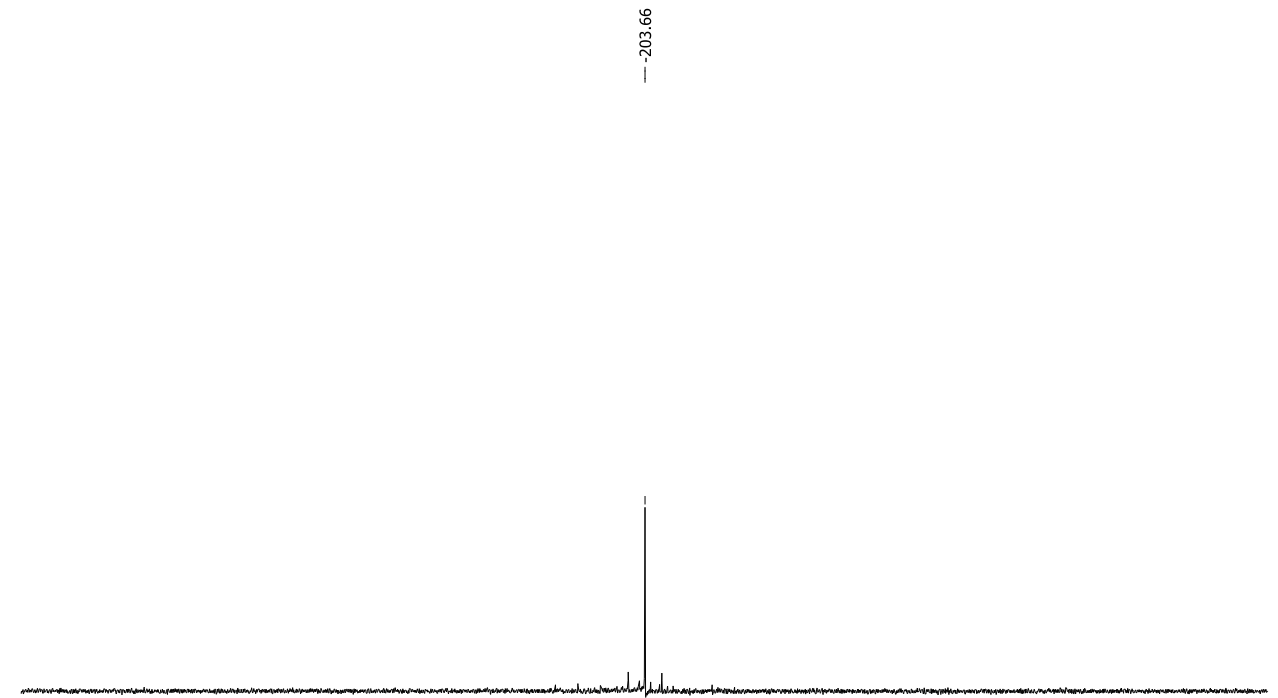

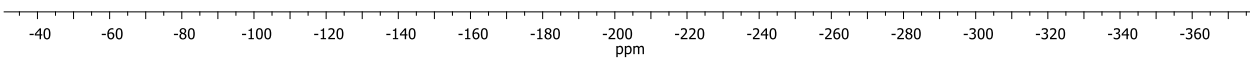

Figure 6.1.6.2 : ${ }^{119} \mathrm{Sn}$ NMR $\left(\mathrm{C}_{6} \mathrm{D}_{6}\right)$ spectrum of 1 


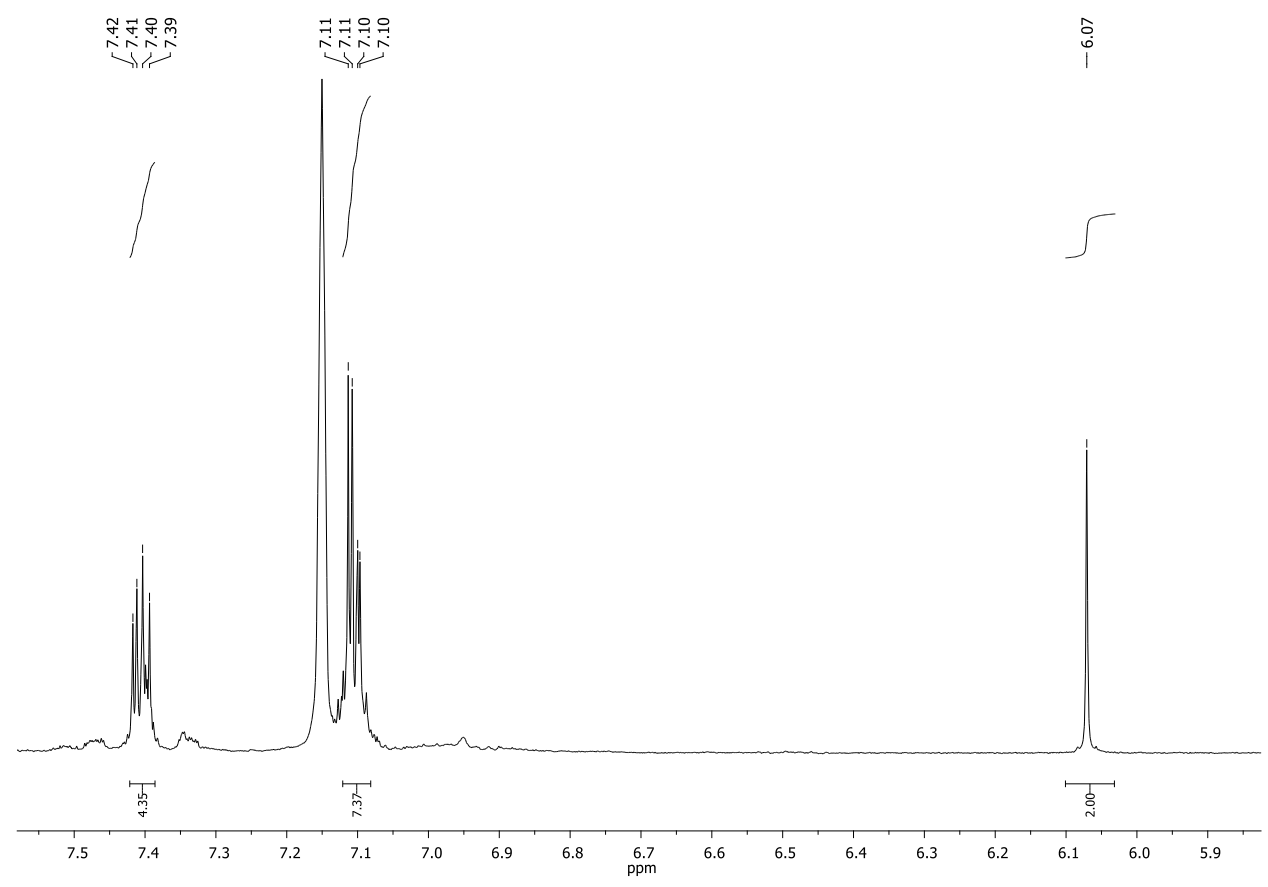

Figure 6.1.6.3 : ${ }^{1} \mathrm{H}$ NMR $\left(\mathrm{C}_{6} \mathrm{D}_{6}\right)$ spectrum of 2

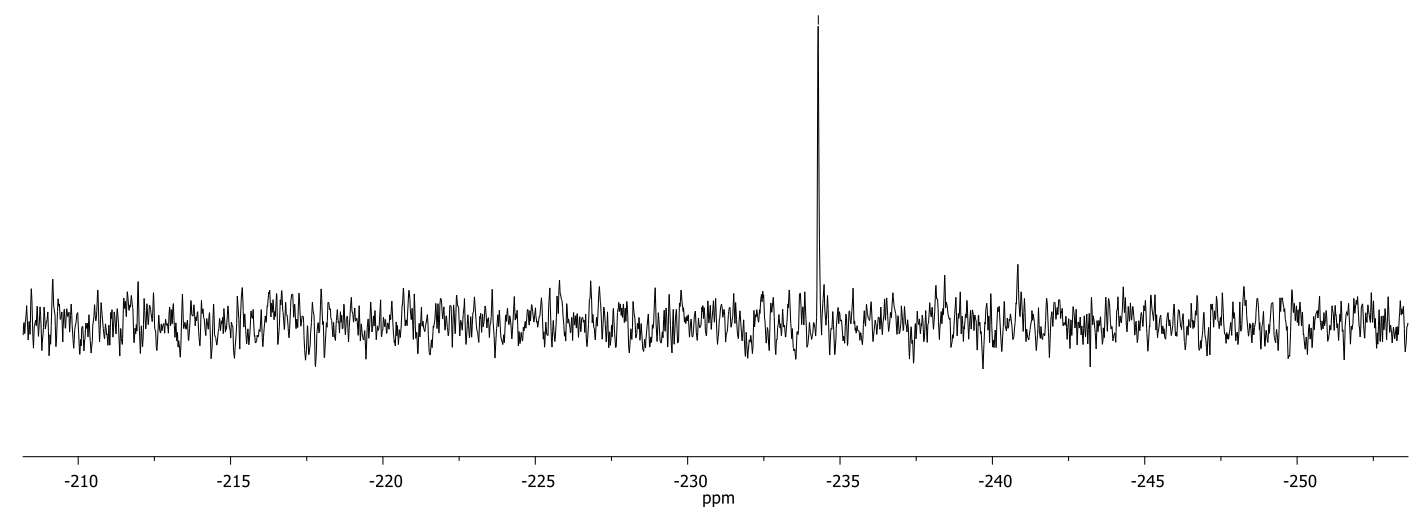

Figure 6.1.6.4- ${ }^{119} \mathrm{Sn}$ NMR $\left(\mathrm{C}_{6} \mathrm{D}_{6}\right)$ spectrum of 2 


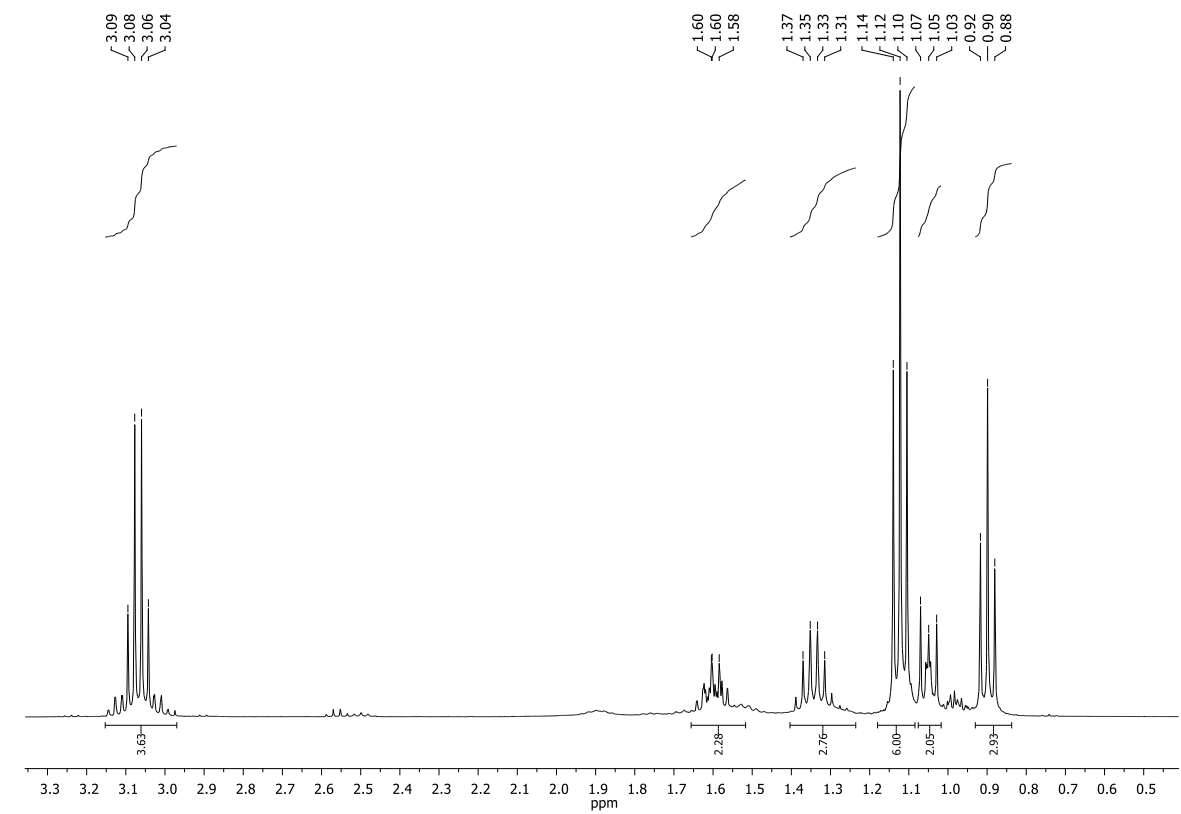

Figure 6.1.6.5- ${ }^{1} \mathrm{H}$ NMR $\left(\mathrm{C}_{6} \mathrm{D}_{6}\right)$ spectrum of 3

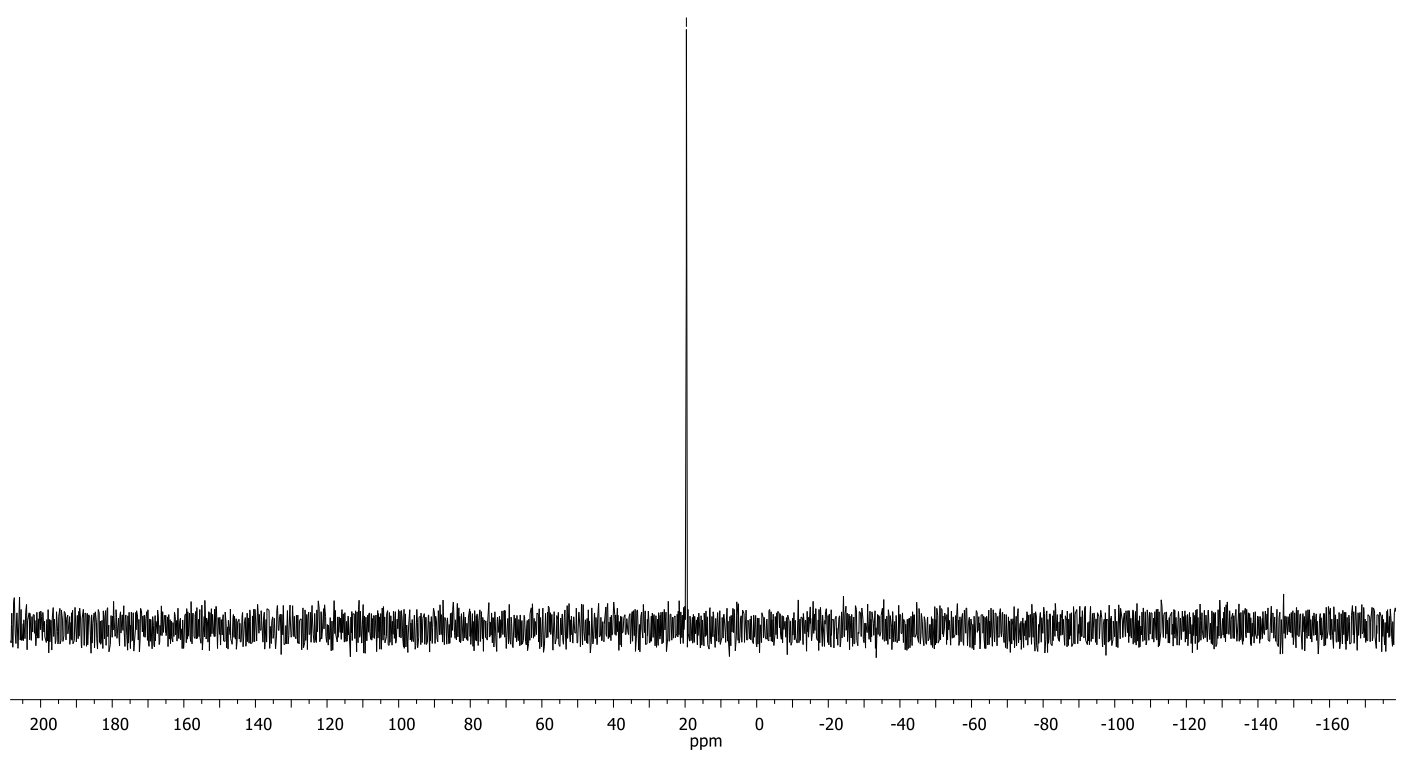

Figure 6.1.6.6 - ${ }^{119} \mathrm{Sn}$ NMR $\left(\mathrm{C}_{6} \mathrm{D}_{6}\right)$ spectrum of $\mathbf{3}$ 


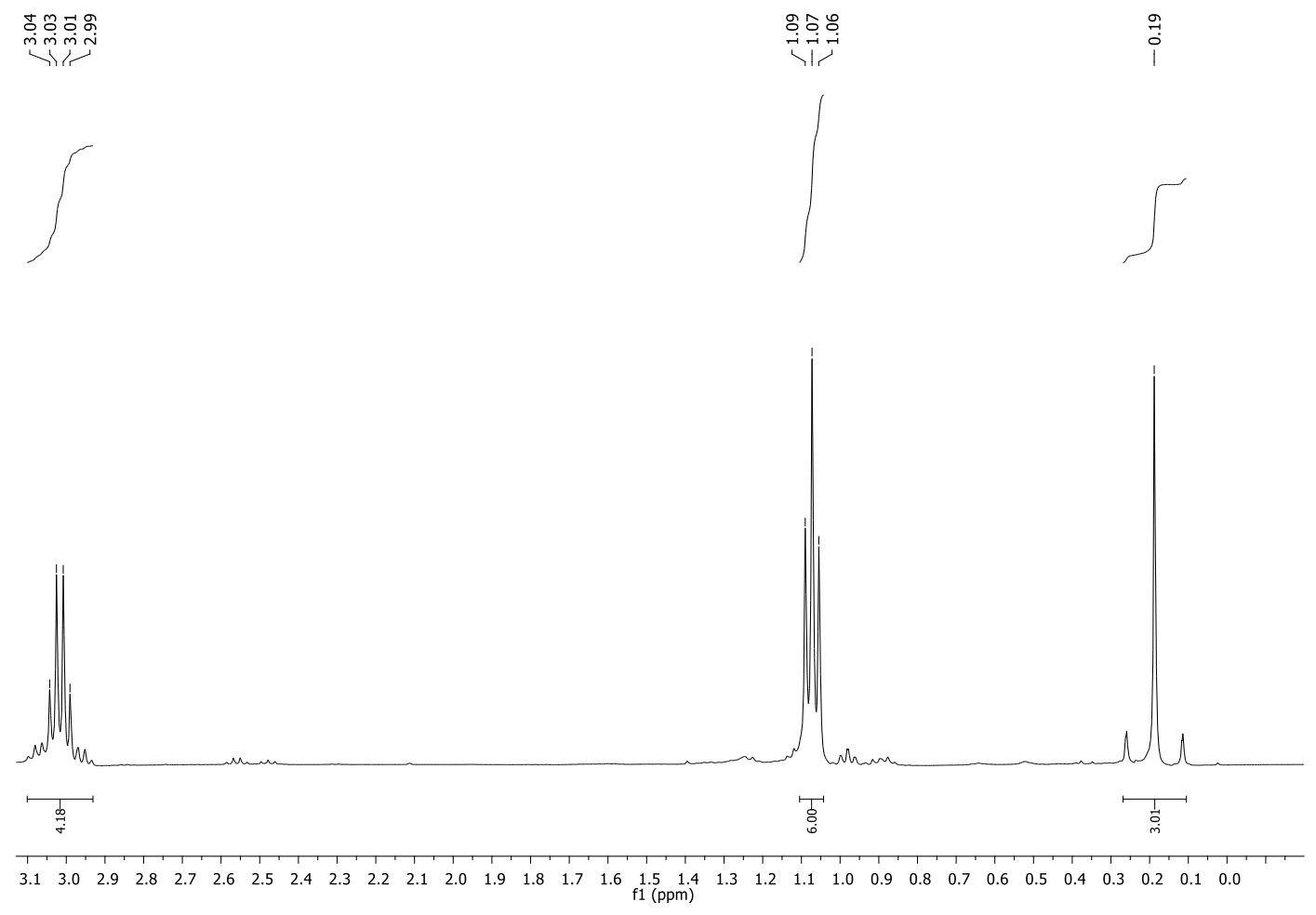

Figure 6.1.6.7 - ${ }^{1} \mathrm{H}$ NMR $\left(\mathrm{C}_{6} \mathrm{D}_{6}\right)$ spectrum of 4

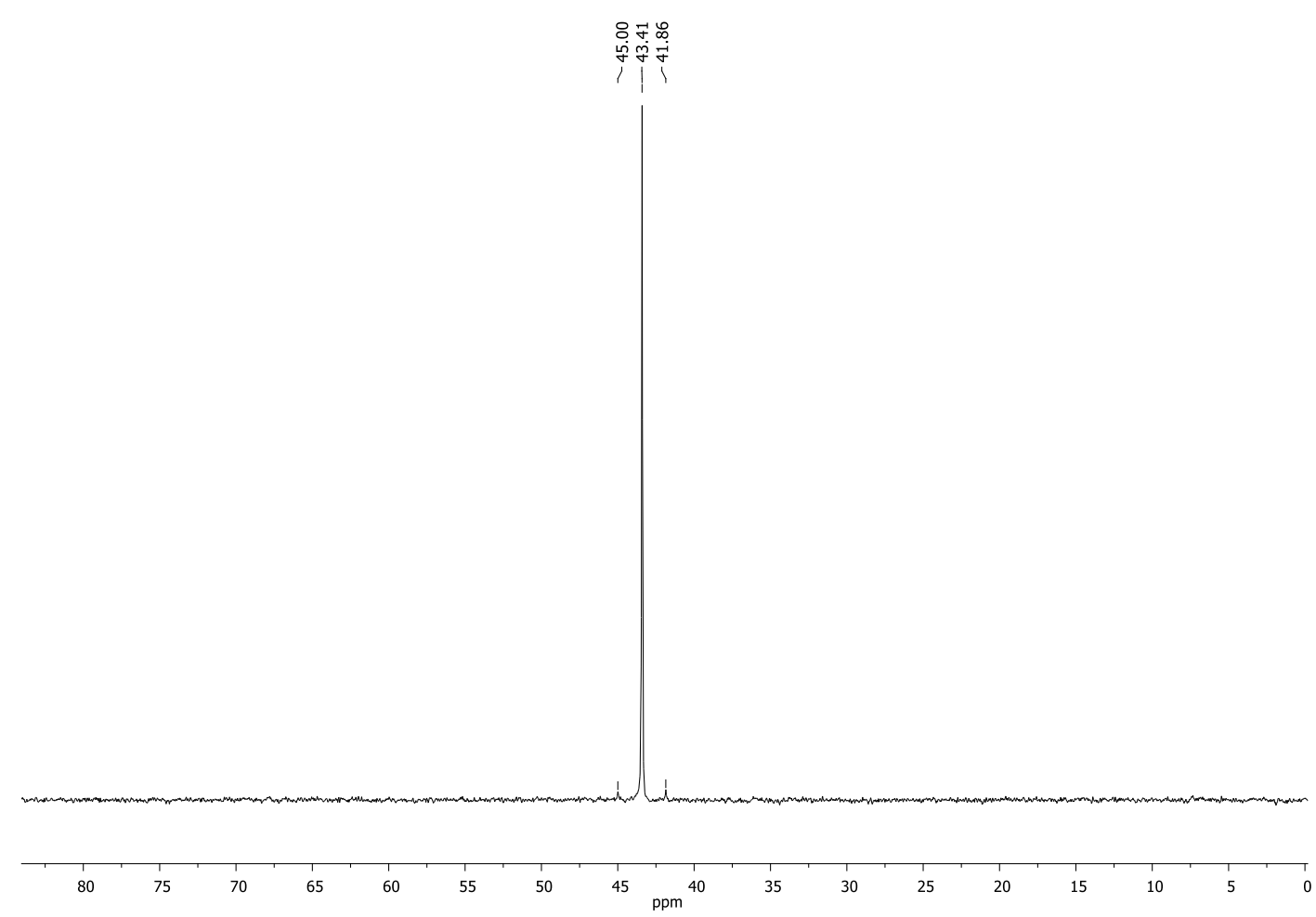

Figure 6.1.6.8 $-{ }^{119} \mathrm{Sn}$ NMR $\left(\mathrm{C}_{6} \mathrm{D}_{6}\right)$ spectrum of 4 


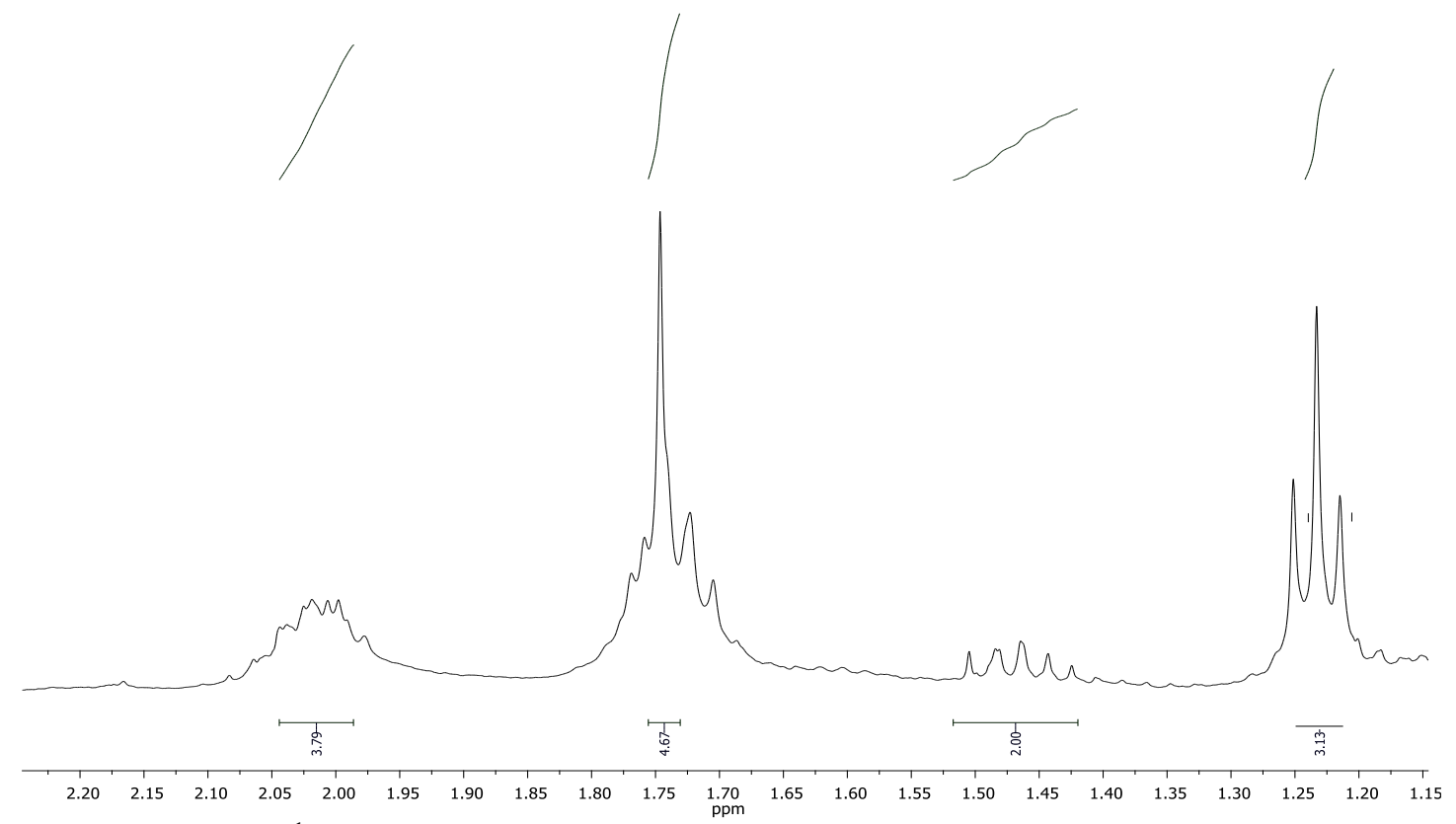

Figure 6.1.6.9- ${ }^{1} \mathrm{H}\left(\mathrm{C}_{6} \mathrm{D}_{6}\right)$ spectrum of 5

i̊ำ

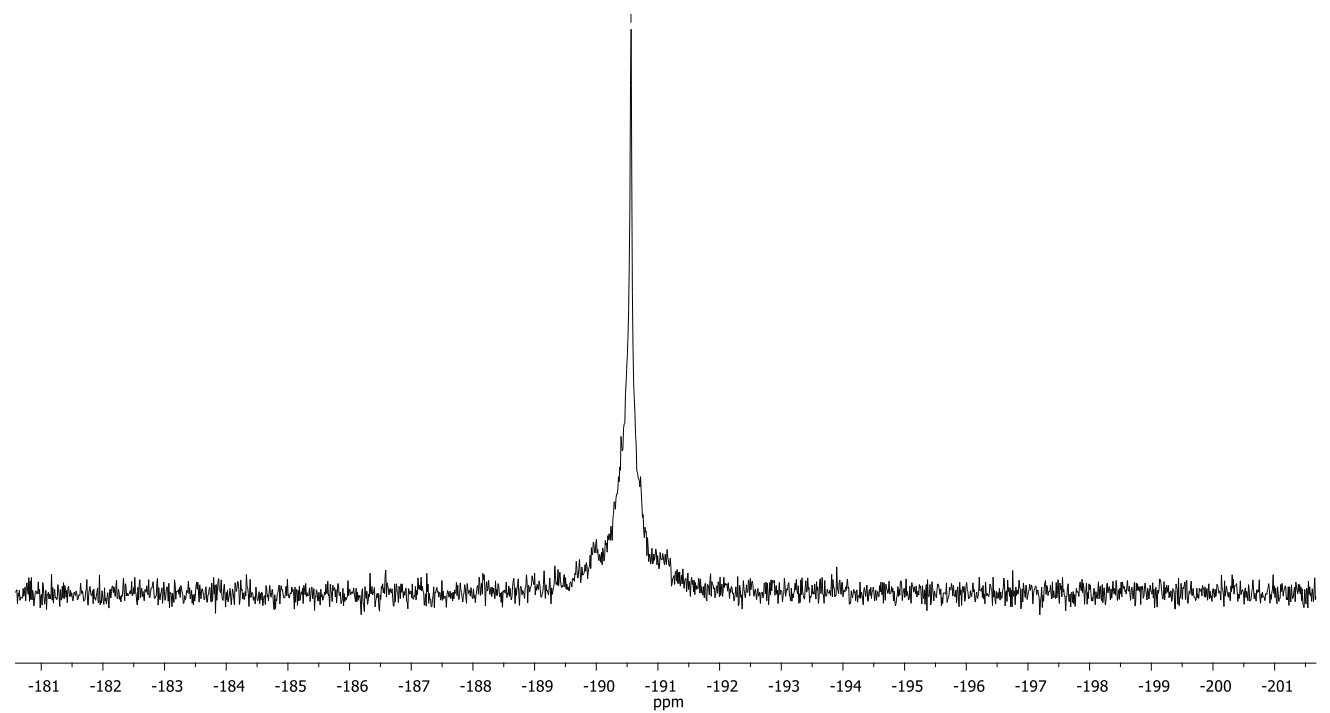

Figure 6.1.6.10- ${ }^{119} \mathrm{Sn}$ NMR $\left(\mathrm{C}_{6} \mathrm{D}_{6}\right)$ spectrum of 5 


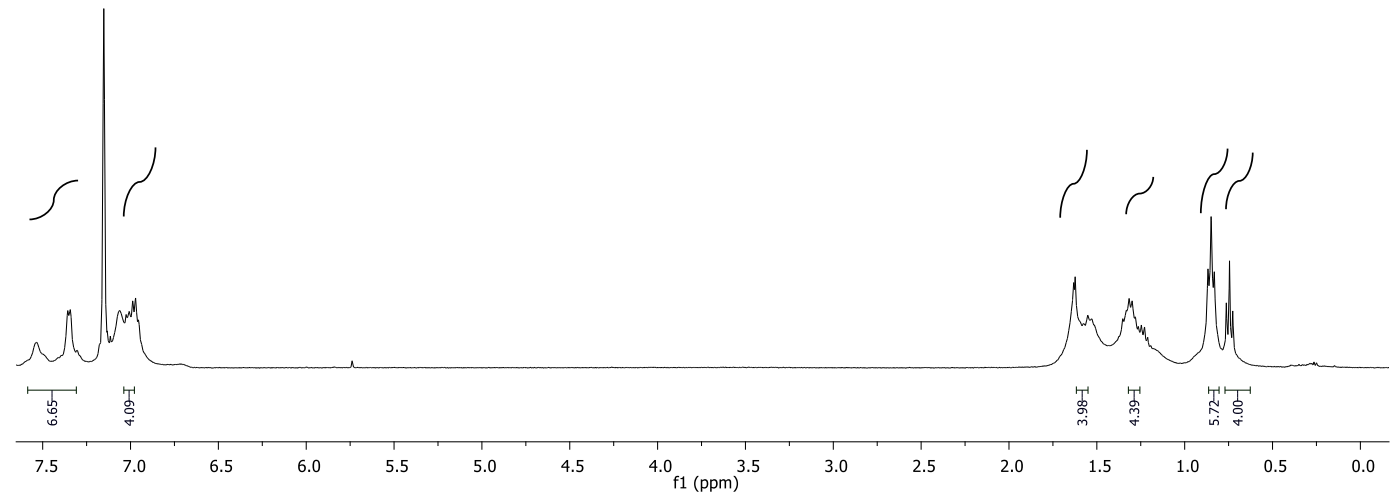

Figure 6.1.6.11 - ${ }^{1} \mathrm{H} N \mathrm{NR}\left(\mathrm{C}_{6} \mathrm{D}_{6}\right)$ spectrum of 6
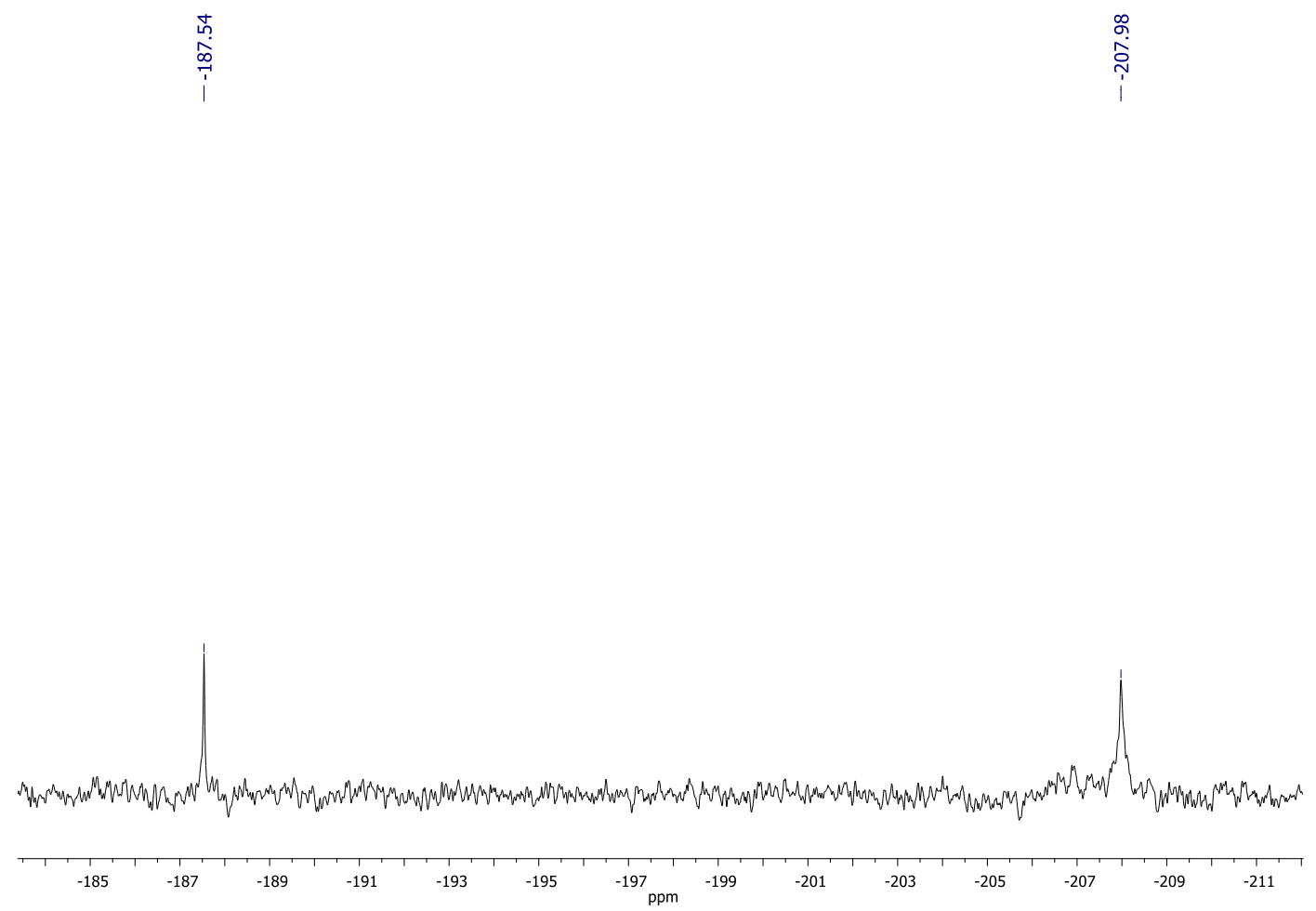

Figure 6.1.6.12 $-{ }^{119} \mathrm{Sn}$ NMR $\left(\mathrm{C}_{6} \mathrm{D}_{6}\right)$ spectrum of 6 


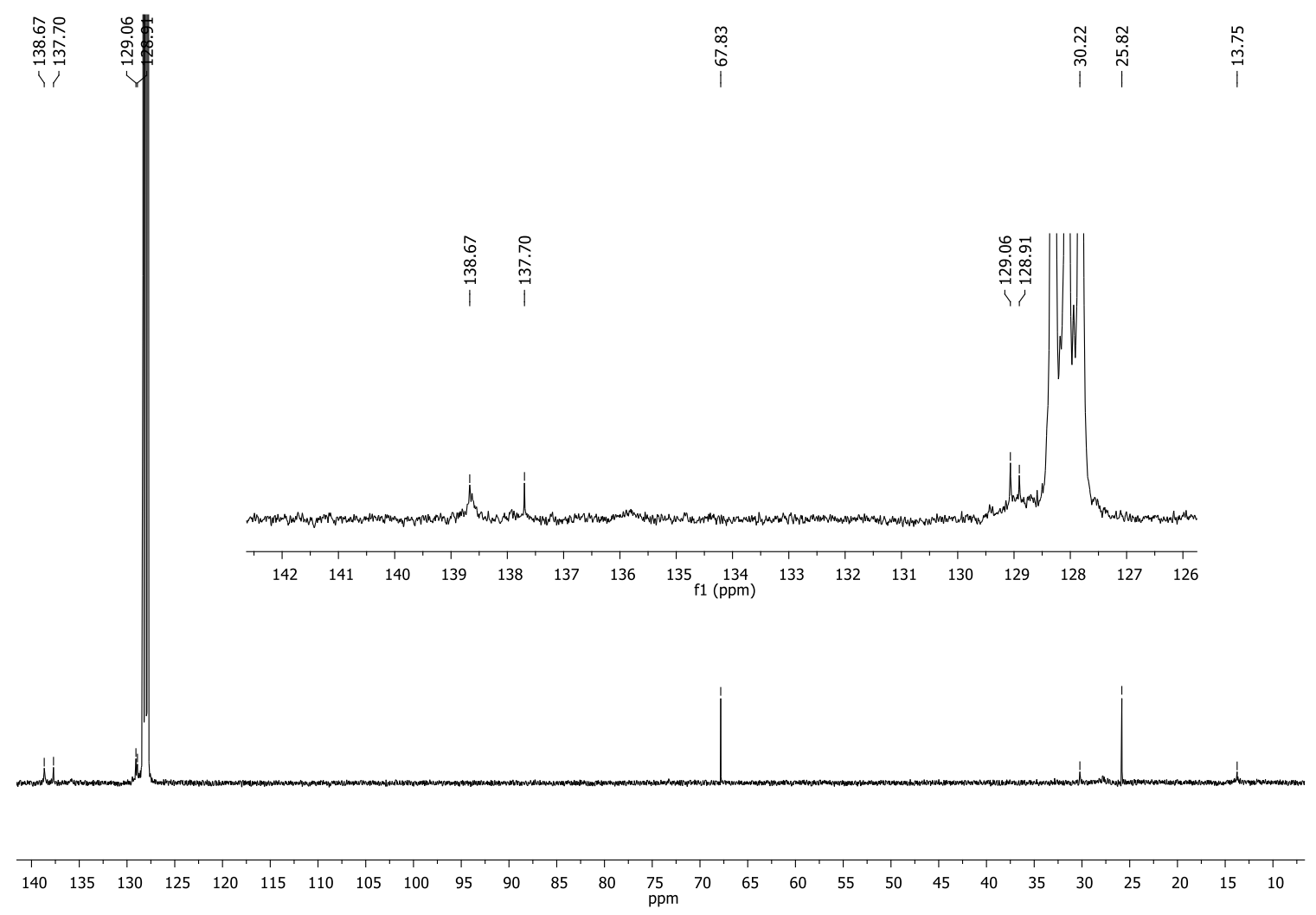

Figure 6.1.6.13- ${ }^{13} \mathrm{C}$ NMR $\left(\mathrm{C}_{6} \mathrm{D}_{6}\right)$ spectrum of 6 


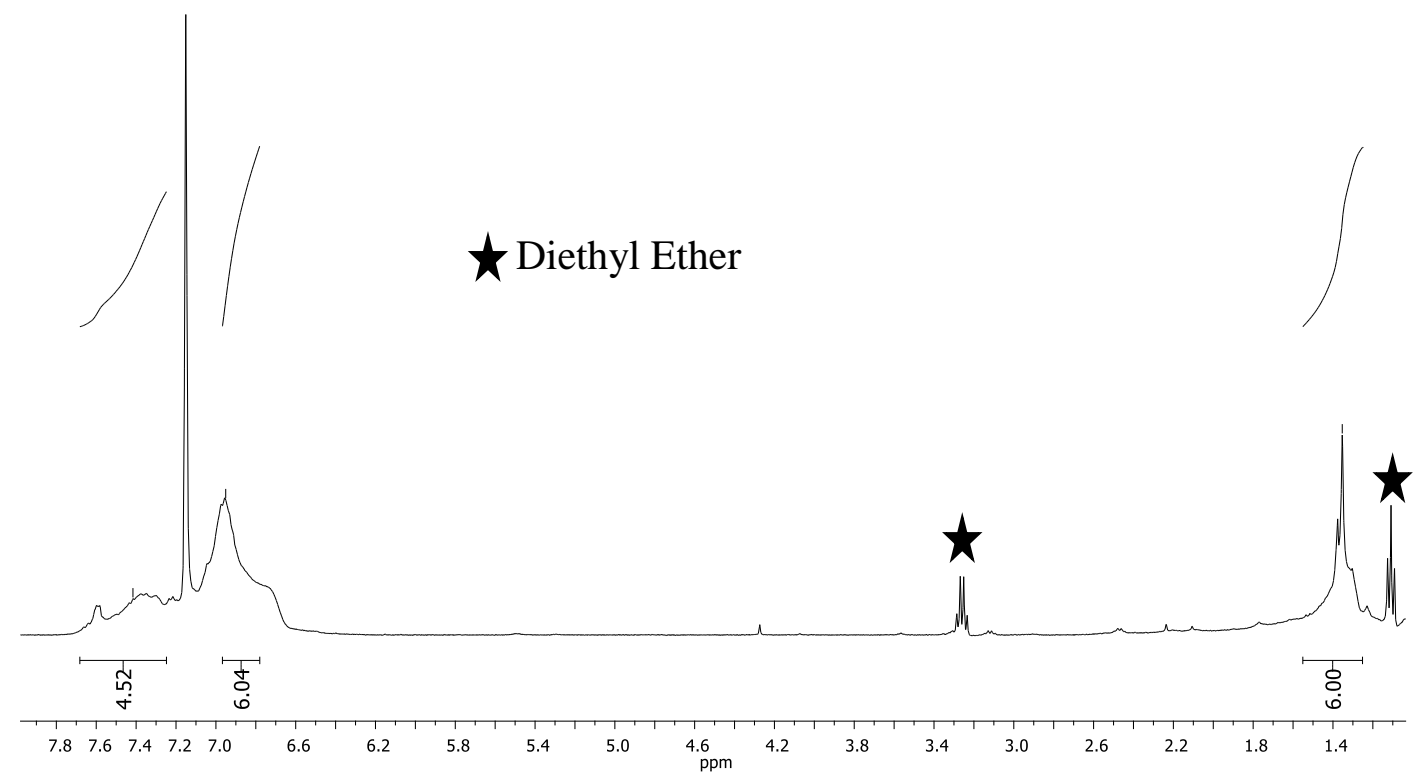

Figure 6.1.6.14 $-{ }^{1} \mathrm{H}$ NMR $\left(\mathrm{C}_{6} \mathrm{D}_{6}\right)$ spectrum of 7

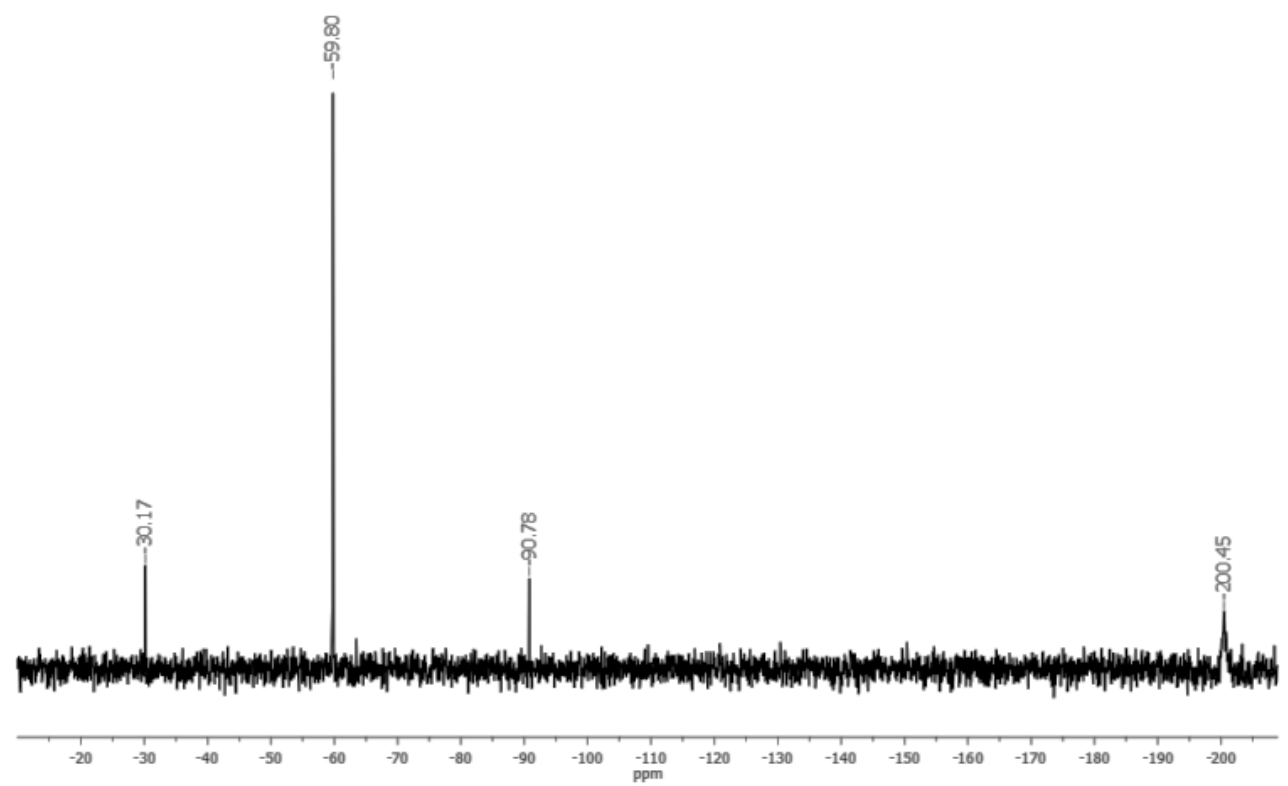

Figure 6.1.6.15 $-{ }^{119} \mathrm{Sn}$ NMR $\left(\mathrm{C}_{6} \mathrm{D}_{6}\right)$ spectrum of 7 


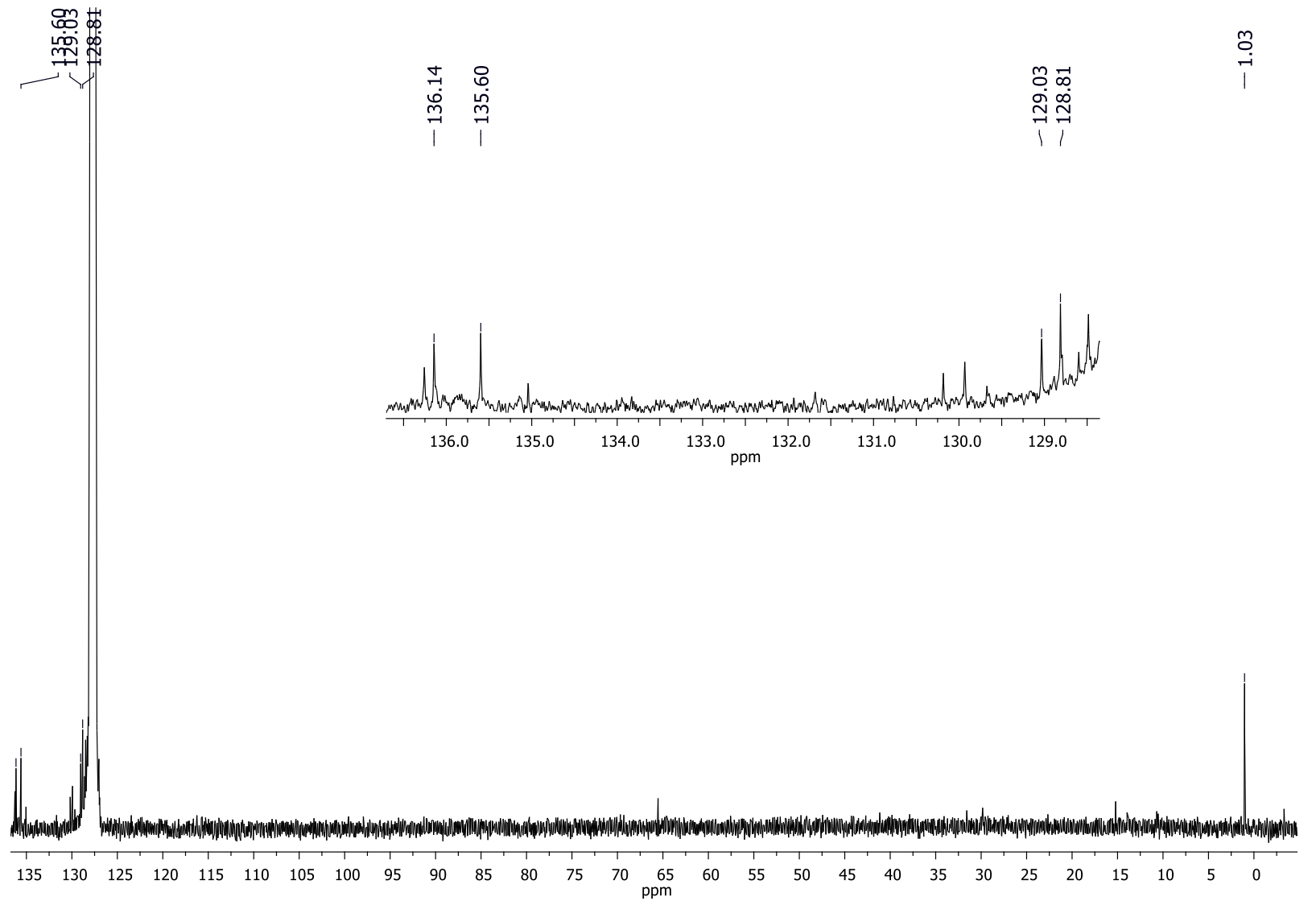

Figure 6.1.6.16 $-{ }^{13} \mathrm{C}$ NMR $\left(\mathrm{C}_{6} \mathrm{D}_{6}\right)$ spectrum of 7 


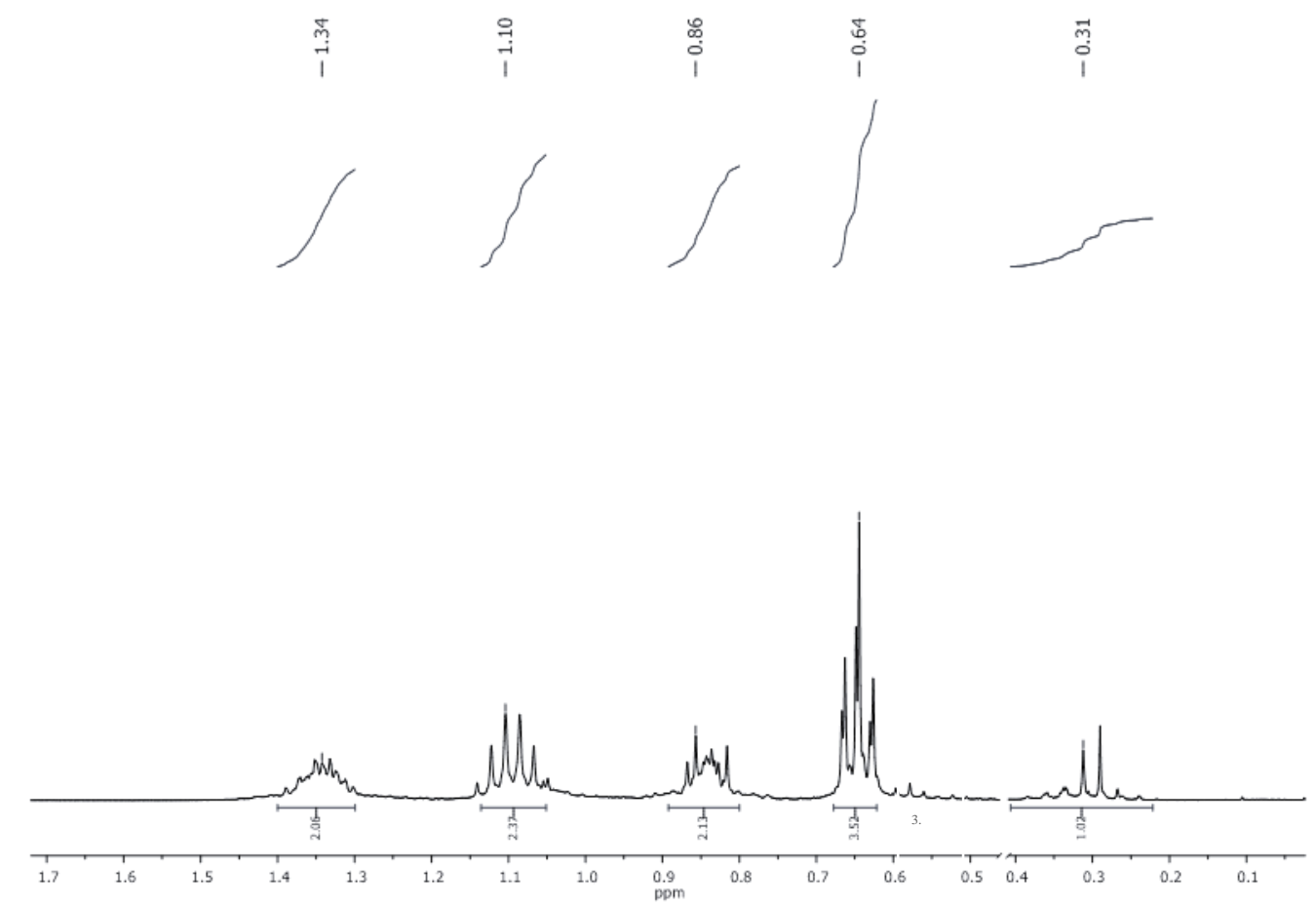

Figure 6.1.6.17 $-{ }^{1} \mathrm{H}$ NMR $\left(\mathrm{C}_{6} \mathrm{D}_{6}\right)$ spectrum of 8
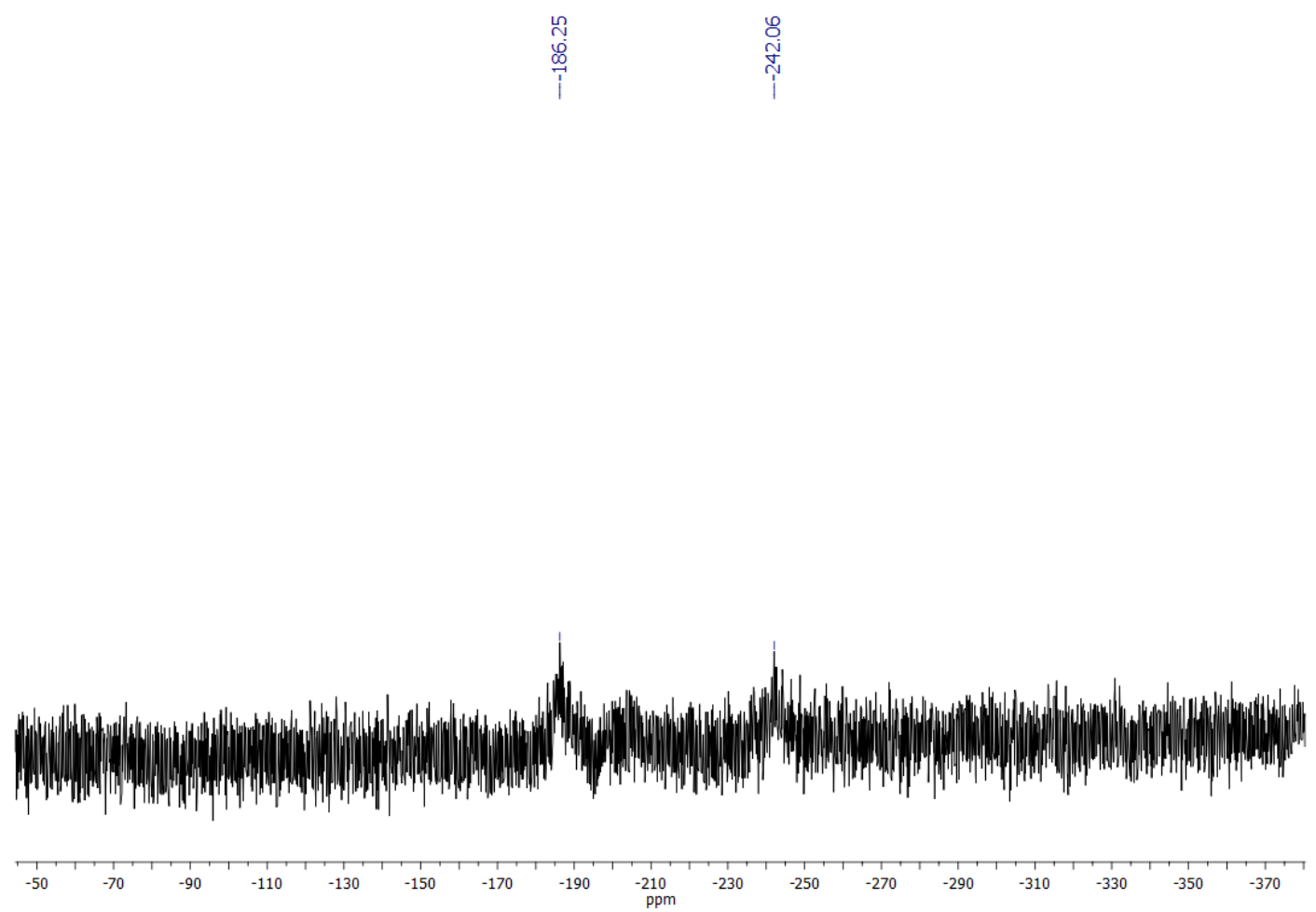

Figure 6.1.6.18- ${ }^{119} \mathrm{Sn}$ NMR $\left(\mathrm{C}_{6} \mathrm{D}_{6}\right)$ spectrum of $\mathbf{8}$ 


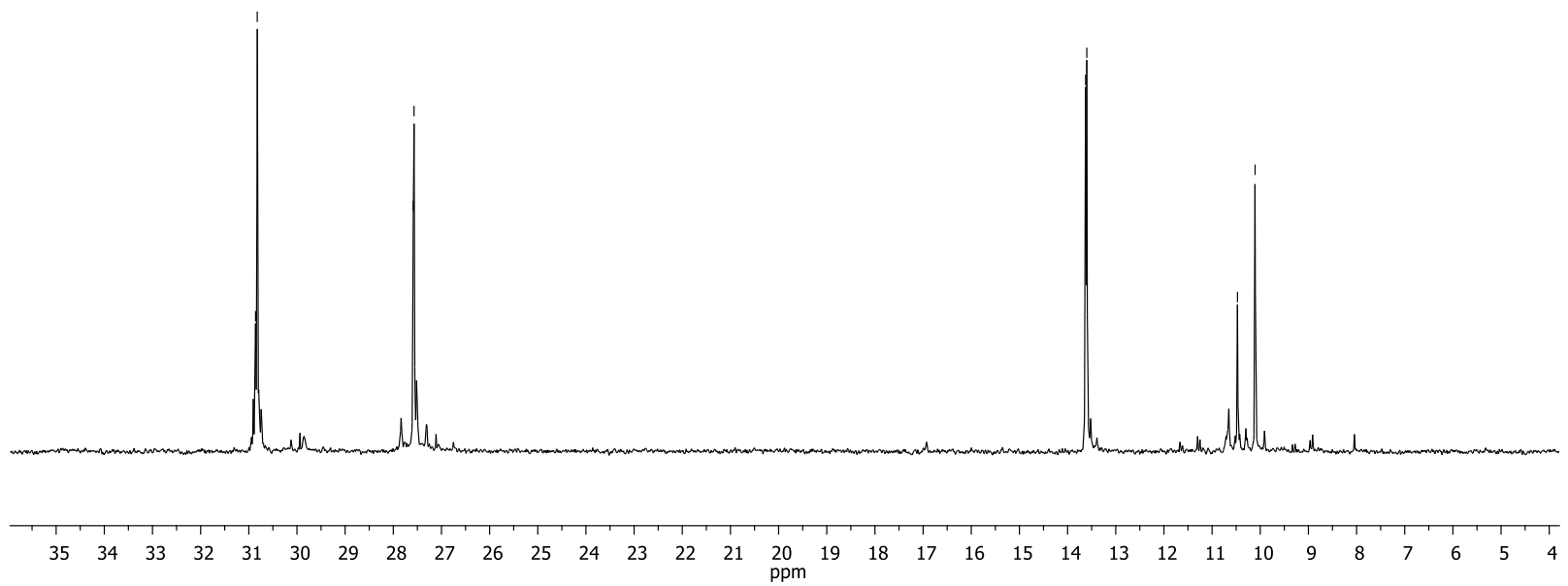

Figure 6.1.6.19 $-{ }^{13} \mathrm{C}$ NMR $\left(\mathrm{C}_{6} \mathrm{D}_{6}\right)$ spectrum of 8 
6.2.-Linear Oligostannanes: a Synthetic and TD-DFT Study

\subsection{1. - Synthesis Summary}

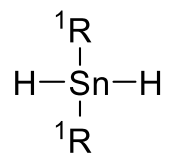

A: ${ }^{1} \mathrm{R}=n-\mathrm{Bu}$

B: ${ }^{1} \mathrm{R}=\mathrm{Ph}$

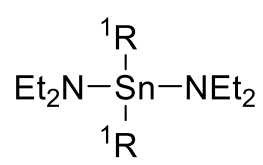

C: ${ }^{1} \mathrm{R}=n-\mathrm{Bu}$

D: ${ }^{1} \mathrm{R}=\mathrm{Me}$

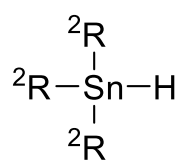

$\mathrm{E}:{ }^{2} \mathrm{R}=n-\mathrm{Bu}$

F: ${ }^{2} \mathrm{R}=\mathrm{Ph}$

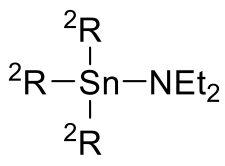

G: ${ }^{2} \mathrm{R}=n-\mathrm{Bu}$

$\mathrm{H}:{ }^{2} \mathrm{R}=\mathrm{Me}$

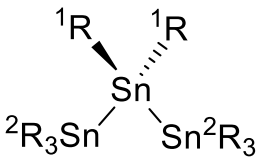
9: ${ }^{1} \mathrm{R}={ }^{2} \mathrm{R}=n-\mathrm{Bu}$
13: ${ }^{1} \mathrm{R}=\mathrm{Me},{ }^{2} \mathrm{R}=\mathrm{Ph}$
10: ${ }^{1} \mathrm{R}=\mathrm{Ph},{ }^{2} \mathrm{R}=n$-Bu 14: ${ }^{1} \mathrm{R}=n-\mathrm{Bu},{ }^{2} \mathrm{R}=\mathrm{Me}$
11: ${ }^{1} \mathrm{R}=\mathrm{Me},{ }^{2} \mathrm{R}=n$-Bu 15: ${ }^{1} \mathrm{R}=\mathrm{Ph},{ }^{2} \mathrm{R}=\mathrm{Me}$
12: ${ }^{1} \mathrm{R}=n-\mathrm{Bu},{ }^{2} \mathrm{R}=\mathrm{Ph}$

Figure 6.2.1.1 Structures of Starting Materials and Tristannanes 8-15 


\subsection{2-NMR Spectra}

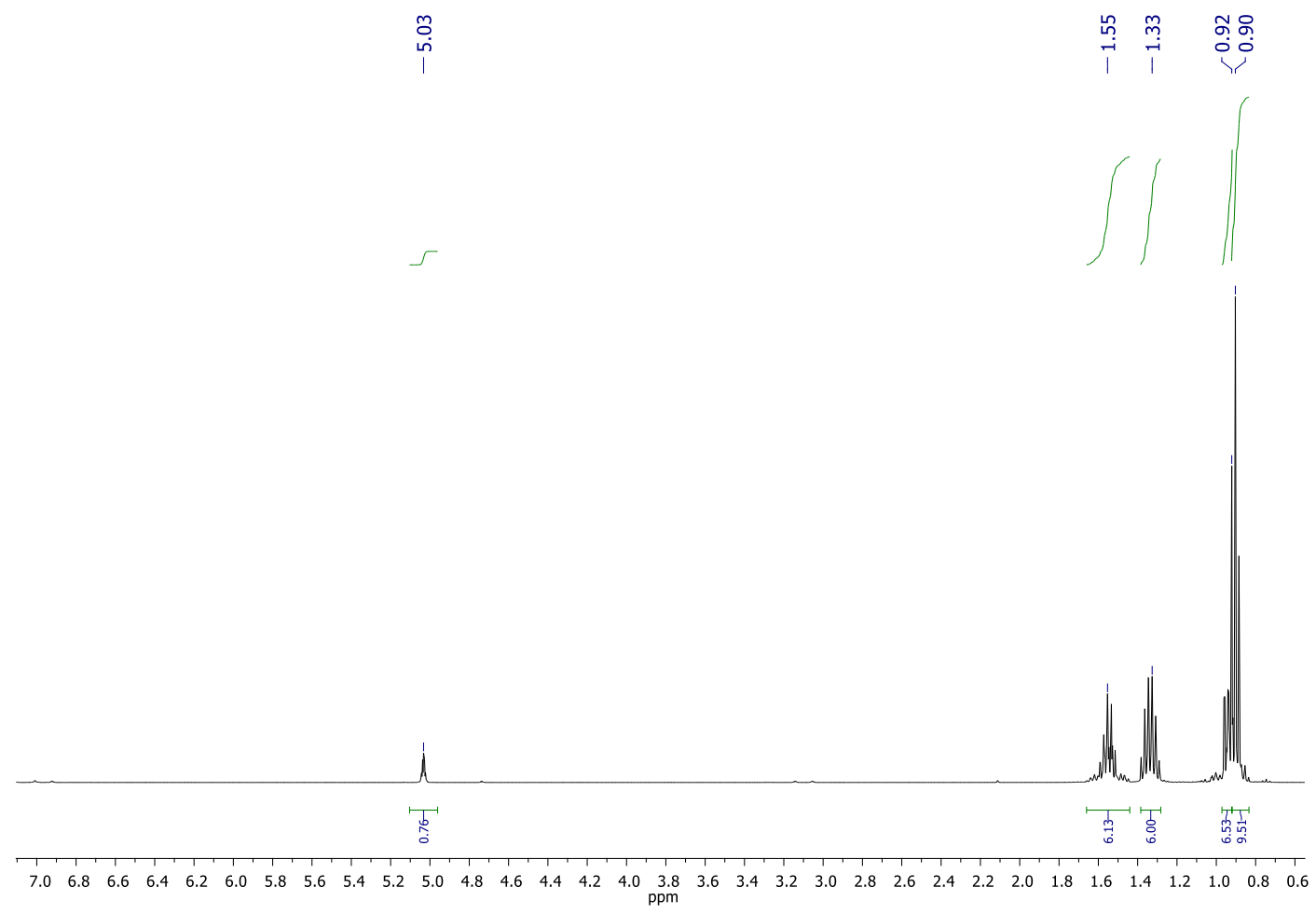

Figure 6.2.2.1- ${ }^{1} \mathrm{H}$ NMR $\left(\mathrm{C}_{6} \mathrm{D}_{6}\right)$ spectrum of $\mathbf{E}$ 


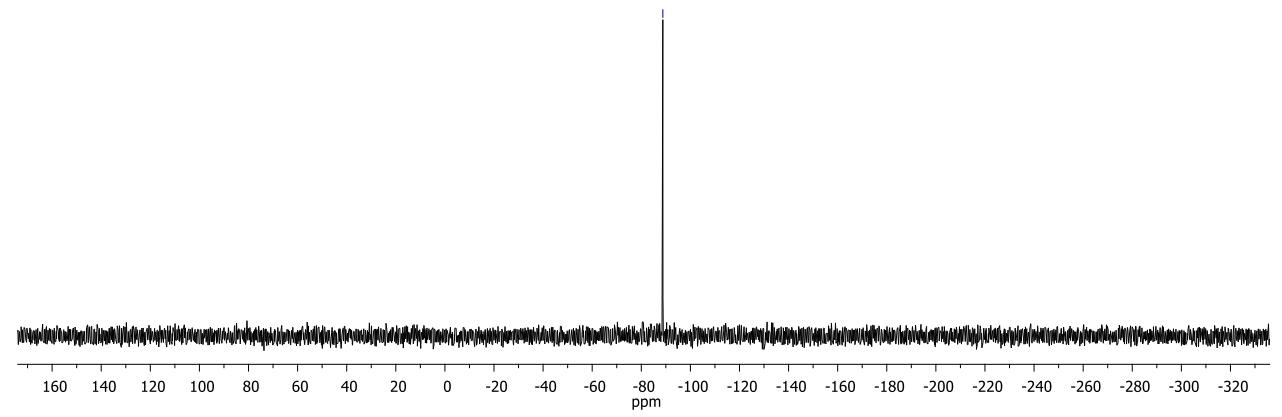

Figure 6.2.2.2 ${ }^{119} \mathrm{Sn} \mathrm{NMR}\left(\mathrm{C}_{6} \mathrm{D}_{6}\right)$ spectrum of $\mathbf{E}$

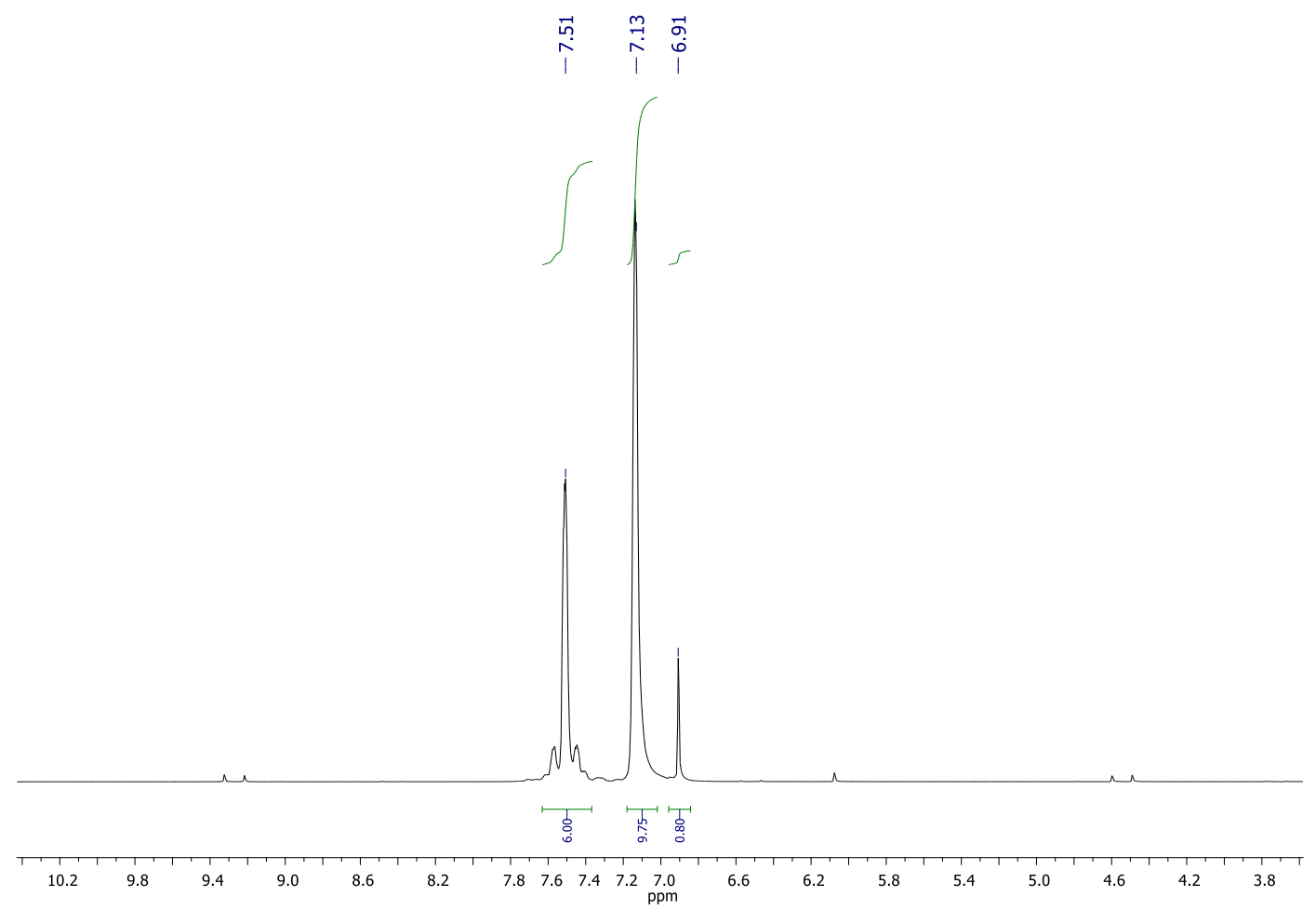

Figure 6.2.2.3- ${ }^{1} \mathrm{H}$ NMR $\left(\mathrm{C}_{6} \mathrm{D}_{6}\right)$ spectrum of $\mathbf{F}$ 


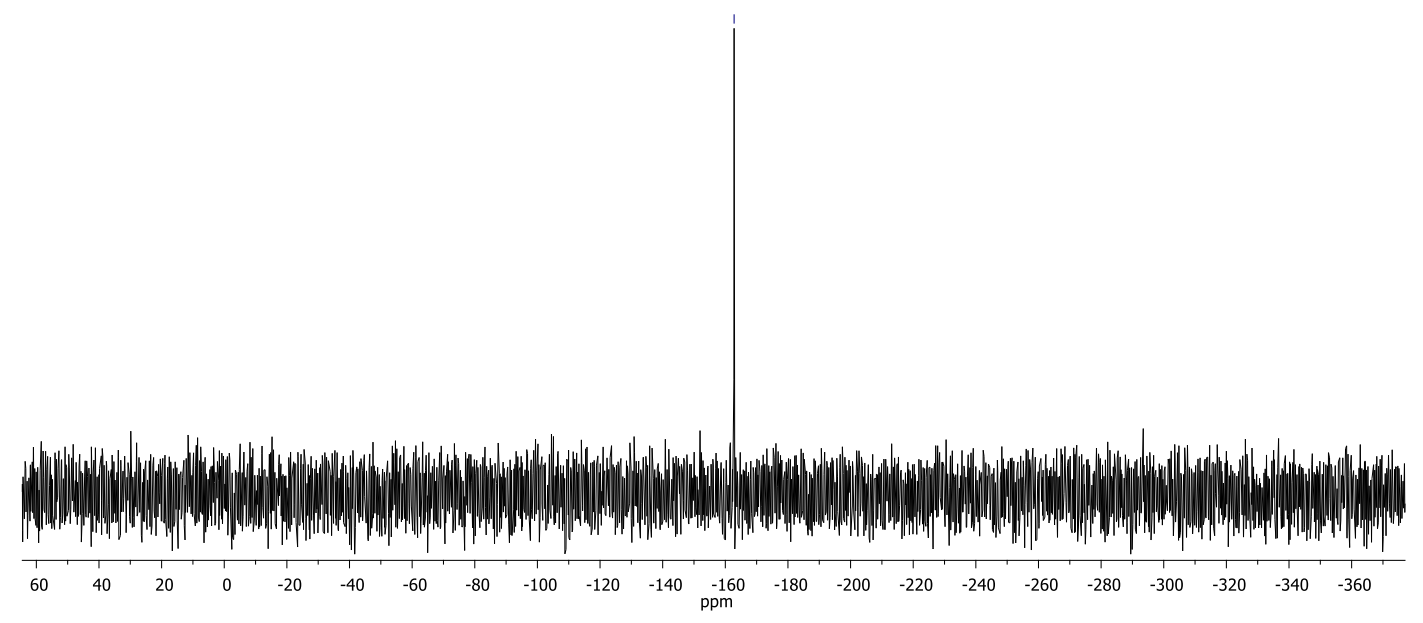

Figure 6.2.2.4 $-{ }^{119} \mathrm{Sn}$ NMR $\left(\mathrm{C}_{6} \mathrm{D}_{6}\right)$ spectrum of $\mathbf{F}$ 


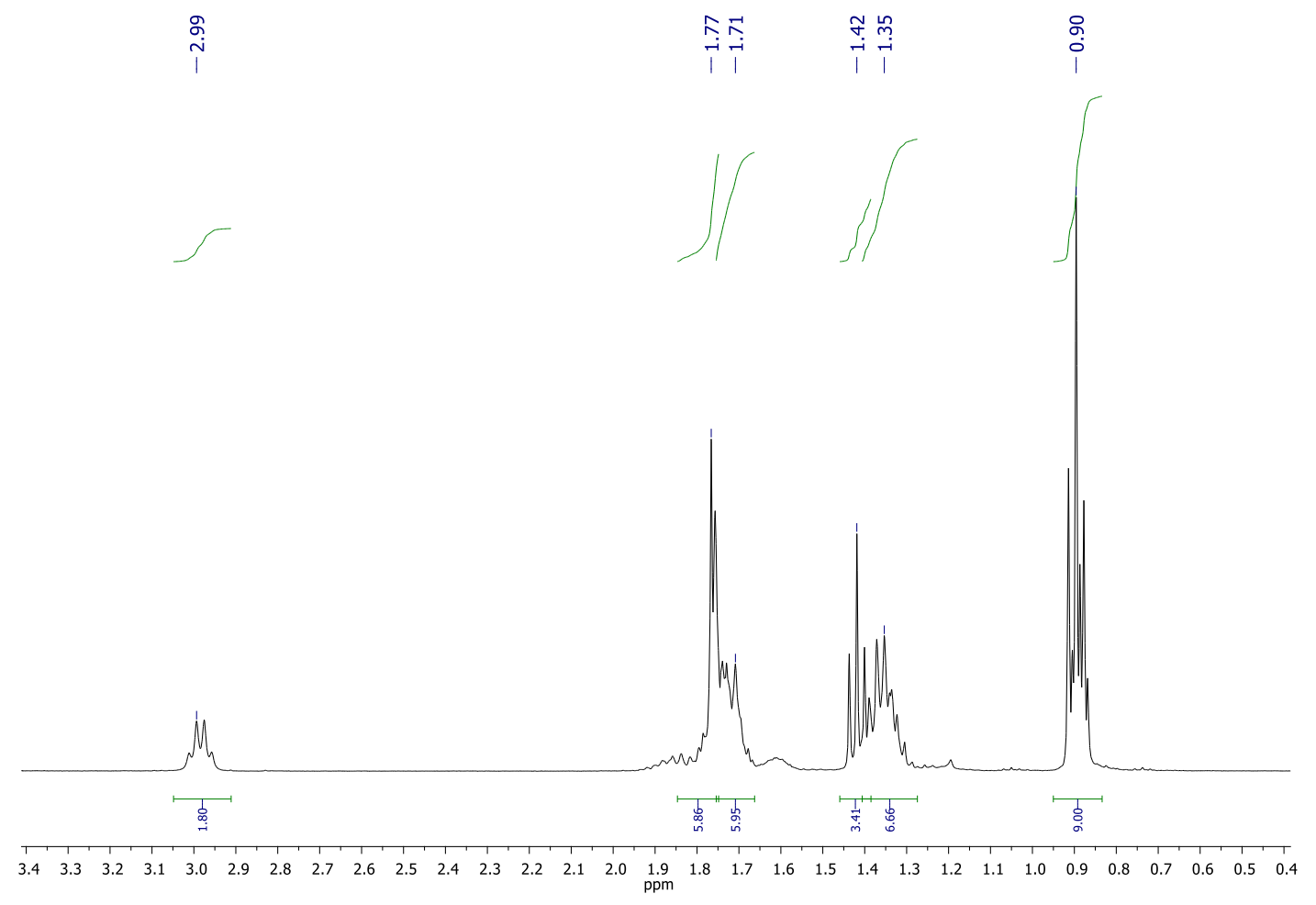

Figure 6.2.2.5 $-{ }^{1} \mathrm{H}$ NMR $\left(\mathrm{C}_{6} \mathrm{D}_{6}\right)$ spectrum of $\mathbf{G}$

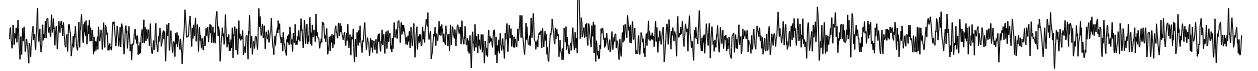

\begin{tabular}{lll|l|l|l|l|l|}
70 & 1 & 1 & 1 & 1 \\
$\mathrm{ppm}$
\end{tabular}

Figure 6.2.2.6 $-{ }^{119} \mathrm{Sn}$ NMR $\left(\mathrm{C}_{6} \mathrm{D}_{6}\right)$ spectrum of $\mathbf{G}$ 


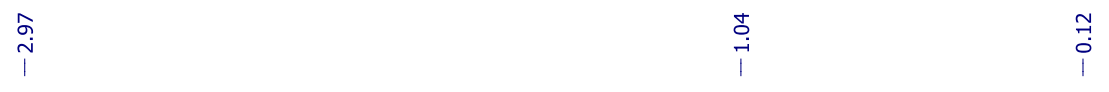

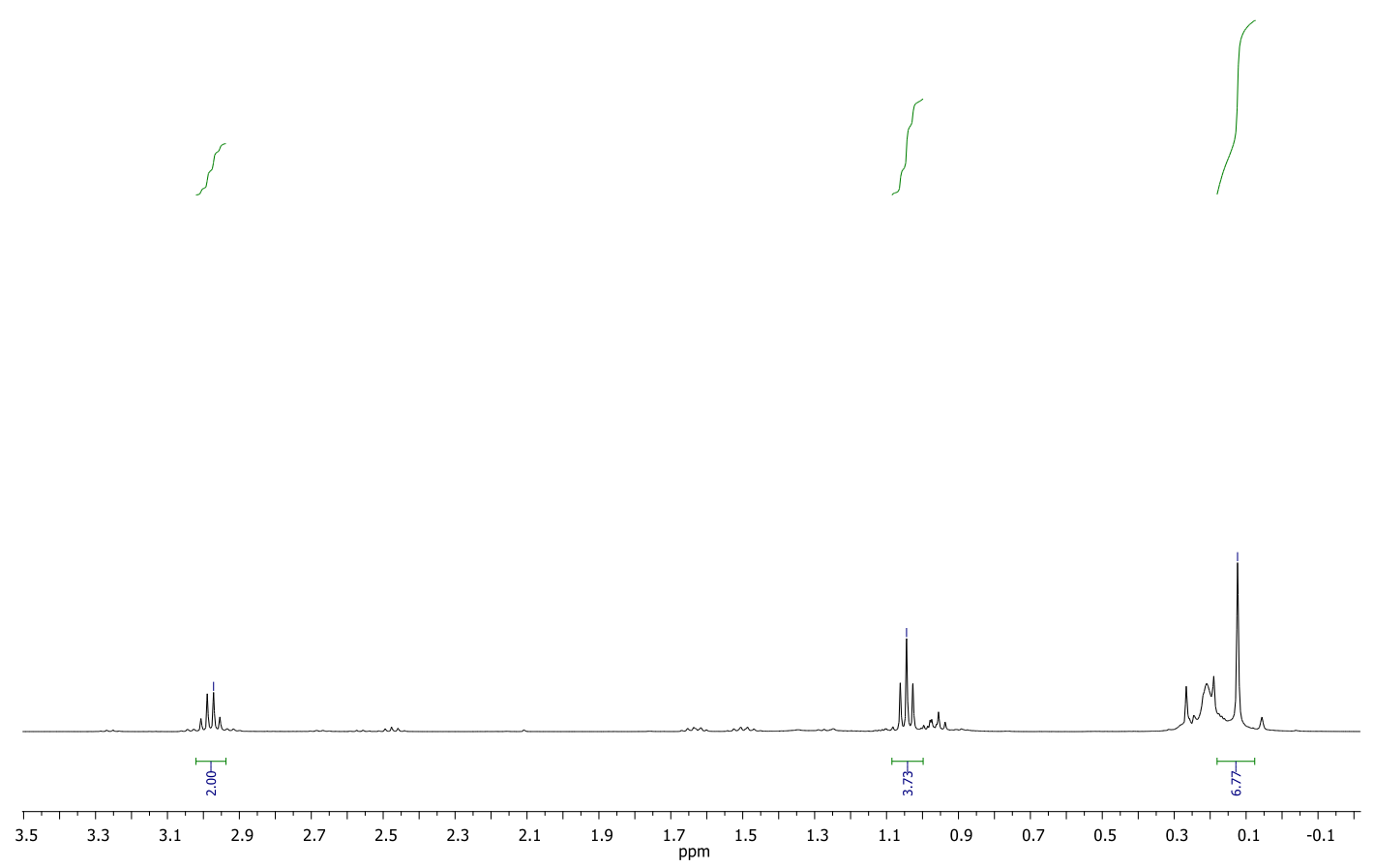

Figure 6.2.2.7- ${ }^{1} \mathrm{H}$ NMR $\left(\mathrm{C}_{6} \mathrm{D}_{6}\right)$ spectrum of $\mathbf{H}$

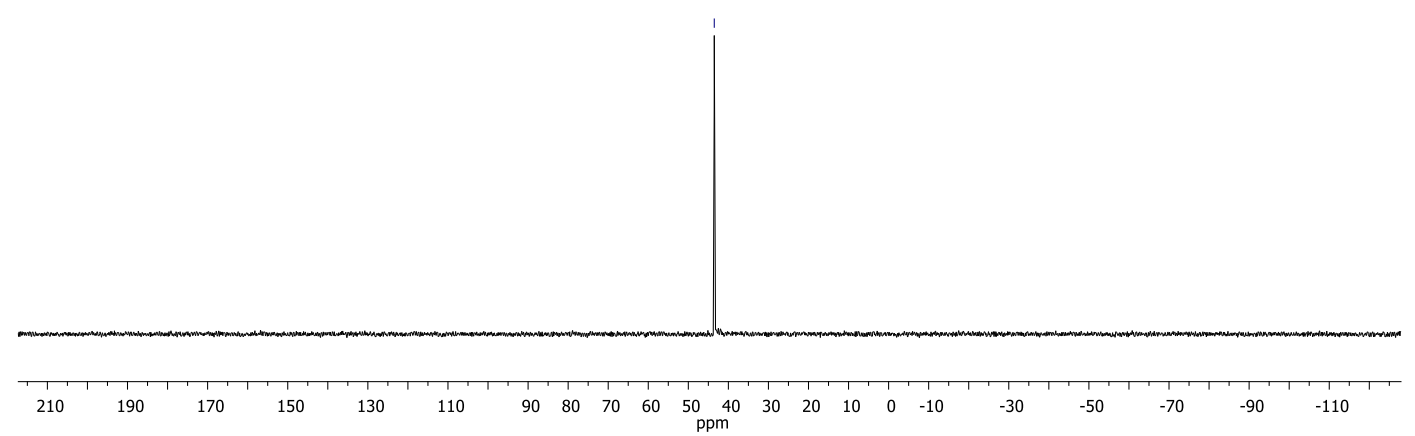

Figure 6.2.2.8 - ${ }^{119} \mathrm{Sn}$ NMR $\left(\mathrm{C}_{6} \mathrm{D}_{6}\right)$ spectrum of $\mathbf{H}$ 

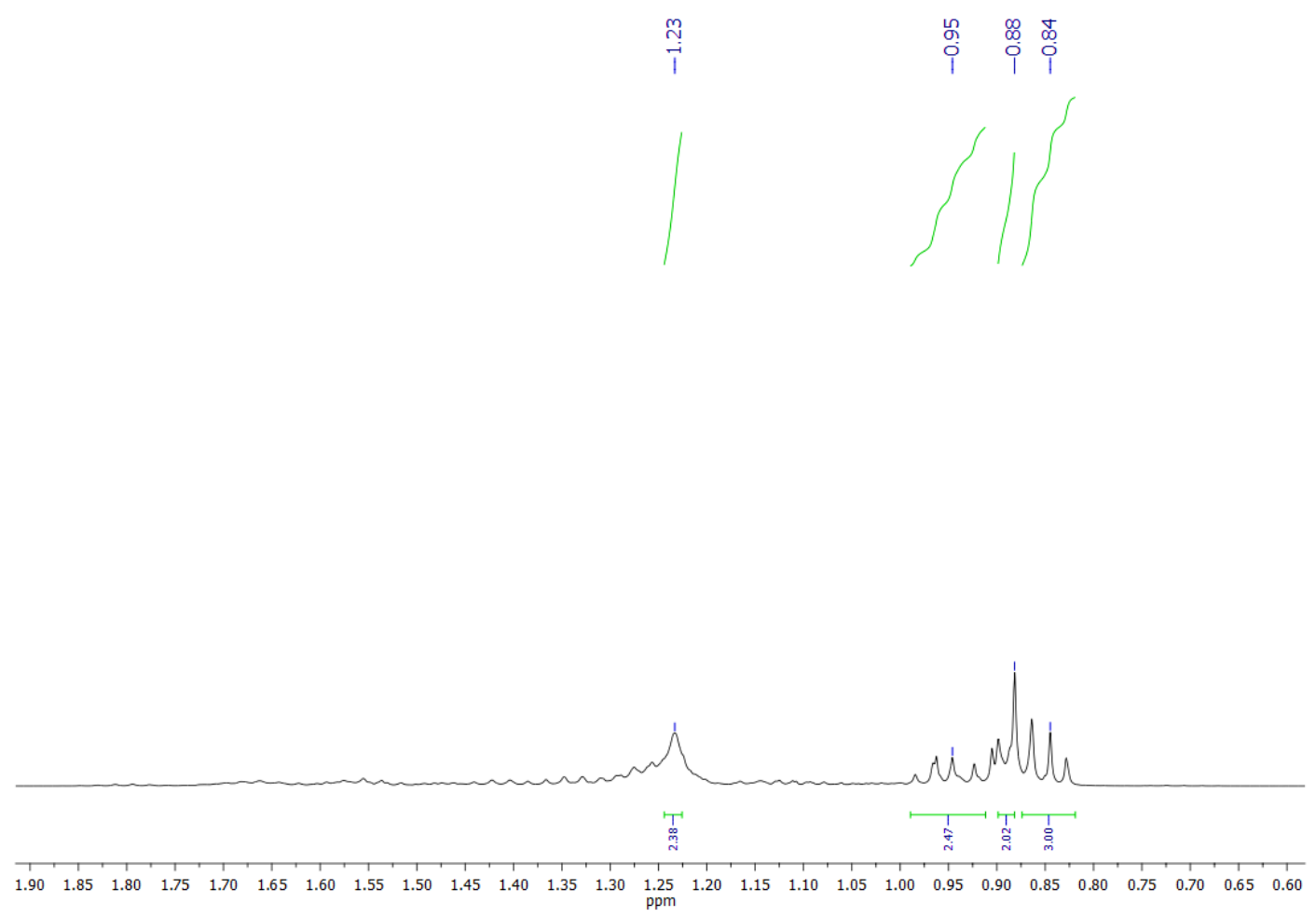

Figure 6.2.2.9 - ${ }^{1} \mathrm{H}$ NMR $\left(\mathrm{C}_{6} \mathrm{D}_{6}\right)$ spectrum of 9

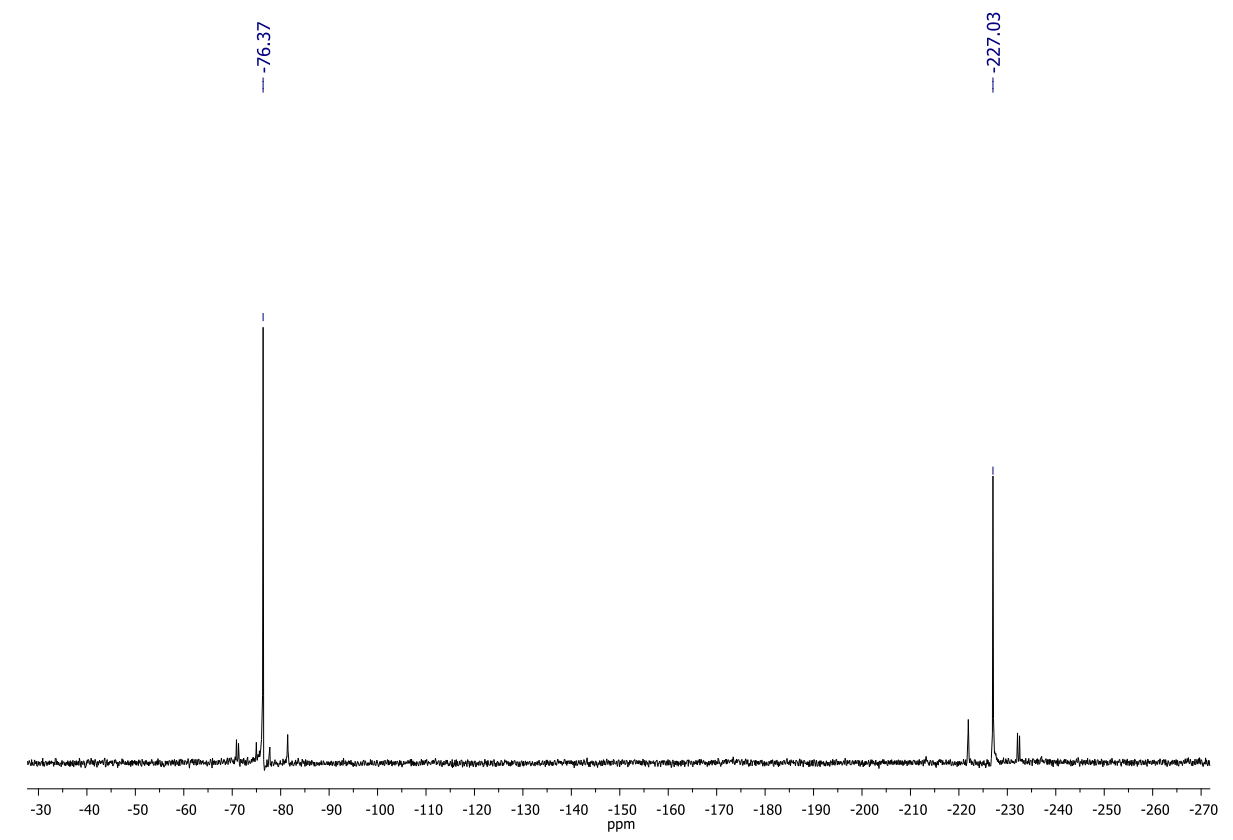

Figure 6.2.2.10 - ${ }^{119} \mathrm{Sn} \mathrm{NMR}\left(\mathrm{C}_{6} \mathrm{D}_{6}\right)$ spectrum of 9 


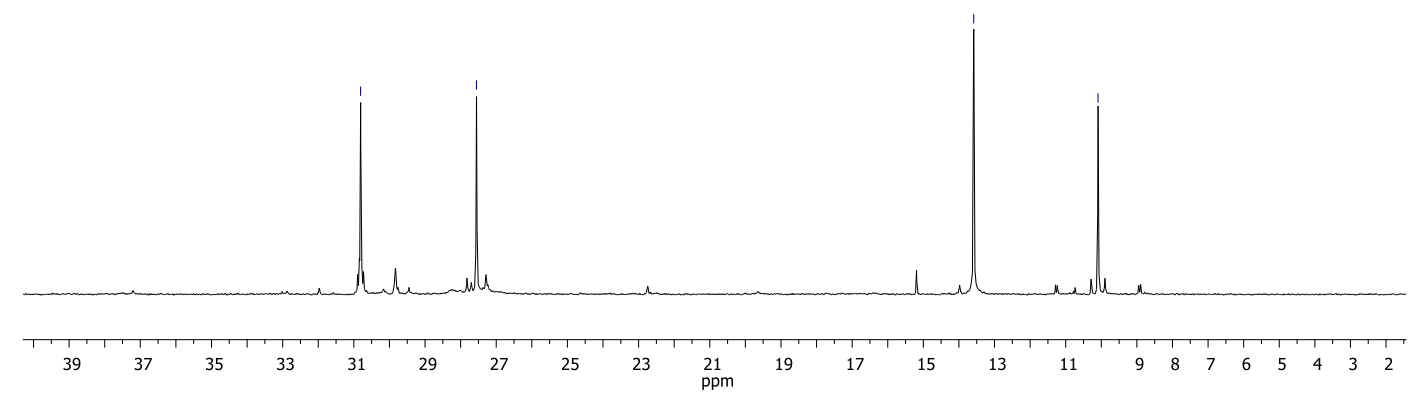

Figure 6.2.2.11 $-{ }^{13} \mathrm{C}$ NMR $\left(\mathrm{C}_{6} \mathrm{D}_{6}\right)$ spectrum of 9 


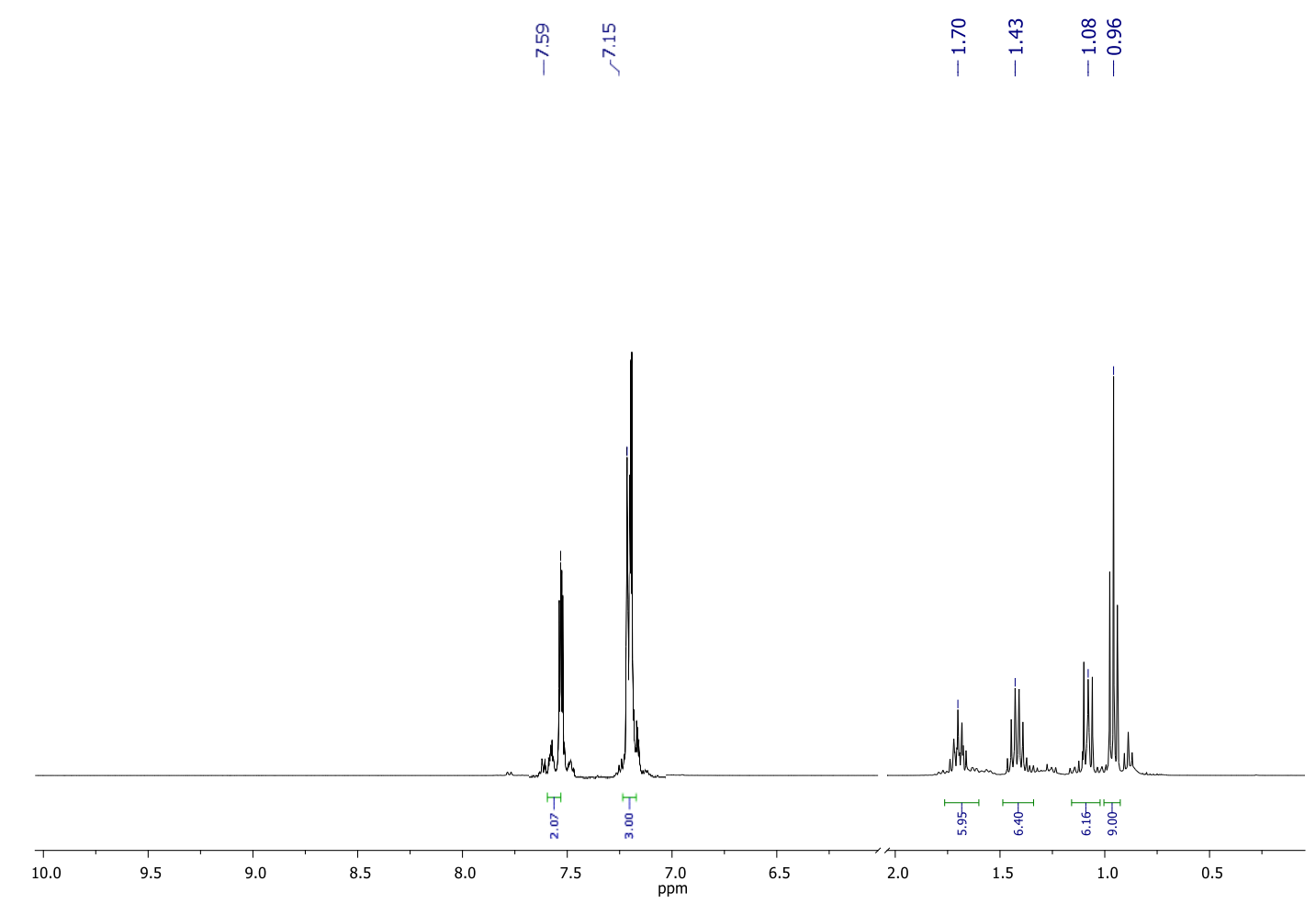

Figure 6.2.2.12- ${ }^{1} \mathrm{H}$ NMR $\left(\mathrm{C}_{6} \mathrm{D}_{6}\right)$ spectrum of $\mathbf{1 0}$

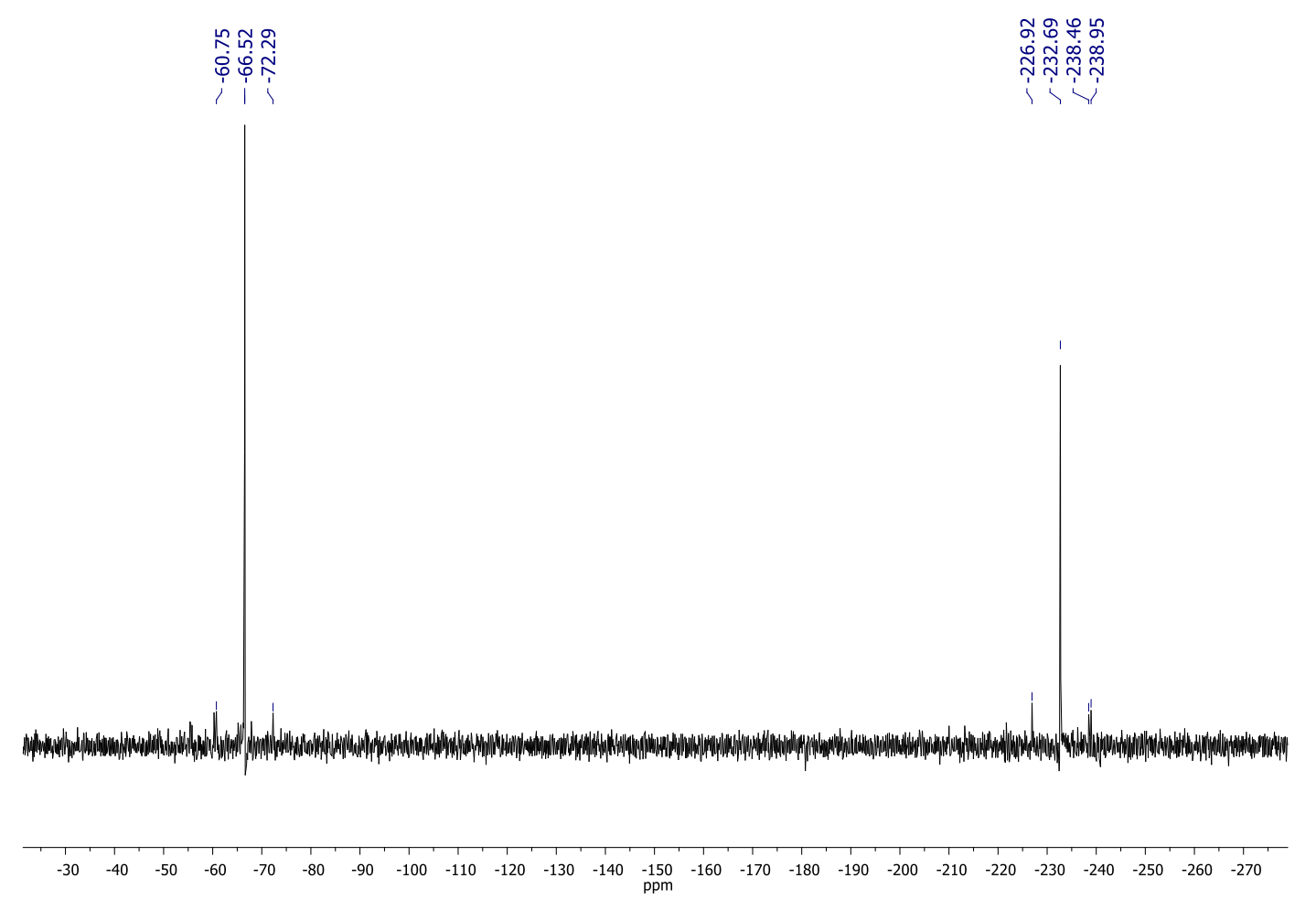

Figure 6.2.2.13- ${ }^{119} \mathrm{Sn} \mathrm{NMR}\left(\mathrm{C}_{6} \mathrm{D}_{6}\right)$ spectrum of $\mathbf{1 0}$ 


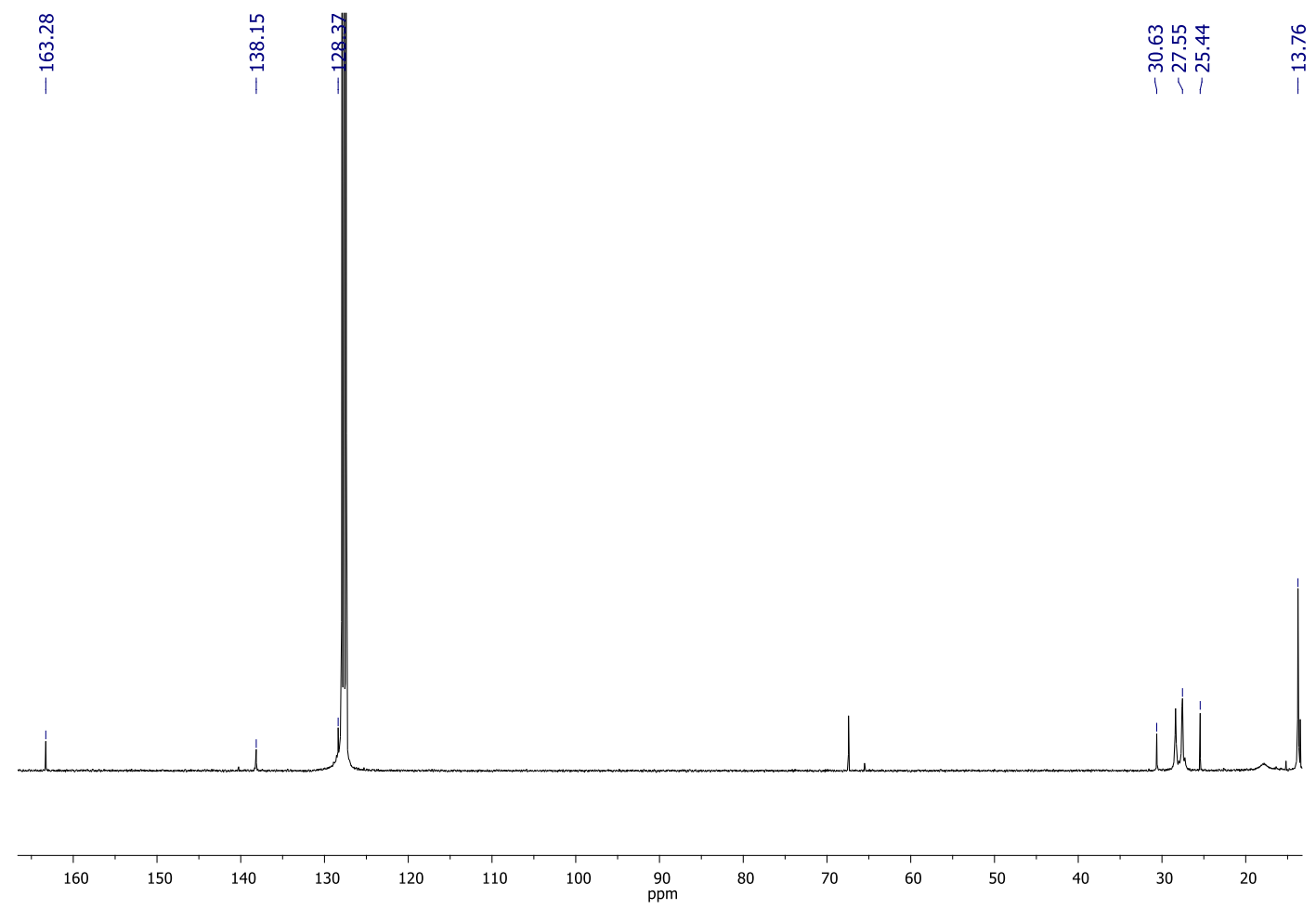

Figure 6.2.2.14- ${ }^{13} \mathrm{C}$ NMR $\left(\mathrm{C}_{6} \mathrm{D}_{6}\right)$ spectrum of $\mathbf{1 0}$ 


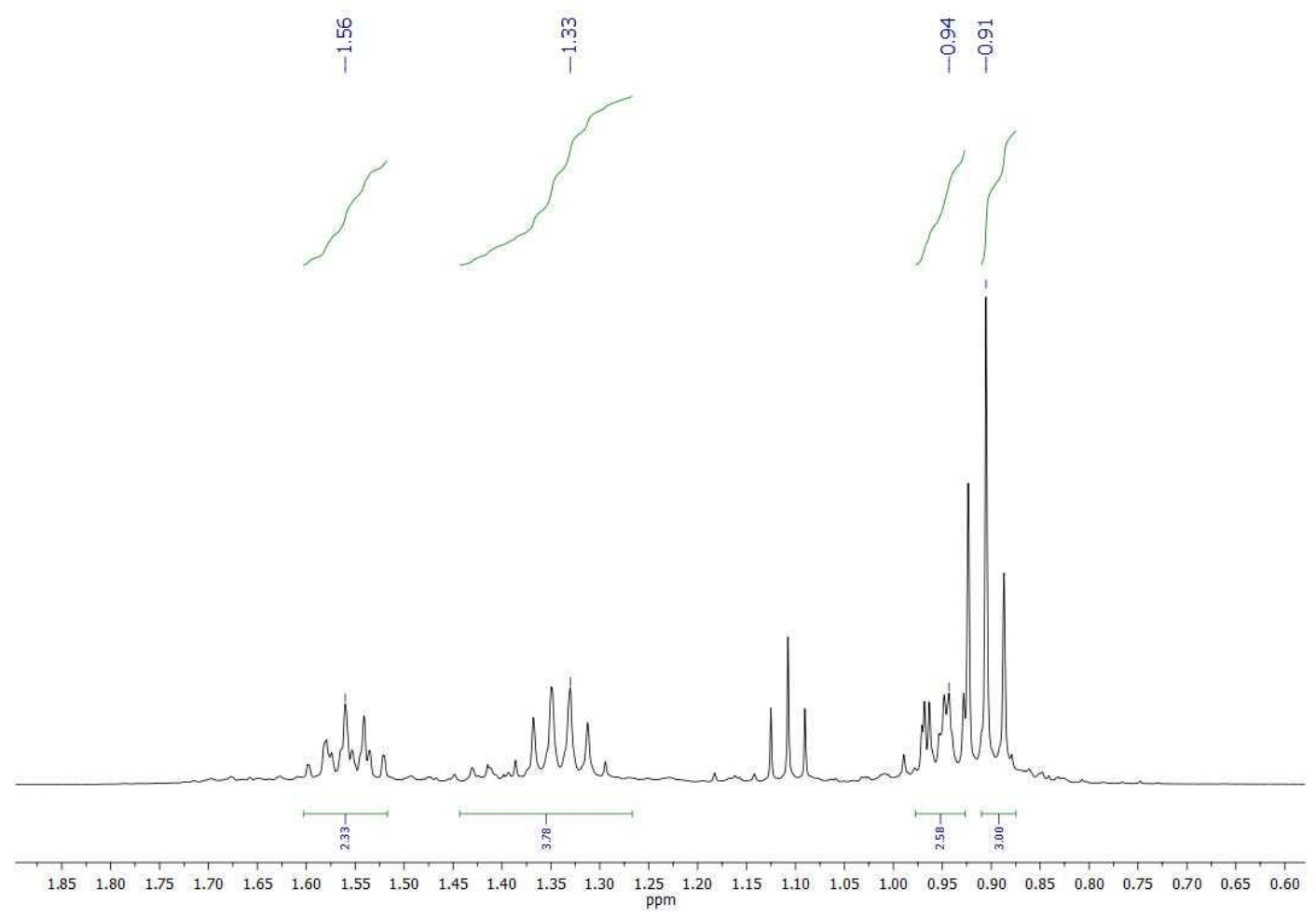

Figure 6.2.2.15 $-{ }^{1} \mathrm{H}$ NMR $\left(\mathrm{C}_{6} \mathrm{D}_{6}\right)$ spectrum of $\mathbf{1 1}$

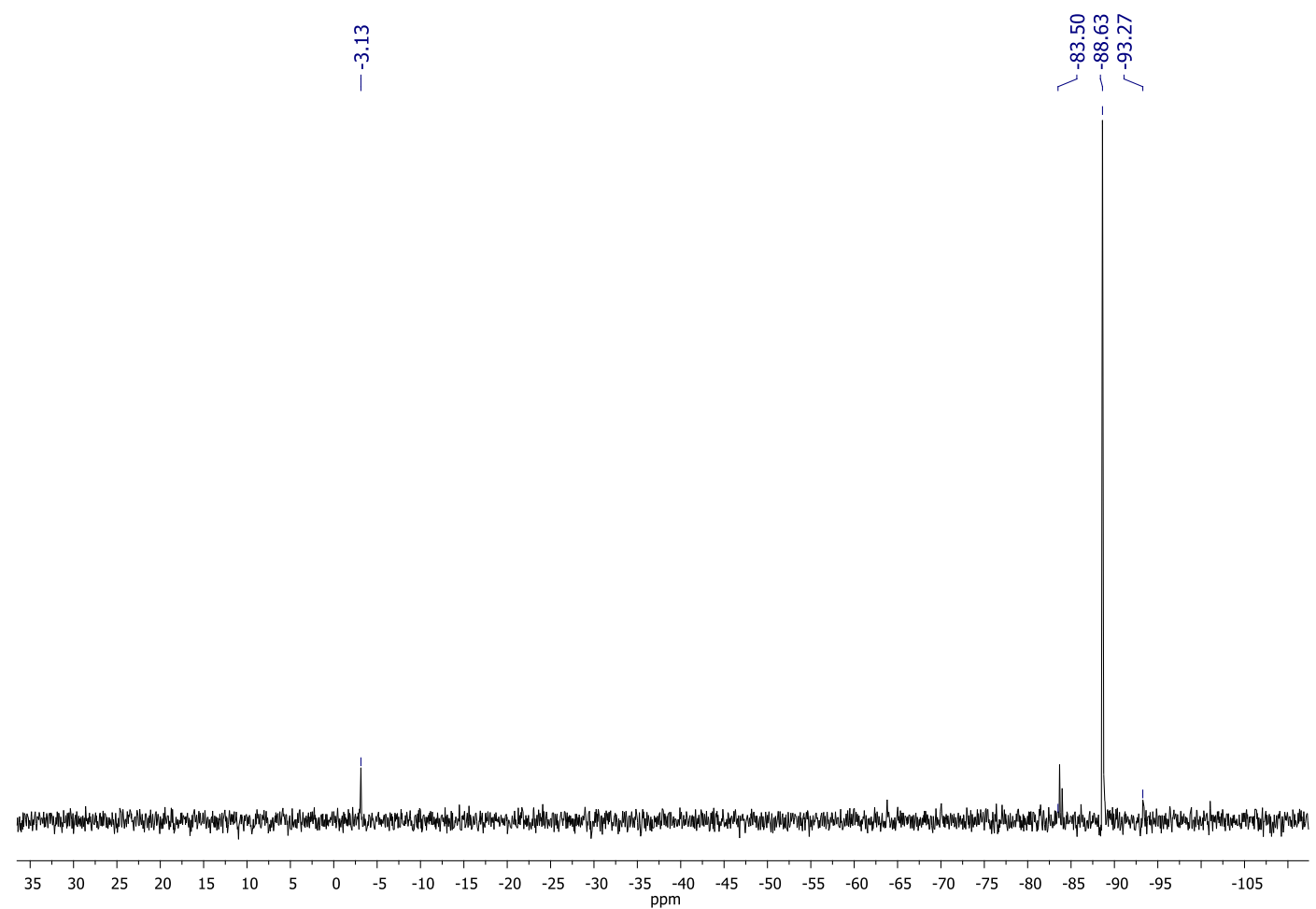

Figure 6.2.2.16- ${ }^{119} \mathrm{Sn}$ NMR $\left(\mathrm{C}_{6} \mathrm{D}_{6}\right)$ spectrum of $\mathbf{1 1}$ 


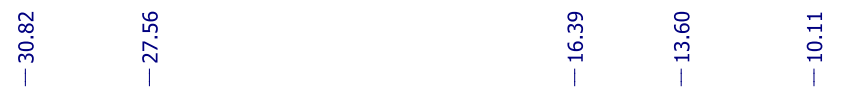

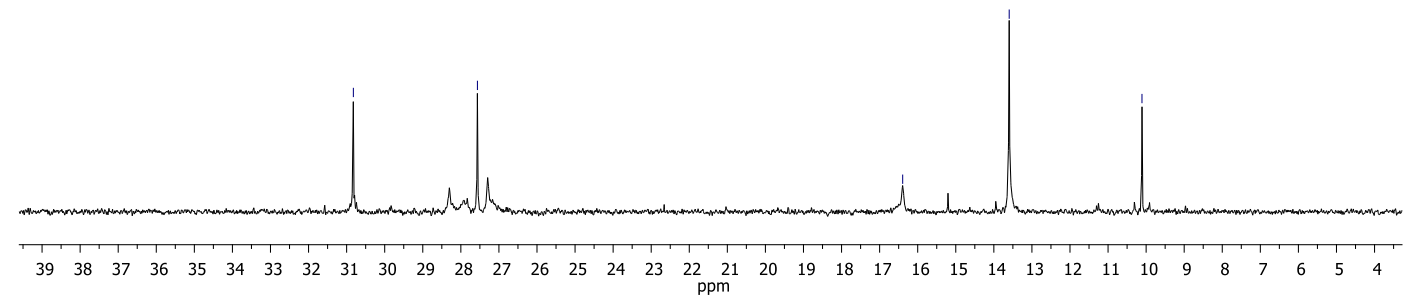

Figure 6.2.2.17 $-{ }^{13} \mathrm{C}$ NMR $\left(\mathrm{C}_{6} \mathrm{D}_{6}\right)$ spectrum of $\mathbf{1 1}$ 


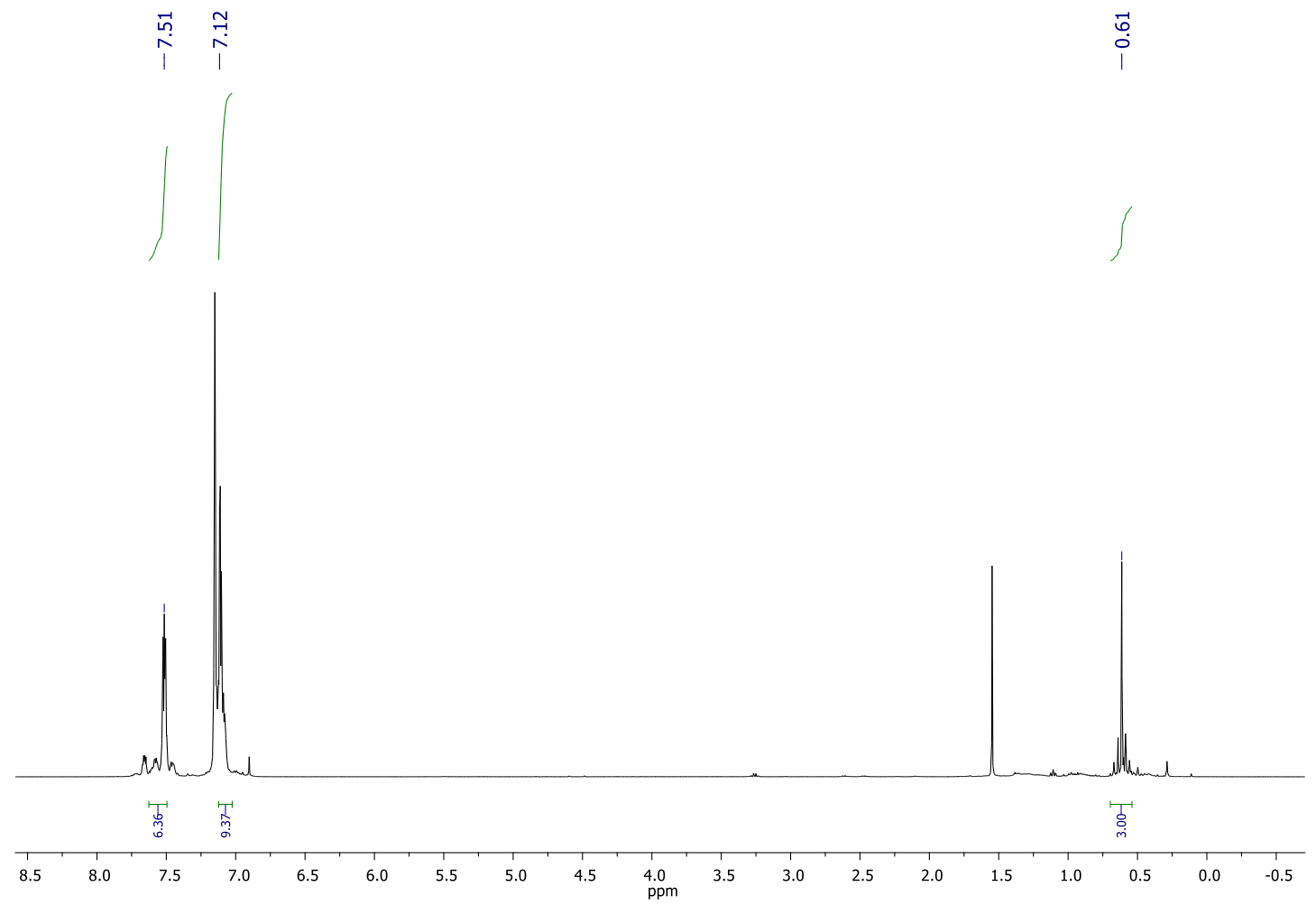

Figure 6.2.2.18 $-{ }^{1} \mathrm{H}$ NMR $\left(\mathrm{C}_{6} \mathrm{D}_{6}\right)$ spectrum of $\mathbf{1 2}$

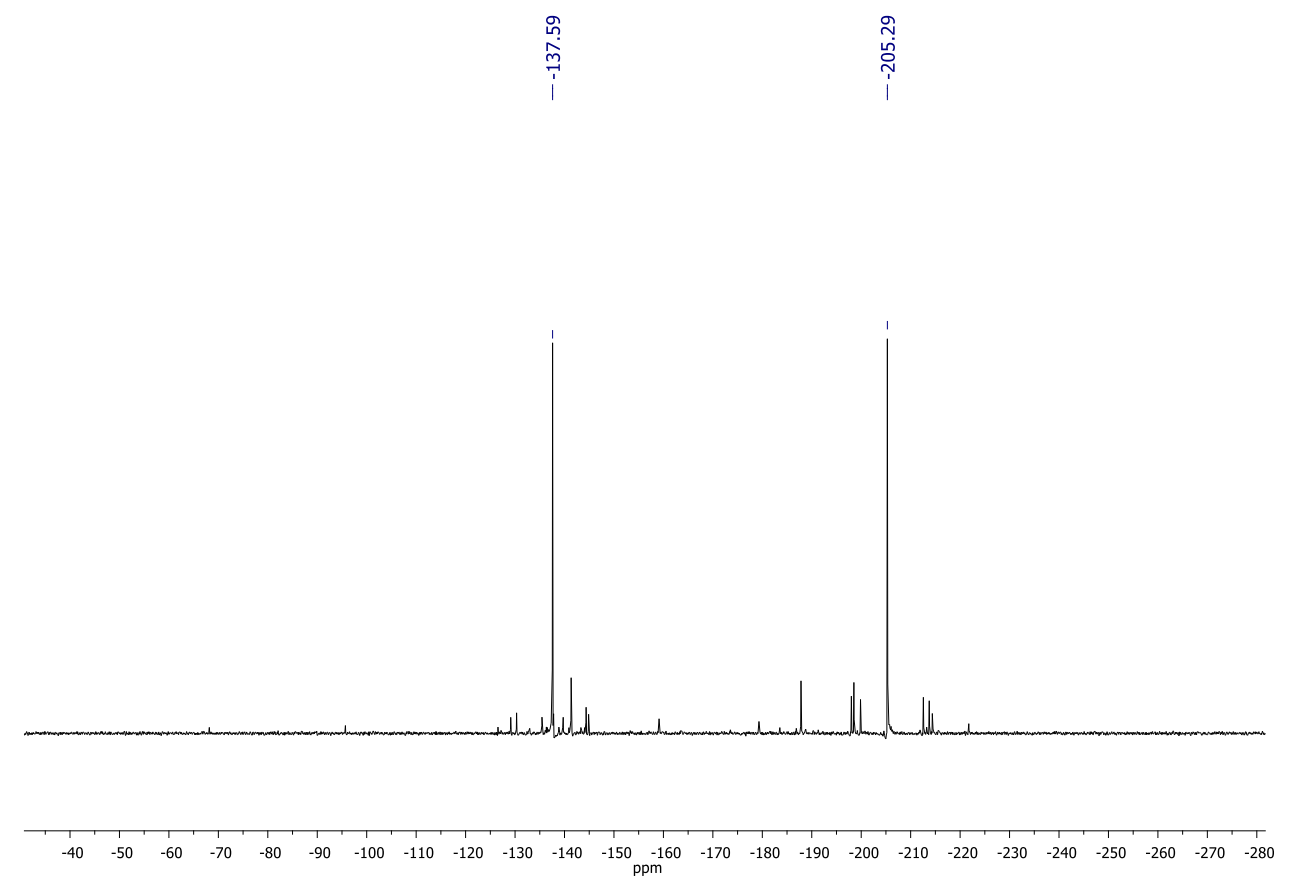

Figure 6.2.2.19- ${ }^{119} \mathrm{Sn}$ NMR $\left(\mathrm{C}_{6} \mathrm{D}_{6}\right)$ spectrum of $\mathbf{1 2}$ 


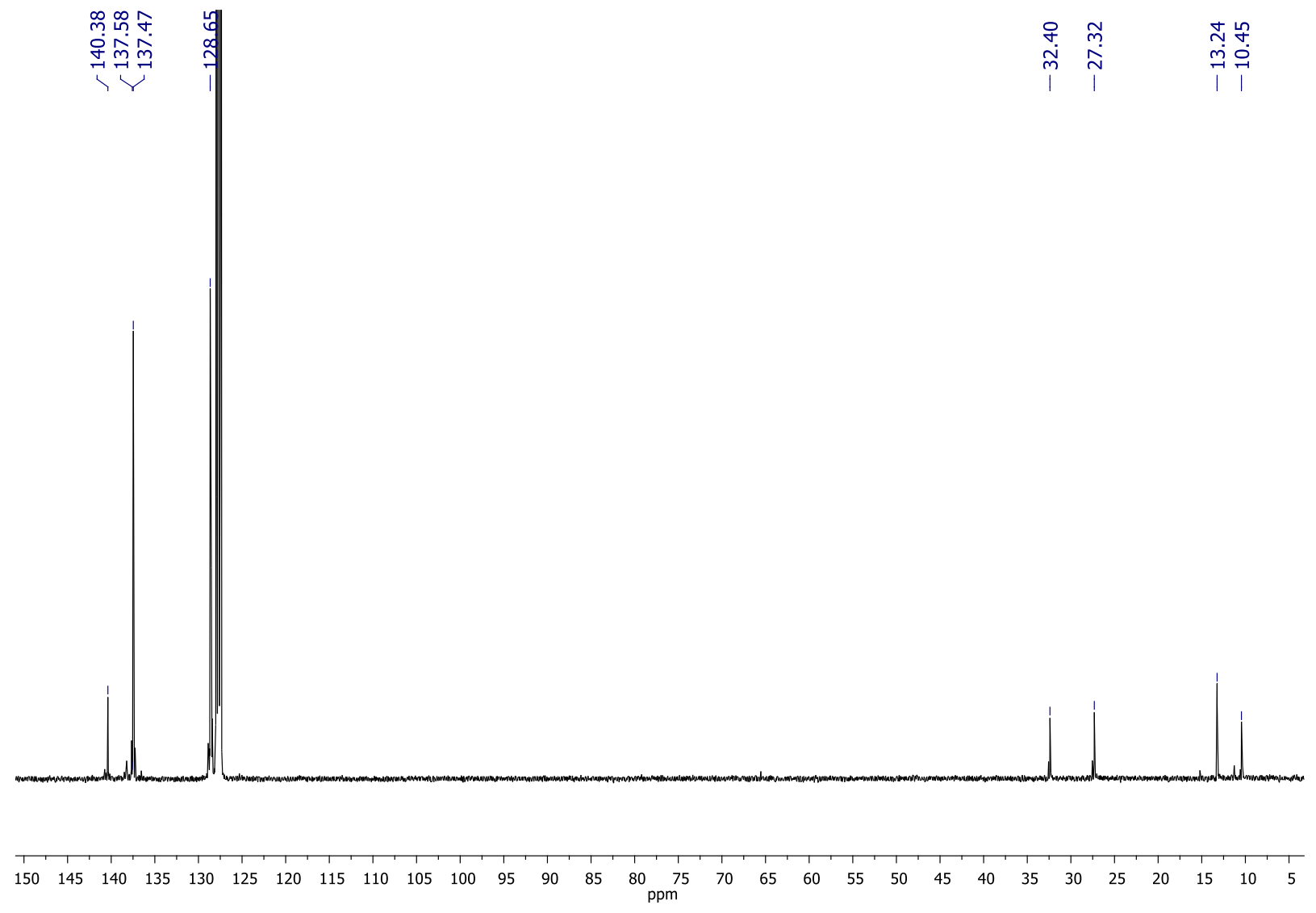

Figure 6.2.2.20 $-{ }^{13} \mathrm{C}$ NMR $\left(\mathrm{C}_{6} \mathrm{D}_{6}\right)$ spectrum of $\mathbf{1 2}$ 


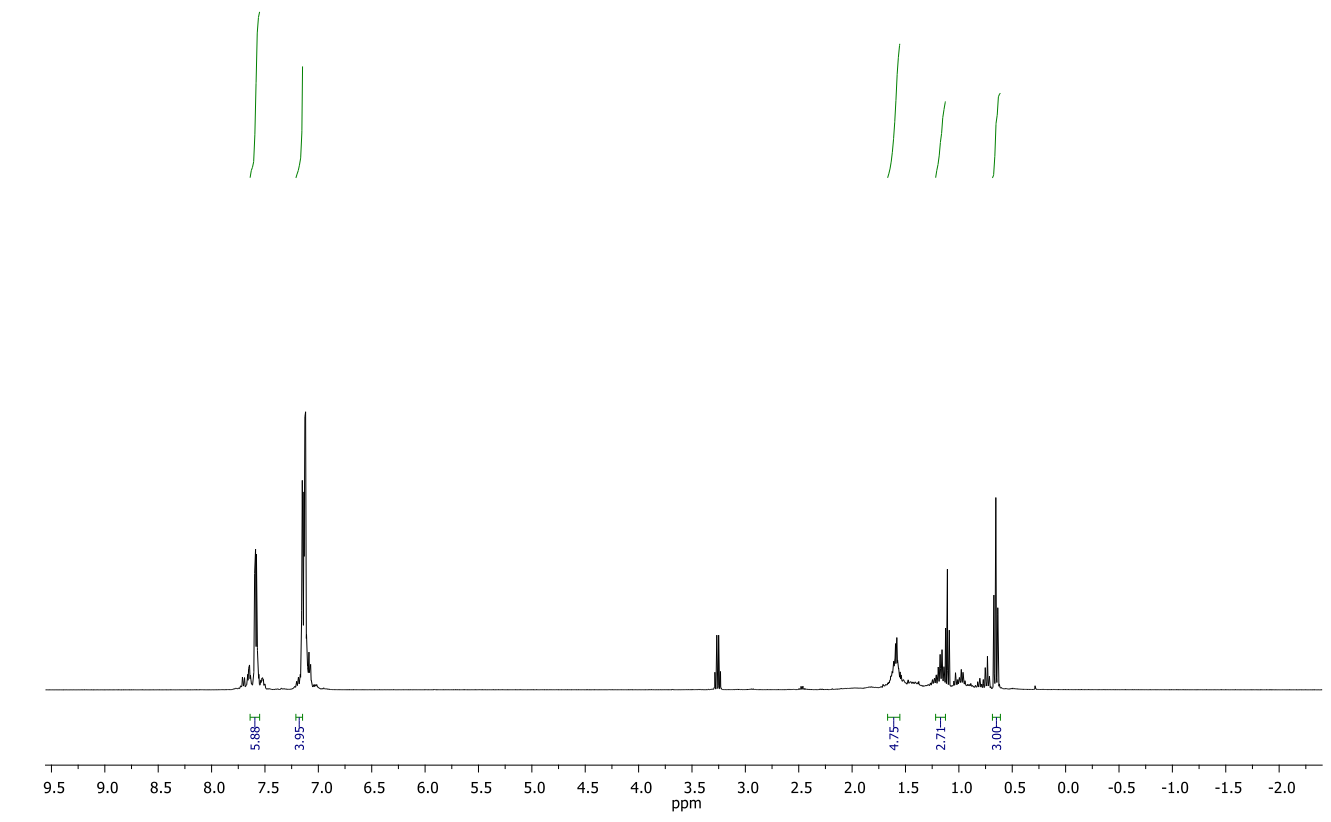

Figure 6.2.2.21- ${ }^{1} \mathrm{H}$ NMR $\left(\mathrm{C}_{6} \mathrm{D}_{6}\right)$ spectrum of $\mathbf{1 3}$
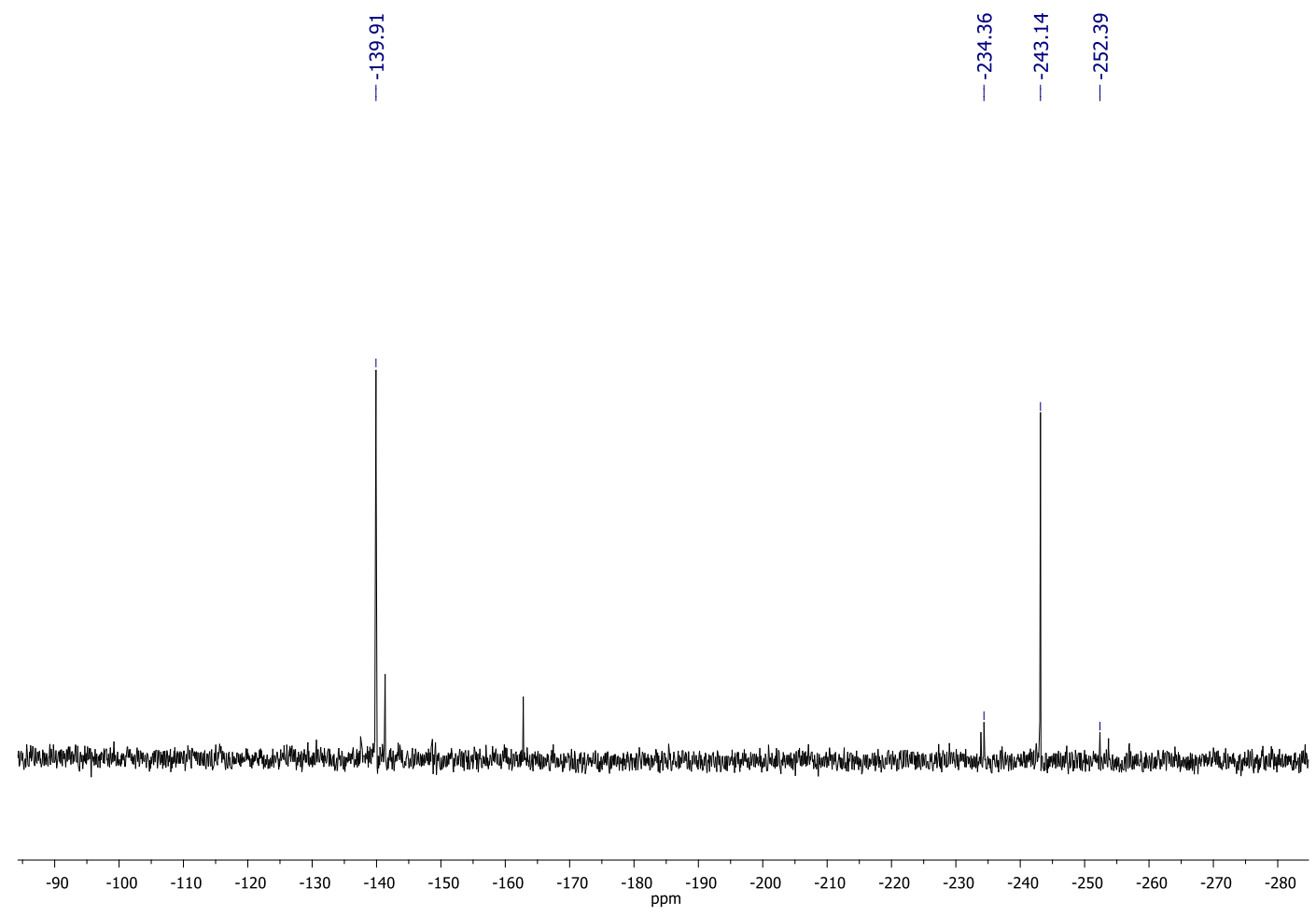

Figure 6.2.2.22 ${ }^{119} \mathrm{Sn}$ NMR $\left(\mathrm{C}_{6} \mathrm{D}_{6}\right)$ spectrum of $\mathbf{1 3}$ 


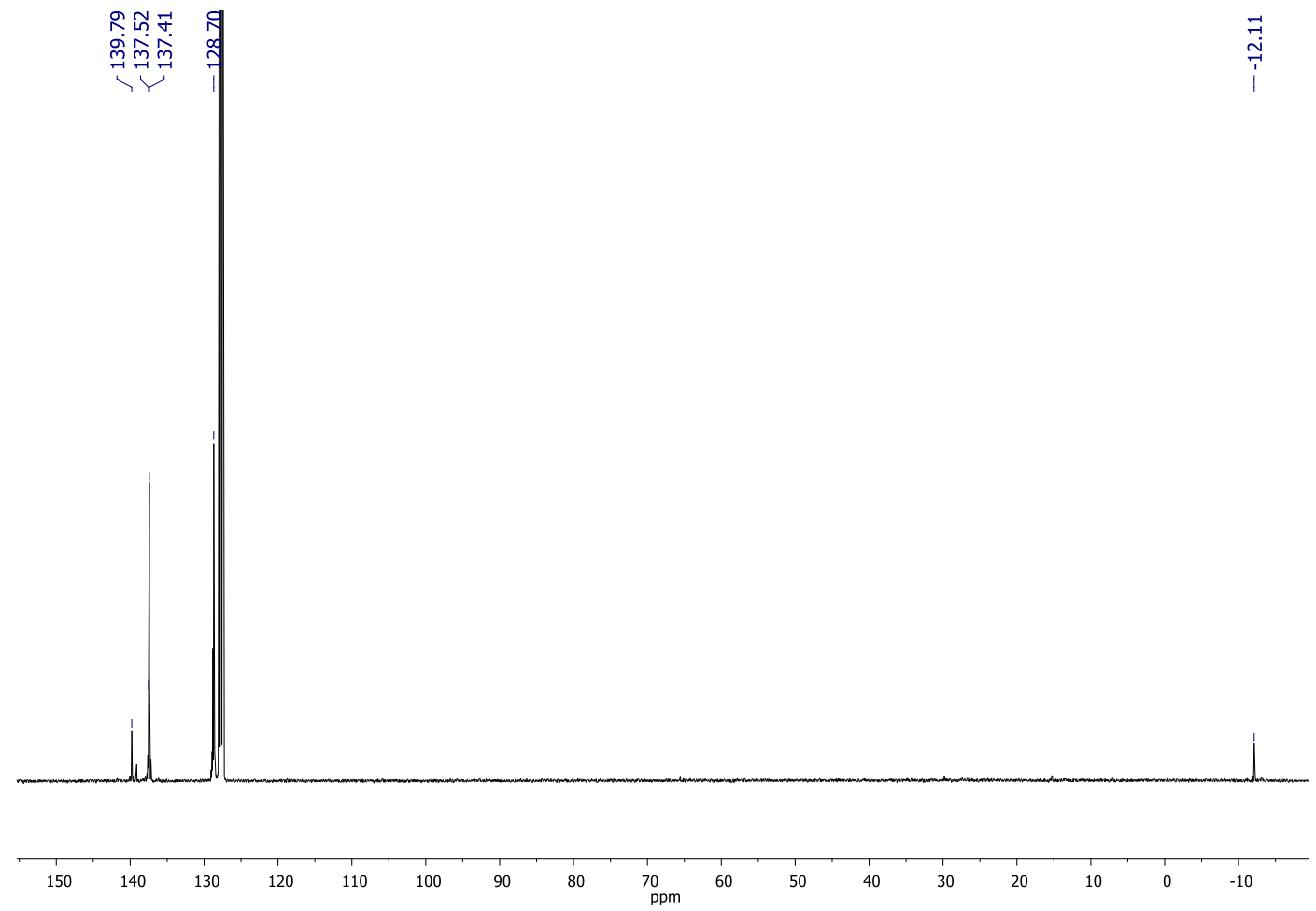

Figure 6.2.2.23- ${ }^{13} \mathrm{C}$ NMR $\left(\mathrm{C}_{6} \mathrm{D}_{6}\right)$ spectrum of $\mathbf{1 3}$ 


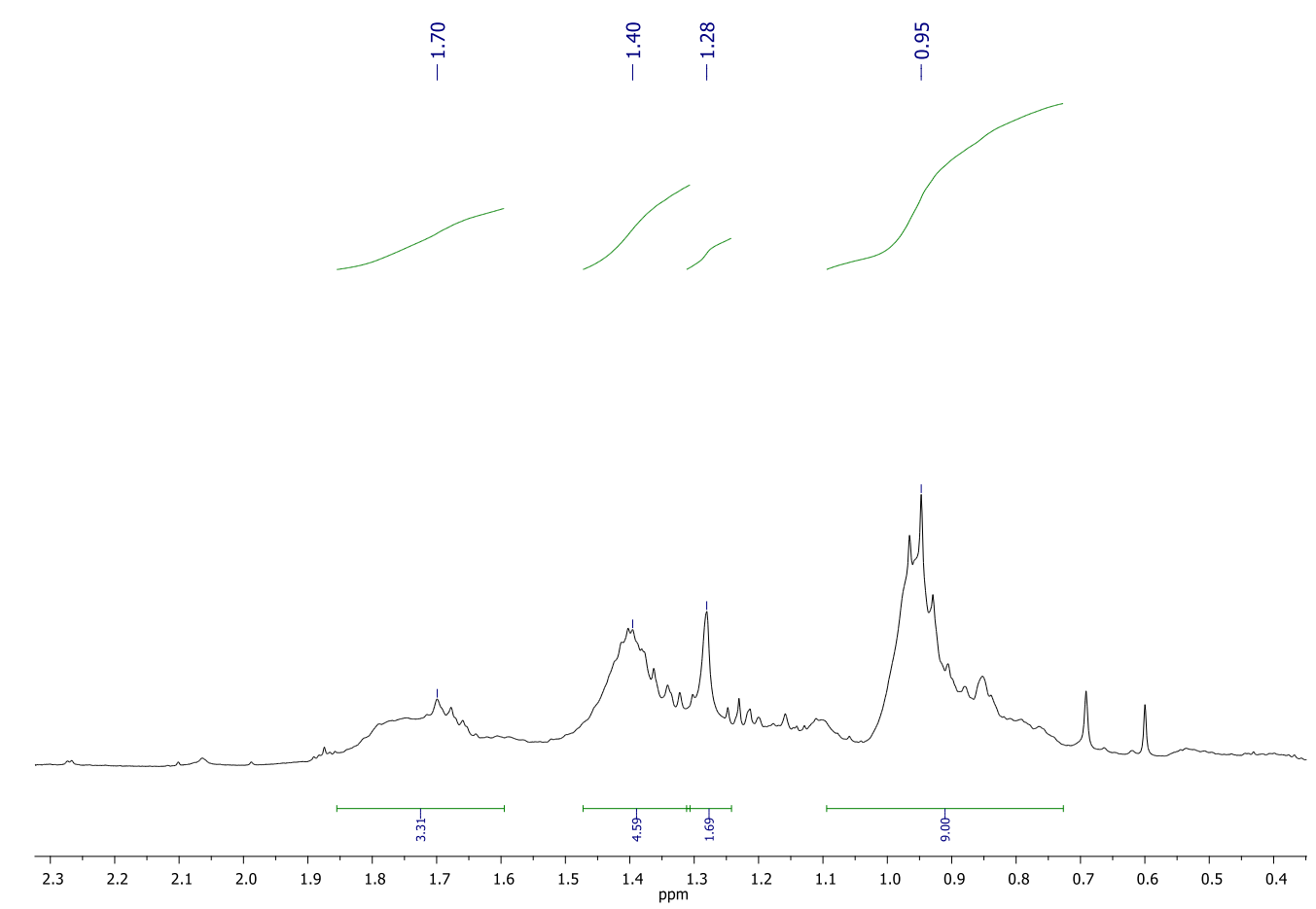

Figure 6.2.2.24 $-{ }^{1} \mathrm{H}$ NMR $\left(\mathrm{C}_{6} \mathrm{D}_{6}\right)$ spectrum of $\mathbf{1 4}$

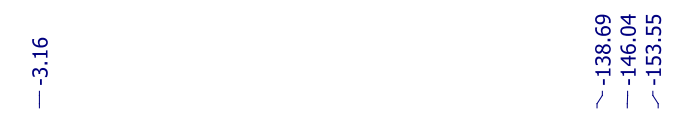

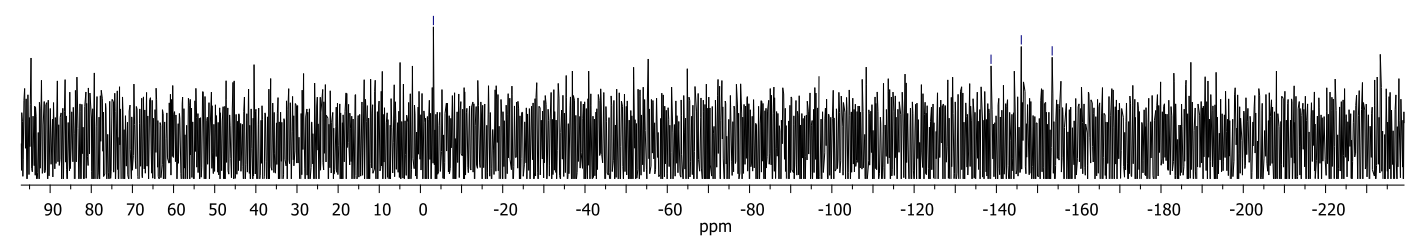

Figure 6.2.2.25 ${ }^{119} \mathrm{Sn}$ NMR $\left(\mathrm{C}_{6} \mathrm{D}_{6}\right)$ spectrum of $\mathbf{1 4}$ 


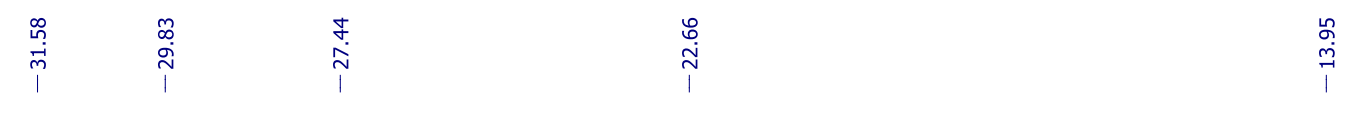

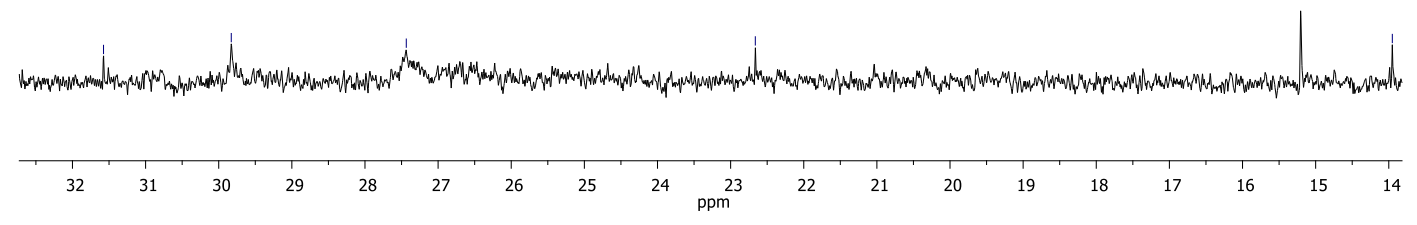

Figure 6.2.2.26 $-{ }^{13} \mathrm{C} \mathrm{NMR}\left(\mathrm{CDCl}_{3}\right)$ spectrum of $\mathbf{1 4}$ 


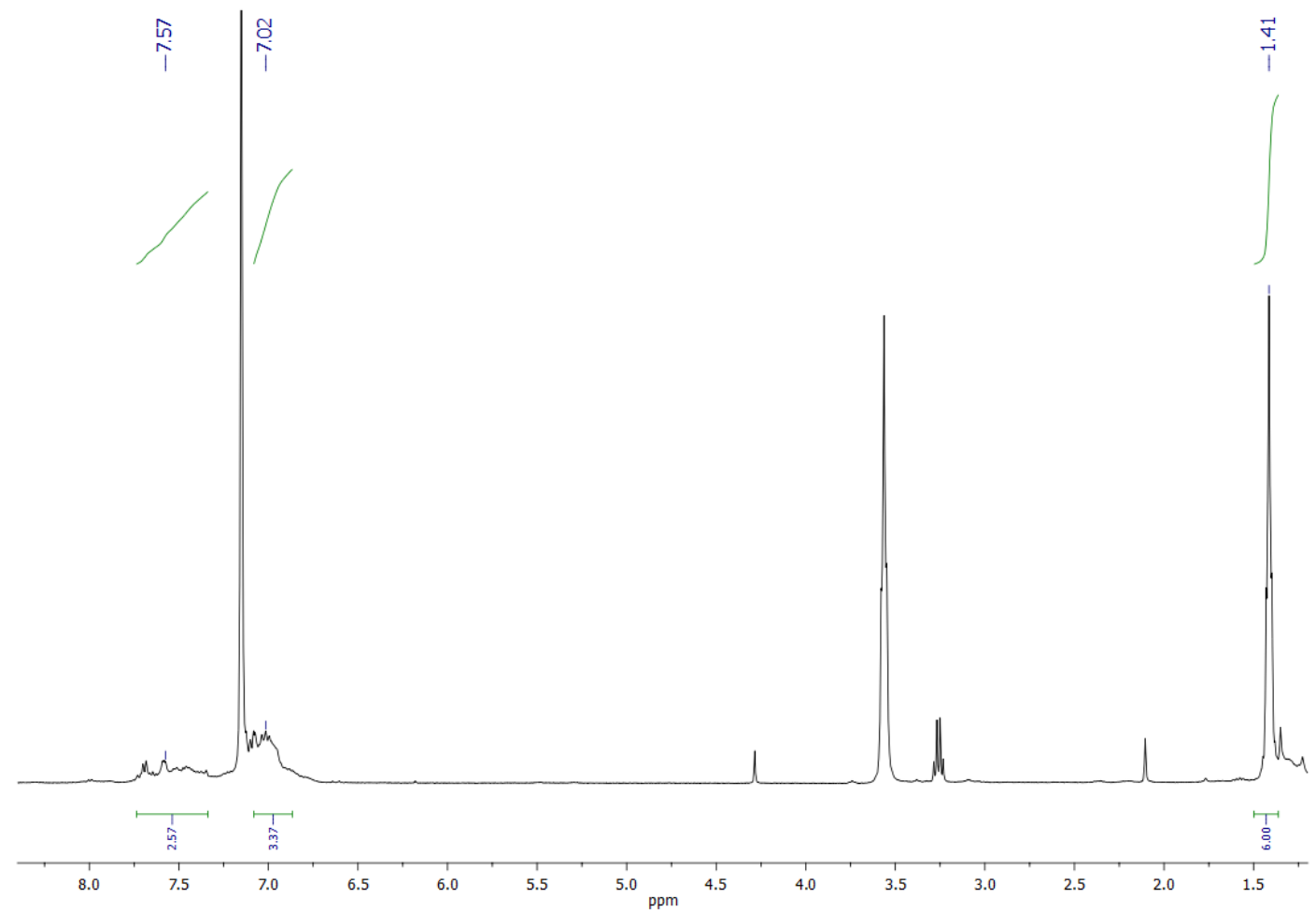

Figure 6.2.2.27- ${ }^{1} \mathrm{H}$ NMR $\left(\mathrm{C}_{6} \mathrm{D}_{6}\right)$ spectrum of $\mathbf{1 5}$

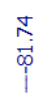

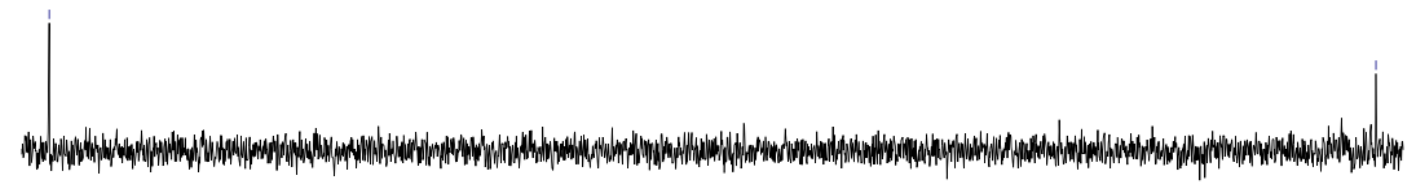

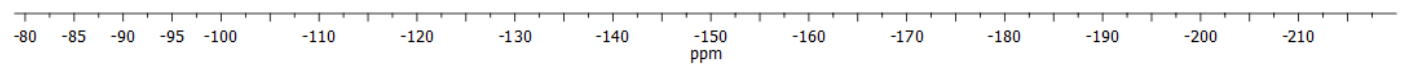

Figure 6.2.2.28 ${ }^{119} \mathrm{Sn} \mathrm{NMR}\left(\mathrm{C}_{6} \mathrm{D}_{6}\right)$ spectrum of $\mathbf{1 5}$ 


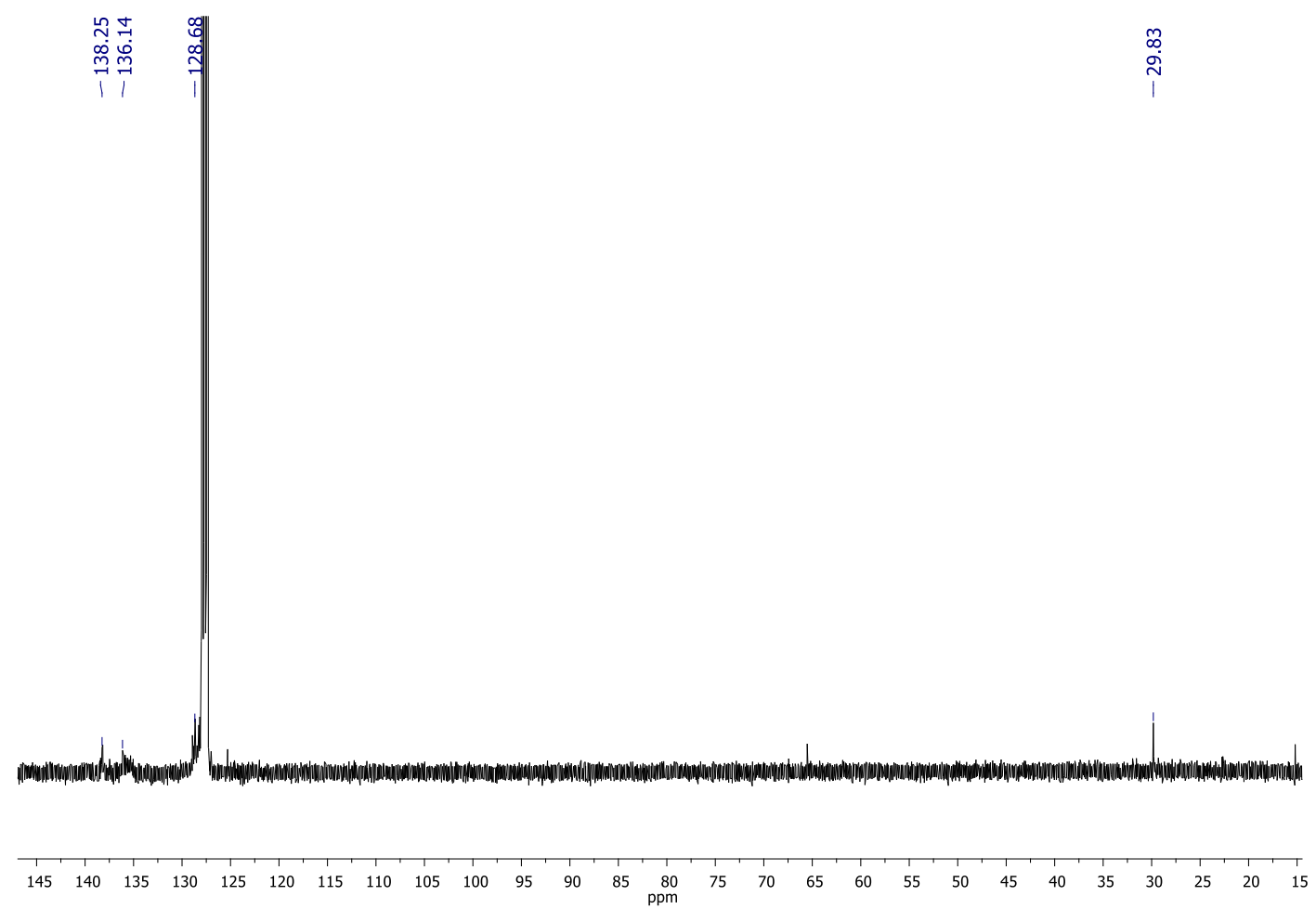

Figure 6.2.2.29 $-{ }^{13} \mathrm{C}$ NMR $\left(\mathrm{C}_{6} \mathrm{D}_{6}\right)$ spectrum of $\mathbf{1 5}$ 


\subsection{3-DFT Figures and Images}

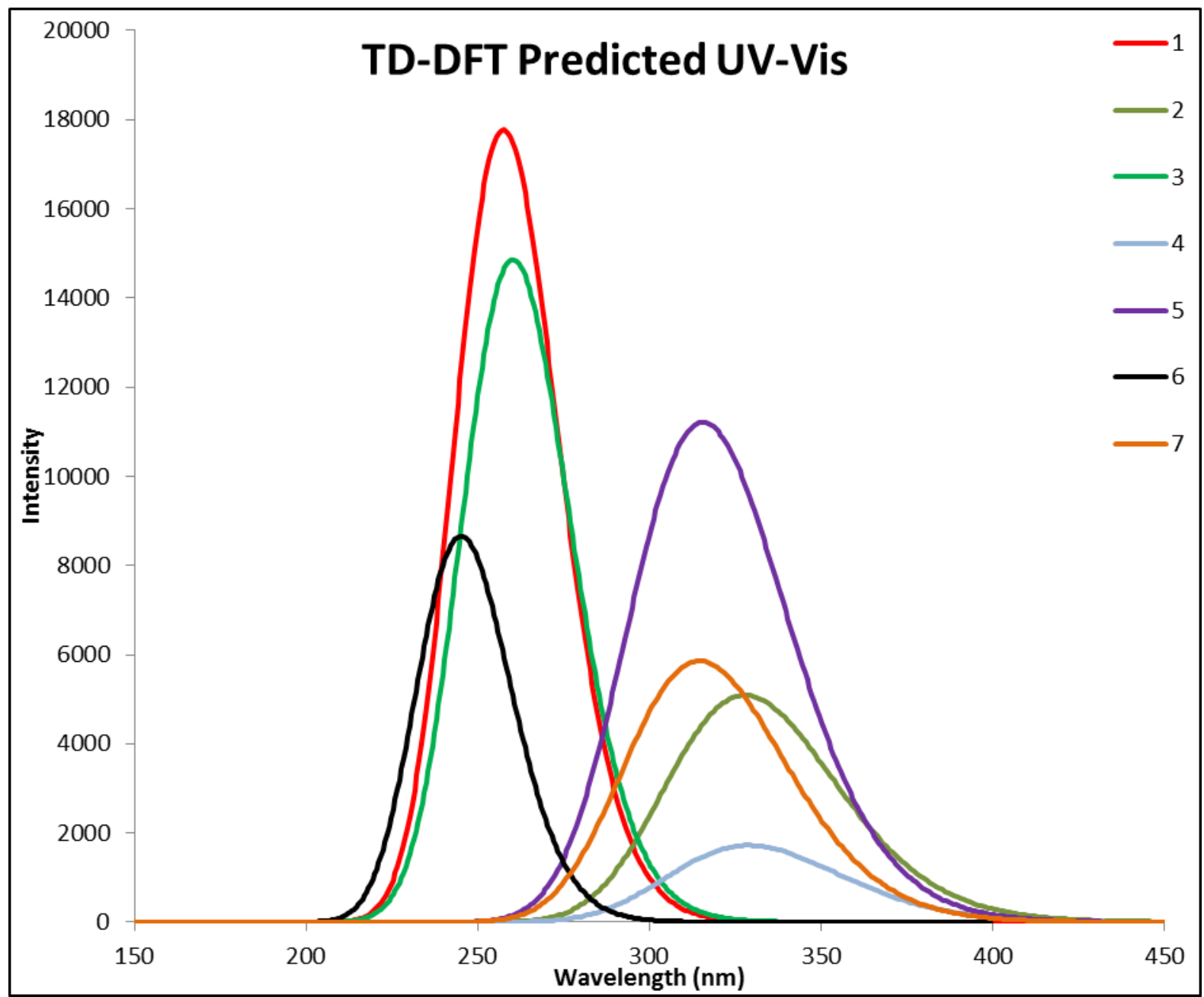

Figure 6.2.3.1: Predicted TD-DFT UV-Vis structures of Trimers 9-15 

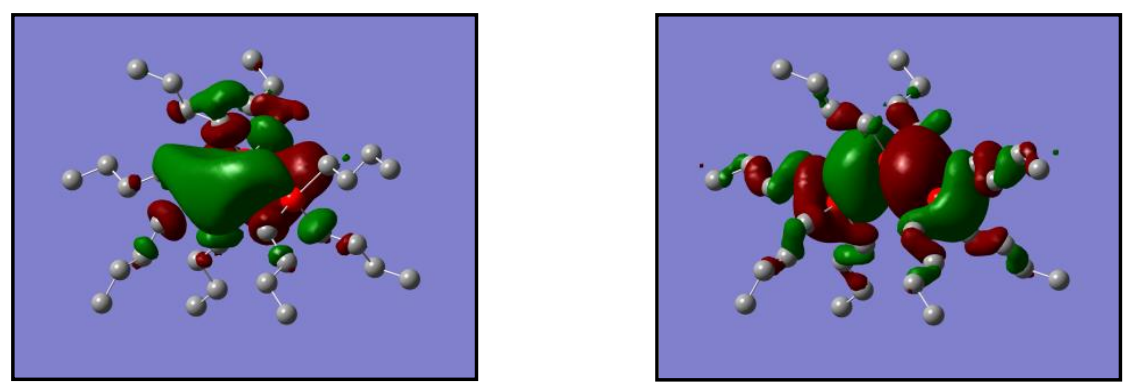

Figure 6.2.3.2 (Left) LUMO (Right) HOMO of 9
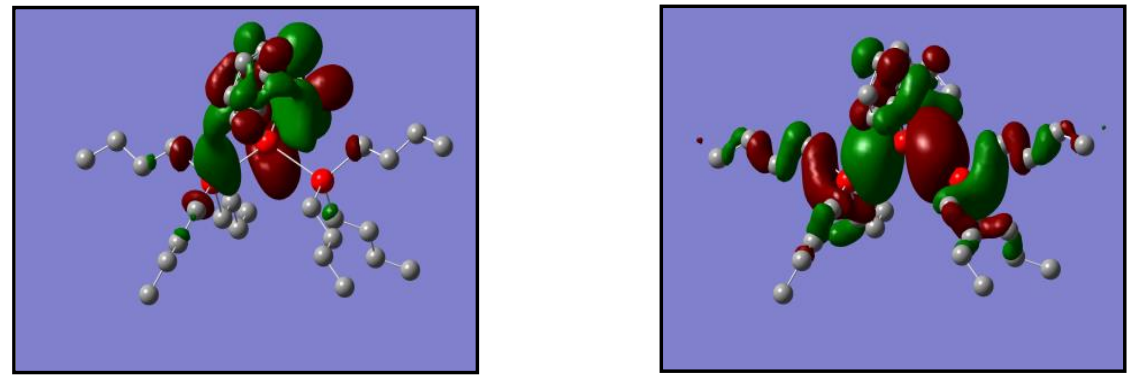

Figure 6.2.3.3 (Left) LUMO (Right) HOMO of $\mathbf{1 0}$
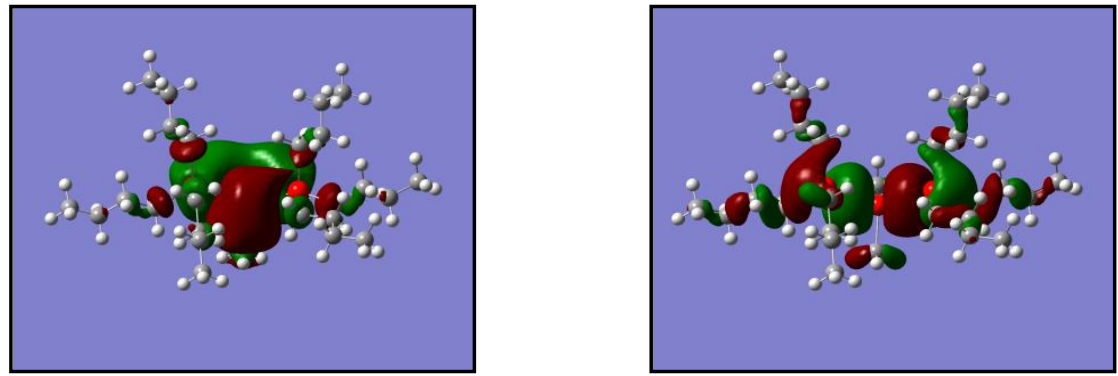

Figure 6.2.3.4 (Left) LUMO (Right) HOMO of 11
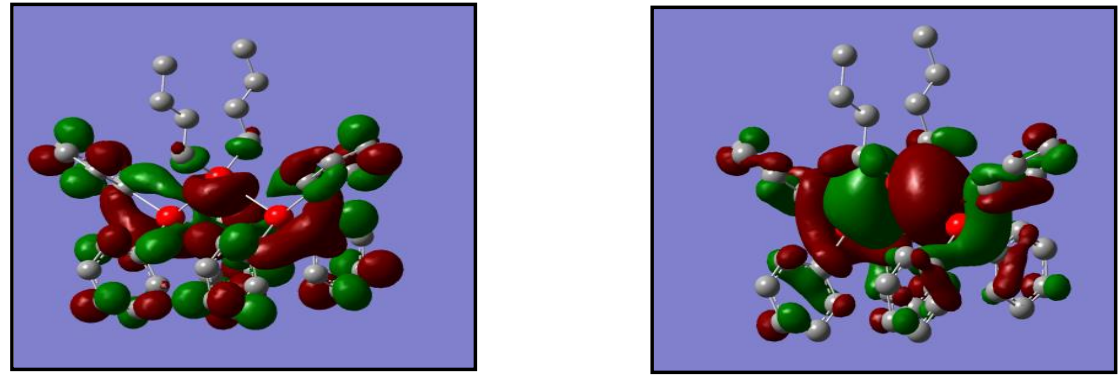

Figure 6.2.3.5 (Left) LUMO (Right) HOMO of 12 

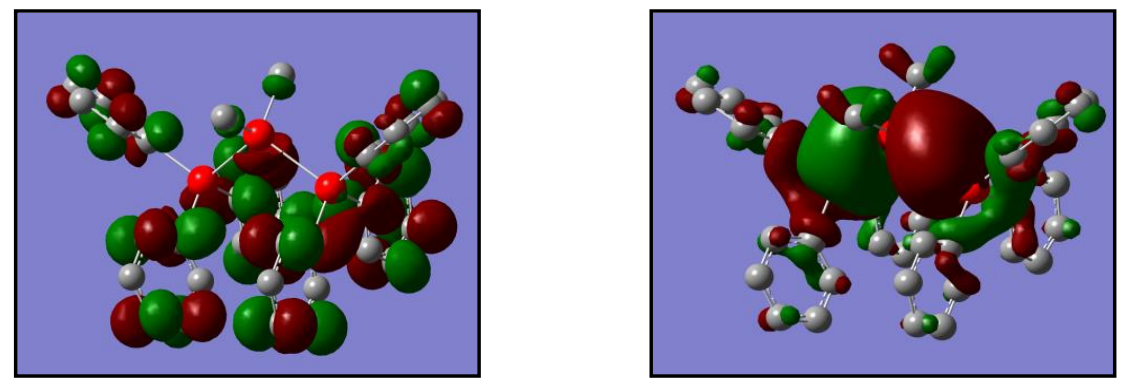

Figure 6.2.3.6 (Left) LUMO (Right) HOMO of 13
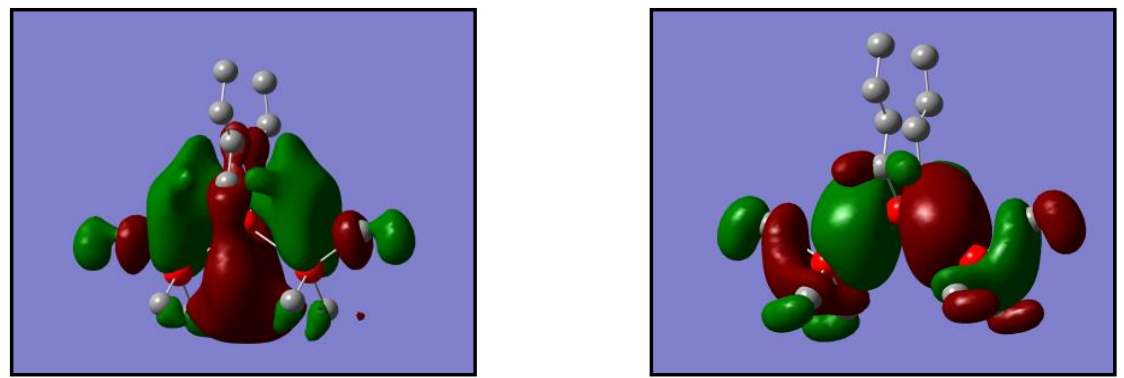

Figure 6.2.3.7 (Left) LUMO (Right) HOMO of $\mathbf{1 4}$
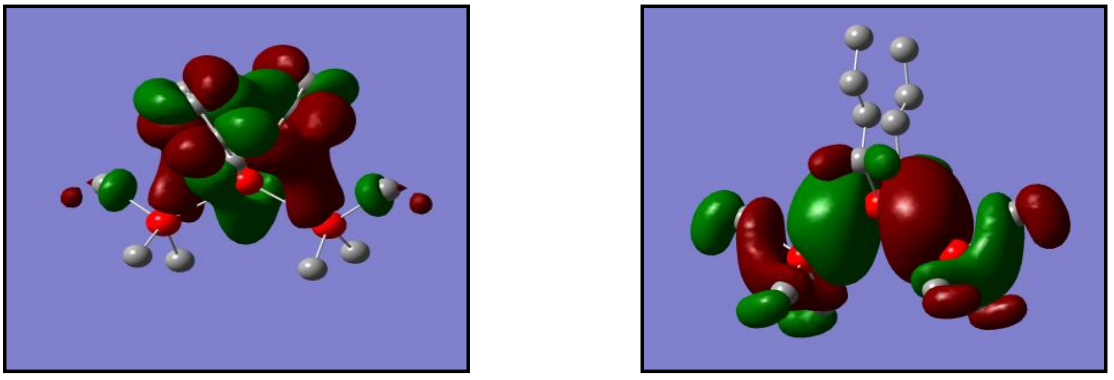

Figure 6.2.3.8 (Left) LUMO (Right) HOMO of 15 


\subsection{4.-Tables}

\begin{tabular}{|c|c|}
\hline Trimer & Minimized Energy \\
\hline 1 & -1266.00 \\
\hline 2 & -1412.67 \\
\hline 3 & -1031.48 \\
\hline 4 & -1907.97 \\
\hline 5 & -1471.30 \\
\hline 6 & -562.41 \\
\hline 7 & -709.07 \\
\hline
\end{tabular}

Table 6.2.4.1: Minimized Trimer Energies using SDD/LSDA basis set

\section{DFT-Hartree-Fock Comparison Table}

\begin{tabular}{c|c|c|c|c|c|} 
Trimer & \multicolumn{2}{c}{ Bond Length } & \multicolumn{2}{c}{ Bond Angle } \\
\hline $\mathbf{1}$ & 2.846 & 2.842 & 112.69 & 97.25 \\
$\mathbf{2}$ & 2.842 & 2.85 & 114.33 & 95.43 \\
\hline $\mathbf{3}$ & 2.845 & 2.842 & 115.77 & 106.88 \\
\hline $\mathbf{4}$ & 2.8 & 2.839 & 109.47 & 109.24 \\
\hline $\mathbf{5}$ & 2.8 & 2.836 & 109.47 & 102.749 \\
\hline $\mathbf{6}$ & 2.78 & 2.839 & 108.52 & 105.51 \\
$\mathbf{7}$ & 2.836 & 2.835 & 115.77 & 101.353 \\
\hline
\end{tabular}

Table 6.2.4.2: Hartree-Fock optimization values and DFT LSDA/SDD optimization values. 


\section{References}

1. Sanderson, R.T. Chemical Bonds and Bond Energy, $2^{\text {nd }}$ ed., Academic Press, New York, 1976. Cotrell, T. L. The strengths of Chemical Bonds, $2^{\text {nd }}$ ed., Buttersworths London, 1958.

2. Sita, L. R. Organometallics, 1992, 11, 1442.

3. Abd-El-Aziz, A.S.; Carraher, C.; Charles, U.; Pitman, J.; Zeldin, M. eds., Macromolecules containing metal and metal like elements, vol.4; Group IVA Polymers, John Wiley \& Sons Inc., 2005, Chap. 10.

4. Jurkschat, K.; Mehring, M. in Organometallic polymers of Germanium, Tin and Lead, Vol. 2, Z. Rappoport, ed., Wiley, New York, 2002, Ch. 22.

5. Imori, T.; Lu, V.; Cai, H.; Tilley, T.D. J. Am. Chem. Soc. 1995, 117, 9931.

6. Lu, V., Tilley, T. D., Marcromolecules 2000, 33, 2403.

7. Okano, M.; Matsumoto, N.; Arakawa, M.; Tsuruta, T.; Hamano, H. Chem. Commun. 1998, 1799.

8. Devylder, N.; Hill, M.; Molloy, K. C.; Price, G. J. Chem. Commun. 1996, 711.

9. Choffat, F.; Smith, P.; Caseri, W. J. Mater. Chem. 2005, 15, 1789.

10. A convenient route to distannanes, oligostannanes and polystannanes. Khan, A.; Gossage, R.;

Foucher, D. Can. J. Chem., 2010, 88, 1046.

11. Adams, S.; Dräger, M.; Main Group Met. Chem. 1988, XI, 151.

12. Zou, W.; Yang, N.; Polym. Prepr. (Am. Chem. Soc. Div. Polym.Chem.) 1992, 33, 188.

98, 1799.

13. Deacon, P. R.; Devylder, N.; Hill, M. S.; Mahon, M. F.; Molloy, K. C.; Price, G. J.; J.

Organometal. Chem. 2003, 687, 46.

14. Mustafa, A.; Achilleos, M.; Ruiz-Iban, J.; Davis, J.; Benfield, R. E.; Jones, R. G.; Granjean, D.;

Holder, S. J.; React. Funct. Polym. 2006, 66, 123.

15. Miles, D.; Burrow, T.; Lough, A.; Foucher, D.; J. Inorg. Organomet. Polym. 2010, $20,544$.

16. Trummer, M. ; Solenthaler, D.; Smith, P.; Caseri, W, RSC Advances, 2011, 1, 823.

17. Trummer, M.; Zemp, J.; Sax, C.; Smith, P.; Caseri, W.; J. Organomet. Chem. 2011, 696, 3041.

18. Imori, T.; Tilley, T. D.; J. Chem. Soc., Chem. Commun. 1993, 1607. 
19. Tilley, T. D.; Imori, T.; High molecular weight polystannanes by metal catalysed dehydropolymerization, US Patent, 5488091A, January 30

20. Babcock, J. R.; Sita, L. R.; J. Am. Chem. Soc. 1996, 118, 12481.

21. Lu, V. Y.; Tilley, T. D, Macromolecules 1996, 29, 5763.

22. Woo, H.-G..; Park, J.-M.; Song, S.-J.; Yang, S.-Y.; Kim, I.-S.; Kim, W.-G.; Bull. Korean Chem. Soc. 1997, 18, 1291.

23. Neale, N. R.; Tilley, T. D.; Tetrahedron 2004, 60, 7247.

24. Thompson, S. M.; Schubert, U.; Inorg. Chim. Acta. 2004, 357, 1959.

25. Choffat, F.; Käser, S.; Wolfer, P.; Schmid, D.; Mezzenga, R.; Smith, P.; Caseri, W.; Macromolecules. 2007, 40, 7878.

26. Choffat, F.; Smith, P.; Caseri, W.; W. Adv. Mater. 2008, 20, 2225.

27. Beckmann, J.; Duthie, A.; Grossman, M.; Semisch, A.; Organometallics, 2008, 27, 1495.

28. Choffat, F.; Buchmüller, Y.; Mensing, C.; Smith, P.; Caseri, W.; J. Inorg. Organomet. Polym. Mater. 2009, 19, 166.

29. Khan, A.; Gossage, R. A.; Foucher, D. A.; Can. J. Chem. 2010, 88, 1046.

30. Choffat, F.; Wolfer, P.; Smith, P.; Caseri, W.; Macromol Mater. Eng, 2010, 295, 210.

31. Trummer, M.; Nauser, T.; Lechner, M.-L.; Uhlig, F.; Caseri, W.; Polym. Degrad. Stab. 2011, $96,1841$.

32. High molecular weight polystannanes 6 and 7 containing alternating alkyl $(n$-Bu, or $\mathrm{Me})$ and $\mathrm{Ph}$ substituents attached to tin centers in the backbone display ready solubility (> $20 \mathrm{mg} / \mathrm{mL}$ ) in common organic solvents (DCM, toluene, THF, $\mathrm{C}_{6} \mathrm{H}_{6}$ ). This is in contrast to an earlier report of poly (diphenylstannane) which is effectively insoluble in organic solvents even at low molecular weights ( 7,000 Da). See V. Lu and T. D. Tilley, Macromolecules, 1996, 29, 5763.

33. W. H. Carothers, Trans. Faraday Soc., 1936, 32, 39.

34. Adams, S.; Dräger, M.; Angew. Chem. Int. Ed. 1987, 26, 1255. 
35. Herberhold, M.; Steffl, U.; Milius, W.; Wrackmeyer, B.; Angew .Chem., Int. Ed. Engl. 1996, $35,1803$.

36. Dobson, S.; Howe, P. D.; Floyd, P.; World Health Organization (WHO). Mono-and disubstituted methyltin, butyltin and octyltin compounds. www.inchem.org/documents/cicads/cicads/cicad73.pdf, 2006.

37. The hydrostannolysis reaction leading to the formation of a Sn-Sn bond from the reaction of tin hydrides with tin amides was first described and the kinetics and mechanism investigated in detail by H. M. J. C. Creamers, F. Verbeek and J. G. Noltes, J. Organomet. Chem. 1967, 8, 469-477 who proposed the reaction proceeds by an electrophilic hydrostannolysis of the tin(IV)-amide bond from the reaction with tin(IV) hydride. They also conclusively ruled out a radical mechanism by carrying out reactions in the presence of radical traps in which no radical products were observed. The authors of this study suggest the formation of the $\mathrm{Sn}-\mathrm{Sn}$ bond proceeds by either an $\mathrm{S}_{E} 2$ (solvent assisted) or $\mathrm{S}_{F} 2$ (four center) mechanism.

38. Trummer, M.; Choffat, F.; Smith, P.; Caseri, W.; Macromol. Rapid. Comm. 2012, 33, 448.

39. Ward, J.; Al-Alul, S.; Harrypersad, S.; Foucher, D. A.; Can. J. Chem. 2014, 92, 525.

40. Petti, L.; Rippa, M.; Capasso, R.; Nenna, G.; De Girolamo Del Mauro, A.; Maglione, M. G.; Minarini, C.; Nanotechnology. 2013, 24, 315206.

41. Yan, H.; Chen, Z.; Zheng, Y. ; Newman, C.; Quinn, J. R.; Dötz, F.; Kastler, M. ; Facchetti, A.; Nature. 2009, 457, 679.

42. Rogers, J. A.; Bao, Z. J.; Polym. Sci. Part A: Polym. Chem. 2002, 40, 3327.

43. Takeda, K.; Shiraishi, K.; Chem. Phys. Lett., 1992, 195, 121.

44. V. Galiatsatos Computational Methods for Modeling Polymers: An Introduction, in Reviews in Computational Chemistry, Volume 6 (eds K. B. Lipkowitz and D. B. Boyd), John Wiley \& Sons, Inc., Hoboken, NJ, USA. 1995. 
45. Drenth, W.; Noltes, J. G.; Bulten, E. J.; Creemers, H. J. C.; J. Organomet. Chem. 1969, 17, 173.

46. Braunstein, P.; Morise. X.; Chem. Rev. 2000, 100, 3541.

47. Hill, M. S.; Hitchcock, P. B.; Pongtavornpinyo. R.; Science. 2006, 31, 1904.

48. G. Wulfsberg, Inorganic Chemistry; University Science Books, 2000.

49. Drenth, M.; Janssen, M. J.; van der Kerk, G. J. M.; Vliegenthart, J. A.; J. Organomet. Chem. 1964, 2, 265.

50. Miller, R. D.; Michl. J.; Chem. Rev. 1989, 89, 1359.

51. Trefonas, P.; West. R; J. Polym. Sci., Part A: Polym. Chem. 1985, 23, 2099.

52. Sita, L. R.; Terry, K. W.; Shibata, K.; J. Am. Chem. Soc. 1995, 117, 8049.

53. Balaji, V.; Michl, J.; Polyhedron, 1991, 10, 1265.

54. Sita, L. R.; Acc. Chem. Res.1994, 27, 191.

55. Casado, J.; Pappenfus, T. M.; Miller, L. L.; Mann, K. R.; Ortf, E.; Viruela, P. M.; PouAmérigo, R. ; Hernández, V. ; López Navarrete. J. T.; J. Am. Chem. Soc. 2003, 125, 2524.

56. Pitt, C. G.; Jones, L. L.; Ramsey. B. G.; J. Am. Chem. Soc.1967, 89, 5471.

57. Boberski, W. G.; Allred. A. L.; J. Organomet. Chem. 1975, 88, 65.

58. Bande, A.; Michl, J.; Chem. Eur. J. 2009, 15, 8504.

59. Tin Chemistry, Fundamentals, Frontiers and Applications; Davies, A., Gielen, M., Pannell, K., Tiekink, E., Eds.; Wiley, 2008; p 269.

60. Gaussian 09, Revision D.01, M. J. Frisch, G. W. Trucks, H. B. Schlegel, G. E. Scuseria,M. A. Robb, J. R. Cheeseman, G. Scalmani, V. Barone, B. Mennucci, G. A. Petersson, H. Nakatsuji, M. Caricato, X. Li, H. P. Hratchian, A. F. Izmaylov, J. Bloino, G. Zheng, J. L. Sonnenberg, M. Hada, M. Ehara, K. Toyota, R. Fukuda, J. Hasegawa, M. Ishida, T. Nakajima, Y. Honda, O. Kitao, H. Nakai, T. Vreven, J. A. Montgomery, Jr., J. E. Peralta, F. Ogliaro, M. Bearpark, J. J. Heyd, E. 
Brothers, K. N. Kudin, V. N. Staroverov, R. Kobayashi, J. Normand, K. Raghavachari, A. Rendell, J. C. Burant, S. S. Iyengar, J. Tomasi, M. Cossi, N. Rega, J. M. Millam, M. Klene, J. E. Knox, J. B. Cross, V. Bakken, C. Adamo, J. Jaramillo, R. Gomperts, R. E. Stratmann, O. Yazyev, A. J. Austin, R. Cammi, C. Pomelli, J. W. Ochterski, R. L. Martin, K. Morokuma, V. G. Zakrzewski, G. A. Voth, P. Salvador, J. J. Dannenberg, S. Dapprich, A. D. Daniels, Ö. Farkas, J. B. Foresman, J. V. Ortiz, J. Cioslowski, and D. J. Fox, Gaussian, Inc., Wallingford CT, 2009.

61. Vosko, S. H.; Wilk, L.; Nusair, M.; Can. J. Phys. 1980, 58, 1200.

62. (a) Staroverov, V. N.; Scuseria, G. E.; Tao, J.; Perdew, J. P.; J. Chem. Phys. 2003, 119, 12129.

(b) Staroverov, V. N.; Scuseria, G. E.; Tao, J.; Perdew, J. P.; J. Chem. Phys. 2004, 121, 11507.

63. Dolg, M.; Wedig, U.; Stoll, H.; Preuss, H.; J. Chem. Phys. 1987, 86, 866.

64. Hay, P. J.; Wadt, W. R.; J. Chem. Phys. 1985, 82, 299.

65. Marques, M. A. L.; Gross, E. K. U.; Annu. Rev. Phys. Chem. 2004, 55, 427.

66. Harrypersad, S.; Foucher, D. Chem. Commun., 2015, 51, 7120.

67. Zeppek, C.; Pichler, J.; Torvisco, A.; Flock, M.; Uhlig, F.; J. Organomet. Chem. 2013, 740, 41.

68. Tupeiauskans, A. P.; Sergeyev, M.; Ustynyuk, Y. A.; Org. Mag. Reson.1971, 3, 655.

69. Jaiswal, D. K.; Andres, H.; Morimotoa, H.; Williams, P. G.; J. Chem. Soc. Chem. Commun. 1993, 907.

70. Cuvigny, T.; Normant, H.; C.R. Acad. Sci., Paris, Ser. C. 1969, $268,834$.

71. Jousseaume, B.; Chanson, E.; Bevilaqua, M.; Saux, A.; Pereyre, M.; Barbe, B. ; Petraud, M.; J. Organomet. Chem.1985, 294, C41.

72. Sharma, H. K.; Miramontes, A.; Metta-Magaña, A. J.; Pannell, K. H.; Organometallics. 2011, 30,4501 .

73. Shibata, K..; Weinert, C. S.; Sita. L. R.; Organometallics. 1998, 17, 2241.

74. Fa, W.; Zeng, X. C.; Chem. Commun. 2014, 50, 9126. 